University of Louisville

ThinkIR: The University of Louisville's Institutional Repository

Electronic Theses and Dissertations

$12-2015$

\title{
Spare parts on demand using additive manufacturing : a simulation model for cost evaluation.
}

Stefan Jedeck

Follow this and additional works at: https://ir.library.louisville.edu/etd

Part of the Business Administration, Management, and Operations Commons, Engineering Science and Materials Commons, Industrial Engineering Commons, Industrial Technology Commons, Materials Science and Engineering Commons, Operational Research Commons, Operations and Supply Chain Management Commons, and the Technology and Innovation Commons

\section{Recommended Citation}

Jedeck, Stefan, "Spare parts on demand using additive manufacturing : a simulation model for cost evaluation." (2015). Electronic Theses and Dissertations. Paper 2290.

https://doi.org/10.18297/etd/2290

This Doctoral Dissertation is brought to you for free and open access by ThinkIR: The University of Louisville's Institutional Repository. It has been accepted for inclusion in Electronic Theses and Dissertations by an authorized administrator of ThinkIR: The University of Louisville's Institutional Repository. This title appears here courtesy of the author, who has retained all other copyrights. For more information, please contact thinkir@louisville.edu. 
SPARE PARTS ON DEMAND USING

ADDITIVE MANUFACTURING:

\title{
A SIMULATION MODEL FOR COST EVALUATION
}

By

Stefan Jedeck

Dipl.-Ing. (FH), Fachhochschule Köln, 2006

Dipl.-Wirt.-Ing (FH), Fachhochschule Köln, 2007

\author{
A Dissertation \\ Submitted to the Faculty of the \\ J.B. Speed School of Engineering of the University of Louisville \\ in Partial Fulfillment of the Requirements for the \\ Doctor of Philosophy in Industrial Engineering \\ Department of Industrial Engineering \\ University of Louisville \\ Louisville, Kentucky, USA
}

December 2015 
(C) Copyright 2015 by Stefan Jedeck

All rights reserved 



\title{
SPARE PARTS ON DEMAND USING
}

\section{ADDITIVE MANUFACTURING:}

\section{A SIMULATION MODEL FOR COST EVALUATION}

\author{
By \\ Stefan Jedeck \\ Dipl.-Ing. (FH), Fachhochschule Köln, 2006 \\ Dipl.-Wirt.-Ing (FH), Fachhochschule Köln, 2007
}

A Dissertation Approved on

December 01, 2015

by the following Dissertation Committee

Professor Lihui Bai, Committee Chair

Professor Li Yang, Committee Chair

Professor John S. Usher

Professor Ellen G. Brehob 


\section{ABSTRACT \\ SPARE PARTS ON DEMAND USING ADDITIVE MANUFACTURING: \\ A SIMULATION MODEL FOR COST EVALUATION \\ Stefan Jedeck}

December 1, 2015

Little is known about the impact of additive manufacturing in the spare part supply chain. A few studies are available, but they focus on specific parts and their applications only. A general model, which can be adapted to different applications, is nonexistent. This dissertation proposes a decision making framework that enables an interested practitioner/manager to decide whether using additive manufacturing to make spare parts on demand is economical when compared to conventional warehousing strategy. The framework consists of two major components: a general discrete event simulation model and a process of designing a wide range of simulation scenarios. The goal of the dissertation is to help verify existing as well as gain new knowledge about operations of additive manufacturing and the cost implication in the spare parts supply chains. Particularly, the proposed model enables simulation based analysis with various strategies, setups, specific parts, machines and system operating parameters. Furthermore, the process related issues of interest are the influence of building speed, building space volume, material price, machine purchase price and cool down time. Strategy related issues are multi-machine and multi-material production strategies in several setups. Also simulation investigation of different spare part stock properties are executed and analyzed by using different part size distributions.

This dissertation establishes fundamental understanding of the characteristics of the additive manufacturing system for spare part supply strategies. This model could directly help the decision-making processes in whether to adopt additive manufacturing technology, and also helps the evaluation of different additive manufacturing strategies when the technology is adopted. 
Both decisions (adoption and strategies) are made based on cost analysis for spare parts in a broader supply chain. 
LIST OF TABLES.

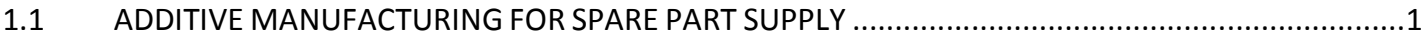

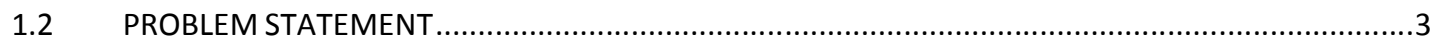

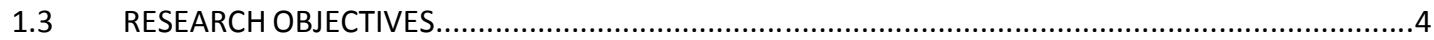

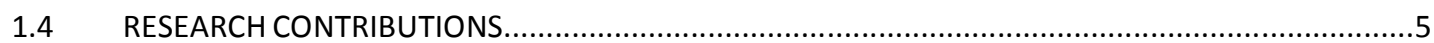

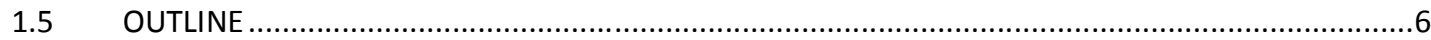

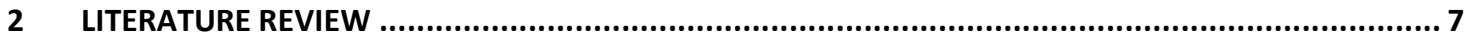

2.1 OPPORTUNITY FOR ISOLATED SYSTEMS AND REMOTE PRODUCTION CONTROL........................10

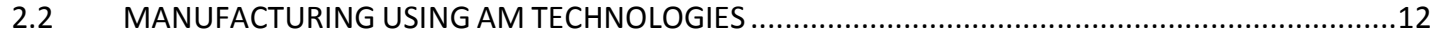

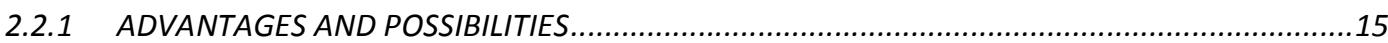

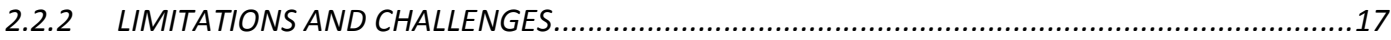

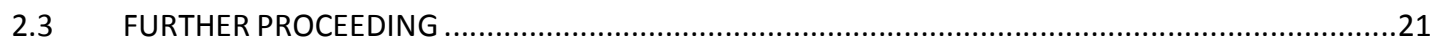

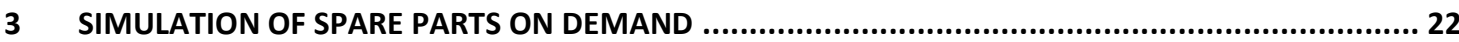

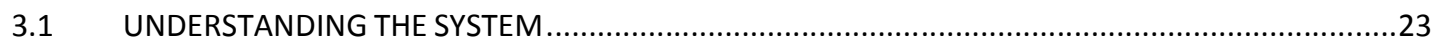

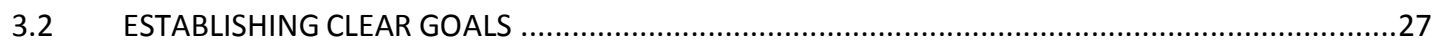

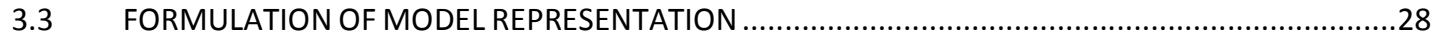

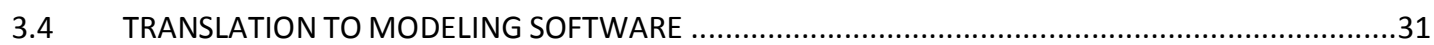

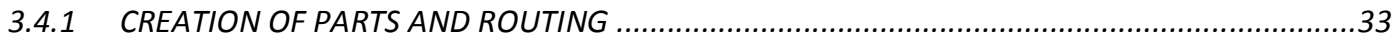




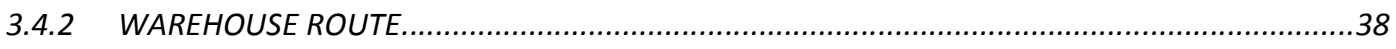

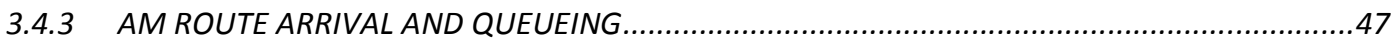

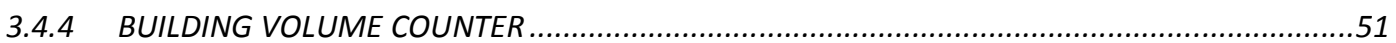

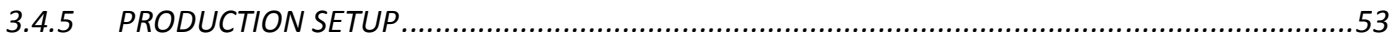

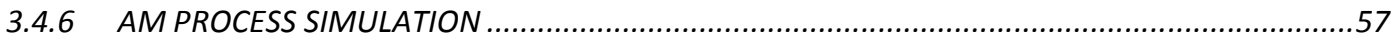

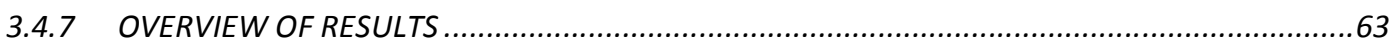

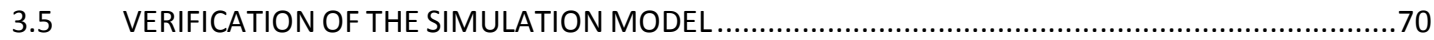

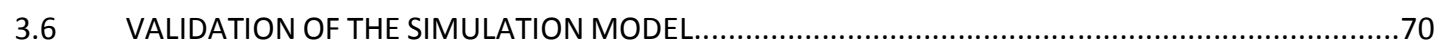

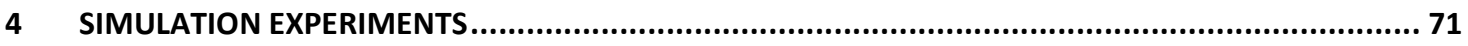

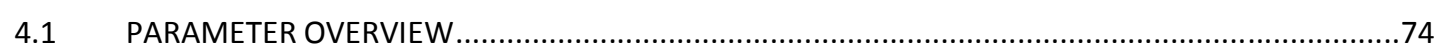

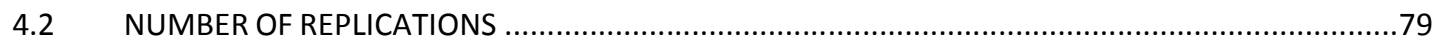

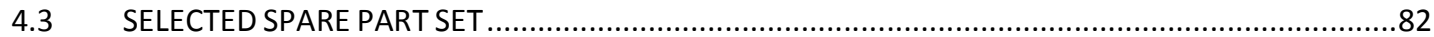

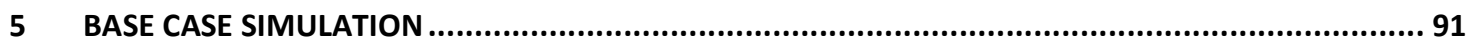

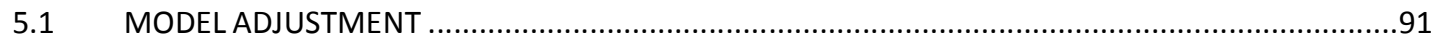

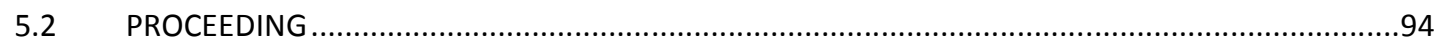

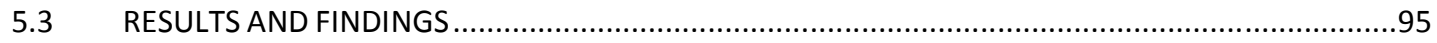

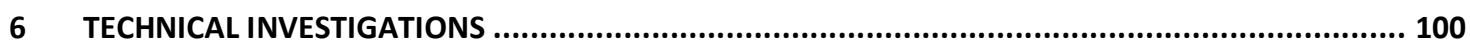

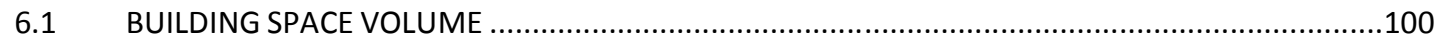

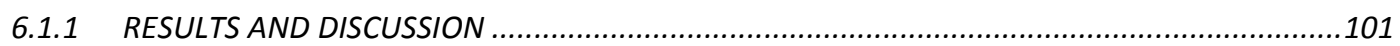

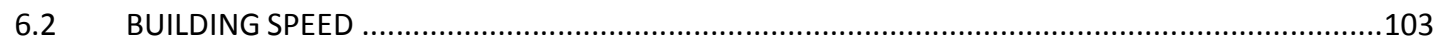

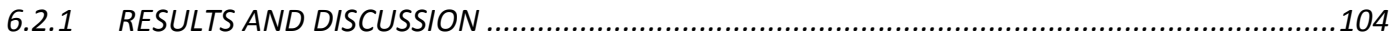

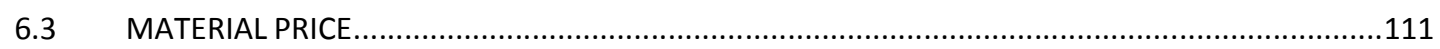

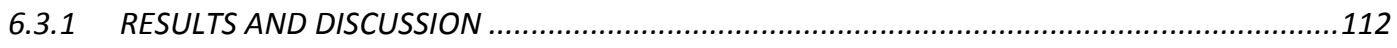

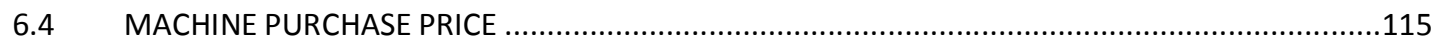

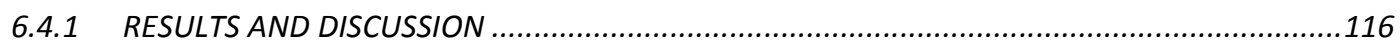




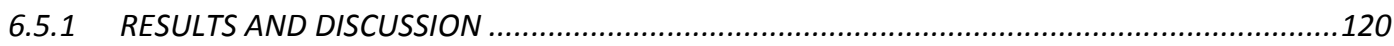

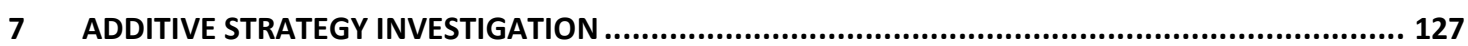

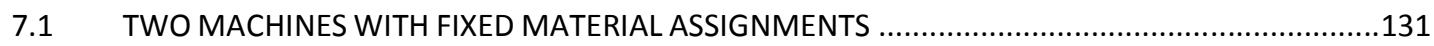

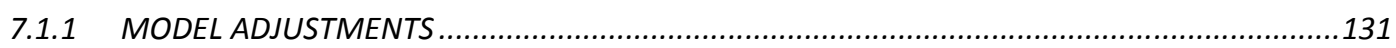

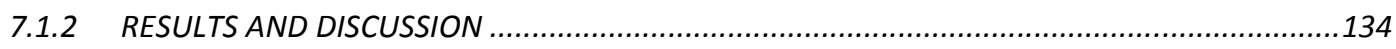

7.2 TWO MACHINES WITH FLEXIBLE MATERIAL ASSIGNMENT ................................................. 141

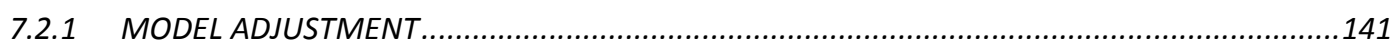

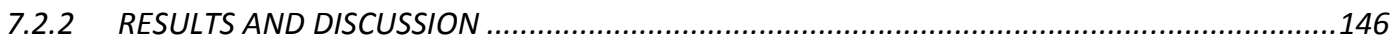

7.2.3 THREE MACHINES WITH FIXED MATERIAL ASSIGNMENT ..............................................152

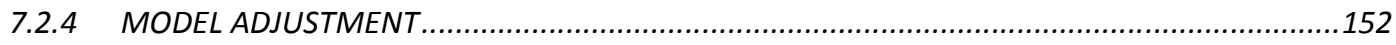

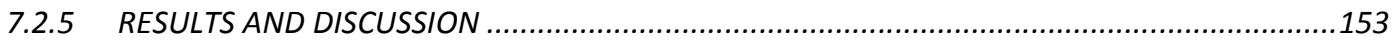

7.3 THREE MACHINES WITH FLEXIBEL MATERIAL ASSIGNMENT ...............................................158

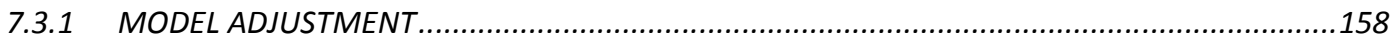

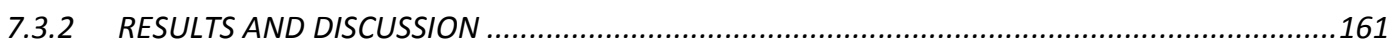

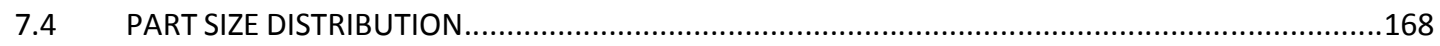

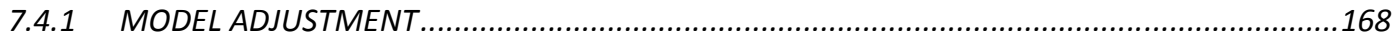

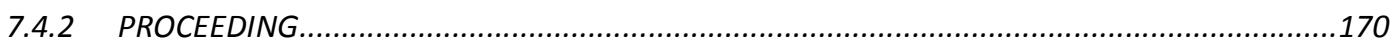

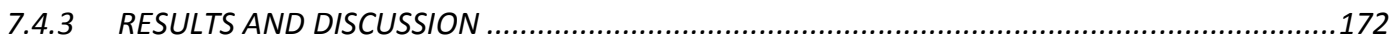

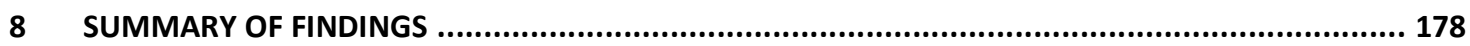

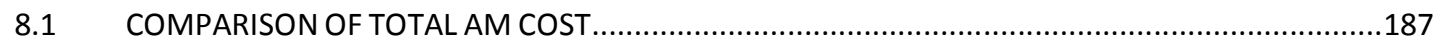

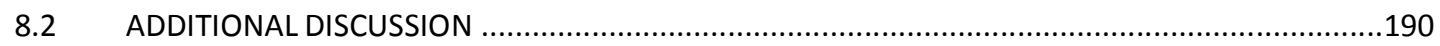

8.2.1 AM SPARE PART STRATEGY ANALYSIS FOR CASE STUDY ............................................... 190

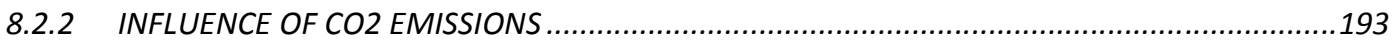

8.3 SPARE PARTS ON DEMAND - A SIMULATION BASED FRAMEWORK ........................................195

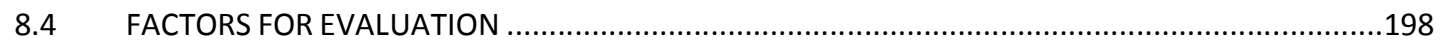




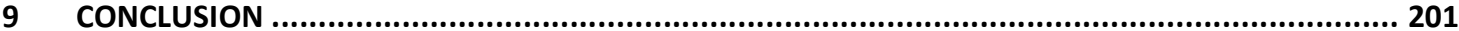

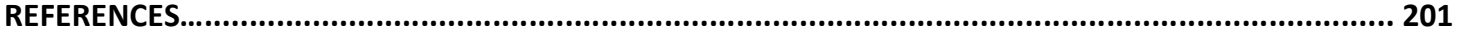

APPENDIX

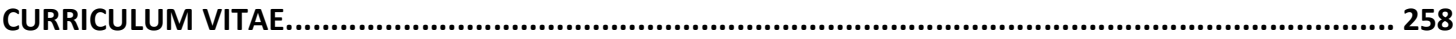




\section{LIST OF TABLES}

Table 3-1: Assignment of attributes to part at "Part parameter request 1" assignment module .... 34

Table 3-2: Calculation of consumption and cost

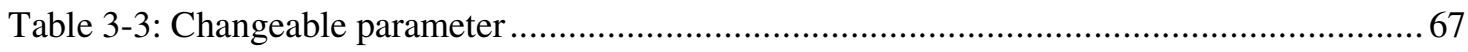

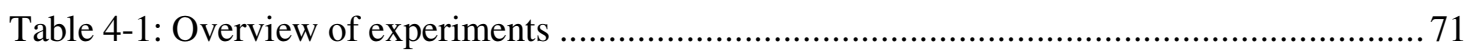

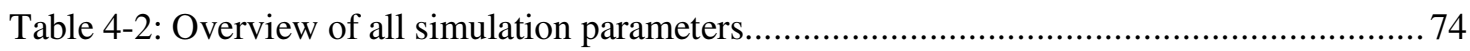

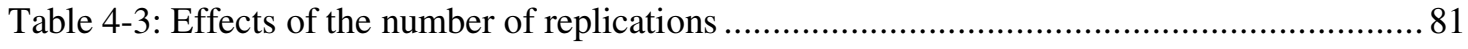

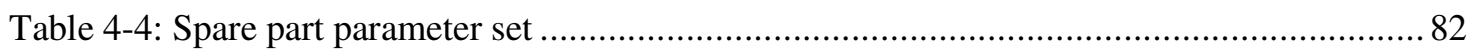

Table 4-5: Extract of machine data of Eosint M 280 (400 Watt Laser) ......................................... 84

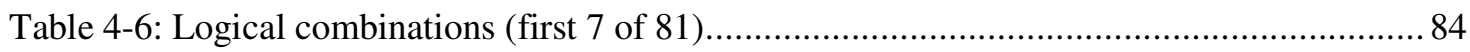

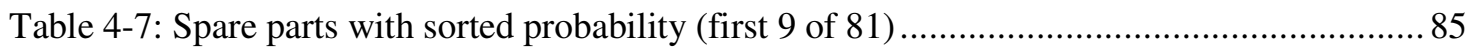

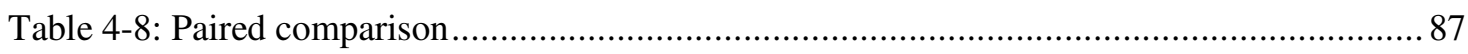

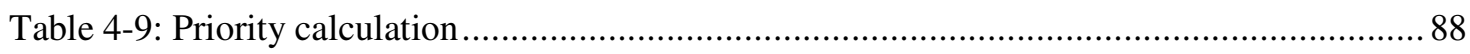

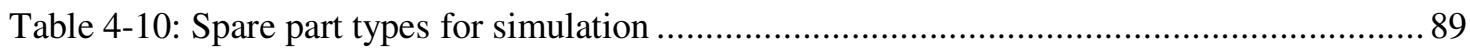

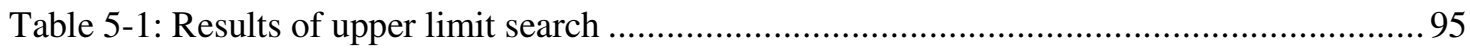

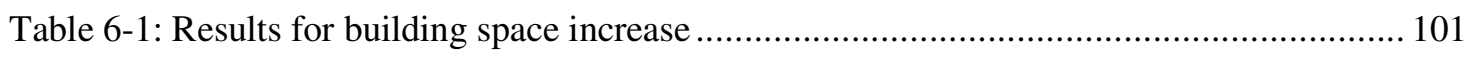

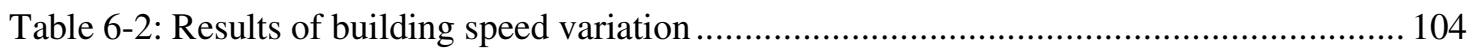

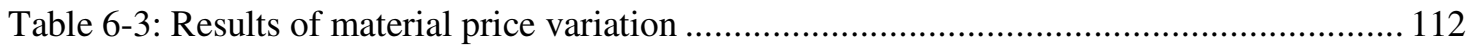

Table 6-4: Results of machine purchase price variation ........................................................ 116

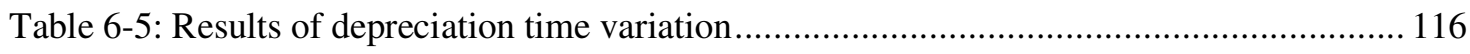

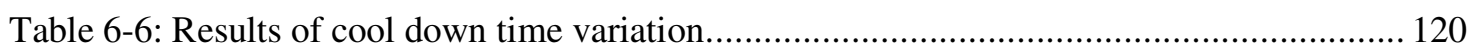


Table 7-1: Results of two machines with fixed material assignment- Upper limit No-waiting/ Waiting 134

Table 7-2: Machine assignment and material changeover logic

Table 7-3: Two machines with flexible material assignment - Upper limit No waiting/ Waiting

Table 7-4: Three machines with fixed material - Upper limit No waiting/ Waiting 153

Table 7-5: Machine assignment and material changeover logic - three machines 160

Table 7-6: Three machines with flexible material assignment - Upper limit No waiting/ Waiting

Table 7-7: Selected variations of part size distributions 171

Table 7-8: Upper limit results of spare part size variation - No waiting and waiting 173

Table 7-9: Possibility of simultaneous production 175

Table 8-1: Discussion of base case simulation 179

Table 8-2: Discussion of AM strategy investigations 180

Table 8-3: Comparison of different strategies - Upper limit - No waiting. 181

Table 8-4: Comparison of different strategies - Upper limit - Waiting 182

Table 8-5: Comparison of different strategies - Preheat and cool down - No waiting 183

Table 8-6: Comparison of different strategies - Preheat and cool down - Waiting 184

Table 8-7: Comparison of different part size setups - No waiting. 185

Table 8-8: Comparison of different part size setups - Waiting. 186

Table 8-9: Overview of different strategies - Upper limit search - No waiting. 188

Table 8-10: Consumption profile of spare part set 191

Table 8-11: AM parts out using two, three or the base case strategy with flexible material 192

Table 8-12: Non-required part on stock 194

Table 9-1: Results of two machines with fixed material - Upper limit - No waiting.... 232

Table 9-2: Results of two machines with fixed material - Upper limit - Waiting 232 
Table 9-3: Results of two machines with fixed material - Preheat and cool down - No waiting 233

Table 9-4: Results of two machines with fixed material - Preheat and cool down - Waiting ..... 234

Table 9-5: Results of two machines with fixed material - Start volume - Waiting.......................235

Table 9-6: Results of two machines with fixed material - Elapse time - Waiting ....................... 235

Table 9-7: Results of two machines with flexible material - Upper limit - No waiting................236

Table 9-8: Results of two machines with flexible material - Upper limit - Waiting...................... 236

Table 9-9: Results of two machines with flexible material - Preheat and cool down - No waiting

Table 9-10: Results of two machines with flexible material - Preheat and cool down - Waiting 238

Table 9-11: Results of two machines with flexible material - Start volume - Waiting 239

Table 9-12: Results of two machines with flexible material - Elapse time - Waiting 239

Table 9-13: Results of two machines with flexible material - Change over time - Waiting 240

Table 9-14: Results of two machines with flexible material - Change over time - No waiting .. 241

Table 9-15: Results of three machines with fixed material - Upper limit - No waiting 242

Table 9-16: Results of three machines with fixed material - Upper limit - Waiting. 242

Table 9-17: Results of three machines with fixed material - Preheat and cool down - No waiting

Table 9-18: Results of three machines with fixed material - Preheat and cool down - Waiting. 244

Table 9-19: Results of three machines with fixed material - Start volume - Waiting 245

Table 9-20: Results of three machines with fixed material - Elapse time - Waiting. 245

Table 9-21: Results of three machines with flexible material - Upper limit - No waiting 246

Table 9-22: Results of three machines with flexible material - Upper limit - Waiting. 246

Table 9-23: Results of three machines with flexible material - Preheat and cool down - No waiting......

Table 9-24: Results of three machines with flexible material - Preheat and cool down - Waiting 
Table 9-25: Results of three machines with flexible material - Start volume - Waiting 249

Table 9-26: Results of three machines with flexible material - Elapse time - Waiting

Table 9-27: Results of three machines with flexible material - Material changeover time -

Waiting......

Table 9-28: Results of three machines with flexible material - Material changeover time - No

waiting......

Table 9-29: Results of part size simulations - Upper limit - No waiting

Table 9-30: Results of part size simulations - Upper limit - Waiting 255

Table 9-31: Results of part size simulations - Upper limit summary - No waiting 258

Table 9-32: Results of part size simulations - Upper limit summary - Waiting... 258 


\section{LIST OF FIGURES}

Figure 2-1: Comparison of time distribution for various strategies of spare parts procurement

(Pérès \& Noyes, 2006)

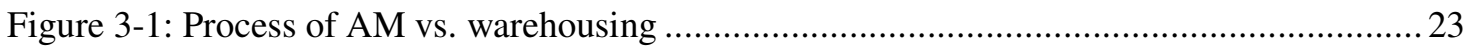

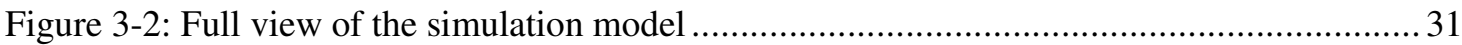

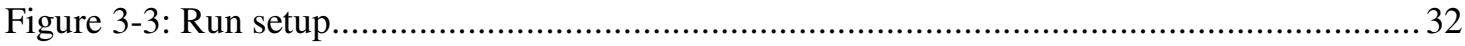

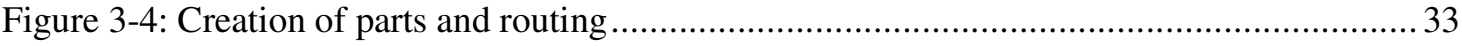

Figure 3-5: Creation of spare part request and attribute assignment........................................... 34

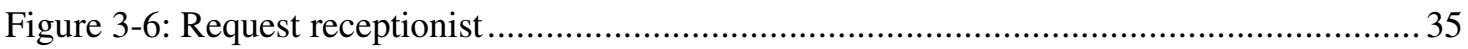

Figure 3-7: Duplicate part requests and route to warehouse route.............................................. 36

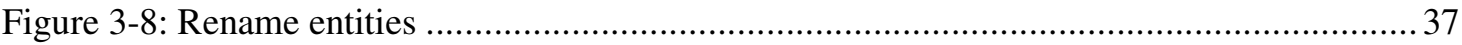

Figure 3-9: Warehouse route station, split up and path for Part request 1 ................................. 38

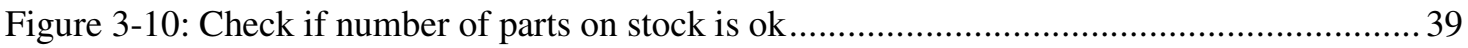

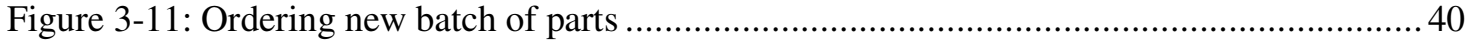

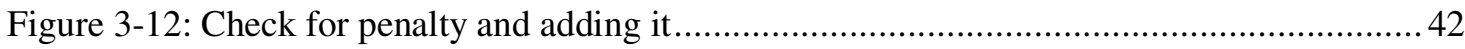

Figure 3-13: Graphical display of Part 1 on stock and Part 1 Penalty (after simulation run)........ 42

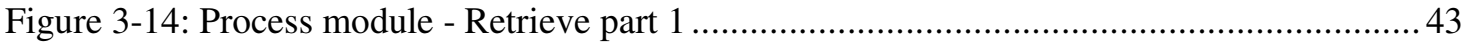

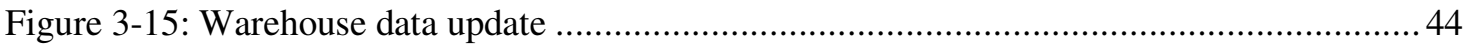

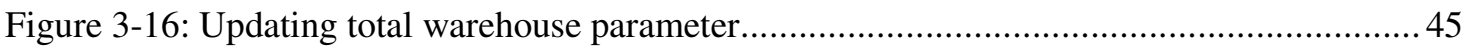

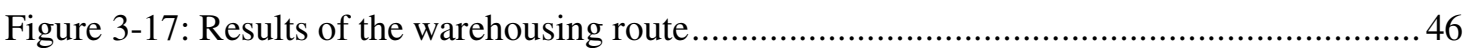

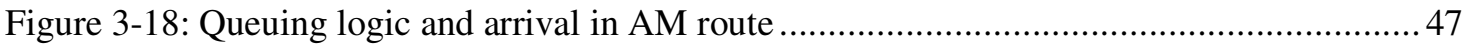

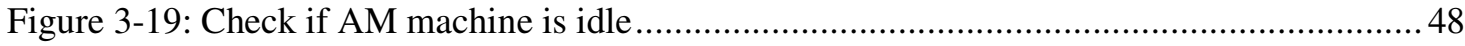


Figure 3-20: Queuing logic

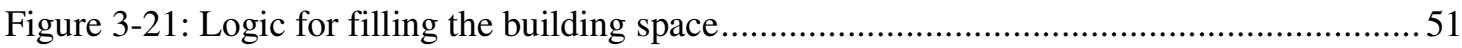

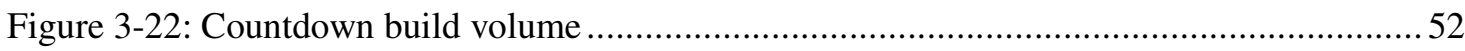

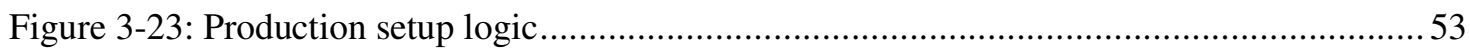

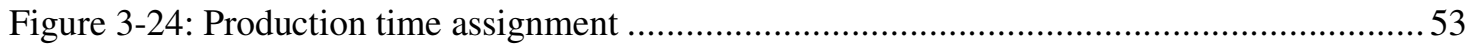

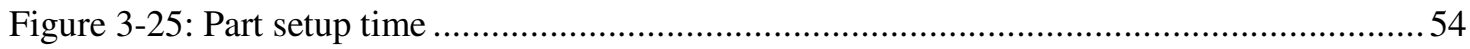

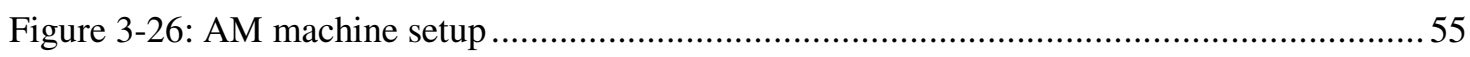

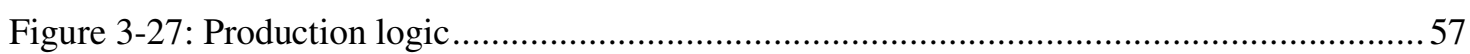

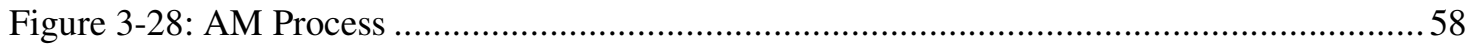

Figure 3-29: Hold for finished parts in building space ……................................................... 58

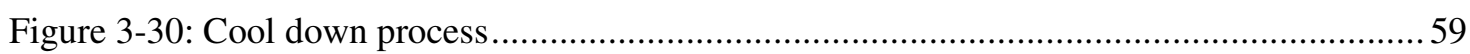

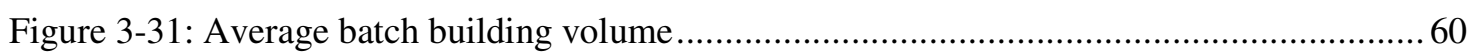

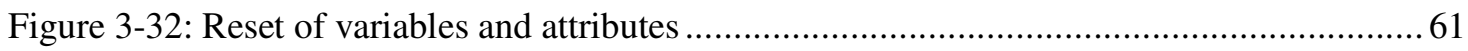

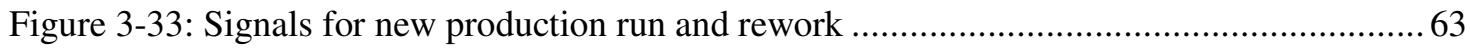

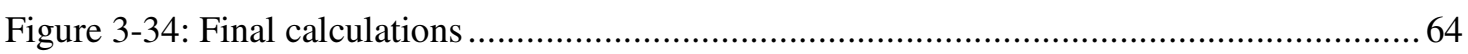

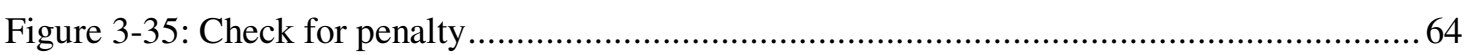

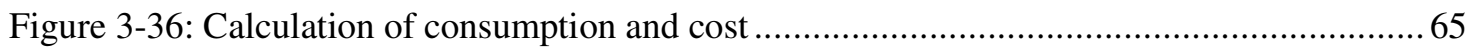

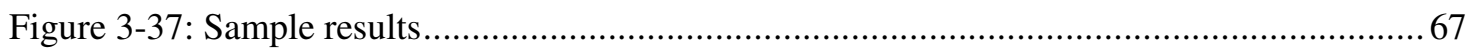

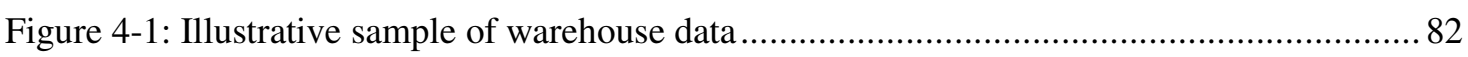

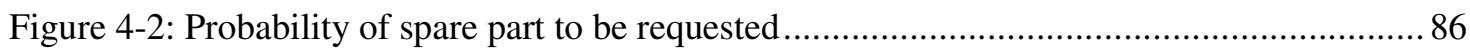

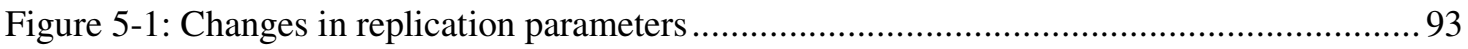

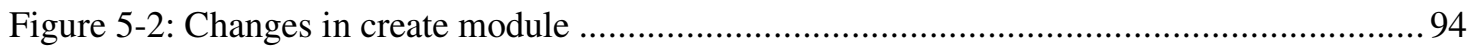

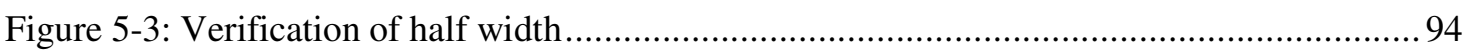

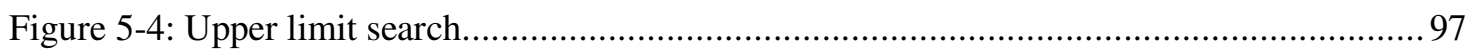

Figure 5-5: Correlation between machine utilization and queuing ...........................................99

Figure 6-1: Building space volume vs. AM and warehousing cost ........................................ 101 
Figure 6-2: Building speed and upper limit search.....

Figure 6-3: Building speed and upper limit search - details

Figure 6-4: Cost compared to building material price

Figure 6-5: Machine depreciation vs. purchase price

Figure 6-6: Years of depreciation vs. machine depreciation...

Figure 6-7: Cool down time variation.

Figure 6-8: Cool down time variation - detail

Figure 7-1: Adjusted AM rout arrival and queueing logic

Figure 7-2: Material assignment

Figure 7-3: Modification of queueing logic

Figure 7-4: Changes in building volume counter logic

Figure 7-5: Two machines with fixed material - Upper limit search - No waiting 135

Figure 7-6: Two machines with fixed material - Upper limit search - Waiting 136

Figure 7-7: Two machines with fixed material - Setup \& cool down time - No waiting ....

Figure 7-8: Two machines with fixed material - Setup \& cool down time - Waiting... 138

Figure 7-9: Two machines with fixed material - Start volume - Waiting ..... 139

Figure 7-10: Two machines with fixed material - Elapse time - Waiting. 140

Figure 7-11: Adjusted AM route arrival and queueing logic 141

Figure 7-12: Check for idle machine 142

Figure 7-13: Machine states follow up by part attributes. 142

Figure 7-14: Machine assignment and material changeover logic 143

Figure 7-15: Two machines with flexible material - Upper limit search - No waiting 147

Figure 7-16: Two machines with flexible material - Upper limit search - Waiting.... 148

Figure 7-17: Two machines with flexible material - Preheat and cool down - No waiting 149

Figure 7-18: Two machines with flexible material - Preheat and cool down - Waiting 149

Figure 7-19: Two machines with flexible material - Material change over time - Waiting 150 
Figure 7-20: Two machines with flexible material - Material change over time - No waiting .. 150

Figure 7-21: Two machines with flexible material - Start volume - Waiting 151

Figure 7-22: Two machines with flexible material - Elapse time - Waiting ...... 151

Figure 7-23: Main adjustment of the model 152

Figure 7-24: Three machines with fixed material - Upper limit search - No waiting..... 154

Figure 7-25: Three machines with fixed material - Upper limit search - Waiting..... 155

Figure 7-26: Three machines with fixed material - Preheat and cool down - No waiting. 156

Figure 7-27: Three machines with fixed material - Preheat and cool down - Waiting... 156

Figure 7-28: Three machines with fixed material - Start volume - Waiting. 157

Figure 7-29: Three machines with fixed material - Elapse time - Waiting..... 157

Figure 7-30: Adjusted AM route arrival and queueing logic 158

Figure 7-31: Machine assignment and material changeover logic - three machines. 159

Figure 7-32: Three machines with flexible material - Upper limit search - No waiting ....... 162

Figure 7-33: Three machines with flexible material - Upper limit search - Waiting.... 163

Figure 7-34: Three machines with flexible material - Material change over time - Waiting ...... 164

Figure 7-35: Three machines with flexible material - Start volume - No waiting. 165

Figure 7-36: Three machines with flexible material - Preheat and cool down - No waiting....... 165

Figure 7-37: Three machines with flexible material - Preheat and cool down - Waiting............ 166

Figure 7-38: Three machines with flexible material - Start volume - Waiting............................. 166

Figure 7-39: Three machines with flexible material - Elapse time - Waiting ............................ 167

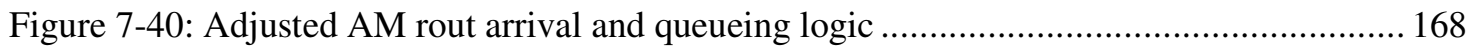

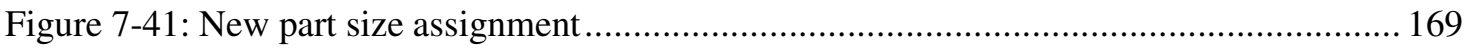

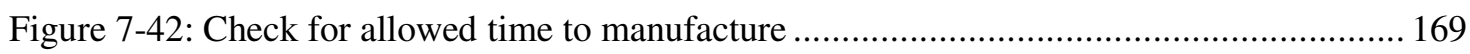

Figure 7-43: Results of part size simulations - Upper limit - No waiting................................ 172

Figure 7-44: Results of part size simulations - Upper limit - Waiting ...................................... 172

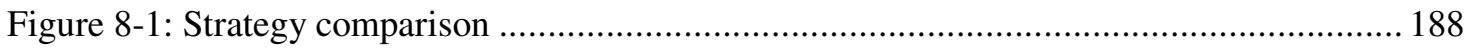


Figure 8-2: Strategy comparison - detail

Figure 8-3: Spare parts on demand - a simulation based framework

Figure 8-4. Comparison of time distribution for various strategies of spare parts procurement

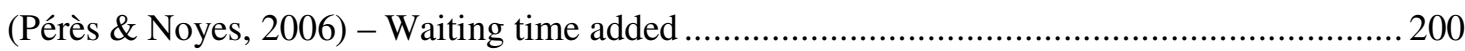

Figure 9-1: Graphical display of connected Arena modules ....................................... 222

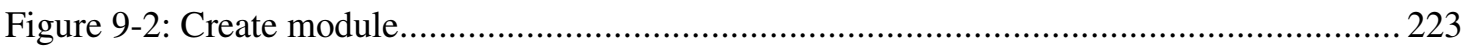

Figure 9-3: Assign module .................................................................................. 224

Figure $9-4$ : Process module and queue ................................................................ 225

Figure 9-5: Decide module.............................................................................. 226

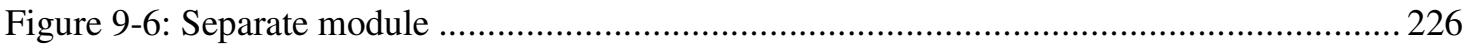

Figure 9-7: Hold module ..................................................................................... 227

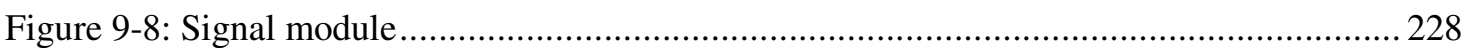

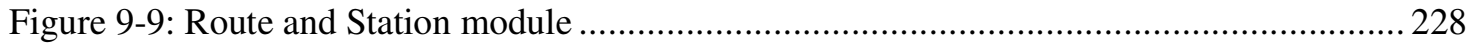

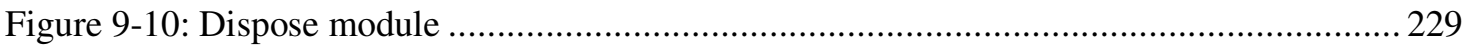

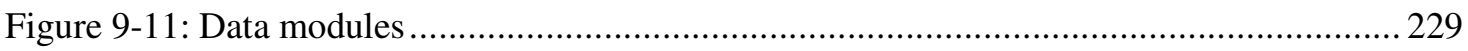

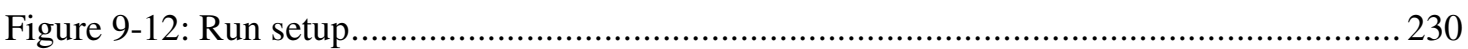




\section{INTRODUCTION}

\subsection{ADDITIVE MANUFACTURING FOR SPARE PART SUPPLY}

Additive manufacturing is a relatively new discipline with a wide range of research opportunities. This thesis explores the application of Additive Manufacturing (AM) in the context of Rapid Manufacturing (RM). It is of special interest which potentials are provided by AM technologies to influence spare part stocks in an industrial environment. This thought can be taken further to isolated environments, meaning that the spare part supply is not possible by a supplier in an optimal way. Examples for application can reach from using AM for the spare part supply on an air craft carrier, space or arctic missions and in ordinary workshops which need to store simple parts due to a geographical, temporary or logistical isolation. A practical example can be an automotive supplier. Nowadays they need to store the spare parts, and/ or special tools, to react fast to an uncertain demand over an undefined period of time. This strongly affects the supply strategy and leads to economical drawbacks. Producing spare parts on demand by using AM is a good option to avoid high inventory and the related drawbacks. In comparison to ordinary part manufacturing, where relatively long lead times are common, spare part production on demand has strong restrictions with respect to delivery time of the parts. If a faulty part needs to be replaced and delivery or the replacement takes too long, this might lead to significant production losses and therefore high penalties. Due to this, "spare parts on demand" needs to be a wellconsidered concept, especially with respect to the application and performance of AM. 
$\mathrm{AM}$ is a new form of manufacturing technology, which could have the potential to replace several manufacturing technologies and produce parts directly. When the requirements for a cost efficient manufacturing process can be met, AM technology can be a viable option for an improved supply of spare parts in industrial environments. According to Holmström et al (2010) "Further research is needed to develop conceptually the development of AM in the spare parts supply chain. However, the greatest challenge for research is empirical research. Field research and case research is needed to describe actual solution designs considered by different $\mathrm{OEMs}^{1}$, as well as collecting empirical evidence on the effects and challenges of introducing AM in the spare parts supply chain" (Holmström, Partanen, Tuomi, \& Walter, 2010)

To date, it is not common to integrate AM into the spare part supply chain. This is due to the unawareness of potential users, the ongoing development of the technology, and missing field experience of application. To contribute to the field of AM, this work will gain knowledge about the impact of AM to the spare part supply chain. In particular, we propose a cost evaluation framework that enables managers to decide is using AM to make spare parts is cost effective. The most instrumental to the proposed decision framework is a simulation model that helps to systematically evaluate and verify the performance of AM in the spare part supply chain. The simulation allows the change of parameters in a given set of conditions and foresees the effects on the performance. The goal is to execute fundamental research by simulating with the key parameters building space volume, building speed, machine purchase price, material cost and several production strategies in order to execute sensitivity analysis. Once validated, this model will allow to make predictions from a logistic and strategic perspective of including AM into the spare part supply, and therefore support decision making based on the understanding of spare part supply system characteristics.

\footnotetext{
${ }^{1}$ Original equipment manufacturers
} 


\subsection{PROBLEM STATEMENT}

Today not much is known about the performance of AM machines in the spare part supply chain. Several authors worked on the development of strategies for spare part selection, maintenance and warehousing strategies. These studies are highly specific, depending on the particular parts being studied and the associated companies. In a more general setting, it is not yet clear how AM contributes to the spare part supply chain. This study intends to fill this gap.

The limited literature on simulation models for AM (for example Holmström et al (2010)) only address the economic effects of implementing AM for spare part supply. They do not allow for direct changes of performance parameters of the AM machines. In our view, it is essential to have the ability to change system parameters or technology to verify system behavior in several setups and gain fundamental knowledge. Given the fact that a variety of AM systems exist, practical testing is nearly impossible, especially in regards to their effects on the supply chain. Thus, it is necessary to develop a simulation model that enables simulation of realistic spare part scenarios, and to evaluate and verify the performance of AM for improvement of spare part supply. 


\subsection{RESEARCH OBJECTIVES}

The objective of this work is to emphasize the establishment of understanding to the potential impact of additive manufacturing on the spare part supply strategy. Simulation is the selected tool that allows to compare different setups and strategies of using AM for spare part supply. The simulation model itself is meant as a framework, which will verify and gain fundamental knowledge. That is an important approach for the decision-making processes and supports evaluation of different AM strategies or setups. Strategies and setups will include specific spare part parameters such as geometric dimensions, material, or time to delivery ${ }^{2}$ and machine specific parameters such as building speed, building volume or possible materials. These kind of parameters are used to evaluate changes in the supply strategy and/ or in the AM technology. Through this model the total cost generated by using AM spare part supply can be compared directly to other supply chain strategies such as classic warehousing strategies. The model is intended to be general and capable of being adapted to different applications.

The first step for reaching the defined goal is to execute a literature review on existing models and a summary of the findings. The second step is to develop a simulation model using Arena. The simulation model for spare parts on demand will be able to simulate the AM process for a given set of spare parts, taking into account technical and economic factors. One of the results will also be a comparison between classic warehousing and the abilities of AM. This could mean to compare warehousing cost to the total part cost when using AM. The third step calculates relevant scenarios with different parameters and machine setups. Scenarios reach from evaluation of upcoming trends in AM (for example increasing building space) to simple spare part strategy changes and the effect on the total AM cost. Lastly, results are compared, analyzed and documented.

\footnotetext{
${ }^{2}$ Time until the spare part must to be available to avoid further negative consequences.
} 


\subsection{RESEARCH CONTRIBUTIONS}

Integrating new technologies into industrial environments bears certain technical and economic risks. Therefore AM requires careful evaluation before it can be applied. For this reason, it is important that realistic scenarios can be simulated to ensure that targets can be reached. In general, this work is an extension to the work by Pérès and Noyes (2006) or Holmström et al (2010). Pérès and Noyes focus on the strategies for spare part selection on a qualitative level and Holmström et al on the simulation issue, in regards to specific make-or-buy decisions.

As contribution to the body of knowledge, a simulation model is applied, representing a framework, which will verify and gain fundamental knowledge about the characteristics of the AM spare part on-demand supply strategies. A rigorous and quantitative approach is important for decision-making processes and to support evaluation of different AM strategies or setups on an economic and technical basis. The model can be applied for flexible spare part sets and it is variable-based to allow for a quick change in the parameter set according to the topic of interest. These changes can be done for warehousing strategies (for example lead times, EOQ), spare parts (for example material, built volume, priority) and AM (for example building speed, build volume). The ability to change parameter values enables optimization of process parameters and sensitivity analysis.

A similar model enabling such a level of detail was not found during literature review.

Application for the proposed work can be found in every area where spare parts or warehousing take part. As mentioned before, examples for application of the established model can range from using AM for the spare part supply on an air craft carrier, space missions to an ordinary workshop which needs to store simple parts due to geographic, temporary or logistical isolation, or other strategic reasons, for example form postponement. When the technology has matured to reach a 
wider group of interested users, the ability to simulate properly is a strong support for the decision process if it is an option to supply spare parts by AM.

\subsection{OUTLINE}

The dissertation gives an overview of the existing work and presents the proceeding and findings of this work. The following chapters are structured as follows:

Chapter 2 - is a literature review on existing works for simulating spare parts on demand by AM.

Chapter 3 - introduces the procedure of applying a simulation model and presents the developed simulation model in detail. Planned experiments and tasks are described.

Chapter 4 - describes the planned experiments.

Chapter 5, $6 \& 7$ - describe adjustments of the applied simulation models, proceeding, results and findings of the technical investigations and additive strategy investigations.

Chapter 8 - summarizes findings of chapter 5, 6, and 7, contains further conclusions and presents a process description for simulation of spare parts by AM, important factors for evaluation and an option to fit the spare part stock to AM.

Chapter 9 - presents an overview of the application of spare parts on demand by AM, taking the latest findings into consideration.

Appendix - introduces the reader to Arena by describing basic components of Arena and contains all results calculated during simulation. 


\section{LITERATURE REVIEW}

Several publications focus on production by AM and point out that it can have benefits compared to other common manufacturing techniques, especially with small lot sizes. This literature review will not focus on that issue, except of the work by Brody and Pureswaran (2013) or Simkin and Wang (2014), which can be seen as the initiating reports for this work, and which can also be adjusted to the spare part issue. It is of interest which activities were done for the use of AM in the spare part supply chain.

Brody and Pureswaran (2013) published a report which describes the combined impact of 3D manufacturing, intelligent robotics and open source electronics. They analyzed the bills of materials down to the part, modeled the manufacturing and the distribution of manufacturing over the planet, and applied a software defined supply chain. The model allowed changes to the requirements, scale, location, cost, etc.

The result is the assumption that a "reconfigured global supply chain will emerge in the coming decade. It will radically change the nature of manufacturing in the electronic industry, shifting global trade flows and altering the competitive landscape for both enterprise and policy makers." (Brody \& Pureswaran, 2013) They found that cost savings can reach an average of $23 \%$, the economies of scale are reduced by $90 \%$ and the $\mathrm{CO}_{2}$ "supply chain" footprint has the potential to be reduced.

This report was the most complete model found during the review. In fact, it is mind opening but does not allow a direct view on the spare part problem, since it focuses on the supply chain and the impact of new technologies on it. The further proceeding is adapted to the spare parts on 
demand issue described previously. The proceeding and results of this work can be used as input for further studies in this field.

In 2014 Simkin and Wang presented a cost-benefit analyses for final produced parts. In general they analyze if "just because a part can be produced using AM does not necessarily mean that it should be" (Simkin \& Wang, 2014). They apply a cost-benefit analysis for a specific part and simulate the effects of changes in the AM parameter setup on this specific case on a cost basis, which is similar to what is presented in this work. But again the main focus is on regular production and the related cost. Specific issues related to spare parts are not taken into consideration.

Not many researchers did research on the application on AM in the spare part supply, but several articles were found by two researchers in cooperation with other scientists.

Pérès and Noyes (2006) present an interesting article "Making spare parts on demand in situ and on demand - State of the art and guidelines for further developments" (Pérès \& Noyes, 2006). They focus on isolated systems and how AM can influence the spare part supply situation. They describe several isolated situations and present a comparison of time distribution for various strategies of spare part procurement. The comparison of the strategies is qualitative and compares classical maintenance (spare parts on stock), classical maintenance (no spare parts on stock), and rapid spare part manufacturing. Basically, it has demonstrated that order-, waiting time, and reception in a classic supply system can be significantly reduced by application of AM. Also examples of testing AM technology for use in space missions or the concept of the mobile part hospital, used by military in geographically isolated situations, is presented. Based on their experience they propose several fields where research is valuable. To sum these points up, research is required to check for the applicability of AM in the spare part supply chain. 
The basic assumptions of Pérès and Noyes (2006) are comparable to industrial situations, since time and cost aspects are the same for industry.

Holmström et al (2010) work on the concept of including AM into the spare part supply chain. They compare distributed and centralized AM to replace inventory holding and conventional distribution. They present an example of deployment of distributed AM in the aircraft spare parts supply chain, where significant reductions in holding cost with an improved service level were achieved. They conclude that centralized AM by specialized service providers will show the biggest benefits at the current state. However, this will change to decentralized AM when the technology matures to a better state. This means a movement of the AM technology closer to the point of use. Also this article recommends further research to find possible applications of AM and the setup in the supply chain.

Other work by Hasan and Rennie or Peng et al (2013) strongly refer to the work of Holmström and extend the issue to the effects of AM to the supply chain for specific cases. Peng et al (2013) apply the Supply Chain Operations Reference Model (SCOR) for the aircraft spare part supply chain, and they conclude that AM is contributing to improvements.

General research for common industrial situations is missing, especially how AM centers perform in a decentralized setup. 


\subsection{OPPORTUNITY FOR ISOLATED SYSTEMS AND REMOTE PRODUCTION CONTROL}

Next to applied maintenance, warehousing and supply strategies in industry such as spare part analysis, outsourcing, postponement and relocating the decoupling point, AM also gives the option to work in isolated systems and remote controlled.

The supply and warhousing issue is more complicated when the facility or any other system is isolated. To illustrate this issue, more information and definitions about isolated systems and supply strategies follow.

Pérès and Noyes (2006) describe the following isolated systems:

Geographically isolated - When accessibility is difficult because of lack of communication (polar regions, high mountains, thick forest, etc.), the nature of the environment (air, sea, space, ...) or possible on-site risks (for example battle fields, epidemiological areas).

Logistically isolated - Whenever external conditions govern the supply operations (Pérès F., Grenouilleau, Housseini, \& Martin, 2002).

Temporarily isolated - One example is the system that dependents on elements likely to disappear at the end of a given period of time (for example closure of production lines for profitability reasons).

Having an isolated system, with respect to spare parts, might result in having every part available as a spare part at any given time to maintain a continuous operation. For as long as the stock of spare parts allows such conditions this might be a solution. However, in practice this is not a realistic scenario, since it is an expensive solution. It gets even more difficult when the system becomes complex or big and consists of a large number of parts. It may also be impossible to provide such a stock, due to lack of room or economic reasons. Pérès et al (2002) question how to 
handle the problem of choosing the wrong spare parts or the wrong number of spare parts when having an isolated system, since both can lead to a serious impact on performance and budget. For example elements with a limited life time are easy to maintain (for example filters), but it gets more difficult when unexpected spares are needed.

In contribution to solve the problems of isolated systems a special option arose up during development of information technology and machines using CAD data for processing. Holmström et al (2010) comments that "the introduction of information technology has a potentially revolutionizing effect on the provision of spare parts" (Kennedy, Patterson, \& Fredendall, 2002). Tay et al (2001) underline that AM-technologies can be used in a remote controlled way. Remote controled part preparation becomes possible because CAD or machine specific information like maximum use of building space, can be transfered through adapted networks. Also monitoring the process itself is possible, by installation of for example a camera. Merely the pre- and post-processing dependends on skilled operators until a specific technology is developed to cover these tasks as well. According to Tay et al (2001) especially the use of the internet can bypass logistical problems if the user/ initiator and the physical hardware are separated. One of the aspects is the use for AM, where service providers can benefit in their low volume manufacturing by utilizing their AM-machines by pooling jobs. As a consequence, a remote access to manufacturing in geographically isolated areas becomes possible. In general, this principle is applicable for all AM-technologies. The link to temporary isolated systems is simple too, since CAD data is easy to store and can last as long as the data-storage is available. To mention another point, Holmström et al (2010) state that using information technology in combination with $\mathrm{AM}$ is a strong argument for using 3D design tools to produce seldom used spare parts to order with various manufacturing technologies such as $\mathrm{CNC}$ or AM. Also the logistical isolation is improved as long as the material for manufacturing is available, since new designs can be transferred "online". 


\subsection{MANUFACTURING USING AM TECHNOLOGIES}

As stated previously, AM experienced new developments regarding new technologies and applications. Rapid Manufacturing is based on the same technology basis and has therefore also been developed further (Gebhardt, 2007). To use the AM technology in operative applications, a certain quality, which is equivalent to requirements for the specific element, is necessary at a competitive cost level. Smith P.G. (1999) discussed that product development projects typically balance four objectives to achieve the biggest benefit with applicable technologies. These can also be applied for the spare part issue:

1. Performance objective - The product should satisfy the features and performance levels of the product specification.

2. Cost objective - Meet the cost target for the resulting production.

3. Expense objective - Run the development project in a certain budget.

4. Schedule objective - Run the project in a given time frame.

Pérès and Noyes (2006) take the thought of spare parts on demand even further, which means thinking about spare part manufacturing on request in a short time. Usually companies keep many required spare parts on stock to reach a maximum of availability of spares. As discussed before, the drawback of this strategy is the related cost and that it may not be possible to meet the required targets with this stock. The situation becomes more difficult at the point when a complex system can be defined as a geographically or temporarily isolated system. This combination of isolated and complex system can lead to a high stock volume, which will result in higher cost and, depending on the case, a lack of room or increased warehousing cost.

Zäh (2006) and several other authors state that AM can have a great impact on the spare part stocks. The simplicity is given by manufacturing highly complex geometries by pushing a button at the moment the item is available as a 3D-CAD model. Depending on the specific part and used 
technology, it is possible to work cost efficiently with a lot size of one. Having the opportunity to manufacture complex parts with small lot sizes opens up the chance to reduce stock size to a minimum and replace several steps in the supply chain of spare parts (Pérès \& Noyes, 2006). It might be sufficient to store a 3D-CAD file and reproducing the needed part on demand, which will change the storage of parts to a storage of data, which is more economic than storing parts physically over many years.

Pérès and Noyes (2006) show a good theoretical illustration using RM technologies to improve the maintenance level in temporary isolated situations. Figure 2-1 shows the comparison between "classical maintenance strategies with and without spare parts in stock and the strategy based on the rapid spare parts manufacturing concept", which can be an advantage in specific cases. Smith and Reinertsen (1998) addresses the topic of time compression and time saving opportunities.

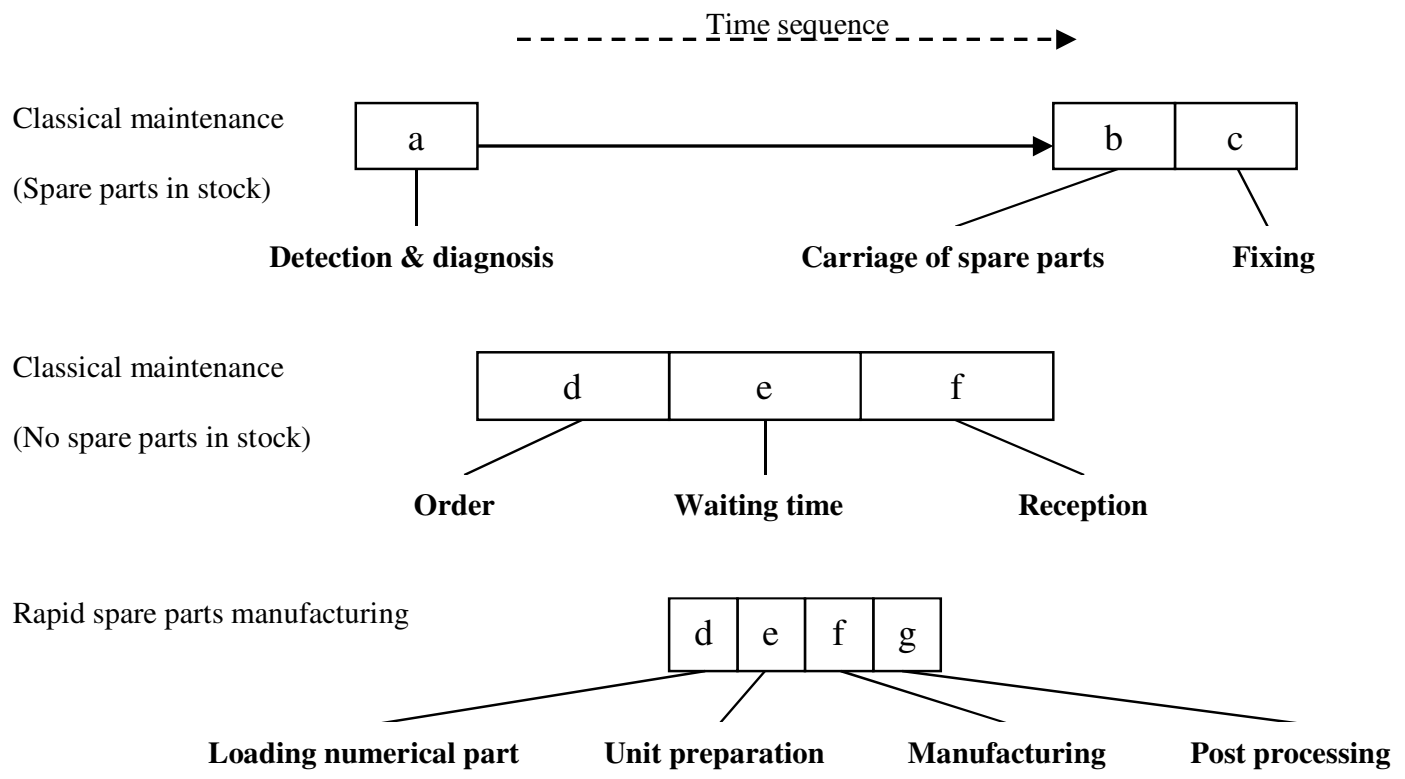

Figure 2-1: Comparison of time distribution for various strategies of spare parts procurement (Pérès \& Noyes, 2006) 
As can be seen, Figure 2-1 does not include time information. It is only a qualitative overview about the idea of the supply concepts, but it is important since it shows the lack of research at this point to show potentials. Pérès and Durand (2002) filled in that lack of information by calculating the required time to maintain a space station sub-system, but this is not valid for a typical industrial environment on earth. To reach more information on this topic, research is necessary in this area.

It must be stated that other manufacturing technologies exist. However, basically traditional manufacturing technologies such as $\mathrm{CNC}$ are a standard in manufacturing and will not be further discussed here, since information is widely available. The use of AM technologies is new because "Producing functional parts is the evolution of layer manufacturing." (Atzeni, Iuliano, Minetola, \& Salmi, 2010). When AM machines are able to deliver sufficient part properties, "product performance through the synthesis of shapes, sizes, hierarchical structures, and material compositions, subject to the capabilities of AM technologies" (Gibson, Rosen, \& Stucker, 2010) can be maximized. 


\subsubsection{ADVANTAGES AND POSSIBILITIES}

When AM technology matures to the point that it can be easily used for manufacturing it will have advantages to traditional manufacturing. Especially with respect to isolated systems Pérès and Noyes (2006) list several strong reasons for the use of AM technologies in supply issues:

- "Due to their nature, these technologies are fast and can be adapted to the reactivity need inherent in the resumption of the operation of the system by replacing a faulty component.

- They are also self-sufficient in so far nearly no intermediary operation takes place between the digital file making and the part making.

- Once the manufacture is launched, no operator has to supervise the work in progress.

- They make it possible to achieve excellent identical parts because of the automated process. $^{3}$

- In some cases they can be multi-purpose and can be used to work out parts made of various materials (plastics, metal, ceramics, ...)

- Most of them need only raw materials from which several articles will be made irrespectively of their functionality.

- Implementation of these technologies does usually not require bulky machines for which large floor room is necessary, but portable ones." (Pérès \& Noyes, 2006)

Also Holmström et al (2010) contribute by mentioning that AM is an alternative to classical concepts to "reduce supply chain cost while at the same time improving service". They add the following arguments:

\footnotetext{
${ }^{3}$ Precisely duplicating means having a reusable CAD-dataset to be used for manufacturing. (Gibson, Rosen, \& Stucker, 2010)
} 
- No tooling is needed significantly reducing production ramp-up time and expense.

- Small production batches are feasible and economical.

- Possibility to quickly change design. ${ }^{4}$

- Allows products to be optimized for function (for example optimized cooling channels).

- Allows economical customized products (batch of one).

- Possibility to reduce waste.

- Potential for simpler supply chains, shorter lead times, lower inventories.

- Design customization." (Holmström, Partanen, Tuomi, \& Walter, 2010)

Another advantage is that non-identical parts can be produced in one production run, as long as building space allows it (Hopkinson \& Dickens, 2001), which further supports the ability of mass customization (Atzeni, Iuliano, Minetola, \& Salmi, 2010). Dimitrov et al (2007) add that AM has the unique ability to produce highly complex parts quickly. Gibson et al (2010) state that CNC mainly differs in that it is primarily a subtractive rather than additive process, requiring a block of material that must be at least as big as the part which is to be made. This is a clear advantage of AM, since every shape can be formed out of a bag of powder.

Another interesting option for AM is the possibility of reverse engineering, which can also be used for remanufacturing. This is mentioned by Xing et al (2011), where used components are rebuild to a like-new condition. This addresses the field of reverse engineering, where used parts are acquired and available on demand to meet the needs of remanufacturing.

\footnotetext{
${ }^{4}$ This becomes possible due to the use of CAD-datasets, and can support in-situ optimization or remote control. (Pérès \& Noyes, 2006) It can be understood as electronic "spare parts". (Gibson, Rosen, \& Stucker, 2010)
} 
Reverse engineering is the term for the generation of 3D-data based on an existing part. To catch the geometry of the parts calipers and coordinate measurement devices are traditional methods for generating 3D-data, which can be substituted by modern technologies today. For example laser scanning based technology does not even require direct contact to the part. This can be important for fragile or sensitive parts ${ }^{5}$ (Zhang, Tsou, \& Rosenberger, 2000). In general reverse engineering might be a solution in specific situations. Christensen and Bandyopadhyay (2000) present a general overview about the mainstream reverse systems.

Postponement is another important key-word for AM with future potential. The work of Yuen (2003) presents a framework to assist developers in choosing a good postponement strategy. The term postponement stands for a system where common platforms, components or modules are used, but the final assembly or customization does not occur until the final customer requirements are known. Van Hoek et al (1998) state that improvements in the area of postponement strategies have potential to improve distribution service quality and make companies more responsive to customers (and therefore the availability of spare parts). The point of postponement strategies is that risk and uncertainty costs can be reduced by the differentiation of goods.

\subsubsection{LIMITATIONS AND CHALLENGES}

During literature review it became obvious that several general challenges exist in regards to the implimentation of RM in an industrial environment. Pérès and Noyes (2006) found that previous analysis, performed by Alström, did not include the use of AM techniques. This means that there

\footnotetext{
${ }^{5}$ An example for a traditional method: "The traditional method for object reconstruction in paleontology is two-step process beginning with forming latex molds from fossils or specimens, and followed by creating epoxy cast of the object." (Zhang, Tsou, \& Rosenberger, 2000)
} 
is a lack of knowledge about the performance of AM in an industrialized environment, especially when it comes to spare parts.

According to Holmström et al (2010) another challenge is the limited part range, allowing an application only in specific situations.

Based on Neef et al (2005) the weaknesses can be categorized in seven bullet-points:

Speed - Even the fastest RM-machines cannot meet the speed of traditional machines. The success of AM is strongly dependent on a reduction of manufacturing time. Only when the total production cycle is taken into consideration, AM can show its potential (from design to the delivered product).

Quality - Quality is not at the same level as the quality produced by traditional machines. Postprocessing might be required to reach the acceptable quality level. But AM is continuously improving this issue and results equal to traditional products will be reached.

Object size - The current state of the art allows only a limited object size for common AM machines. As a rule of thumb, an increased size of an object increases the manufacturing time, which affects the use of AM significantly and may lead to ineffectiveness. The effect inverts when the size decreases, which may lead to an advantage of AM. But this advantage can be limited by a minimal wall thickness, dependent on the used process. Dimitrov et al (2007) contribute that it is possible to manufacture parts that are bigger than the space available in the AM-machine, by splitting the part into several parts that are to be assembled later on. This may affect the assembly time and therefore enlarges the manufacturing time.

Cost - To buy and maintain an AM machine is often not economic for a company. But it is expected that an increasing market will decrease the overall cost. 
Material drawbacks - The scope of materials used for AM has not yet reached the scope of traditional manufacturing, so there are no equivalents for every case (mechanical, thermal or electrical properties). However, AM offers also new possibilities such as mixing different materials in one piece, variable properties of photopolymers or upcoming possibilities in Nanotechnology. Material research and development is a continuous process.

Legal issues - Main issue in the context of legal issues or intellectual property is the copy potential of parts that are available. This might lead to discussions about protecting the rights of the supplier of a specific technology, since the economic impact can be significant. At the moment, only weak protection systems are in use.

Internal difficulties and general skepticism - In addition to the mentioned points, no company will reorganize its manufacturing until noticeable benefits are certain to be the result. Established technologies complicate the implementation of AM as well. A good chance for AM is expected where highly customized products in very low quantities are required (for example customized ear plugs).

Pérès and Noyes (2006) identify other interesting issues. It is stated that today even the strongest AM technology is not ready to fulfill all the requirements of spare parts manufacturing, but good progress was made in the past years. This fact raises the question about what technology improvements are required to make AM technology a realistic option for making spare parts on demand in an industrialized environment.

Wohlers (1995) reports the biggest upcoming changes and improvements in the ratio price/ performance, material property, accuracy, software ("interface and process") and "technology enhancements (different technologies)". He further states that the properties most desired by industry are a reduced time for manufacturing functioning objects, a reduced process chain from initial design to the finished product and based on that a speed-up development process. This 
might be true for classical production companies, but it is not clarified whether it is also valid for spare parts.

Ruffo et al (2007) see that "there is a lack of work on the implementation of AM as a mainstream manufacturing process" (Ruffo, Tuck, \& Hague, 2007). Hull et al (1995) tell about the "bad experience" of possible users. These users experienced an insufficient quality of their products with an earlier state of the art technology. They recommend a regular update about the technology to keep possible users informed, since AM is in a continuous improvement process. Atzeni et al (2010) see a challenge in the redesign for AM applications, since traditional manufacturing processes can be different compared to AM processes.

To sum up, following drawbacks exist for the implementation of AM in an industrial environment:

AM process performance - Process properties and possible object size are limited.

Limited scope of materials - The scope of materials, constant part quality and the material price are an ongoing issue.

Design - Parts need to be designed or redesigned for AM.

Management, organization and implementation - It is still difficult to get over general skepticism in industry.

Cost - It is expensive to buy and maintain an AM machine which is able to hold an industrial standard. 


\subsection{FURTHER PROCEEDING}

As mentioned several times during review, further research is required. Unfortunately, not many practical applications are known. For this reason simulation seems to be an appropriate tool to estimate the behavior of AM machines when they are placed in a decentralized supply chain. The software which will be used to execute the simulation is Arena. This software is fully hierarchical and allows the user to setup simulations by use of a simple graphical interface. A short introduction into Arena can be found in the appendix, which gives readers who are not familiar with the software an overview about its concept and functionality.

It should be stated here that simulation is strongly dependent on available data, which requires an intense data collection to have a representative model. Due to the fact of unavailable practical data the input data will have to be estimated. Selection of the right interfaces of the model can allow for reduced required input, focusing on performance data. Regardless, simulation seems an appropriate tool, since it allows to measure system performance, effects of various inputs, or improved system setups as well as detailed analysis of a system. All of this can be done without the physical system, and allows to run experiments without inflicting harm on an actual system. 


\section{SIMULATION OF SPARE PARTS ON DEMAND}

In order to define the problem an extended literature review was executed to define an appropriate problem which would be able to contribute to ongoing research activities. Over the course of several discussions it became clear that a simulation model, showing the performance of an AM machine, would be of biggest interest. This is in accordance with other manufacturing simulation approaches, where a variety of cases is simulated to evaluate performance of manufacturing. Often the goal of these simulations is "to develop a simulated workshop for designers to conceptual design work while taking into account manufacturing process information" (Xu, Zhao, \& Baines, 2000). Other problems were decided to be of minor interest for the scope of this work, so it was possible to set clear boundaries for the research problem. The system and concept of the simulation will be discussed in the following chapters.

Kelton et. al (2010) present several aspects which are typical and important for a simulation study. They sum things up as a multi-step procedure to support the development of simulation studies. The steps of the procedure are to (1) understand the system, (2) be clear about goals, (3) formulate the model representation, (4) translate into modeling software, (5) verify the simulation model, (6) validate the model, (7) design the experiments, (8) run the experiments, (9) analyze the results, (10) get inside the results, (11) document what is done.

The proceeding is applied for the development of the simulation model. 


\subsection{UNDERSTANDING THE SYSTEM}

Two points of interest were found in regards to spare parts on demand. One is to select the correct spare parts and the other is to test if the system will work in an acceptable range. Since the main interest of this work is to evaluate the performance of an AM machine, simulation was found promising in gaining results without having a real system to perform tests. To do so, the AM process with all of its parameters was analyzed to get a full picture of what happens when the AM machine is set in a spare part supply chain. It is important to mention that the model aims to be on a generic level and based on this allows to make predictions of future development. The further work will assume that the process of spare part selection was executed previously to deliver input for the simulation model.

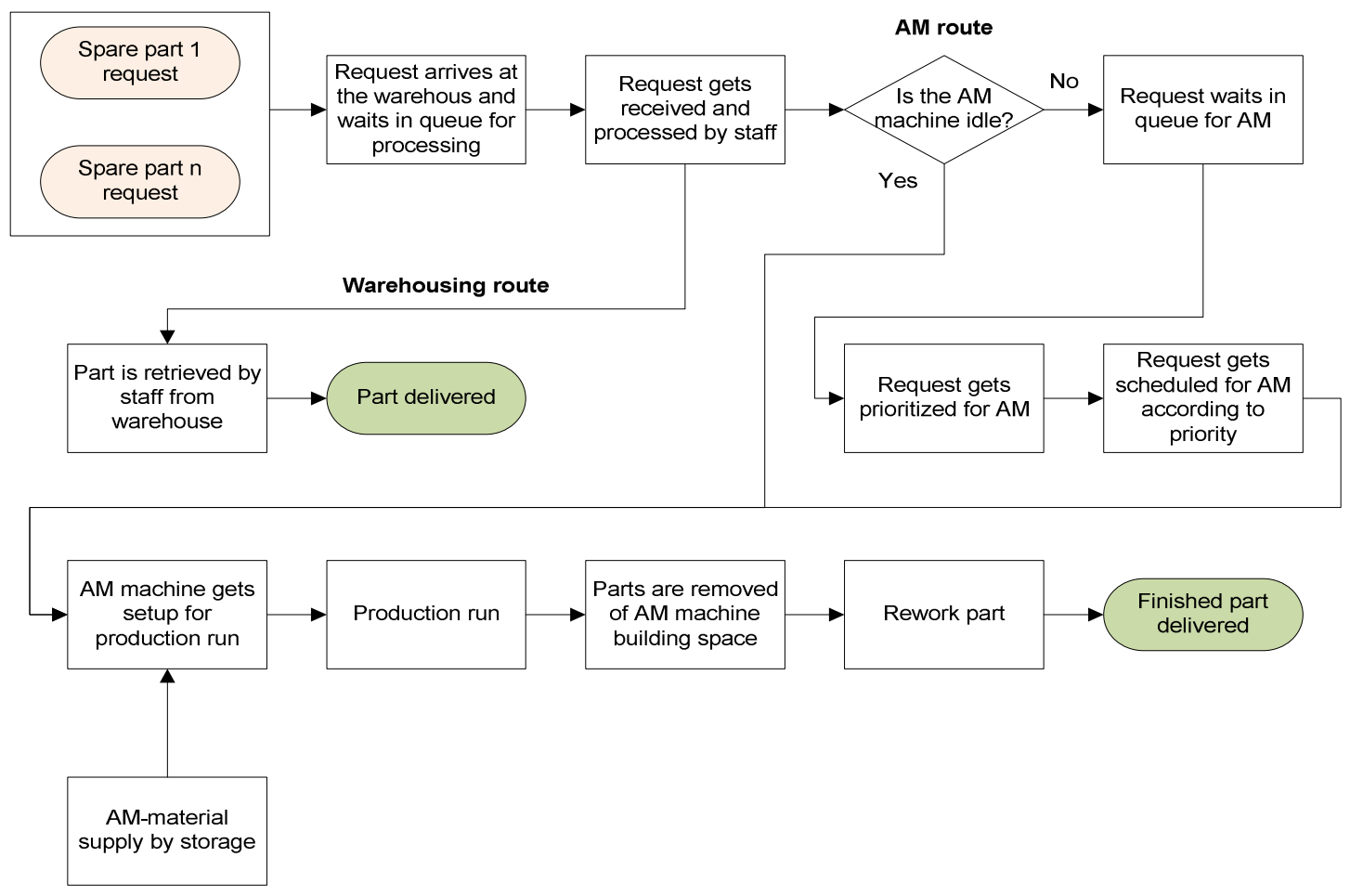

Figure 3-1: Process of AM vs. warehousing 
In the following paragraphs the simulation model will be mapped out and explained in detail to help the understanding of the process. This will also define the scope of the simulation, which ranges from the arrival of a spare part request all the way to the final delivery of the requested item. Since the simulation model aims to compare the AM results with classical warehousing, so both will be included in the simulation. Accurate details will be included when the model is translated to Arena.

Spare part request - The process starts when a spare part is requested, which can be understood as order of a spare part. The request for the part can be based on various reasons. It can be based on a maintenance strategy or a random request for a part. For this work it will be assumed that it is possible for every requested part to be manufactured by AM. Furthermore it is assumed that all pre-work to allow AM has already been done. This means that engineering was done and the CAD data is available to run the AM process. In consequence all part information like material, geometric parameters, time to manufacture, priority or cost of unavailability are available.

Request waits in queue for processing - The request will arrive and has to wait until a member of staff can receive it. This time is based on the availability of the staff, following opening times or shifts. This is an important factor when spare parts must be available in a relatively narrow time window.

Request gets received and processed - When the staff is ready to receive the request it will be processed further, which contains a processing time for the request. At this point the process is split up. One route follows the warehousing route, the other one will follow the AM route. To enable the comparison between AM and warehousing parts both processes run in parallel. The warehouse route will be explained first. 
Part retrieved by staff from warehouse - The staff picks the part from the warehouse and delivers the part directly. This often results in a relatively short processing time. The related cost and warehouse data are updated and available immediately when the part is delivered and leaves the system. A blink on Figure 3-1 allows to see that the process of warehousing follows a simpler process than AM. Since a wider scope of the model is assumed not to be beneficial for the results, the model is not more detailed for the warehousing route.

Check if AM machine is idle - The first step in the AM route is to check if the AM machine is idle. When the AM machine is idle the production can start immediately. If the machine is not idle the part has to wait in queue until the AM machine is idle.

Request waits in queue - When direct spare part supply by AM is the target, the AM process has longer processing times than warehousing, therefore queuing of the requests becomes a relevant issue and prioritization is necessary to have the right part available on time. The required lead time of parts can reach from several weeks, having to be available as soon as possible, or somewhere in-between. The time in queue is an important factor for the overall system performance.

Request gets prioritized for AM - The basic prioritization should already be predefined in the priority of the part when it enters the system. Prioritization in this case is a loop process, updating the priorities before each production run. It may happen that parts have to wait for several production runs due to their lower priority or that parts need to be produced immediately. This means that the prioritization needs to follow a logic that always updates the priority, setting up the most important parts for the next production run.

Request gets scheduled for production - Based on the latest priorities the production run is planned. This means that the building space is planned to be filled with parts until the volume is filled up. The batch is then ready for production. 
AM machine setup for production run - Before a production run starts, the AM machine needs to be prepared by staff who will take the necessary actions such as for example preheating and assuring conditioning of the machine to fulfill the production run without failure.

AM material supply - The AM material is a consumable for the AM process. Material must be available during the whole process, in order to have a successful production run. Therefore storage of the material is important to keep the process running.

Production run - The production runs automatically and no further activities are needed during production. The production itself is dependent on the performance parameters of the AM machine. The best example for a performance parameter is the building speed, which has a strong influence on the production time. The production will run until the batched parts are finished.

Removal of parts from building space - The parts are removed by staff from the building space. Depending on the setup of the machine that might influence the proceeding. for example fixed building space compared to exchangeable building space. The removal of parts also includes maintenance actions such as cleaning the machine.

Rework of part - After production of the part it is possible that a part may need rework in order to reach the final quality. Parts which need rework will need some extra time before they are delivered, while parts that do not need rework, only cleaning, can be delivered directly. Cleaning is assumed to be a standard rework activity.

Both the AM and the warehousing solution, have benefits and draw backs. While AM is promising in reducing warehousing cost, problems might occur when spare parts are not available on time due to the AM process time. On the other hand warehousing generates higher cost for parts which are used seldom, but parts are available immediately up on request. The simulation model is able to compare both, and makes it possible to compare both solutions on an economical 
basis and to find boundaries for a useful application of AM in the spare part supply chain, and to evaluate the impact of parameter changes.

\subsection{ESTABLISHING CLEAR GOALS}

Having defined the targets for the simulation model, we now discuss which method will produce realistic results to meet the targets.

1. A simulation model is to be developed, representing reality as close as possible. The model should be verified to have trust in the results and variations in the performance parameter. However, a validation will not be possible, due to a missing real system.

2. A realistic base case is to be set up. This means integrating a spare part request, staff and AM performance parameters, warehousing cost, and other assumptions on a realistic level. If real information is available, it is used. Examples for assumptions are spare part requests or warehousing costs. Defined parameters are available for the AM machines or materials.

3. Communicate the base case and set up alternative scenarios for further evaluation and execute experiments manipulating the parameters of interest. At the current state the machine parameters building space, building speed and material cost are of major interest, such as several production strategies.

A variety of actions have been considered in achieving the above scope. The overall goal is to make the effect of changes in the performance parameter set visible. Simulation will support decisions in the development of AM machines, especially focusing on the application of AM in the spare part supply chain. 


\subsection{FORMULATION OF MODEL REPRESENTATION}

The model follows the described process. It seems most effective to follow the requests through the process and see what the effect is on the system and how fast parts can be delivered, which is important for spare parts.

The request generation can be assumed to be an easy task, since it follows probabilistic distributions which can be formulated easily. The arrival in the system and waiting for processing also does not need a lot of attention.

The process gets more complicated when parts are already in production and queuing occurs. The parts in the queue will need special attention with respect to prioritization. The model allows to bring the parts in an appropriate order for the next production run. The rules for prioritization will be described in detail in Chapter 3.4. Prioritization is essential for having the parts in time as often as possible. The prioritization should include the allowed time for manufacturing, processing time, time in queue, priority of the part, and the resulting place in the queue for the next production run. When the prioritization is clarified the rest of the process is a straight forward calculation of the results of interest.

For the calculation of the results and processing times the model needs a carful setup so that all important factors can be taken into account. A detailed description of this will be included in Section 3.4.

It is of major interest to have a flexible model that allows manipulating the arriving part requests and to exchange the AM machine type.

Since the model should result in a comparison of AM and warehousing in the spare part supply, the warehouse should be represented on a level of detail which allows an acceptable insight. It is decided that the stock values of a stock represent the basis to calculate the warehousing cost. It 
must be assured that changes in the stock are tracked. It is further assumed that the generated warehousing costs are directly related to the individual part and no further calculations are required. Also, the relevant warehouse data will be explained in Section 3.4.

The time frame for the model cannot be set without a given set of requested spare parts. Spare parts can be stocked for many years without being used once. Depending on the case, a spare part type can also have a daily turnover. Predictions of usage are not possible for every case. A practical solution to solve this issue is to stress the system with a spare part set and focus on the volume of the parts. To illustrate, the AM machine is able to supply spare parts with an average of 24 hours when the average requested build volume is $7000 \mathrm{~cm}^{3}$. With respect to the building cycles which can easily extent to over 8 hours, and bearing in mind that staff may work according in shifts or on fixed opening times, it is proposed to simulate over the course of one year. In this year planned and unplanned requests should occur with different states of priority. When real data is available, the request simulation and the time frame can be adjusted accordingly.

When real data becomes available, several information is of interest. It starts with the basic spare part information. For each part a description, unique ID, number on stock, material, value per part, usage statistics, associated storage cost, priority, geometric information, EOQ and the accepted time to delivery should be known. To gather this data it is likely that different sources will be used. The warehousing data is probably accessible in form of historical in-house data, observations, or other kinds of log books or lists. What will most likely not be included in the warehouse data is the priority and accepted time to delivery of each part. When warehousing, parts are typically available immediately and it is not necessary to define these attributes. The assignment of priorities and accepted time to deliver each part should be done as a group between the model developer and representatives of the organization interested in the topic. It might require an extensive work load and discussions to define the attributes for each part properly. 
Schedules for staff can be collected and included in the simulation model.

AM machine data is provided by suppliers of AM machines and is available. Websites or direct communication with the supplier is sufficient to find proper information.

Further details and proceedings were setup during the work and are described in the further text. 


\subsection{TRANSLATION TO MODELING SOFTWARE}

After describing the model it needs to be translated to the modeling software. The used software is Arena, what allows a good graphical display of the model. This chapter describes in detail the setup and abilities of the model. Figure 3-2 shows the finished base model after a simulation run.

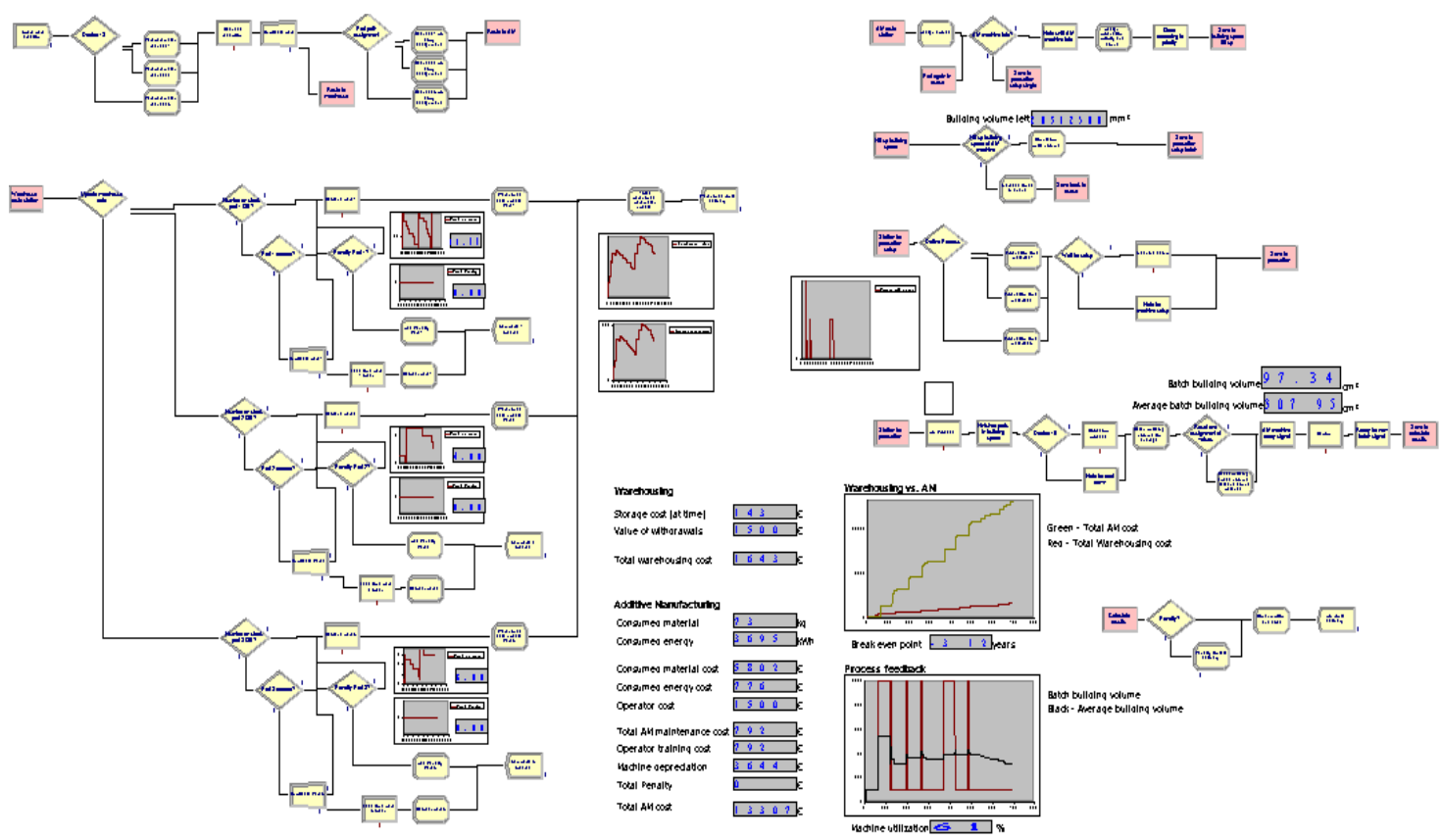

Figure 3-2: Full view of the simulation model

At this point the setup of the base model is explained in detail to keep a better overview about the different modules and sections of the model. After the general description of the simulation model the extensions to the full model will be described in later chapters.

This will include the issues selected spare part set, run times, replications of simulation runs and further model adjustments to meet the specific scenarios. During experiments several parameters or settings might be changed due to required adjustments. Changes of are documented when they are executed. 
The model begins with at the run setup where initial model parameters are set. Figure 3-3 shows the used parameters in the run setup dialogue box. To reduce the standard deviation of the results, the model will run 150 times for each scenario. The model will have a warm up period of 720 hours (one month). This allows to start observing the system when it is in a steady state. The total run time for each replication will be 1440 hours (simulation over 2 month). Based on this, the replication length represents one month. The basic model assumes a 24/7 schedule, since the machine must produce whenever it is needed to meet the spare part requirements. The used base time unit is in hours through the whole model.

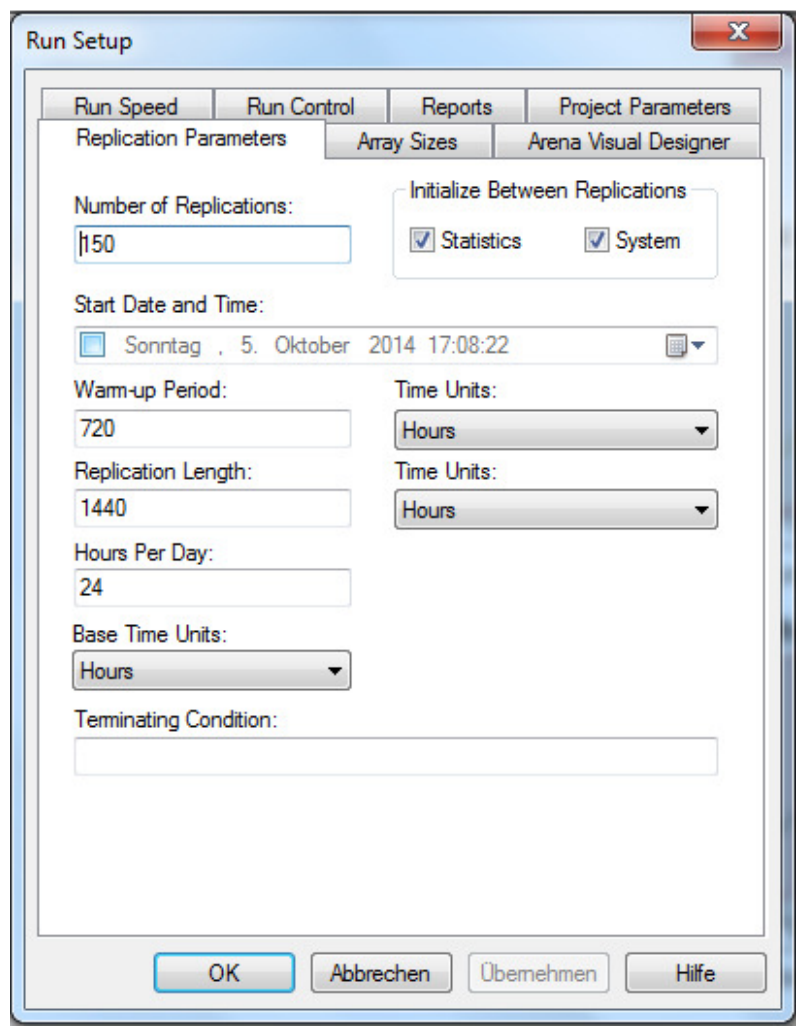

Figure 3-3: Run setup 


\subsubsection{CREATION OF PARTS AND ROUTING}

Figure 3-4 shows the first section of the model where spare part requests are created, parameters assigned, parts are duplicated, routed to the warehouse and the AM machine for further processing.

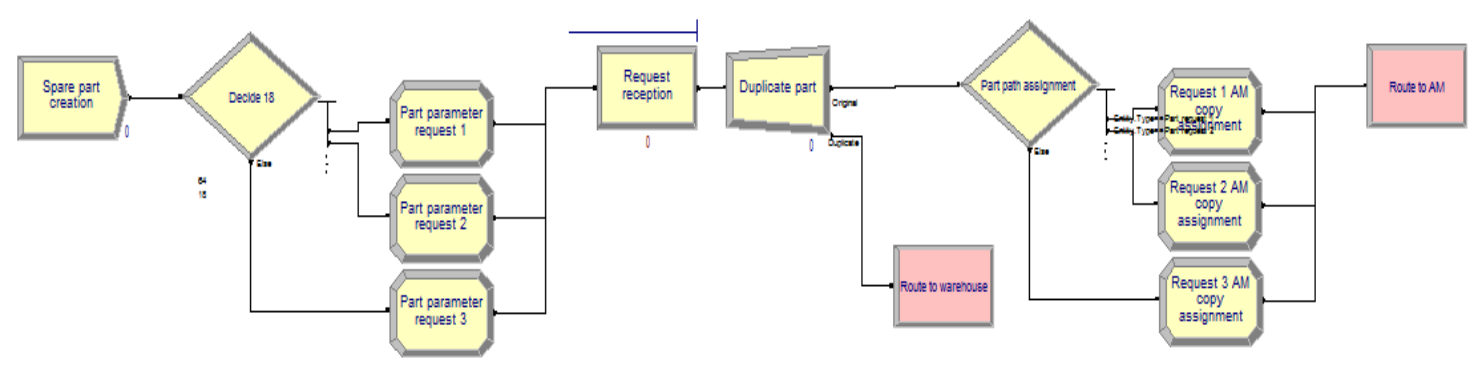

Figure 3-4: Creation of parts and routing

The model starts with a create module which generates all spare part requests. The time between arrivals is set to a uniform distribution with a minimum of $0.25 \mathrm{hrs}$ and a maximum of $45 \mathrm{hrs}$. According to Kelton et al (2010) a uniform distribution should be used when only little is known about the present situation and provides a "worst case" setting. If more information should become available, it is possible to change this setting accordingly. The number of generated entities per arrival is one.

After an entity is created, it enters a decide module. The decide module is set to $\mathrm{N}$-way by chance, which routes the arriving entities to the following assign modules, based on a percentage chance. The assign module assigns part specific attributes to each part request. The appendix holds an overview about all attributes and variables used in the model. Specifically, the following attributes are assigned in the "Part parameter request" module: 
Table 3-1: Assignment of attributes to part at "Part parameter request 1" assignment module

\begin{tabular}{|l|l|l|}
\hline Name & Description & Unit \\
\hline Building volume & Product of building height, width and length of the part. & $\mathrm{mm}^{3}$ \\
\hline Building depth & Describes the building depth of the part. & $\mathrm{mm}$ \\
\hline Building width & Describes the building width of the part. & $\mathrm{mm}$ \\
\hline Bulding height & Describes the building height of the part. & $\mathrm{mm}$ \\
\hline EOQ Part 1 & Economic order quantity of part 1. & $\mathrm{pcs}$ \\
\hline Material type & Material type assignment by use of integer number. & --- \\
\hline Operator cost & Estimated cost of required operator for this part. & $€ / \mathrm{pcs}$ \\
\hline Part value Part 1 & Purchase price of part 1. & $€ / \mathrm{pcs}$ \\
\hline Penalty & Receives the penalty value of each part for further calculation. & $€ / \mathrm{pcs}$ \\
\hline Penalty Part 1 & Penalty when part 1 is not delivered in time. & $€ / \mathrm{pcs}$ \\
\hline Priority & Pre-assigned priority of part as production order basis. & --- \\
\hline Reorder point part 1 & Reorder point of part 1. & $\mathrm{pcs}$ \\
\hline
\end{tabular}

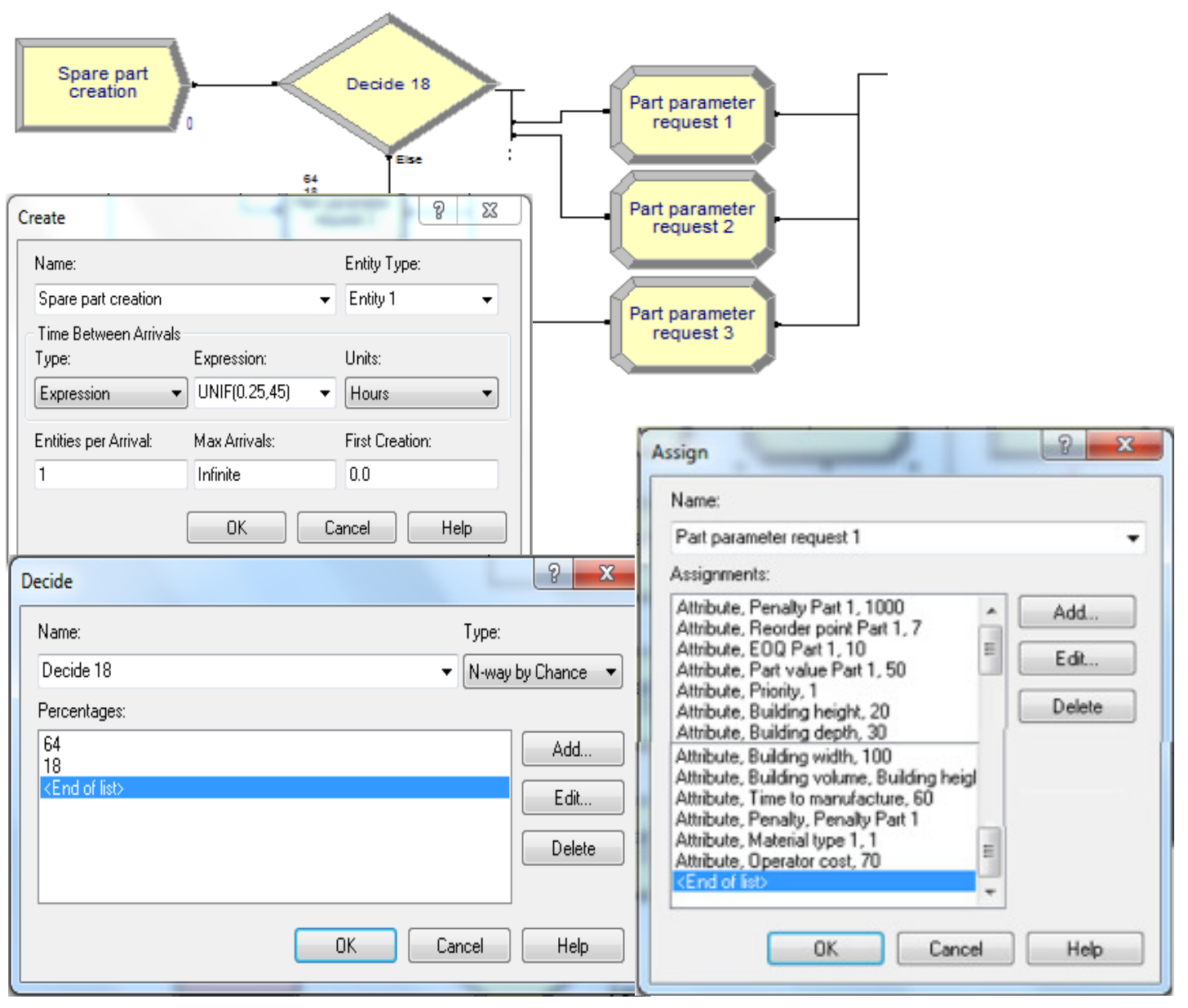

Figure 3-5: Creation of spare part request and attribute assignment 
Attributes marked with a number (for example "Part 1") are valid for the specific part only and are used to allow a precise routing and treatment of the part throughout the model. Attributes which do not have the numbering are general and assigned to each spare part request regardless of the type of spare part. For example, in the second (and further) assign module "Part parameter request 2" "Penalty Part 1" is called "Penalty Part 2", while Priority is again named priority.

A process module in the setting "Seize Delay Release" is the next step for each entity. The process module is called "Request reception" and simulates what its name states. The reception seizes a Reception Staff who will need an average of 0.1 hours to process the request. For this model it is assumed that one receptionist is available 24 hours each day. It could be an option to use more receptionists or to use a shift plan by applying a schedule. Also, the time for processing can be changed and adjusted to the individual case.
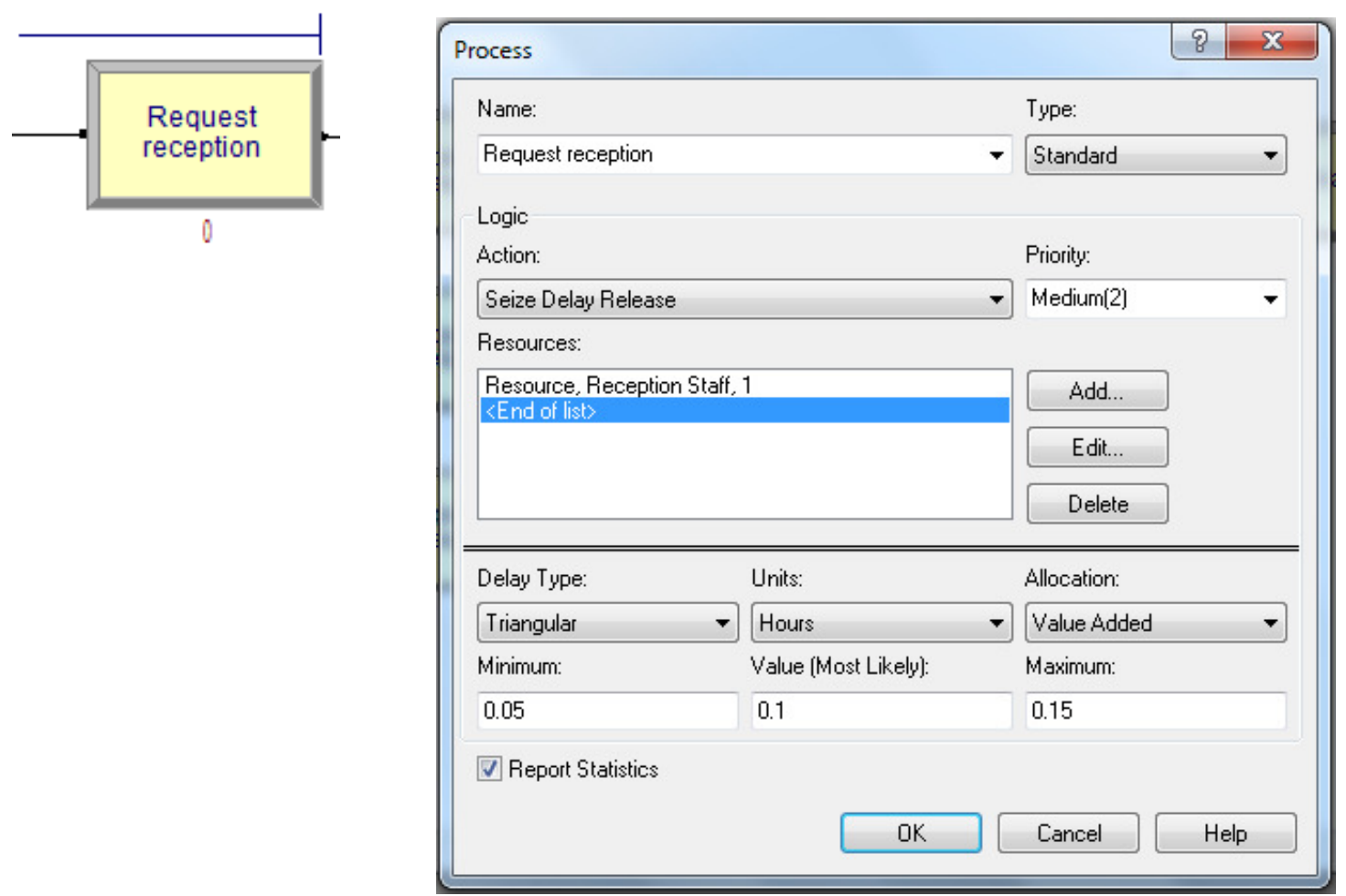

Figure 3-6: Request receptionist 


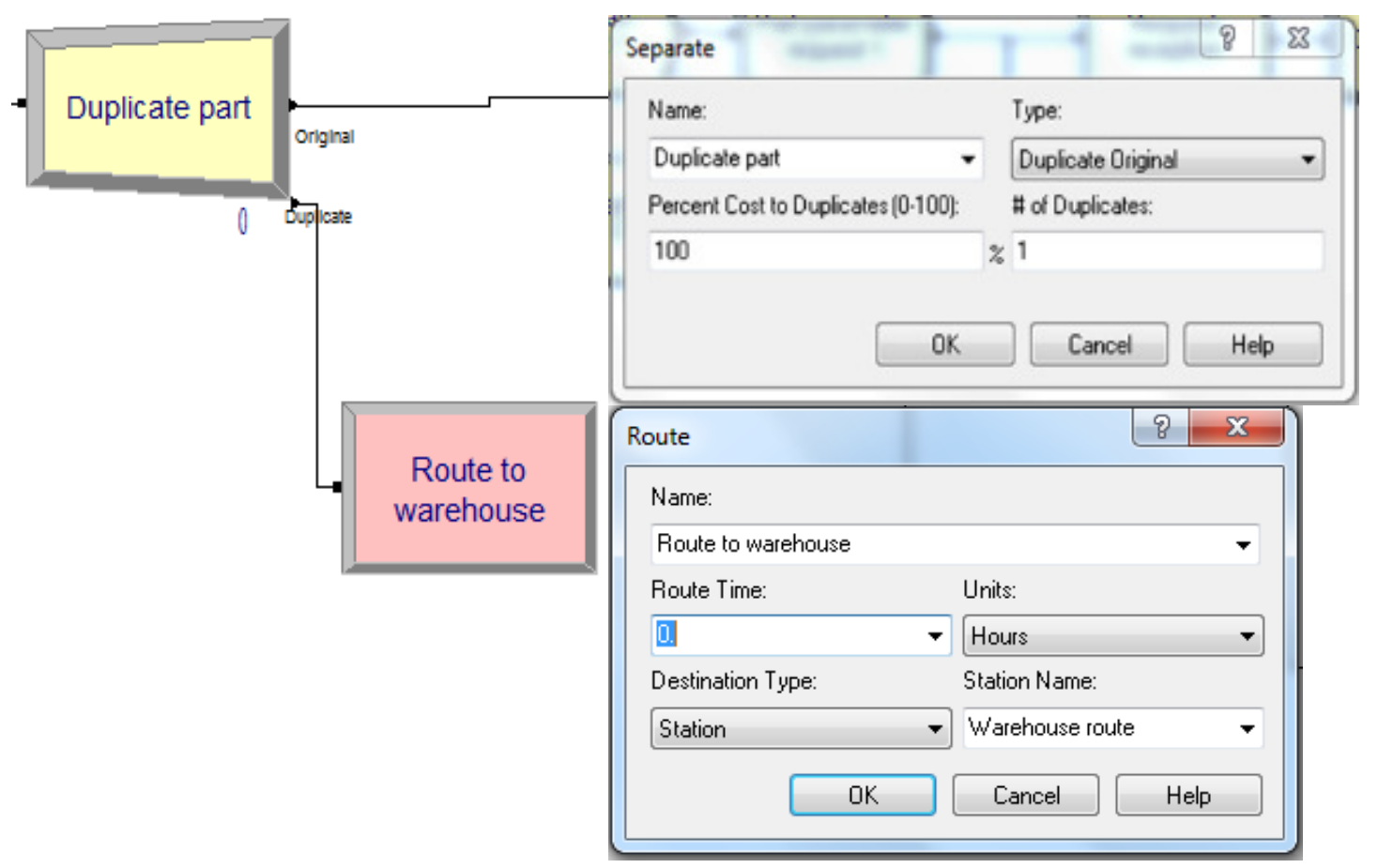

Figure 3-7: Duplicate part requests and route to warehouse route

When the entity is registered at the reception, it continues its way through the model and is duplicated. The duplicate is directly send to the warehouse route where it is processed, while the original part is routed in the direction of the AM process.

Before the part is allowed to enter the AM route another assignment must be done. To do this, a decide module is used in combination with assign modules to make the correct assignments.

The decide module splits the arriving entities based on the entity type. "Part request 1 " follows path one, "Part request 2" follows path two and so on. This way, each entity is directed to the correct assign module. Each entity type is now renamed in the assign module with addition "AM". Example: "Part request 1" is renamed "Part request 1 AM". The entities can then be routed to the AM path by use of a route module. 
To duplicate the original part is important to have the original named parts and the renamed parts separately in the model, which is essential to treat both independently and reach full flexibility of the model. It is also essential to analyze both independently in the results later on. It is possible to look into for example processing times or other statistics in detail of "Part request 1" and "Part request $1 \mathrm{AM}$ " in detail which allows to compare both directly.

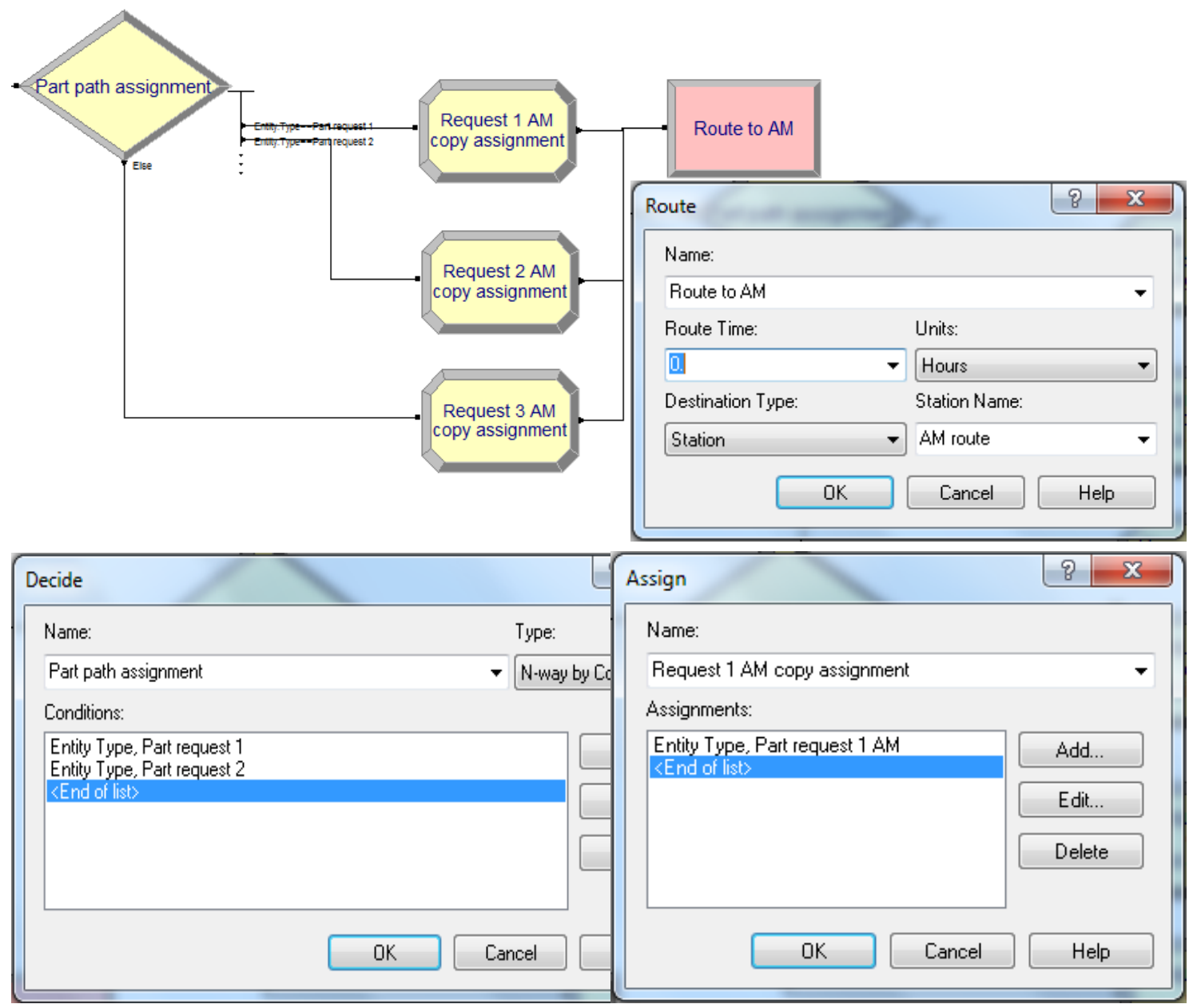

Figure 3-8: Rename entities 


\subsubsection{WAREHOUSE ROUTE}
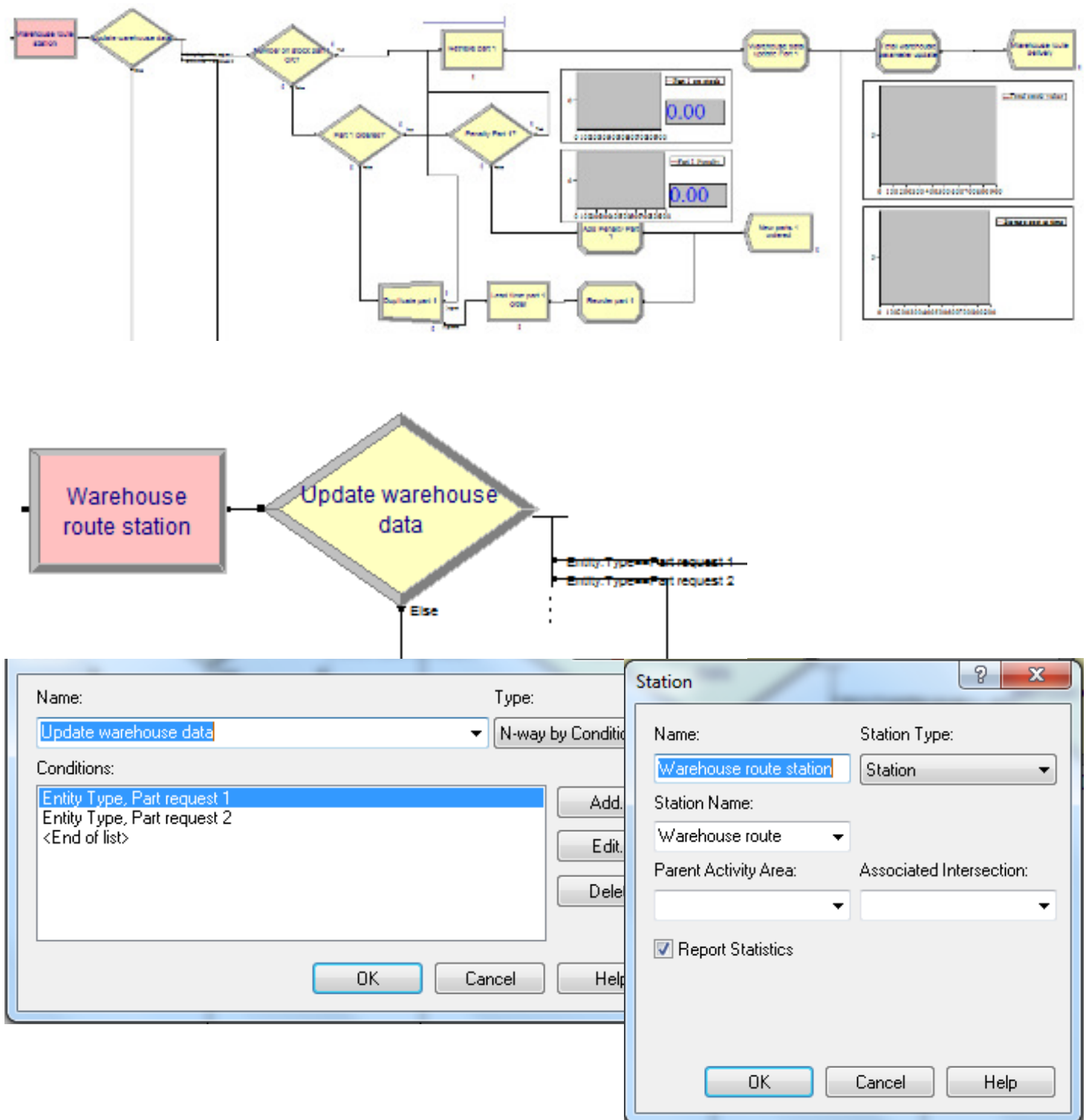

Figure 3-9: Warehouse route station, split up and path for Part request 1

First the warehouse route is described. The entities are sent from the route module and arrive at the "Warehouse route station", which is called "Warehouse route". The spare part requests are now in the ware house simulation part of the model. After the station module the spare part requests are split up according to their entity type in a decide module called "Update warehouse 
data" to update the warehouse data on an individual basis. Part request 1 follows path one, Part request 2 follows path two and so on. This way of dividing the paths allows to keep track of every spare part and stock individually.

In this description only the path of Part request 1 is followed. All other paths are equal in the setup, except that they are set up as an independent path for another part request. A decide module occurs first on the individual path. It is checked if the Number on stock of Part 1 is bigger than the reorder point. If this is true the part request can continue on its way, otherwise new parts must be ordered.
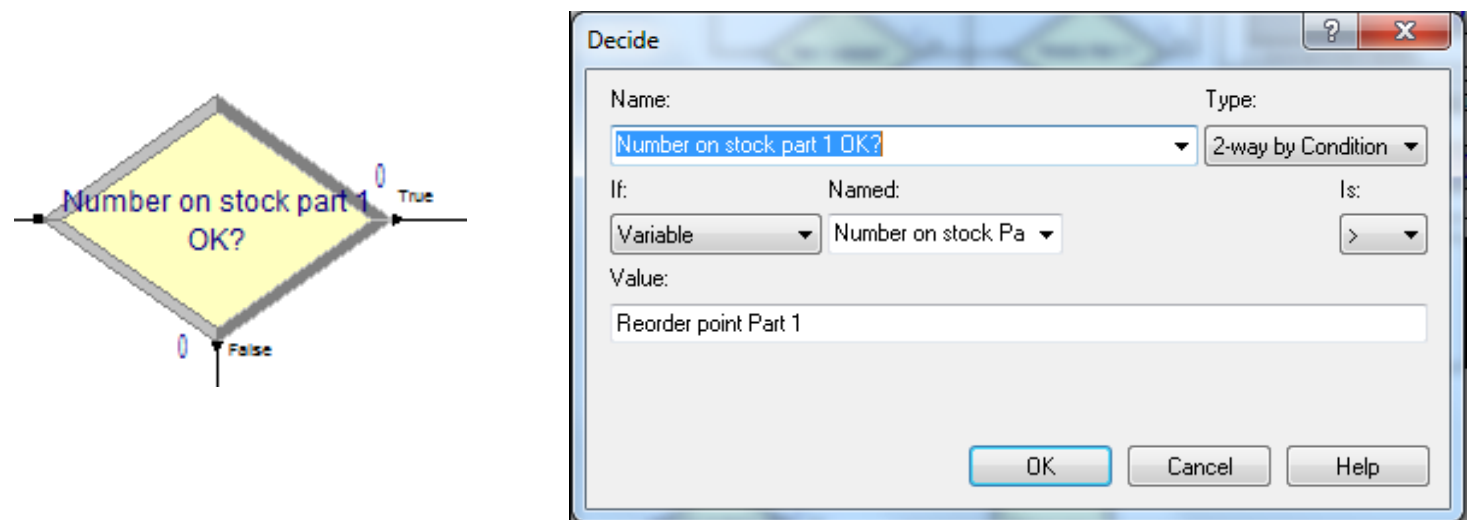

Figure 3-10: Check if number of parts on stock is ok

Next it must be checked if an order is already placed. Therefore the process module "Lead time part 1 order" is used in combination with a decide module. The process module uses the logic action Delay applying a uniform distribution with a minimum of 7.5 hours and a maximum of 36 hours. This time represents the reorder lead time of a specific part type. The type of distribution and values can be adjusted in every intended way to fit the purpose. When there is no entity in the process the WIP is set equal to 0 , while it is 1 when the process is active. The WIP is used to control the way of the part requests. 


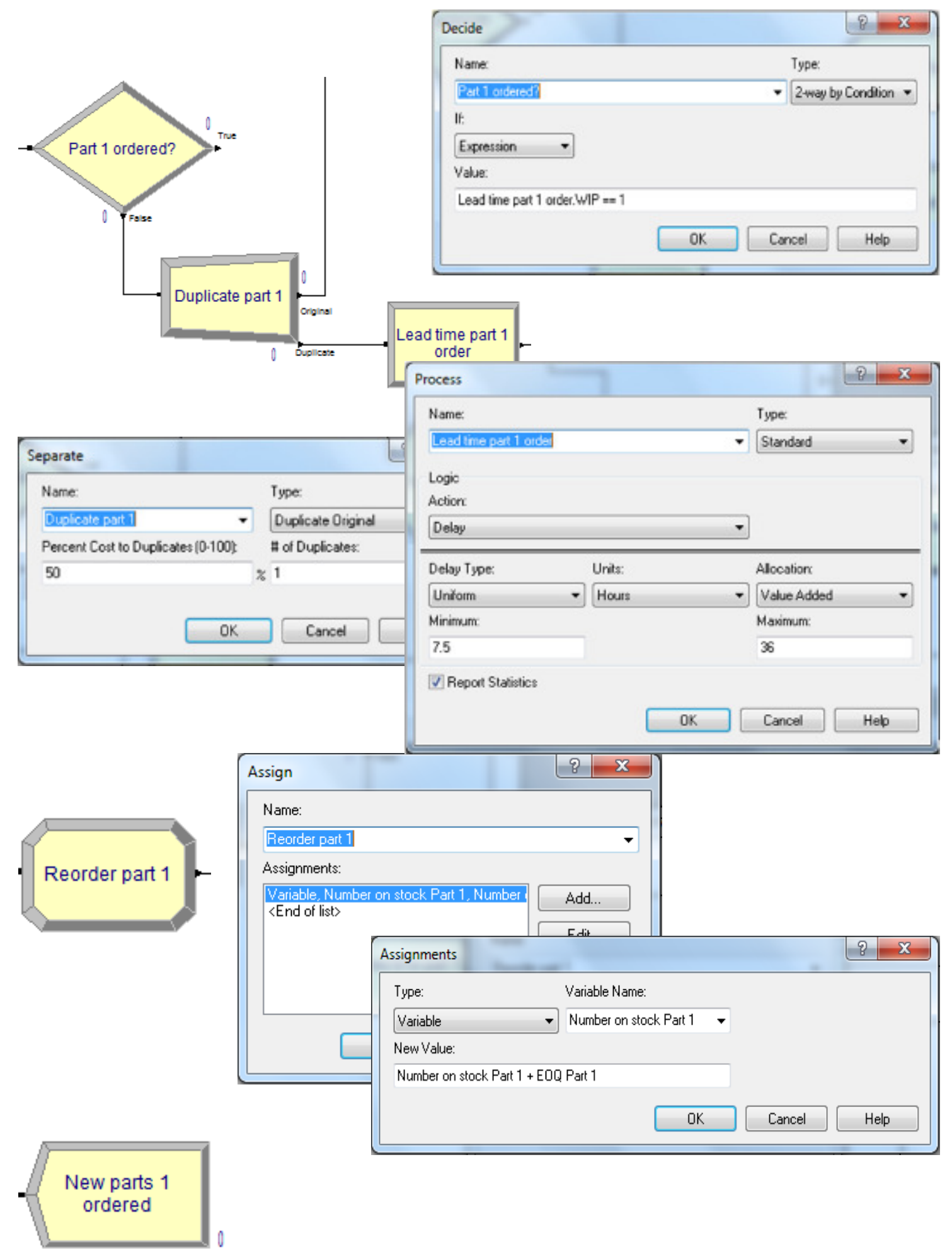

Figure 3-11: Ordering new batch of parts 
The decide module "Part 1 ordered" checks if the process of "Lead time part 1 order" is active or not. When it is active the part request is seen as true and follows this path. Otherwise the part request follows the false path and enters the process module, where it simulates the lead time until the new batch arrives. After the lead time is over, the part request enters an assign module, where the number of parts on stock is updated. The updated number on stock adds up the current number on stock and the EOQ. (Both, reorder lead time and EOQ can later be used to optimize the spare part stock.) After the assignment, the request is disposed in the dispose module "New parts 1 ordered". In order to keep the running request active, a separate module is used to make a copy of the part request. The original part request returns to the normal path, while the copy enters the process module to delay the part order. This means the duplicate is just used to initiate the order. The original part is then treated as every other part following this path and enters the process module "Retrieve part 1". The retrieve process module will be described later.

The true path of the decide module "Part 1 ordered" leads to a decide module called "Penalty Part $1 "$. The decide module checks if the number of part 1 on stock is bigger than 0 . If the number on stock is bigger than 0 the part request is send to the process module "Retrieve part $1 "$. If the number on stock is equal to 0 , it is not possible to deliver the part and a penalty is charged. To charge the penalty an assign module is used. The new variable "Part 1 Penalty" is defined at this position. If a penalty is charged, related to part one, it is added to "Part 1 Penalty", which represents the total penalty of part one during the simulation run. When the new value of "Part 1 Penalty" is assigned the part request is disposed at the dispose module "New parts 1 ordered", which was also used for the reorder logic. 


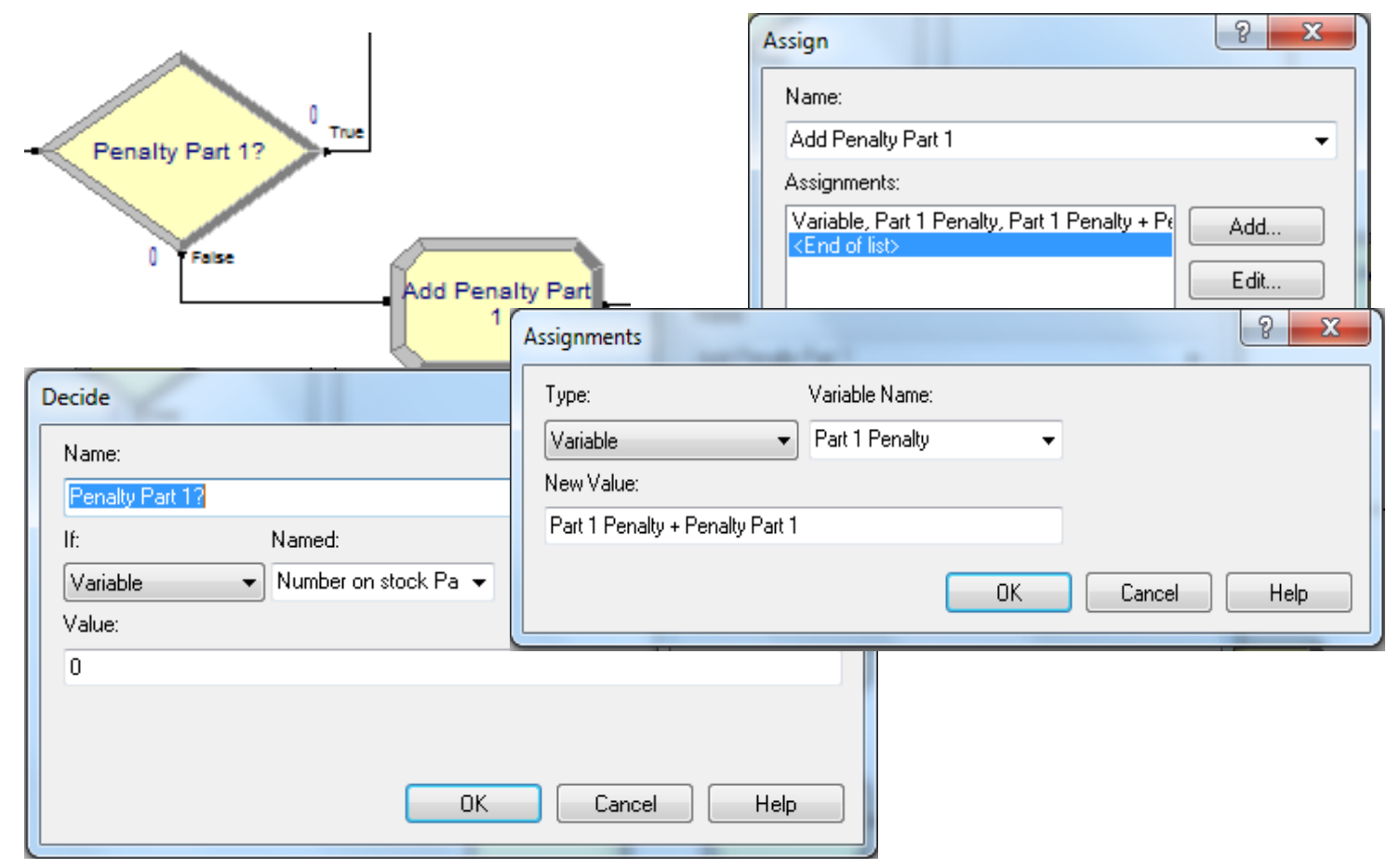

Figure 3-12: Check for penalty and adding it
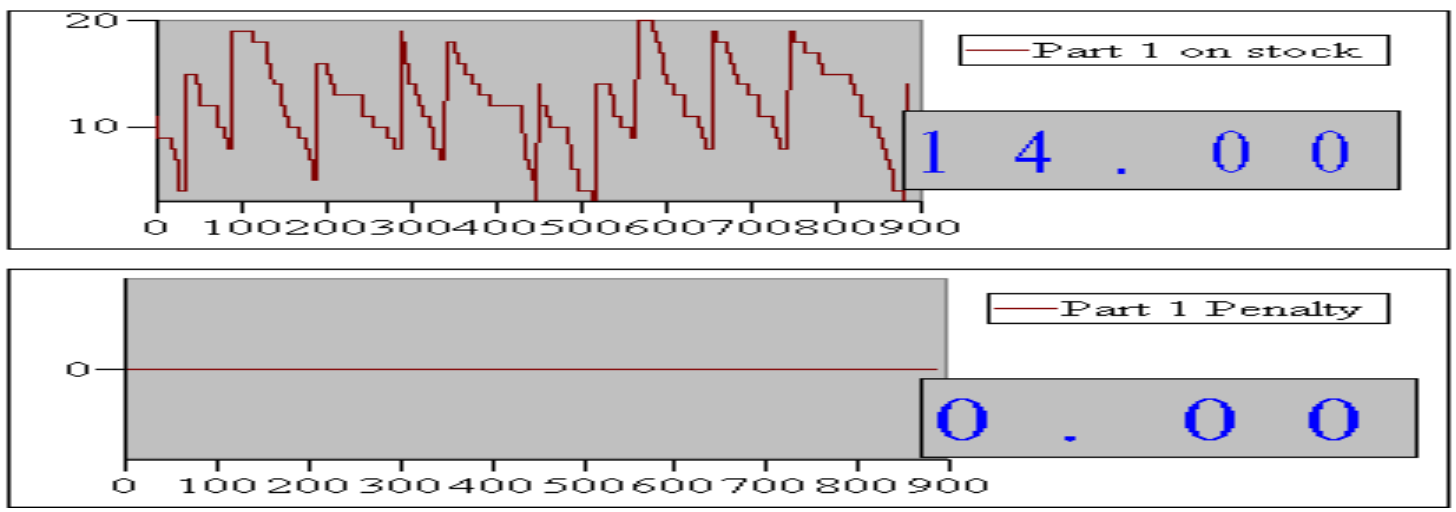

Figure 3-13: Graphical display of Part 1 on stock and Part 1 Penalty (after simulation run)

At this point it might be interesting to introduce to the two graphs in Figure 3-13. One tracks the variable "Number on stock Part 1", the other one "Part 1 Penalty". The displays are mainly used for debugging and an overview of the stock behavior. Both graphs are used to minimize the parts on stock in the later proceeding, for each spare part type individually. A general policy for the 
stock will be one of each part type will be on stock, EOQ is set to zero and the reorder lead time follows the previously mentioned distribution. A penalty will not be accepted for any part type. If a penalty occurs during simulation, the number of stored parts and EOQ are increased for the specific item until no penalty is created. No changes on the reorder lead time are intended.

The process module "Retrieve part 1" simulates the picking of the parts from the warehouse. A resource called Picker Staff is used to execute this action. In this model 1 picker is used to get all requested parts from the warehouse (Part 1,2, and 3). The number of pickers might be extended and/ or schedule based. Also the processing time can be adjusted.
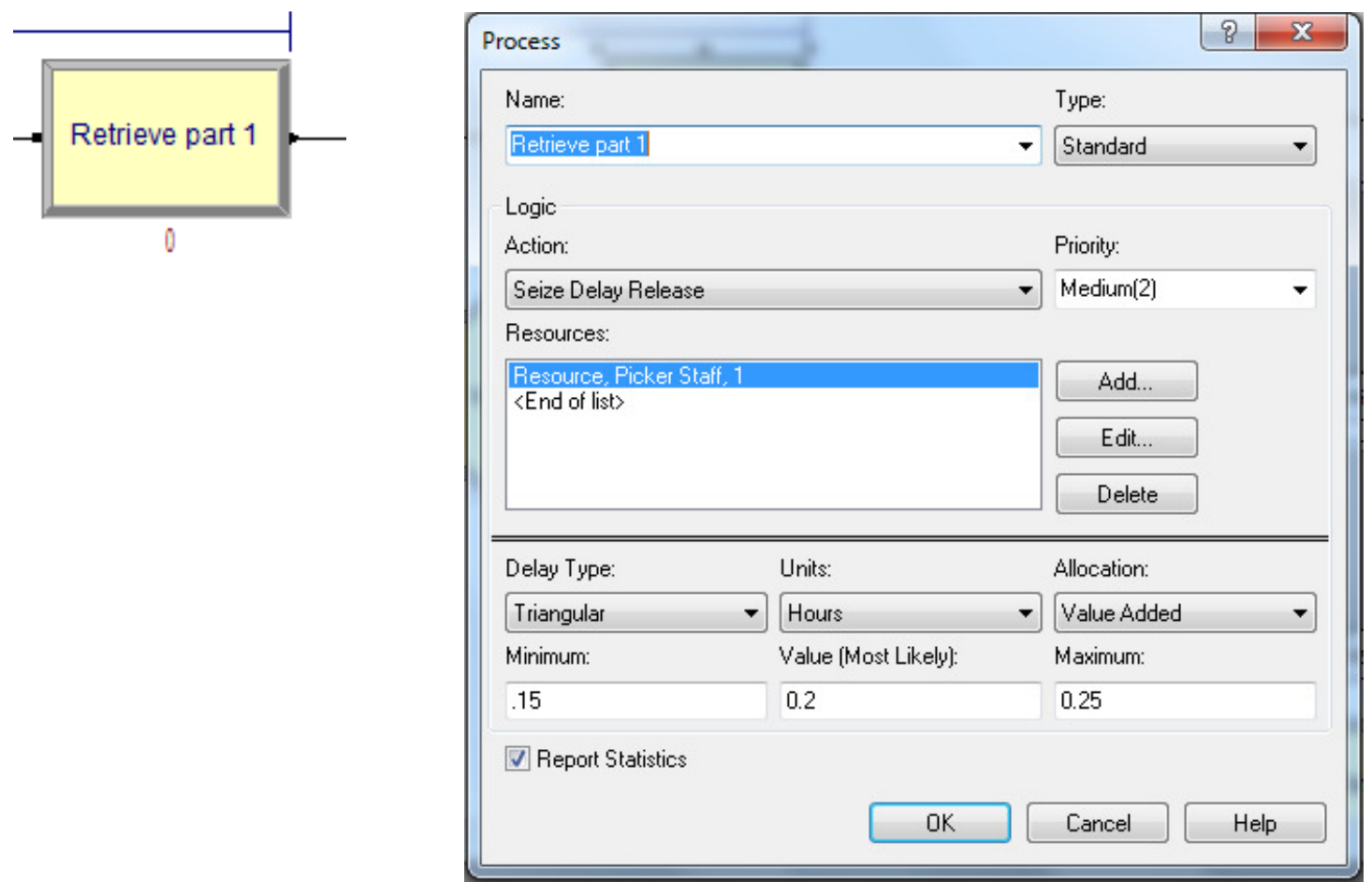

Figure 3-14: Process module - Retrieve part 1

After retrieving part 1 from the warehouse and serving the spare part request the warehouse data must be updated. An assign module is used to do so. Three new variables are defined. "Value withdrawals Part 1consumed parts", "Stock value of Part 1" and "Number on stock part 1". The 
related calculations can be seen in Figure 3-15. What should be noted is that the initial values of each defined variable is 0 as an internal standard setting of Arena. This is important because the initial value of "Number on stock part 1" is intended to be set to a specific value. This is done in the variable module of the basic process panel. For part 1 it is set to 11 to have a start value (could also be 0 and every other integer number).

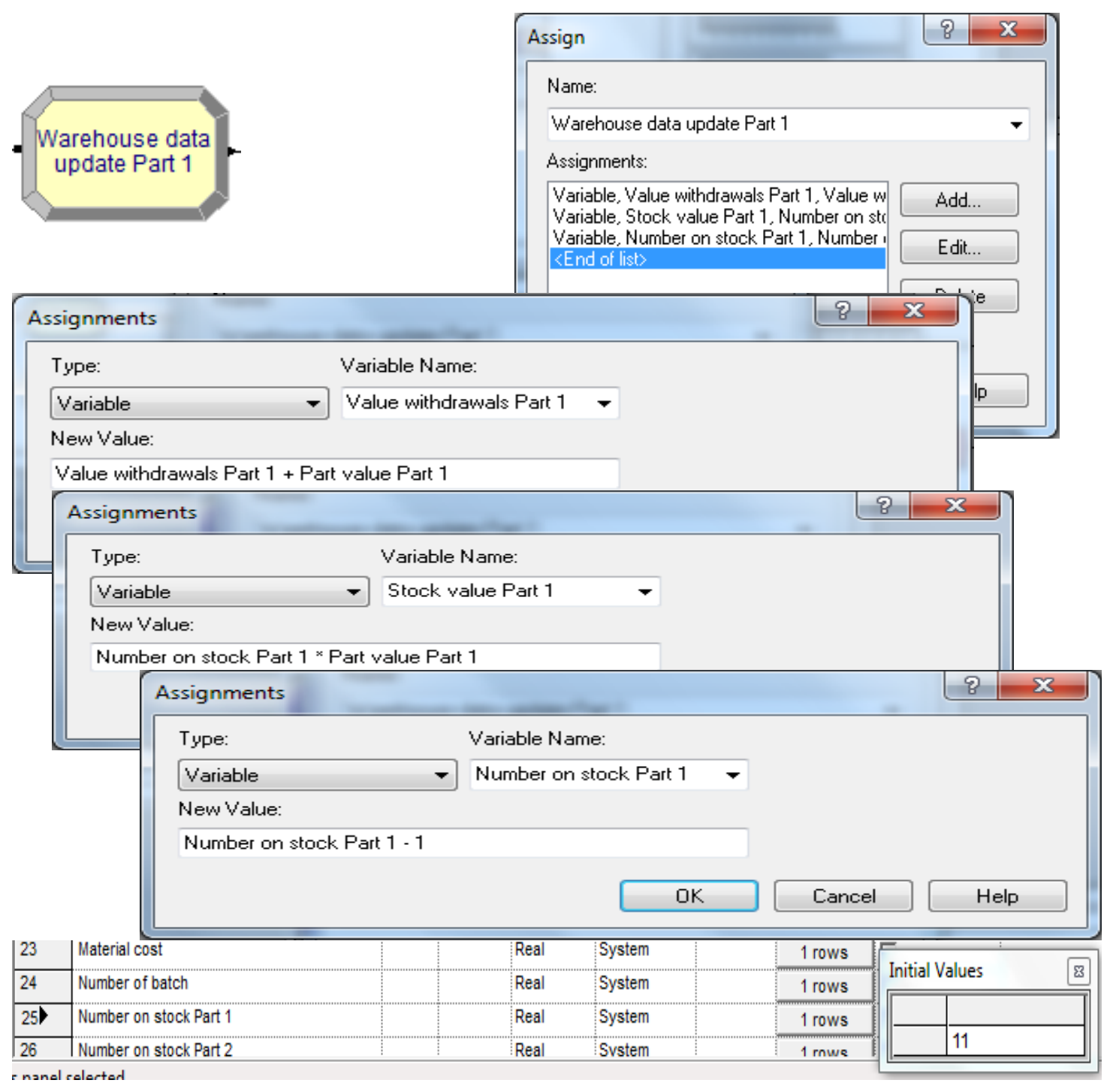

Figure 3-15: Warehouse data update 
After the warehouse data update of each individual part, the total warehouse parameters are updated. This happens in the assign module "Total warehouse parameter update". Four new variables are defined: "Total stock value" - adds up the total stock value of each spare part type.

"Part value consumed" - Adds up the total value of parts taken from stock

"Storage cost at time" - Takes the total stock value and calculates the storage cost by multiplying the total stock value with the storage cost. "Storage cost" is also a new defined variable. The storage cost are set as a fixed percentage value which assumes that for every part on stock the same percentage of cost is generated based on the part value (set to $13 \%$ in this example), covering all cost.

"Total warehousing cost" - Is the sum of the total withdrawal value and the storage cost at time.

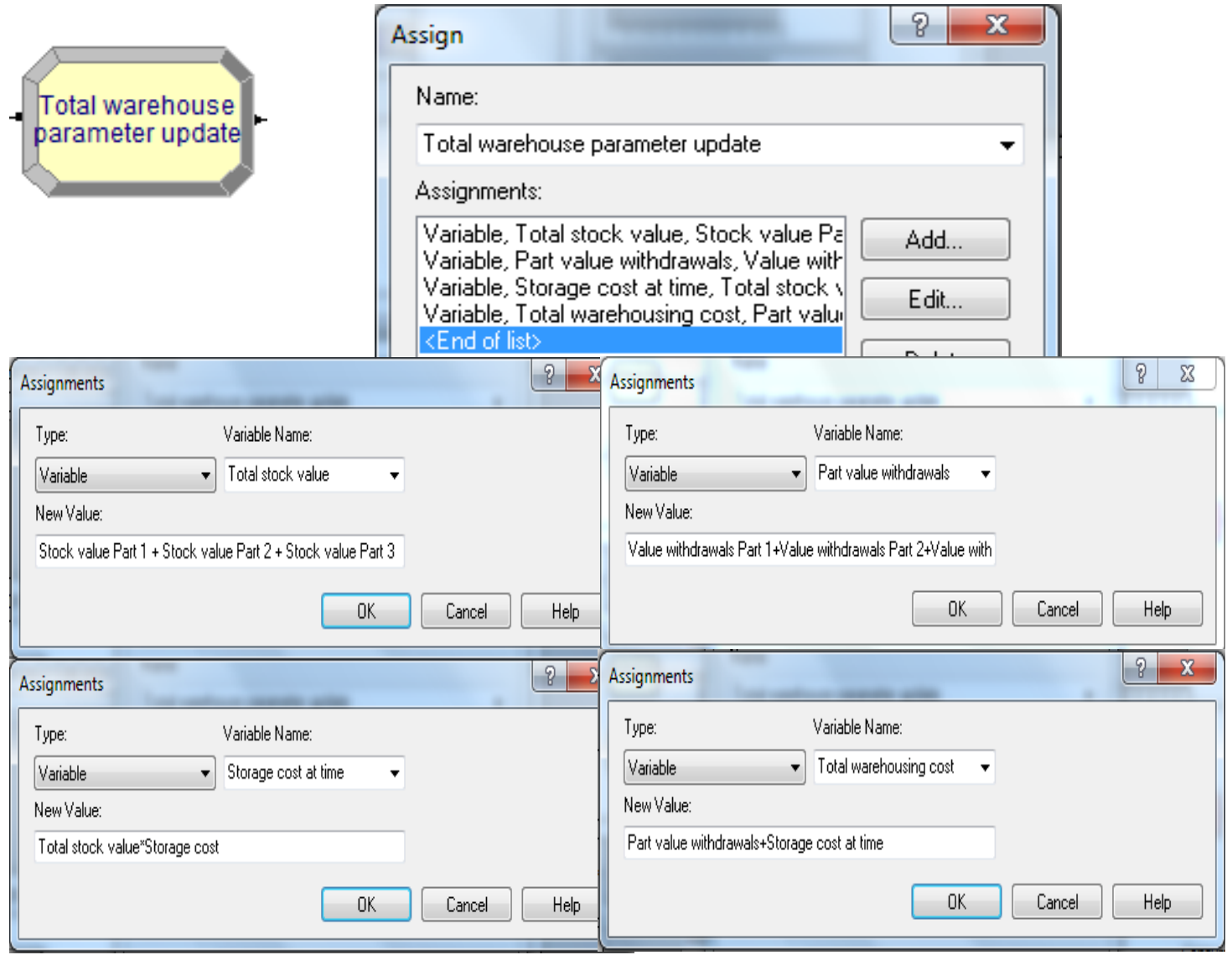

Figure 3-16: Updating total warehouse parameter 
After that the spare part request is disposed in a dispose module called "Warehouse route delivery".

To have an overview of the results of the warehousing route, graphical displays and output fields help. Therefore the relevant displays with sample results are shown in Figure 3-17.
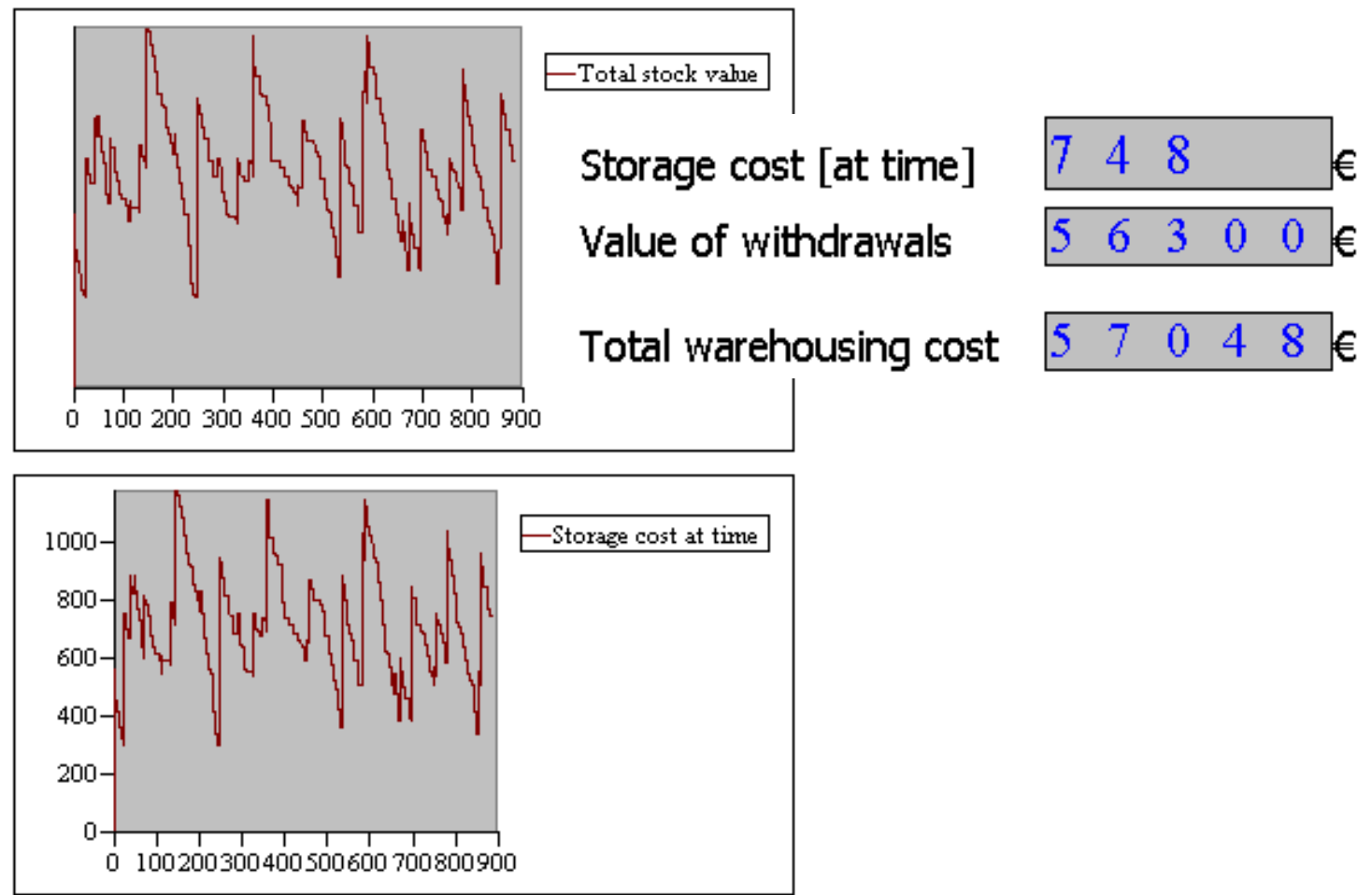

Figure 3-17: Results of the warehousing route 


\subsubsection{AM ROUTE ARRIVAL AND QUEUEING}

As stated earlier the original spare part requests are routed to an AM route, which models the whole AM process from preparation, over the process itself and rework activities.

The AM route starts with a station, "AM route station", followed by an assign module, "Assign arrival". The AM route station follows its function and receives the spare part request. Route and station modules are used often in the following, so they will not be explained in detail, since functionality should be clear.

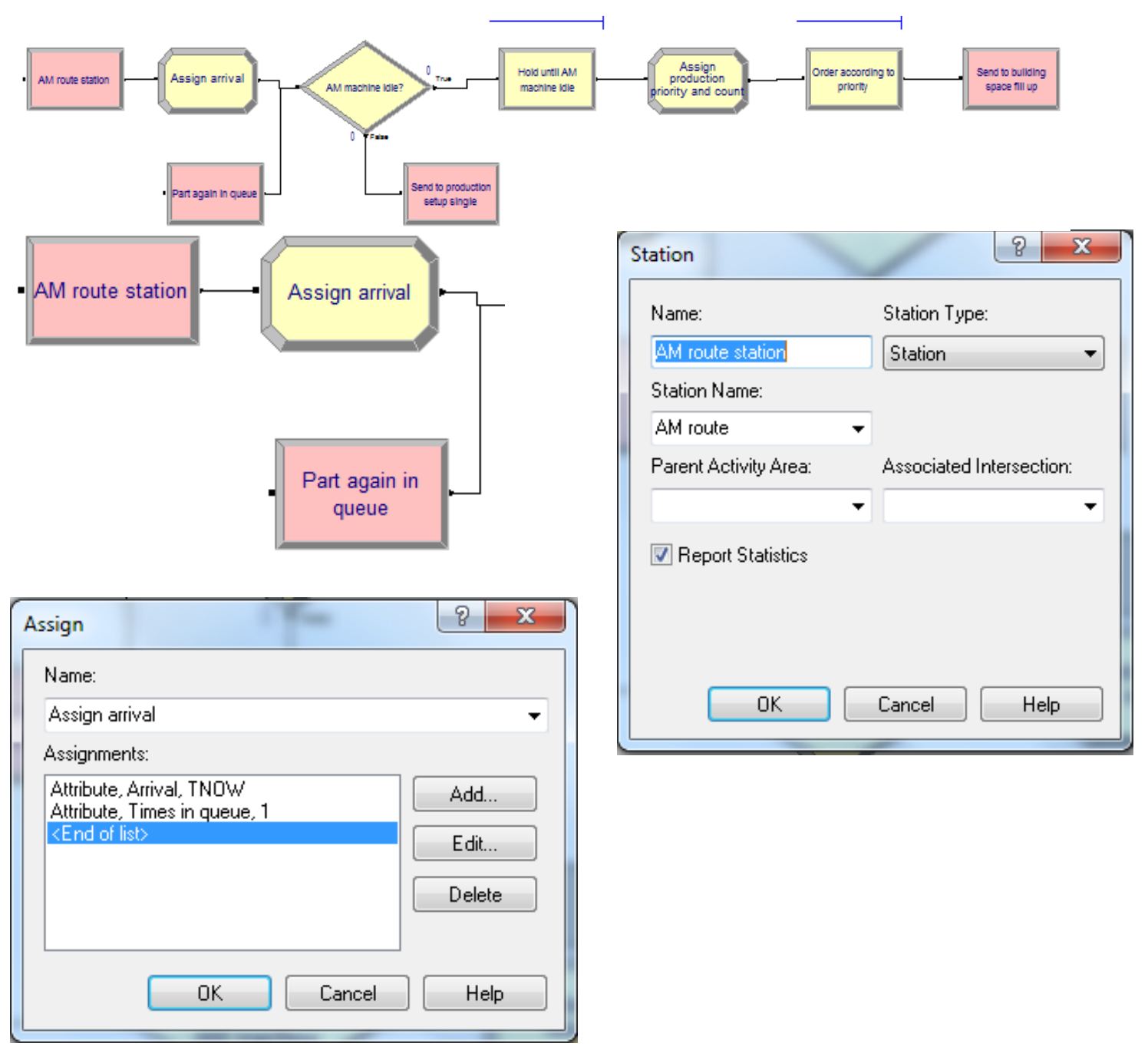

Figure 3-18: Queuing logic and arrival in AM route 
Next the part request enters an assign module, which assigns the arrival time and how often the part entered the queue of the AM processing. "Times in queue" is set to 1 initially because the part request arrives for the first time in the queue. This value will be used and updated through further simulation. Another station module is added to the arrival section. Parts which were not allowed to enter the production process for a production run will arrive at "Part again in queue" and enter the queue for the next production run again.

"AM machine idle?" is a decide module which is used to check if the AM machine is idle and can be used for processing. If the machine is idle the part request will be routed to "Station for production setup" directly and production will be initiated for one part only. Details about production setup will follow later. When the AM machine is not idle, further steps are required due to the fact that queuing will occur, which can have significant impact on the delivery time of the finished parts.
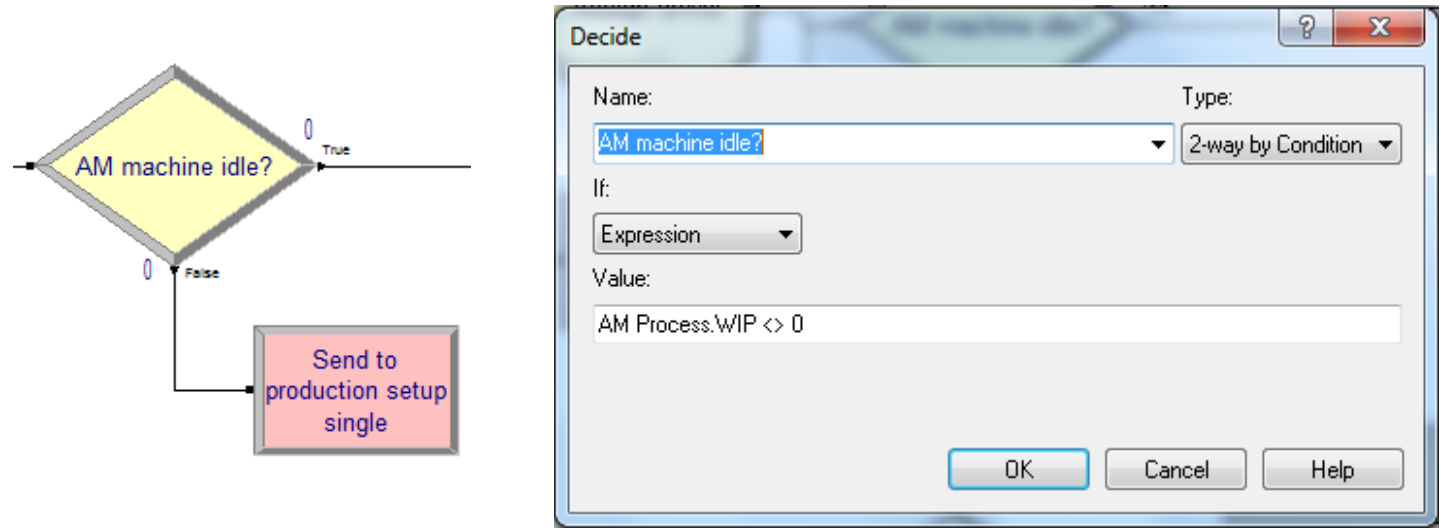

Figure 3-19: Check if AM machine is idle

Modeling the queue follows a specific logic. Arrived part requests need to be prioritized. This is done with a hold module, an assign module and another hold module. The logic uses the fact that logical operations in Arena can happen without that simulation time passes. Details will follow when the production section of the model is explained. After the AM process has finished, parts 
leave the AM machine and enter a first signal module which sends the signal " 1 " to the entire model. This will be explained in depth at a later point. To get back to the hold module, when the signal "1" is generated the hold module will release all parts in queue and forward them to the next module. The same idea is used for the second hold module, which uses the second signal 2 , which is generated a process later than the first hold module.

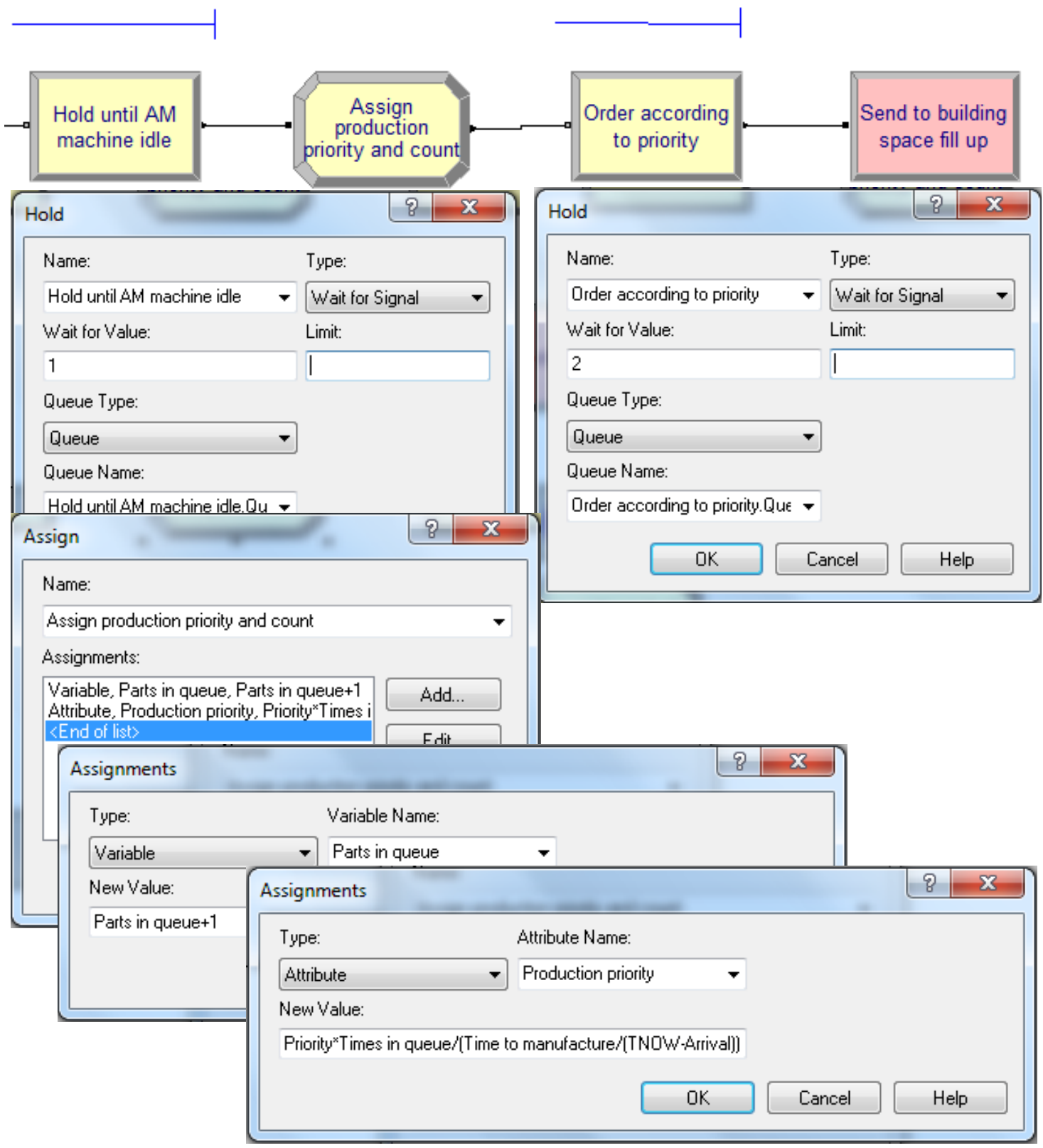

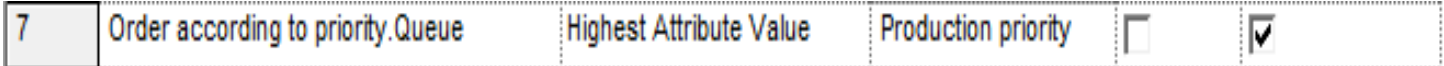

Figure 3-20: Queuing logic 
With this in mind the queue logic should be coherent. The hold module "Hold until AM machine idle" holds all parts in queue until the signal 1 appears. Then all parts enter the assign module "Assign production priority and count". Two things happen in the assign module. "Parts in queue" are counted and the priority for the individual part is defined. "Parts in queue" is used to draw a graph so it is possible to study parts in queue at a specific time. Every queue is followed by Arena automatically, so further queuing statistics are available in the result section.

The priority setting follows a specific rule, which is defined as:

$$
\text { Production priority }=\frac{\text { Piroity } * \text { Times in queue } * \text { Time in system }}{\text { Time to manufacture }}
$$

\section{Def.:}

$\begin{array}{lll}\text { Priority } & --- & \begin{array}{l}\text { Can be every number. In this model } 1 \text { (low), } 2 \\ \text { (medium) and 3 (high) is used. }\end{array} \\ \text { Times in queue } & --- & \begin{array}{l}\text { Counts how often the part entered the queue. } \\ \text { Time in system }\end{array} \\ \text { Time to manufacture } & \mathrm{hr} & \begin{array}{l}\text { Describes how much time the part spent in the system. } \\ \text { Describes the time the part will need for processing. }\end{array}\end{array}$

The formula assigns a production priority to each part request every time before it enters the

"Order according to priority" queue. Each time the part request enters the "Hold until AM machine idle" queue, "Times in queue" and "Time in system" will be increased, which results in a higher production priority for the next production batch.

When the part requests leave the assign module they enter the "Order according to priority" hold module with the according queue. The queue is set to "Highest attribute value first" and uses the attribute "Production priority". As result the part request with the highest production priority will be first in queue and therefore first for processing. The hold module releases the parts from the queue when the signal 2 is sent by the signal module "Ready for new batch signal" which is also located in the production section of the model. All parts are then sent to a logic which fills up the production space. 


\subsubsection{BUILDING VOLUME COUNTER}

Filling up the building volume is modeled by use of a counter. The part requests arrives at a decide module which checks the free volume of the building space. The variable "building volume left" is used for this check. If the building volume left is bigger than the required building volume, the part request is sent the true path for further processing. If the building space left is not enough, the part request will be redirected to the queue logic and the "Times in queue" variable is increased by 1 .

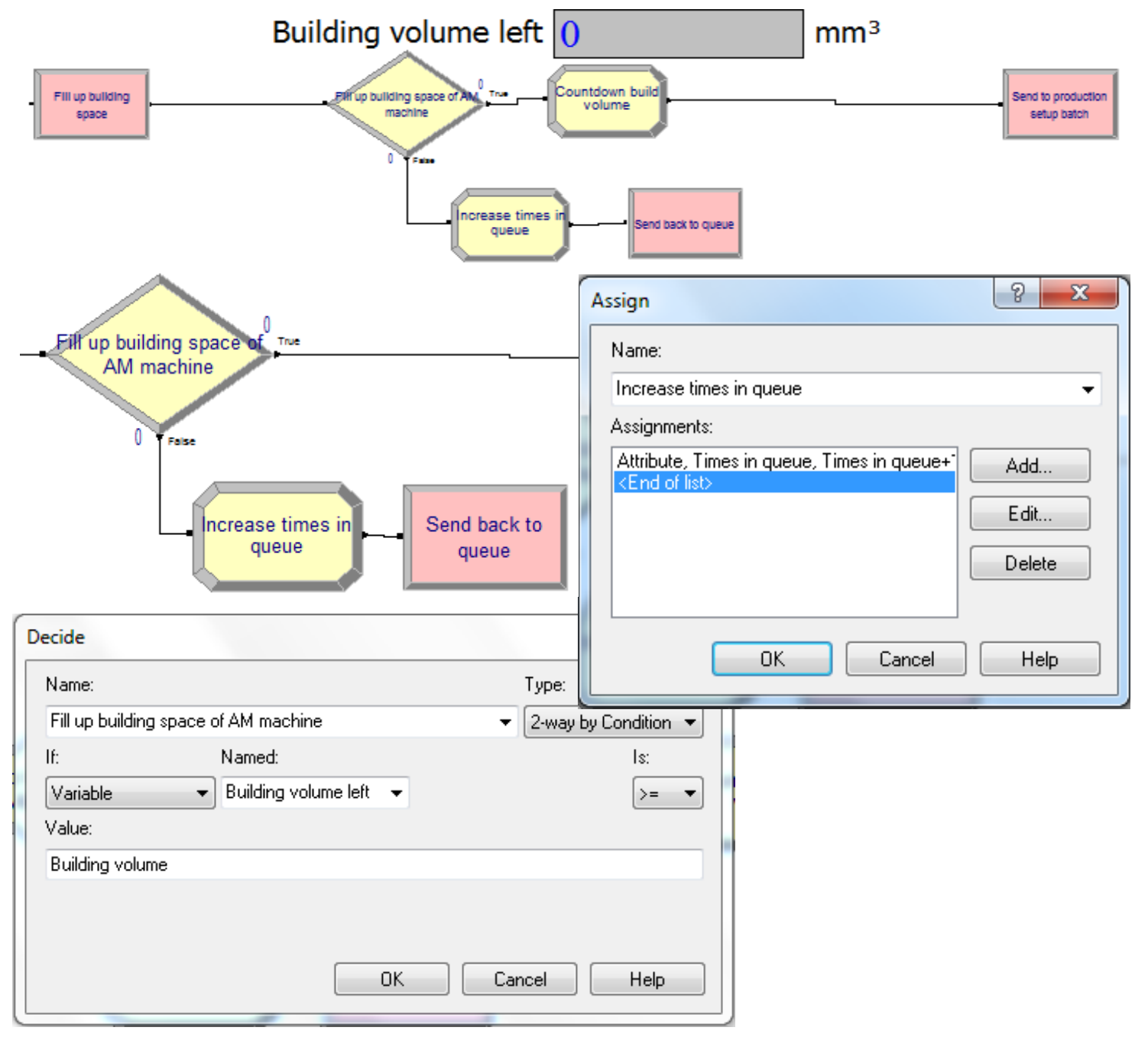

Figure 3-21: Logic for filling the building space 
Following the further processing leads again to an assign module. "Countdown build volume" subtracts the "Building volume" of each part passing the module from the "Building volume left", whose initial value equals the available building volume of the building space. The variable "Part Counter" counts the current number of parts in the build volume. Both, "Building volume left" and "Part counter" are reset to the after each production run.

Then the part request is sent to the production planning logic.

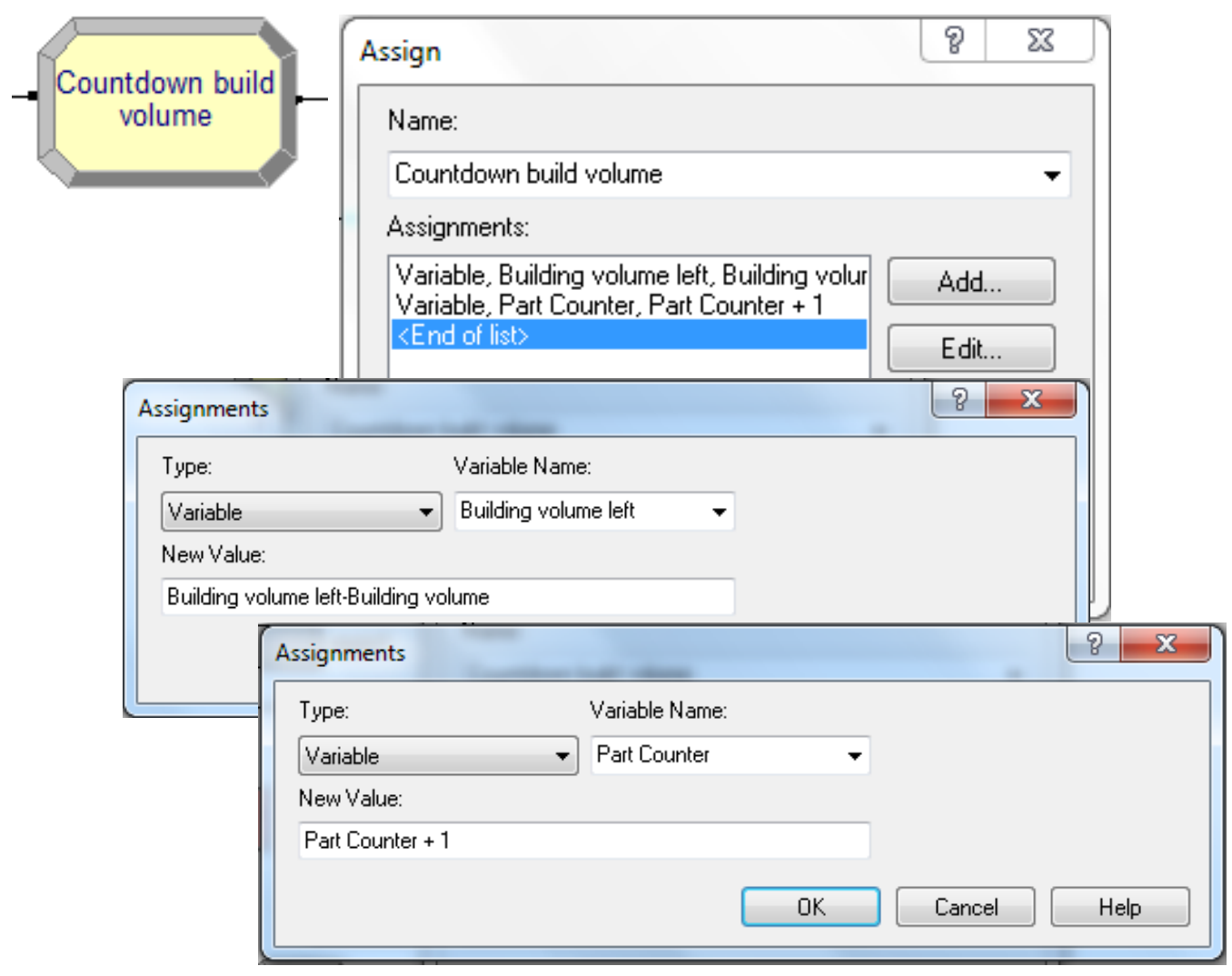

Figure 3-22: Countdown build volume 


\subsubsection{PRODUCTION SETUP}

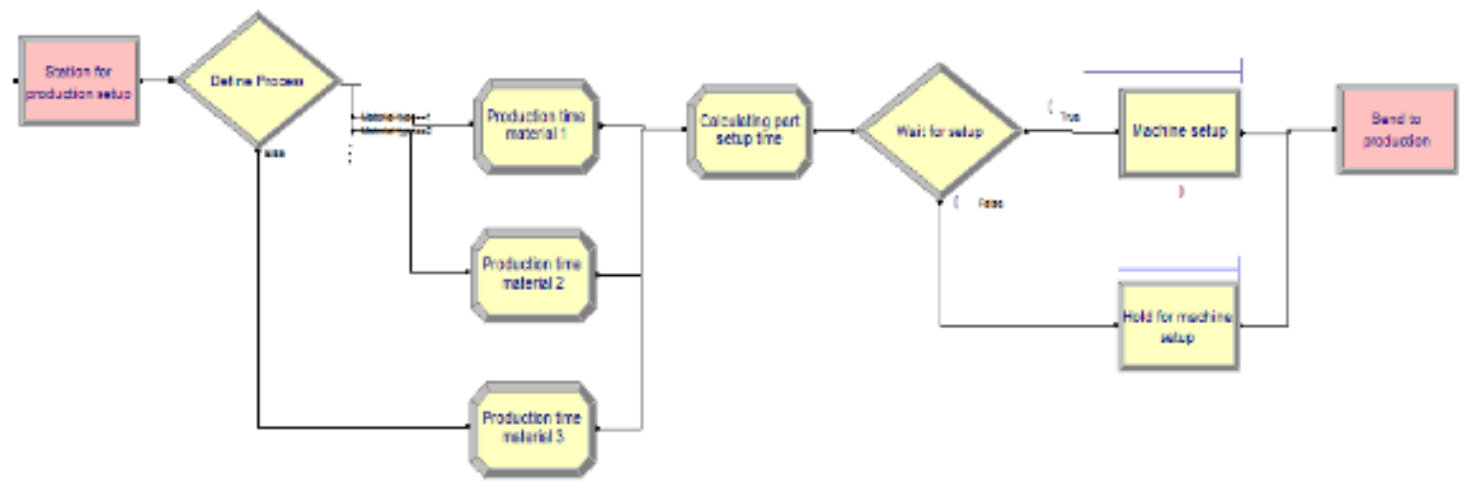

Figure 3-23: Production setup logic
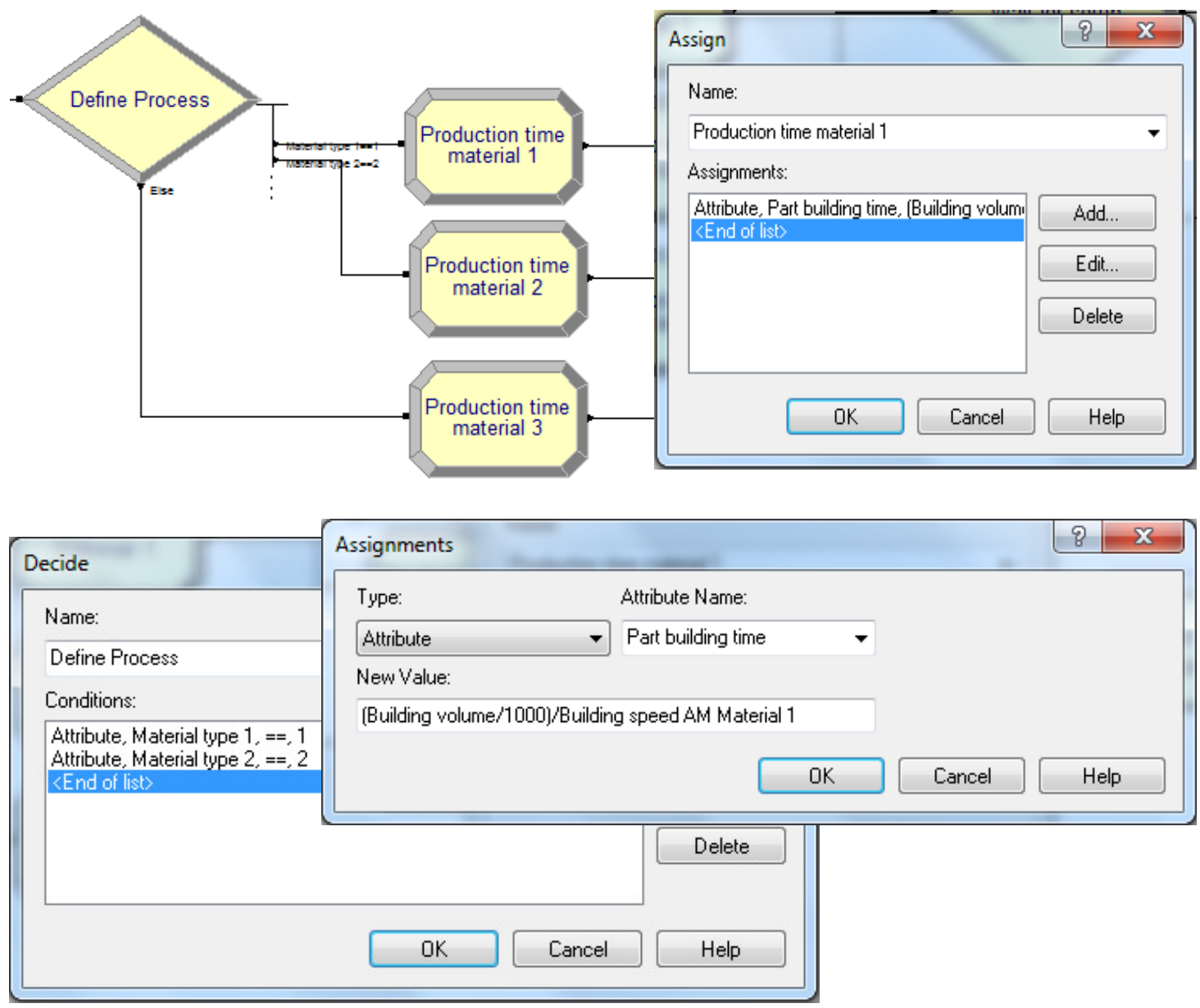

Figure 3-24: Production time assignment 
The production setup logic calculates the production time of based on the material type, the specific setup time of a part and the general machine setup time.

"Define Process" is a decide module which splits the part requests according to the material required for the part. When the part requests are split up, they enter assign modules which are used to assign the production time of the part according to the material. After the assignment all parts follow the same path again and enter the machine setup logic.

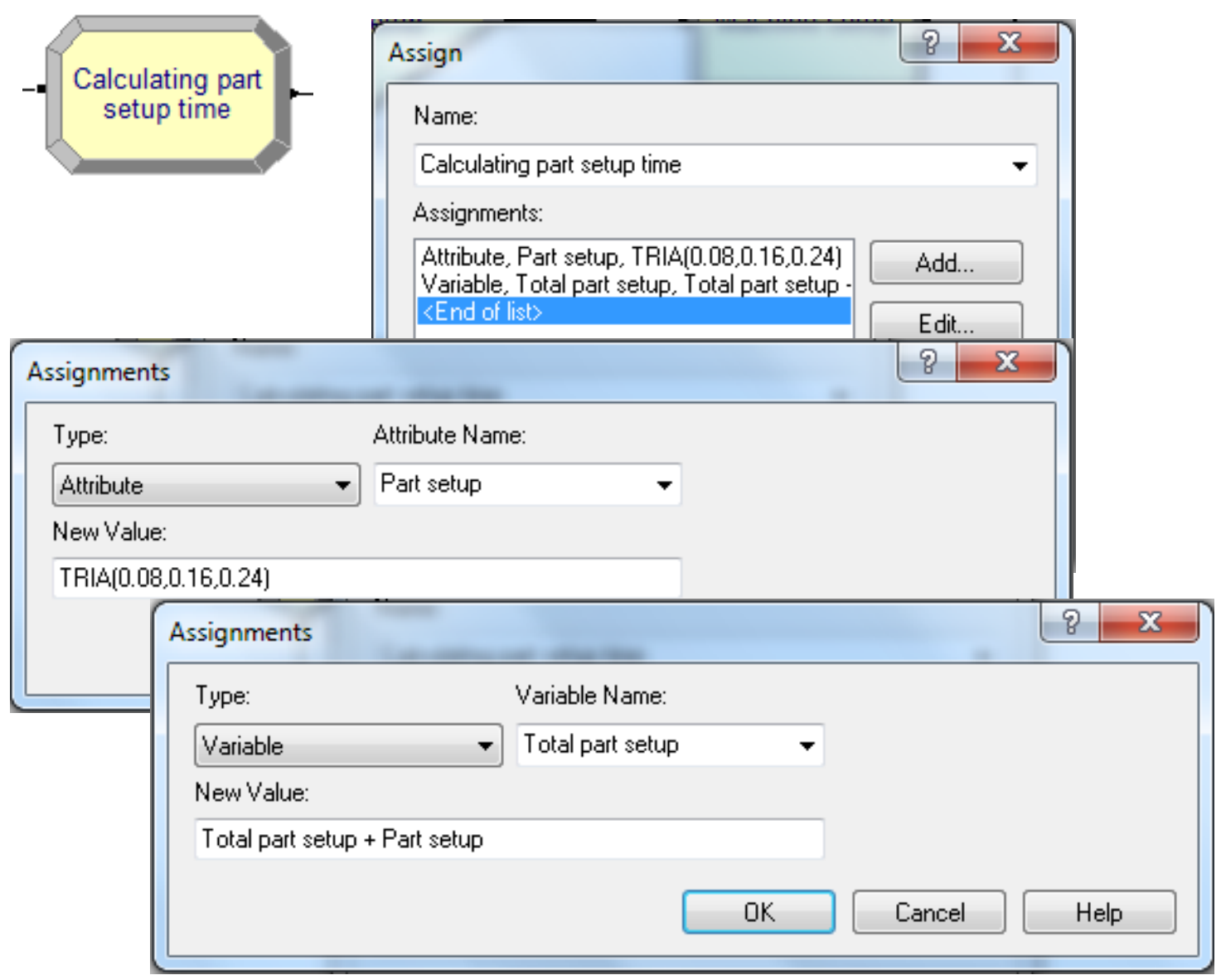

Figure 3-25: Part setup time 
The machine setup logic starts with an assign module which assigns the setup time for the individual part to the individual part. The attribute is called "Part setup" and represents activities like importing the model and setting up the production parameters for the specific part. The basic setup follows a triangular distribution with min. 5, mean 10 and max. 15 minutes setup time per part. "Total part setup" sums up the setup time for all parts in one production run and will be reset to zero when the production run is finished.

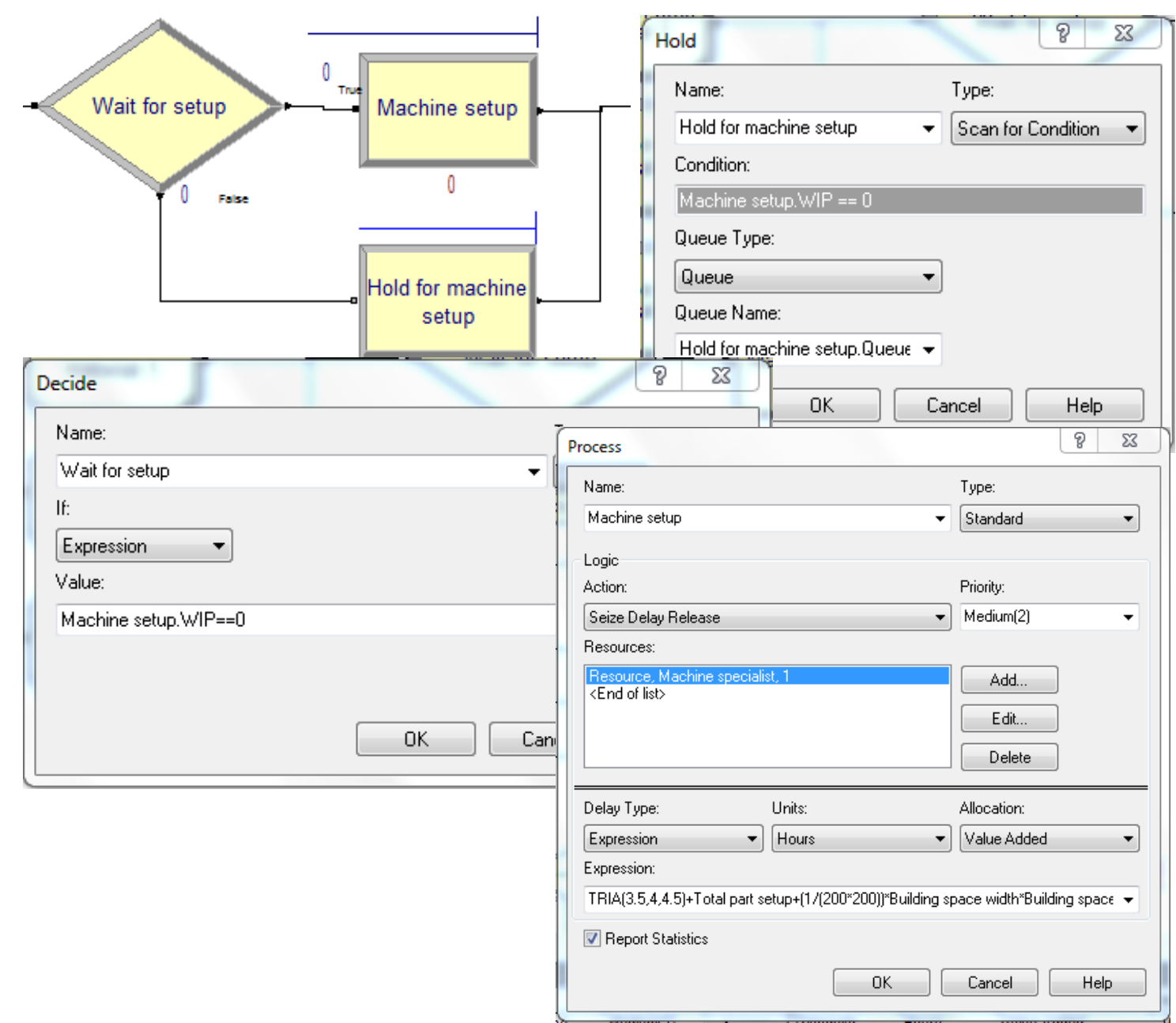

Figure 3-26: AM machine setup 
Next a decide module checks if machine setup is already in progress or not. If the machine setup is not active, the first part request will enter the setup module and activate it. For processing, the resource "Machine specialist" is seized, which can be changed in number and/or according to a schedule. The standard "Machine setup" setting is according to Figure 3-26. Activities like powder bed setup or calibration are assumed to be standard activities which follow a triangular distribution using min. 3.5, mean 4 and max. 4.5 minutes. The total part setup time is added to represent the full setup time. Additionally preheat and atmosphere preparation time is added. The preheat time is set as a linear function of the total substrate area (width and depth of the building space volume). It is assumed that it takes 1 hour to heat up a $200 \times 200 \mathrm{~mm}$ area. The actual preheat time is then scaled up or down depending on the actual build substrate area. Time for atmosphere preparation is added in the same way. It is assumed that it takes 1 hour to prepare a building space atmosphere of $200 \times 200 \times 200 \mathrm{~mm}$. Based on this input the actual time is scaled up or down depending on the actual building space volume. For example a 300 x 300 x $300 \mathrm{~mm}$ building space volume will need $2.25 \mathrm{hr}$ for preheat and $3.375 \mathrm{hr}$ to create the building space atmosphere.

Each following part request in the batch will be sent to a hold module, "Hold for machine setup". "Hold for machine setup" is used to queue the spare part requests and to pretend a batch. When the machine setup becomes inactive, the AM process can start and the hold module releases all parts in queue to be processed by AM. Then the requests are sent simultaneously to the production logic. (This can also be done by a module, but by using this module specific part information gets lost.) 


\subsubsection{AM PROCESS SIMULATION}

The production logic simulates the production of the parts, post processing as well as calculates specific results and resets specific variables.

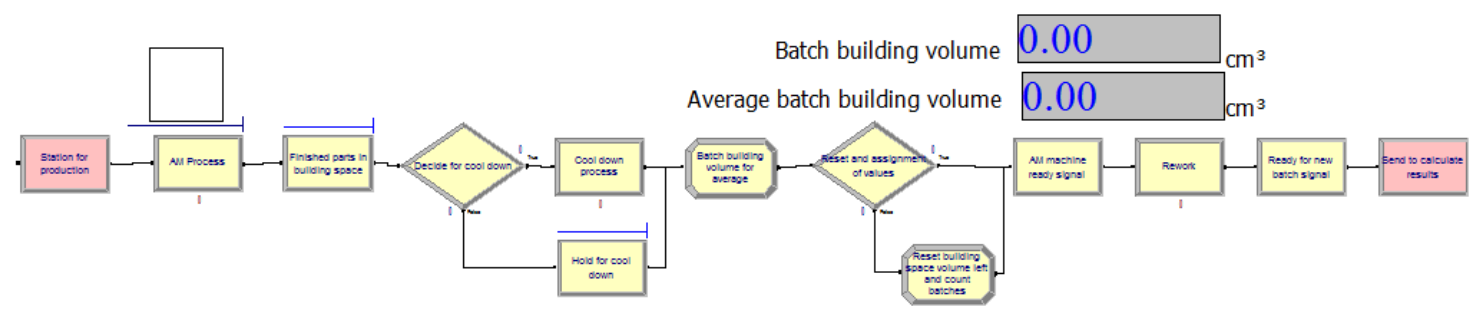

Figure 3-27: Production logic

First the part request enters the AM Process module. Here the actual simulation of the AM process is processed. The resource "AM Machine" is used for doing this. Like every resource the number of the machines can be changed or it can work according to a schedule. As delay time "Part building time" is used, which was calculated in the production setup logic. Each part is simulated to be produced individually, which needs to be corrected, since a production run is executed batch wise. (For simulation of multi material cases a special sorting logic will be integrated to the model in the setup section to arrange arriving part request according to their materials.)

To correct the model for a batch production, the hold module "Finished parts in building space" is applied. The module queues the produced parts until there are no parts in queue in the AM Process queue and the process is not active. All parts are released simultaneously when this condition is true and no part related information is lost. 


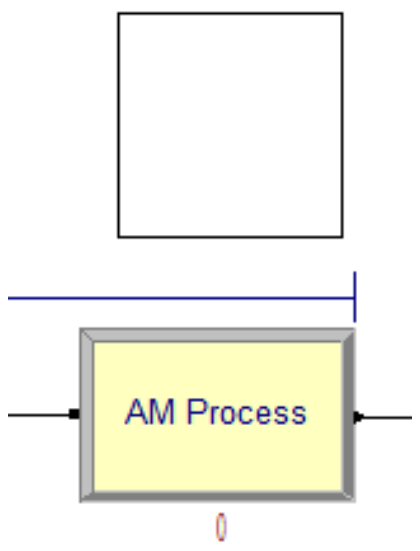

Figure 3-28: AM Process

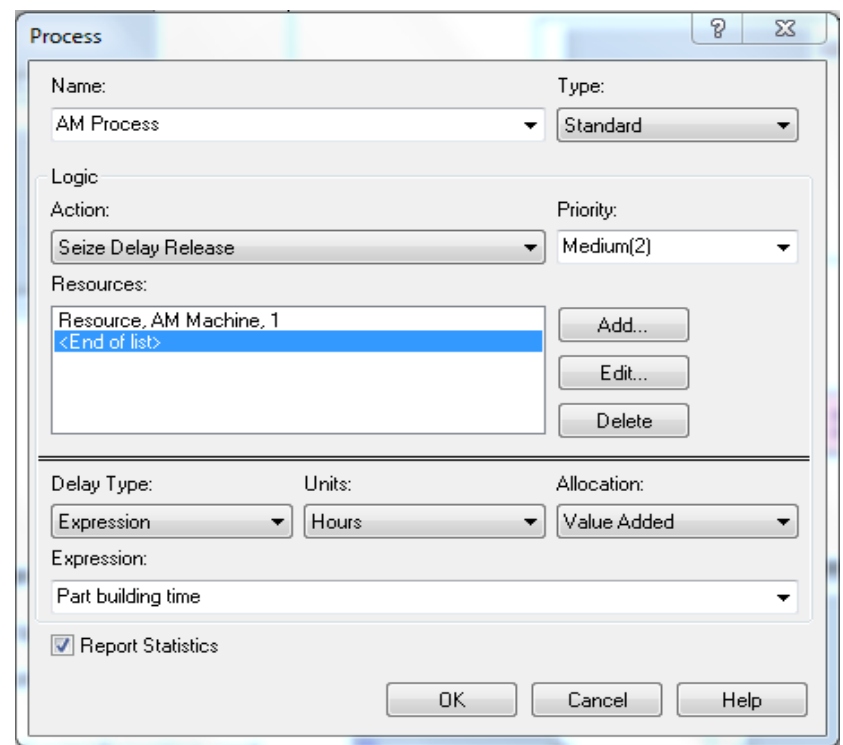

Finished parts
in building
space

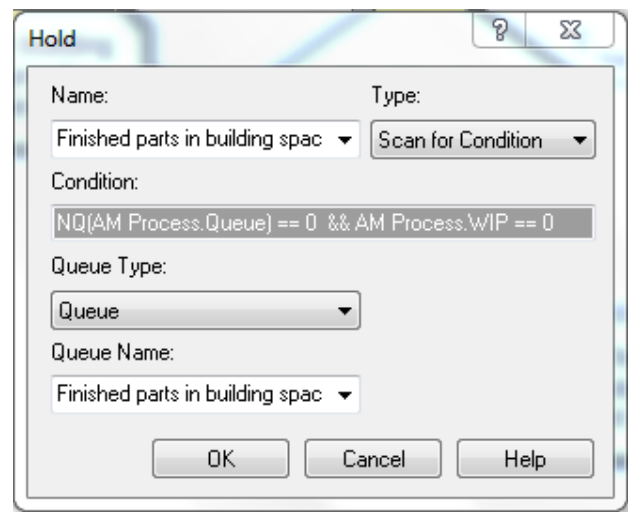

Figure 3-29: Hold for finished parts in building space 


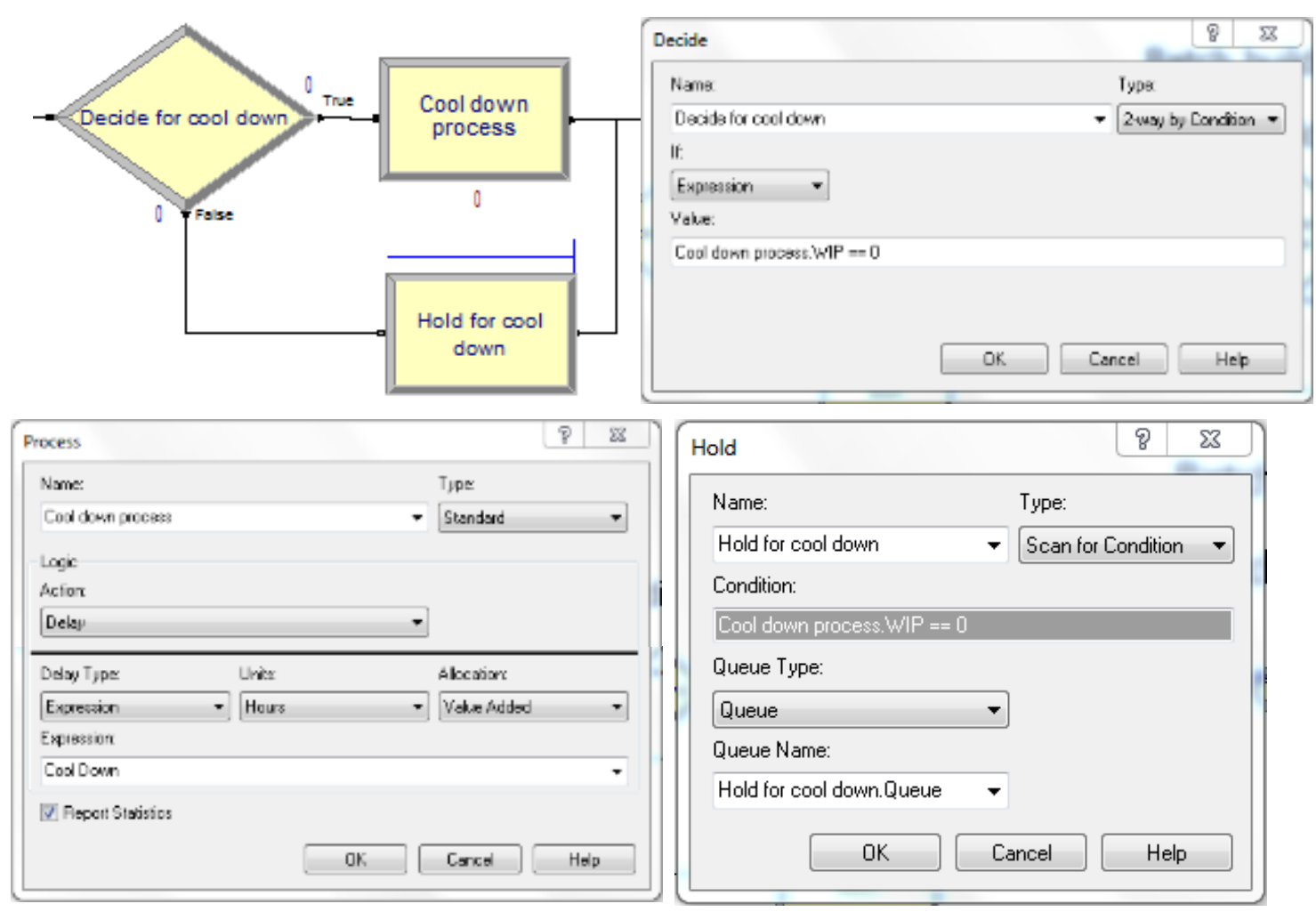

Figure 3-30: Cool down process

The cool down time after a production run needs to be considered as well. It is simulated by use of a decide module, process and hold module. The decide module scans for the condition of the cool down process. If the cool down process is idle, the entity will follow the process path, otherwise the entities will enter the queue of the hold module until the cool down process has ended. The time of cooling down is defined in the variable "Cool down". When the cool down process ends the hold module releases all parts in queue and processing continues.

For the model, the average building volume per batch is of interest. Therefore the variable "Batch building volume" is used. It sums up the building volumes of all parts of a batch. This is used later to calculate the average building volume. 


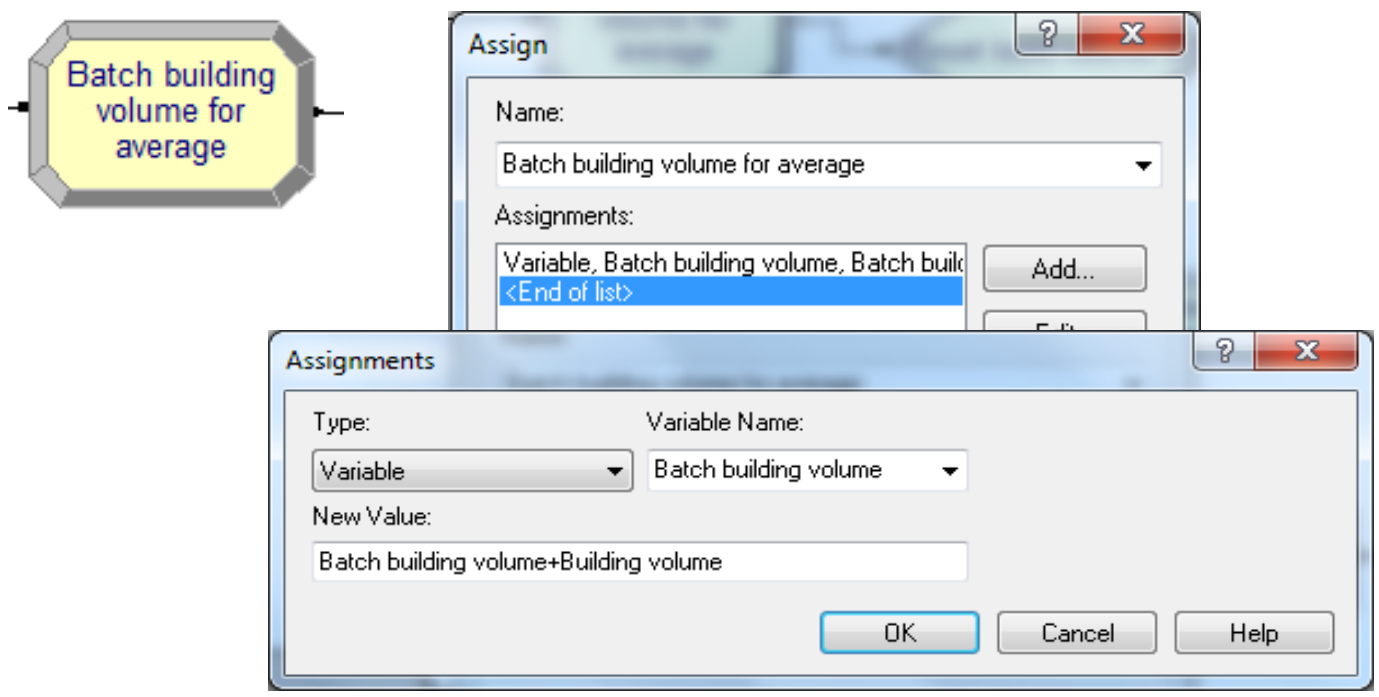

Figure 3-31: Average batch building volume

Next is a decide module, "Reset and assignment of values". The module forwards each part to the next module until the number of "Finished parts in building space.Queue" is 0 . This means that only the last part is send to the assign module "Reset building space volume left and count batches". 


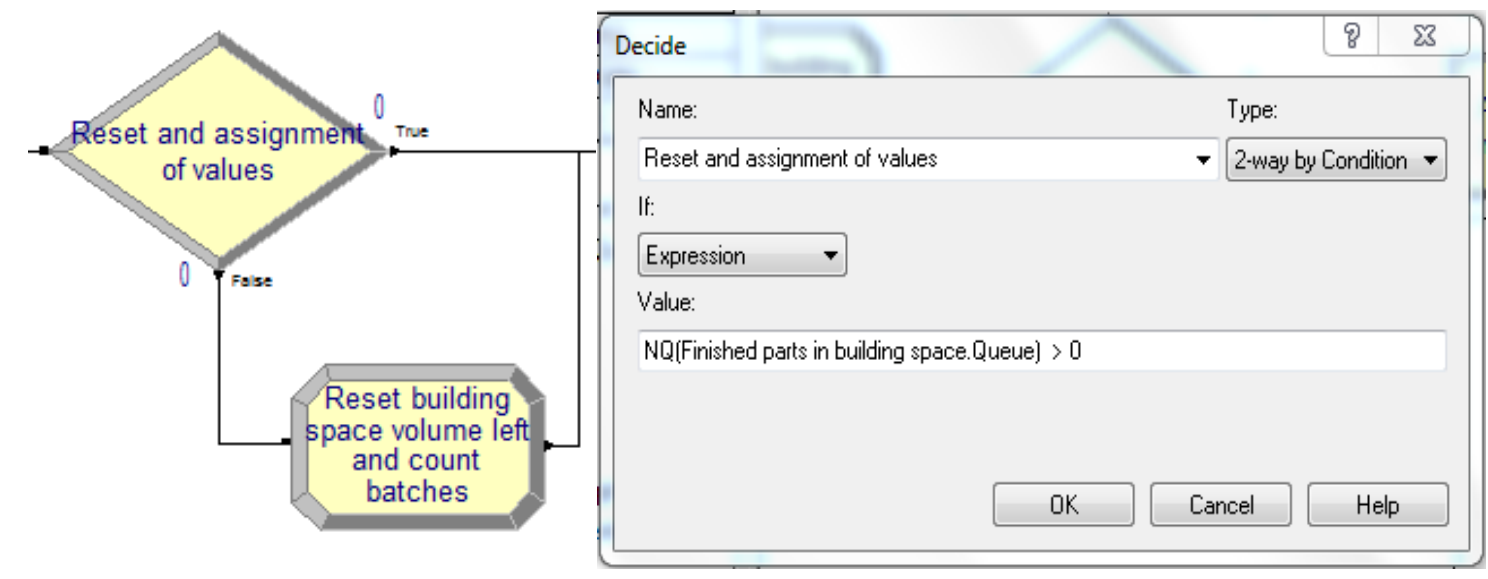

\begin{tabular}{ll} 
Module type & Assign \\
Name & Request building space volume left and count batches \\
\hline Type & Variable \\
Variable name & Building volume left \\
New value & Building space depth*Building space height*Building space width \\
\hline Type & Variable \\
Variable name & Number of batch \\
New value & Number of batch +1 \\
\hline Type & Attribute \\
Variable name & Assigned batch building volume \\
New value & Batch building volume \\
\hline Type & Variable \\
Variable name & Batch building volume \\
New value & 0 \\
\hline Type & Variable \\
Variable name & Building volume per batch \\
New value & Assigned batch building volume \\
\hline Type & Variable \\
Variable name & Average building volume \\
New value & Average building volume*(Number of batch -1$) /$ Number of batch + \\
& Building volume per batch/ Number of batch \\
\hline Type & Variable \\
Variable name & Part counter \\
New value & 0 \\
\hline Type & Variable \\
Variable name & Total part setup \\
New value & 0
\end{tabular}

Figure 3-32: Reset of variables and attributes 
The assign module fulfills several functions. First, it resets the variable building volume left back to the initial value before the next parts are allowed to enter the process. This is essential for filling up the building space again.

All other attributes and variables in this assign module are used to calculate the average batch volume. The number of batches is updated by adding 1 each time a part passes the assign module. "Assigned batch building volume" is an attribute, directly assigned to the part. By doing this the "Batch building volume" is stored in an independent variable and is not lost when the "Batch building volume" is set back to its initial value of 0 , which happens in the next assignment. Since "Assigned batch building volume" is an attribute and directly related to a part, it needs to be transformed back to an independent variable which is available in the whole model. This is done by the variable "Building volume per batch" which takes the value of "Assigned batch building volume". Next, the "Average building volume" is calculated.

After the reset and the calculation of the average building volume, the part meets a combination of signal modules and a process module. The first signal module "AM machine ready signal" sends the signal 1 . As described earlier in this text the signal allows the waiting part requests on the module "Hold until AM machine idle" (queue logic) to move further along in the model, meaning that the parts get sorted in the following queue according to their priority when the signal 1 is set.

The process module "Rework" simulates the rework activities, by seizing a resource for these activities. The time for processing follows specific values in this example, but this can be adjusted to each individual case. In the base setup a triangular distribution is selected with min. 5 , mean 60 and max. 120 minutes. 
When the first part leaves the "Rework" process module it enters the signal module "Ready for new batch signal". This module sends the signal 2 into the model. This signal causes the hold module "Order according to priority" (see queuing logic) to release all parts for further processing.
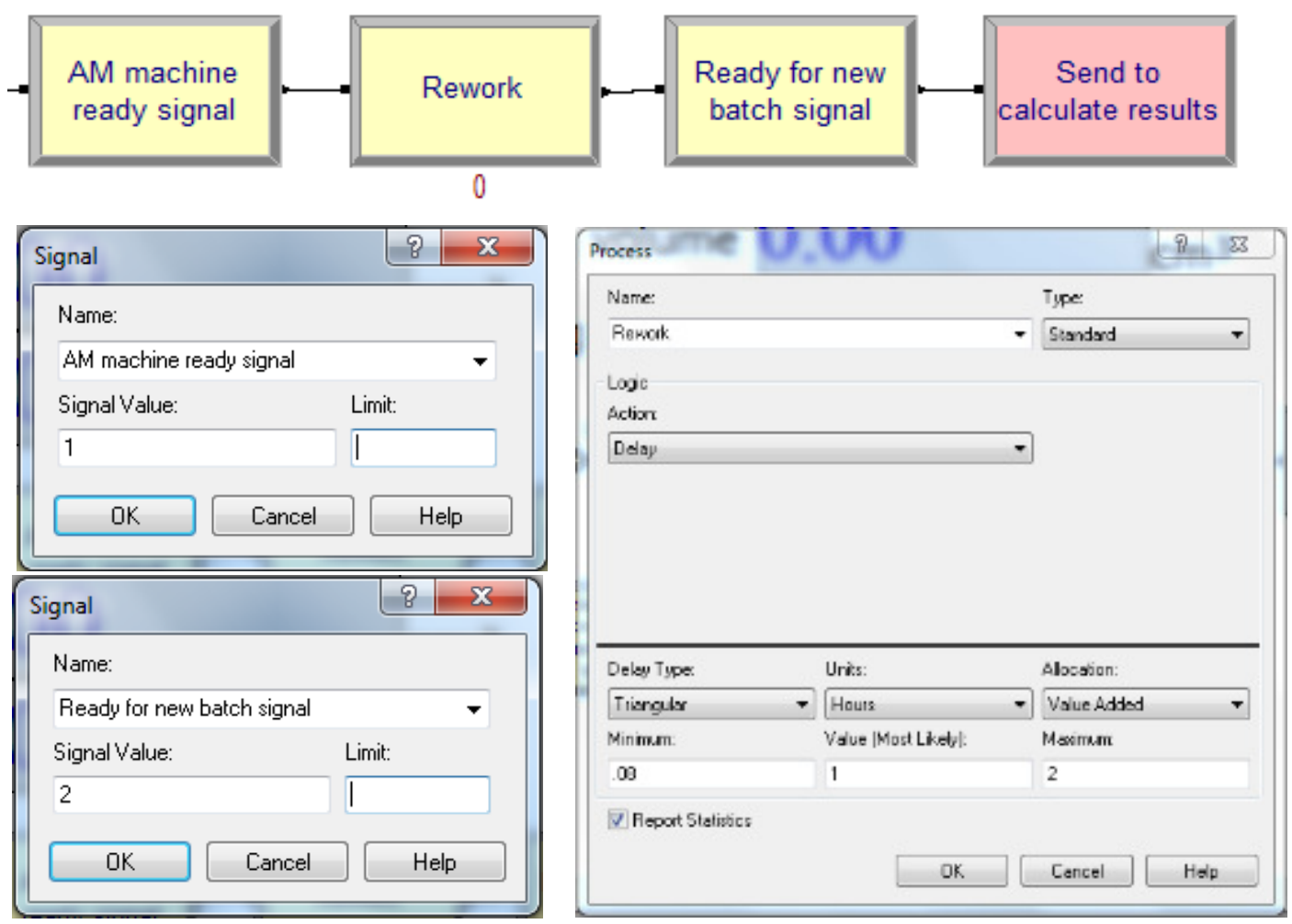

Figure 3-33: Signals for new production run and rework

\subsubsection{OVERVIEW OF RESULTS}

After the production logic final calculations are executed according to the points of interest.

For final calculations it is checked if the parts meet the delivery requirements. This is done by the decide module "Penalty?", which calculates the time from the initial spare part request until the finished part leaves the system and checks if the allowed "Time to manufacture" is exceeded. If the allowed time to manufacture is exceeded a penalty must be paid. The assign module sums up all penalties in the variable "Total penalty". 


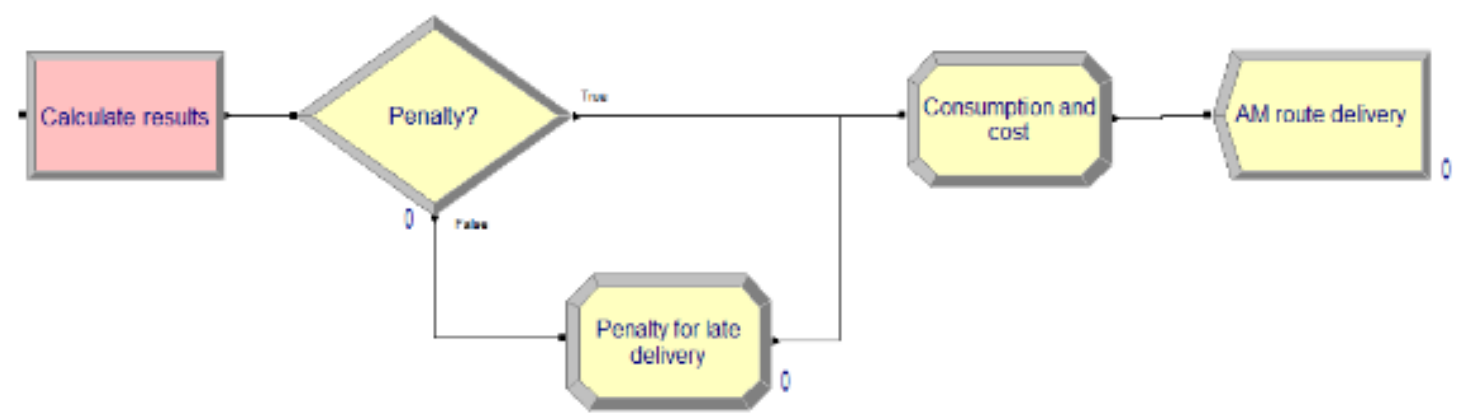

Figure 3-34: Final calculations

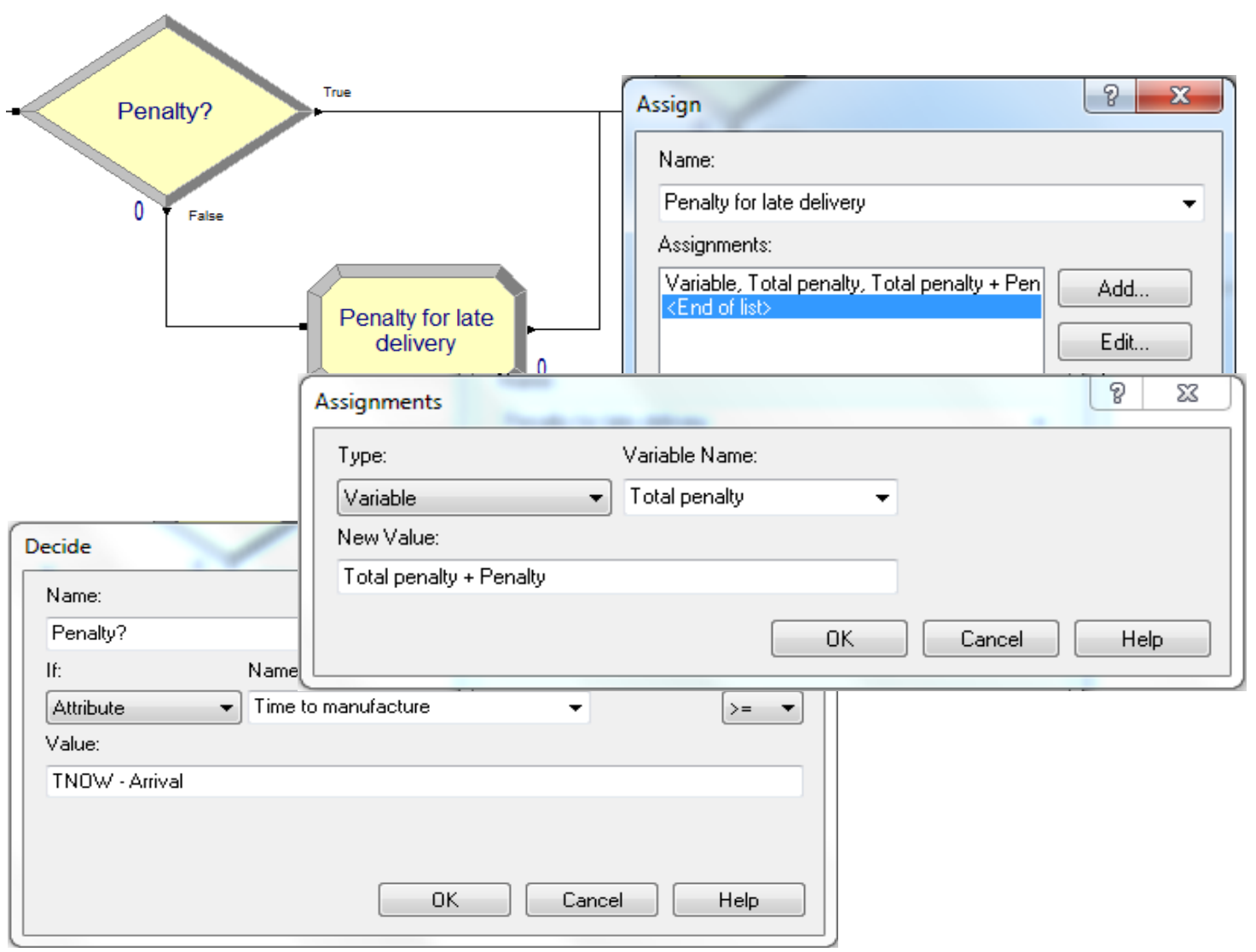

Figure 3-35: Check for penalty

The last module of the model is the assign module "Consumption and cost". Final calculations are executed in this assign module. The calculations are listed in Figure 3-36. After this assign module the spare part leaves the model by the use of a dispose module. 
Figure 3-36: Calculation of consumption and cost

Table 3-2: Calculation of consumption and cost

\begin{tabular}{|c|c|}
\hline $\begin{array}{l}\text { Module type } \\
\text { Name }\end{array}$ & $\begin{array}{l}\text { Assign } \\
\text { Consumption and cost }\end{array}$ \\
\hline Type & Variable \\
\hline Variable name & Material consumption \\
\hline New value & Material consumption + Building volume \\
\hline Type & Variable \\
\hline Variable name & Total operator cost \\
\hline New value & Total operator cost + Operator cost \\
\hline Type & Variable \\
\hline Variable name & Consumed material cost \\
\hline New value & ((Material consumption/1000)*7.85/1000)*Material cost \\
\hline Type & Variable \\
\hline Variable name & Consumed energy cost \\
\hline New value & (Material consumption/1000)*Energy consumption*Energy cost \\
\hline Type & Variable \\
\hline Variable name & Total maintenance cost \\
\hline New value & (AM maintenance cost/(365*24))*TNOW \\
\hline Type & Variable \\
\hline Variable name & Operator training cost \\
\hline New value & (Operator training price/ $(365 * 24)) * \mathrm{TNOW}$ \\
\hline Type & Variable \\
\hline Variable name & Machine depreciation \\
\hline New value & $(($ Machine purchase price/Years of depreciation $) /(365 * 24)) * \mathrm{TNOW}$ \\
\hline Type & Variable \\
\hline Variable name & Total AM cost \\
\hline New value & $\begin{array}{l}\text { Consumed material cost+Consumed energy cost+Total operator cost+Tota } \\
\text { maintenance cost+Operator training cost+Machine depreciation+Total } \\
\text { penalty }\end{array}$ \\
\hline Type & Variable \\
\hline Variable name & Break even \\
\hline New value & $\begin{array}{l}\text { Machine purchase price/(((Total warehousing cost-Total AM } \\
\text { cost)/TNOW }) * 365 * 24)\end{array}$ \\
\hline Type & Variable \\
\hline Variable name & Machine utilization \\
\hline New value & $(\text { AM Process.VATime } /(\mathrm{TNOW}+0.001))^{*} 100$ \\
\hline Type & Variable \\
\hline Variable name & Consumed material \\
\hline New value & (Material consumption/1000)*7.85/1000 \\
\hline
\end{tabular}




\begin{tabular}{ll}
$\begin{array}{l}\text { Type } \\
\text { Variable name } \\
\text { New value }\end{array}$ & $\begin{array}{l}\text { Variable } \\
\text { Consumed energy } \\
\text { (Material consumption/1000)*Energy consumption }\end{array}$ \\
\hline Type & Variable \\
Variable name & AM parts out \\
New value & AM parts out+1 \\
\hline Type & Variable \\
Variable name & Machine setup tracking \\
New value & (Machine setup.VATime/TNOW)*100 \\
\hline Type & Variable \\
Variable name & Machine cool down tracking \\
New value & (Cool down process.VATime/ TNOW)*100 \\
\hline Type & Variable \\
Variable name & Total utilization \\
New value & Machine utilization+Machine setup tracking+Machine cool down tracking
\end{tabular}

Once the simulation model has been run, results can be displayed. In the model window several displays are arranged to allow a quick overview about several results. Figure 3-37 shows the results of a simulation run using the parameters shown in Table 3-3. All the parameters shown in the table can be changed, and results can be recalculated. This enables the user to compare different scenarios. 
Warehousing

Storage cost

Value of withdrawals

Total warehousing cost

Additive Manufacturing

Consumed material

Consumed energy

Consumed material cost

Consumed energy cost

Operator cost

Total AM maintenance cost

Operator training cost

Total AM Penalty

Total AM cost
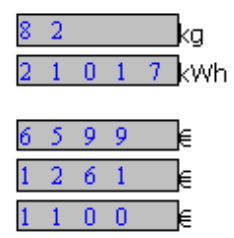

\begin{tabular}{llllll}
\hline 2 & 9 & 1 & 0 & 6 \\
\hline
\end{tabular}

\begin{tabular}{llll}
\hline & 7 & 0 & 2
\end{tabular}

\begin{tabular}{llllll}
\hline 1 & 2 & 5 & 0 & 0
\end{tabular}

\begin{tabular}{llllll}
\hline 6 & 0 & 2 & 6 & 9 \\
\hline
\end{tabular}

\# Parts warehouse route out $2 \quad 2 \quad$ pcs.

\# Parts AM route out

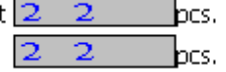

Warehousing vs. AM

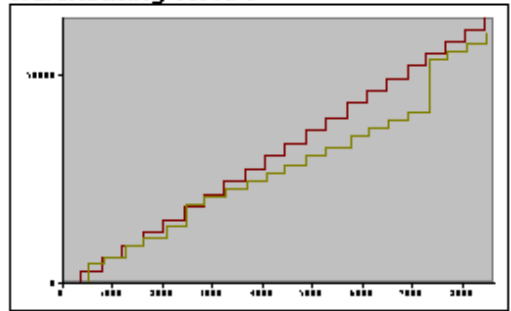

Green - Total AM cost

Red - Total Warehousing cost

Break even point 1225.10 years

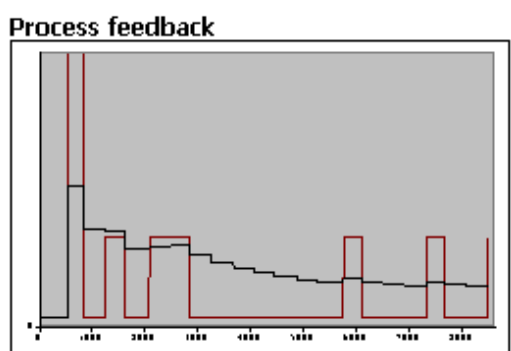

Red - Batch building volume Black - Average building volume

Average building volume $\left[\mathrm{mm}^{3}\right]$ \begin{tabular}{|llllll}
\hline 4 & 7 & 7 & 6 & 4 & 5 \\
\hline
\end{tabular}

Machine depreciation $\begin{array}{lllll}2 & 9 & 7 & 5 & 3 \\ 1\end{array}$

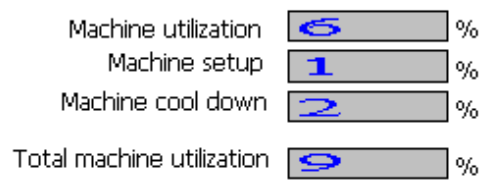

Figure 3-37: Sample results

Table 3-3: Changeable parameter

\begin{tabular}{|c|c|c|c|c|c|}
\hline $\begin{array}{l}\text { Refer- } \\
\text { ence }\end{array}$ & Type & Variablen & Unit & Value & Description \\
\hline \begin{tabular}{|l|}
$\mathrm{AM}$ \\
Proces \\
$\mathrm{s}$
\end{tabular} & Variable & \begin{tabular}{|l}
$\mathrm{AM}$ \\
maintenance \\
cost
\end{tabular} & $€ / y r$ & 30000 & $\begin{array}{l}\text { Cost which is generated by required } \\
\text { maintenance actions for AM. }\end{array}$ \\
\hline $\begin{array}{l}\text { AM } \\
\text { Proces } \\
\text { s }\end{array}$ & Variable & $\begin{array}{l}\text { Building } \\
\text { space depth }\end{array}$ & $\mathrm{mm}$ & 250 & $\begin{array}{l}\text { Describes the building space depth of the } \\
\text { RM machine. }\end{array}$ \\
\hline $\begin{array}{l}\text { AM } \\
\text { Proces } \\
\text { s }\end{array}$ & Variable & \begin{tabular}{|l} 
Building \\
space height
\end{tabular} & $\mathrm{mm}$ & 325 & $\begin{array}{l}\text { Describes the building space height of the } \\
\text { RM machine. }\end{array}$ \\
\hline $\begin{array}{l}\text { AM } \\
\text { Proces } \\
\text { s }\end{array}$ & Variable & $\begin{array}{l}\text { Building } \\
\text { space volume }\end{array}$ & $\mathrm{mm}^{3}$ & $\begin{array}{c}203125 \\
00\end{array}$ & $\begin{array}{l}\text { Describes the building space volume of the } \\
\text { RM machine. }\end{array}$ \\
\hline $\begin{array}{l}\text { AM } \\
\text { Proces } \\
\text { s }\end{array}$ & \begin{tabular}{|l|} 
Variable \\
\end{tabular} & $\begin{array}{l}\text { Building } \\
\text { space width }\end{array}$ & $\mathrm{mm}$ & 250 & $\begin{array}{l}\text { Describes the building space width of the } \\
\text { RM machine. }\end{array}$ \\
\hline $\begin{array}{l}\text { AM } \\
\text { Proces } \\
\text { s }\end{array}$ & Variable & $\begin{array}{l}\text { Building } \\
\text { speed AM } \\
\text { Material } 1\end{array}$ & $\begin{array}{c}\mathrm{cm}^{3 /} \\
\mathrm{h}\end{array}$ & 22 & $\begin{array}{l}\text { Describes the building speed of the RM } \\
\text { machine using material } 1 .\end{array}$ \\
\hline \begin{tabular}{|l} 
AM \\
Proces \\
s
\end{tabular} & Variable & $\begin{array}{l}\text { Building } \\
\text { speed AM } \\
\text { Material } 2\end{array}$ & $\begin{array}{c}\mathrm{cm}^{3 /} \\
\mathrm{h}\end{array}$ & 23 & $\begin{array}{l}\text { Describes the building speed of the RM } \\
\text { machine using material } 2 .\end{array}$ \\
\hline
\end{tabular}




\begin{tabular}{|c|c|c|c|c|c|}
\hline $\begin{array}{l}\text { Refer- } \\
\text { ence }\end{array}$ & Type & Variablen & Unit & Value & Description \\
\hline $\begin{array}{l}\text { AM } \\
\text { Proces } \\
\text { s }\end{array}$ & Variable & $\begin{array}{l}\text { Building } \\
\text { speed AM } \\
\text { Material } 3\end{array}$ & $\begin{array}{c}\mathrm{cm}^{3 /} \\
\mathrm{h}\end{array}$ & 24 & $\begin{array}{l}\text { Describes the building speed of the RM } \\
\text { machine using material } 3 \text {. }\end{array}$ \\
\hline $\begin{array}{l}\mathrm{AM} \\
\text { Proces } \\
\mathrm{s}\end{array}$ & Variable & \begin{tabular}{|l|} 
Energy \\
consumption
\end{tabular} & $\begin{array}{l}\mathrm{kW} \\
\mathrm{h} / \mathrm{c} \\
\mathrm{m}^{3}\end{array}$ & 2 & $\begin{array}{l}\text { Energy consumption on average } \\
\text { production. ( } 20 \% \text { efficiency) }\end{array}$ \\
\hline $\begin{array}{l}\text { AM } \\
\text { Proces } \\
\text { s }\end{array}$ & Variable & Energy cost & $\begin{array}{l}€ / \mathrm{k} \\
\mathrm{Wh}\end{array}$ & 0,06 & Energy price valid for production. \\
\hline \begin{tabular}{|l} 
AM \\
Proces \\
s
\end{tabular} & Variable & $\begin{array}{l}\text { Machine } \\
\text { purchase } \\
\text { price }\end{array}$ & $€$ & 460000 & Machine price when purchased \\
\hline $\begin{array}{l}\text { AM } \\
\text { Proces } \\
\text { s }\end{array}$ & Variable & Material cost & $€ / \mathrm{kg}$ & 80 & Price of AM-material for production. \\
\hline \begin{tabular}{|l}
$\mathrm{AM}$ \\
Proces \\
$\mathrm{s}$
\end{tabular} & Variable & $\begin{array}{l}\text { Operator } \\
\text { training price }\end{array}$ & $€ / y r$ & 10000 & Price of operator training \\
\hline \begin{tabular}{|l} 
AM \\
Proces \\
s
\end{tabular} & Variable & $\begin{array}{l}\text { Years of } \\
\text { depreciation }\end{array}$ & $\mathrm{yr}$ & 15 & $\begin{array}{l}\text { Planned depreciation time for AM } \\
\text { machine. }\end{array}$ \\
\hline \begin{tabular}{|l} 
AM \\
Proces \\
s
\end{tabular} & Variable & Cool down & $\mathrm{h}$ & 8 & $\begin{array}{l}\text { Required time to cool down the building } \\
\text { space. }\end{array}$ \\
\hline Global & Resource & Receptionist & Pcs & 1 & Number of staff at the reception. \\
\hline Global & Resource & AM Machine & Pcs & 1 & Number of AM machines in operation. \\
\hline Global & Resource & Picker Staff & Pcs & 1 & Number of staff picking parts. \\
\hline Global & Resource & $\begin{array}{l}\text { Machine } \\
\text { specialist }\end{array}$ & Pcs & 1 & Number of staff specialized in AM. \\
\hline Part & Attribute & $\begin{array}{l}\text { Building } \\
\text { depth }\end{array}$ & $\mathrm{mm}$ & $\begin{array}{c}30 / 20 / \\
30\end{array}$ & $\begin{array}{l}\text { Describes the building depth of the part. } \\
\text { (Part 1/ Part 2/ Part 3) }\end{array}$ \\
\hline Part & Attribute & $\begin{array}{l}\text { Building } \\
\text { width }\end{array}$ & $\mathrm{mm}$ & $\begin{array}{c}100 / \\
90 / 30 \\
\end{array}$ & $\begin{array}{l}\text { Describes the building width of the part. } \\
\text { (Part 1/ Part 2/ Part 3) }\end{array}$ \\
\hline Part & Attribute & \begin{tabular}{|l|} 
Bulding \\
height
\end{tabular} & $\mathrm{mm}$ & $\begin{array}{c}20 / 10 / \\
30\end{array}$ & $\begin{array}{l}\text { Describes the building height of the part. } \\
\text { (Part 1/ Part 2/ Part 3) }\end{array}$ \\
\hline Part & Attribute & EOQ Part 1 & Pcs & 11 & Economic order quantity of part 1. \\
\hline Part & Attribute & EOQ Part 2 & Pcs & 15 & Economic order quantity of part 2. \\
\hline Part & Attribute & EOQ Part 3 & Pcs & 12 & Economic order quantity of part 3. \\
\hline Part & Attribute & \begin{tabular}{|l|} 
Material type \\
1
\end{tabular} & --- & $1 / 1 / 1$ & $\begin{array}{l}\text { Material type assignment by use of integer } \\
\text { (Part 1/ Part 2/ Part 3) }\end{array}$ \\
\hline Part & Attribute & Operator cost & $€$ & $\begin{array}{c}70 / 60 / \\
50\end{array}$ & $\begin{array}{l}\text { Estimated cost of required operator in } \\
\text { total. (Part 1/ Part 2/ Part 3) }\end{array}$ \\
\hline Part & Attribute & $\begin{array}{l}\text { Part value } \\
\text { Part } 1\end{array}$ & $€$ & 50 & $\begin{array}{l}\text { Purchase price of part } 1 \text {. (Example value - } \\
\text { realistic values in later sections) }\end{array}$ \\
\hline Part & Attribute & $\begin{array}{l}\text { Part value } \\
\text { Part } 2\end{array}$ & $€$ & 50 & $\begin{array}{l}\text { Purchase price of part 2. (Example value - } \\
\text { realistic values in later sections) }\end{array}$ \\
\hline
\end{tabular}




\begin{tabular}{|l|l|l|c|c|l|}
\hline $\begin{array}{l}\text { Refer- } \\
\text { ence }\end{array}$ & Type & Variablen & Unit & Value & Description \\
\hline Part & Attribute & $\begin{array}{l}\text { Part value } \\
\text { Part 3 }\end{array}$ & $€$ & 50 & $\begin{array}{l}\text { Purchase price of part 3. (Example value - } \\
\text { realistic values in later sections) }\end{array}$ \\
\hline Part & Attribute & Penalty Part 1 & $€$ & 1000 & $\begin{array}{l}\text { Penalty when part 1 is not delivered in } \\
\text { time. }\end{array}$ \\
\hline Part & Attribute & Penalty Part 2 & $€$ & 2000 & $\begin{array}{l}\text { Penalty when part 2 is not delivered in } \\
\text { time. }\end{array}$ \\
\hline Part & Attribute & Penalty Part 3 & $€$ & 4000 & $\begin{array}{l}\text { Penalty when part 3 is not delivered in } \\
\text { time. }\end{array}$ \\
\hline Part & Attribute & Priority & --- & $1 / 1 / 1$ & $\begin{array}{l}\text { Pre-assigned priority of part as production } \\
\text { order basis. (Part 1/ Part 2/ Part 3) }\end{array}$ \\
\hline Part & Attribute & $\begin{array}{l}\text { Reorder point } \\
\text { part 1 }\end{array}$ & Pcs & 8 & Reorder point of part 1. \\
\hline Part & Attribute & $\begin{array}{l}\text { Reorder point } \\
\text { part 2 }\end{array}$ & Pcs & 4 & Reorder point of part 2. \\
\hline Part & Attribute & $\begin{array}{l}\text { Reorder point } \\
\text { part 3 }\end{array}$ & Pcs & 5 & Reorder point of part 3. \\
\hline $\begin{array}{l}\text { Wareh } \\
\text { ouse }\end{array}$ & Variable & Lead time & $\mathrm{h}$ & $7.5 / 36$ & Uniform distribution - valid for all parts \\
\hline Part & Attribute & $\begin{array}{l}\text { Time to } \\
\text { manufacture }\end{array}$ & $\mathrm{h}$ & $48 / 72 /$ & $\begin{array}{l}\text { Allowed time to deliver a part. Exceeding } \\
\text { this time leads to a penalty. (Part 1/ Part 2/ } \\
\text { Part 3) }\end{array}$ \\
\hline $\begin{array}{l}\text { Ware- } \\
\text { house }\end{array}$ & Variable & $\begin{array}{l}\text { Number on } \\
\text { stock Part 1 }\end{array}$ & Pcs & 8 & Initiating number of part 1 on stock. \\
\hline $\begin{array}{l}\text { Ware- } \\
\text { house }\end{array}$ & Variable & $\begin{array}{l}\text { Number on } \\
\text { stock Part 2 }\end{array}$ & Pcs & 3 & Initiating number of part 2 on stock. \\
\hline $\begin{array}{l}\text { Ware- } \\
\text { house }\end{array}$ & Variable & $\begin{array}{l}\text { Number on } \\
\text { stock Part 3 } \\
\text { house }\end{array}$ & Pcs & 3 & Initiating number of part 3 on stock. \\
\hline Variable & Storage cost & $\%$ & 0,225 & Storage cost in \%. \\
\hline
\end{tabular}

For further calculations the Process Analyzer (PAN) and OptQuest are used. PAN is an Arena built-in tool which allows a variation of variables by setting up different scenarios. By running the scenarios, results are calculated and shown in a tabular form. For optimization of specific values OptQuest will be used, which is an Arena built in tool for optimization. 


\subsection{VERIFICATION OF THE SIMULATION MODEL}

Kelton et al define the process of verification as a "...process of ensuring that the Arena model behaves in the way it was intended according to the modeling assumptions made." (Kelton, Sadowski, \& Swets, 2010) Kelton et al also describe an easy verification method. The method proposes to send one entity into the process and follow its way through the simulation in a slow mode. In the presented model this was done with every entity type for each relevant parameter setting. Debugging and verification were executed continuously during development either for single parts or the complete model, since changes happened regularly throughout development. For debugging several displays, animations, extreme tests experiments with different discrete distribution times, long run tests and results were used to check the model for internal failures. The verification process assured that the model works in the intended way.

\subsection{VALIDATION OF THE SIMULATION MODEL}

The process of validation is described by Kelton et al as "... the process of ensuring that the model behaves the same as the real system" (Kelton, Sadowski, \& Swets, 2010) In general the validation of a simulation model is assumed to be a difficult task. A good way of validation is to compare the results with those of a real system. This is important, since a model can never achieve absolute validity. Furthermore the subjective focus of involved people may affect several factors.

The presented model is likely to be problematic in that regard since data of a real system is not known or available at the current status. A validation of results is therefore not possible. To validate the model experts in simulation and AM consulted the validation of the model. 


\section{SIMULATION EXPERIMENTS}

According to the previously described goals of the study, the simulation model is used to see how technical changes in the AM process affect the performance of the overall cost as well as logistical attributes of the spare parts (lead time in particular). In particular, technical changes considered in our simulation model are listed in Table 4-1.

Table 4-1: Overview of experiments

\begin{tabular}{|c|c|c|}
\hline \begin{tabular}{l|l|} 
No. & Experiment \\
\end{tabular} & Unit & Description \\
\hline \multicolumn{3}{|l|}{ Base case } \\
\hline Base case setup & $\mathrm{cm}^{3}$ & Reference case for a one machine setup \\
\hline \multicolumn{3}{|l|}{ Technical investigations } \\
\hline Building space volume & $\mathrm{cm}^{3}$ & Variation of the building space for part generation. \\
\hline Building speed & $\mathrm{cm}^{3} / \mathrm{h}$ & Variation of building speed applied for part generation. \\
\hline Material price & $€ / \mathrm{kg}$ & Variation of price of $1 \mathrm{~kg} \mathrm{AM} \mathrm{raw} \mathrm{material.}$ \\
\hline Machine purchase price & $€$ & Variation of purchase price of the machine. \\
\hline Cool down time & hrs & Variation of the applied cool down time. \\
\hline \multicolumn{3}{|c|}{ Additive strategy investigations } \\
\hline Two machines & --- & $\begin{array}{l}\text { Basic setups: } \\
\text { - Fixed vs. flexible material assignment } \\
\text { - Waiting vs. direct production }\end{array}$ \\
\hline Three machines & --- & $\begin{array}{l}\text { Variables of interest: } \\
\text { - } \text { Mean arrival time } \\
\text { - } \text { Sum of setup and cool down time } \\
\text { - } \text { Plapse time (waiting only) } \\
\text { - } \\
\text { Material changeover time } \\
\text { (flexible material assignment only) }\end{array}$ \\
\hline Part size distribution & --- & $\begin{array}{l}\text { Several distributions of part sizes are investigated. For } \\
\text { example } 100 \% \text { small parts or } 100 \% \text { big parts and other } \\
\text { important mixtures. }\end{array}$ \\
\hline
\end{tabular}


Building space volume - A current trend in AM is increasing the building space volume of AM machines, which allows to build bigger parts during a production run. This might be an interesting topic when the time for production is not linked to a penalty, since the production run can be completed in the required time. The effect of an increased building space volume with respect to spare parts is not yet clear. In general, however, it is assumed that the increased building volume increases also the processing time, thus longer delivery times for spare parts. That might be a sensitive issue when penalties must be paid if a part is not delivered on time.

Building speed - Increasing the building speed is a main issue in AM. Increased building speeds will lead to faster processing and the effect on spare part supply should be positive.

Material cost - Material cost is also widely discussed in the literature. It is commonly agreed that the material price is a key factor and limits the application of AM in industry. The price an industrial company would be willing to pay will be investigated with respect to spare part supply.

Machine purchase price - In the literature it is often described that the purchasing price of an AM machine is too high to make it an interesting option for industrial application. It will be interesting to see how high or low the purchasing price has to be in order for the AM be an economically competitive option.

Cool down time - AM machines need a cool down time after production. Since this time can be several hours, the impact of the cool down time is also of interest for evaluation.

Two machines - It is reasonable that the application of two machines in parallel will improve the total system performance. We particularly investigate how the system will react given the following conditions due to the existence of two parallel machines. :

First set of conditions - In a two machine setup, a fixed material type can be produced by one machine only. This results in a total of two possible materials for production. This setup can run 
in two modes. The first mode will start the production process for each spare part request immediately after the spare part request arrives. The second mode is a waiting mode in which the system will wait until a certain amount of elapsed time or a certain amount of building space volume is filled for a production run.

Second set of conditions - In this two machine setup, both machines can produce with two kinds of materials. When the material setting is different than the designated material for the next production run, a material changeover time must be considered to simulate the exchange of production material. Also this setup will run in the waiting and no waiting mode.

Three machines - The conditions and modes of the model are similar to the two machine investigations except that three machines will be able to apply three materials.

Part size distribution - Part size is an attribute which is assumed to have a significant impact on production times. The spare part set has a specific distribution of part sizes. The total system is adjusted to these specific part sizes. A change in the distribution of the part sizes is assumed to have an effect on the system behavior, which we investigate through our simulation model. 


\subsection{PARAMETER OVERVIEW}

Next we lay out in detail the various settings for technical parameters, which may all vary in our simulation runs.

Table 4-2: Overview of all simulation parameters

\begin{tabular}{|c|c|c|c|c|}
\hline Type & Variable & Reference & Description & Formula \\
\hline Variable & $\begin{array}{l}\text { AM } \\
\text { maintenance } \\
\text { cost }\end{array}$ & \begin{tabular}{|l|} 
AM \\
Process
\end{tabular} & $\begin{array}{l}\text { Cost which is generated } \\
\text { by required maintenance } \\
\text { actions for AM. }\end{array}$ & \\
\hline Attribute & Arrival & Part & $\begin{array}{l}\text { Contains the arrival time } \\
\text { of each part request. }\end{array}$ & TNOW \\
\hline Variable & Break even & $\begin{array}{l}\text { Calculatio } \\
\mathrm{n}\end{array}$ & $\begin{array}{l}\text { Calculates the breakeven } \\
\text { point for AM. }\end{array}$ & $\begin{array}{l}\text { Machine purchase } \\
\text { price/(((Total warehousing } \\
\text { cost-Total AM } \\
\text { cost }) / \text { TNOW }) * 365 * 24)\end{array}$ \\
\hline Attribute & $\begin{array}{l}\text { Building } \\
\text { depth }\end{array}$ & Part & $\begin{array}{l}\text { Describes the building } \\
\text { depth of the part. }\end{array}$ & \\
\hline Variable & $\begin{array}{l}\text { Building } \\
\text { space depth }\end{array}$ & $\begin{array}{l}\text { AM } \\
\text { Process }\end{array}$ & $\begin{array}{l}\text { Describes the building } \\
\text { space depth of the RM } \\
\text { machine. }\end{array}$ & \\
\hline Variable & $\begin{array}{l}\text { Building } \\
\text { space height }\end{array}$ & $\begin{array}{l}\text { AM } \\
\text { Process }\end{array}$ & $\begin{array}{l}\text { Describes the building } \\
\text { space height of the RM } \\
\text { machine. }\end{array}$ & \\
\hline Variable & $\begin{array}{l}\text { Building } \\
\text { space } \\
\text { volume }\end{array}$ & $\begin{array}{l}\text { AM } \\
\text { Process }\end{array}$ & $\begin{array}{l}\text { Describes the building } \\
\text { space volume of the RM } \\
\text { machine. }\end{array}$ & $\begin{array}{l}\text { Building space } \\
\text { depth*Building space } \\
\text { height*Building space width }\end{array}$ \\
\hline Variable & $\begin{array}{l}\text { Building } \\
\text { space width }\end{array}$ & $\begin{array}{l}\text { AM } \\
\text { Process }\end{array}$ & $\begin{array}{l}\text { Describes the building } \\
\text { space width of the RM } \\
\text { machine. }\end{array}$ & \\
\hline Variable & $\begin{array}{l}\text { Building } \\
\text { speed AM } \\
\text { Material } 1\end{array}$ & $\begin{array}{l}\text { AM } \\
\text { Process }\end{array}$ & $\begin{array}{l}\text { Describes the building } \\
\text { speed of the RM machine } \\
\text { using material } 1 .\end{array}$ & \\
\hline Variable & $\begin{array}{l}\text { Building } \\
\text { speed AM } \\
\text { Material } 2\end{array}$ & $\begin{array}{l}\text { AM } \\
\text { Process }\end{array}$ & $\begin{array}{l}\text { Describes the building } \\
\text { speed of the RM machine } \\
\text { using material } 2 \text {. }\end{array}$ & \\
\hline Variable & $\begin{array}{l}\text { Building } \\
\text { speed AM } \\
\text { Material } 3\end{array}$ & $\begin{array}{l}\text { AM } \\
\text { Process }\end{array}$ & $\begin{array}{l}\text { Describes the building } \\
\text { speed of the RM machine } \\
\text { using material } 3 \text {. }\end{array}$ & \\
\hline Attribute & $\begin{array}{l}\text { Building } \\
\text { volume }\end{array}$ & Part & $\begin{array}{l}\text { Describes the building } \\
\text { volume of the part. }\end{array}$ & $\begin{array}{l}\text { Building height * Building } \\
\text { width*Building depth }\end{array}$ \\
\hline Variable & $\begin{array}{l}\text { Building } \\
\text { volume left }\end{array}$ & $\begin{array}{l}\text { AM } \\
\text { Process }\end{array}$ & $\begin{array}{l}\text { Calculates the remaining } \\
\text { building space to set up } \\
\text { production plan. }\end{array}$ & $\begin{array}{l}\text { Building volume left- } \\
\text { Building volume }\end{array}$ \\
\hline Attribute & $\begin{array}{l}\text { Building } \\
\text { width }\end{array}$ & Part & $\begin{array}{l}\text { Describes the building } \\
\text { width of the part. }\end{array}$ & \\
\hline
\end{tabular}




\begin{tabular}{|c|c|c|c|c|}
\hline Type & Variable & Reference & Description & Formula \\
\hline Attribute & $\begin{array}{l}\text { Bulding } \\
\text { height }\end{array}$ & Part & $\begin{array}{l}\text { Describes the building } \\
\text { height of the part. }\end{array}$ & \\
\hline Variable & \begin{tabular}{|l|} 
Batch \\
building \\
volume
\end{tabular} & $\begin{array}{l}\mathrm{AM} \\
\text { Process }\end{array}$ & $\begin{array}{l}\text { Adds the part building } \\
\text { volumes up to a batch } \\
\text { volume. }\end{array}$ & $\begin{array}{l}\text { Batch building volume + } \\
\text { Building volume }\end{array}$ \\
\hline Variable & $\begin{array}{l}\text { Number of } \\
\text { batch }\end{array}$ & $\begin{array}{l}\text { AM } \\
\text { Process }\end{array}$ & $\begin{array}{l}\text { Counts the number of } \\
\text { part batches produced. }\end{array}$ & Number of batch +1 \\
\hline Attribute & $\begin{array}{l}\text { Assigned } \\
\text { batch } \\
\text { building } \\
\text { volume }\end{array}$ & $\begin{array}{l}\mathrm{AM} \\
\text { Process }\end{array}$ & $\begin{array}{l}\text { Assigns the batch } \\
\text { building volume to the } \\
\text { last part to have a fixed } \\
\text { value for later } \\
\text { calculation. }\end{array}$ & Batch building volume \\
\hline Variable & $\begin{array}{l}\text { Building } \\
\text { volume per } \\
\text { batch }\end{array}$ & $\begin{array}{l}\text { AM } \\
\text { Process }\end{array}$ & $\begin{array}{l}\text { Works together with } \\
\text { "Assigned batch for } \\
\text { building volume" and } \\
\text { separates the batch } \\
\text { volume logically from the } \\
\text { continuously changing } \\
\text { "Batch building volume". } \\
\text { This value can be used } \\
\text { for calculations. }\end{array}$ & $\begin{array}{l}\text { Assigned batch building } \\
\text { volume }\end{array}$ \\
\hline Variable & $\begin{array}{l}\text { Average } \\
\text { building } \\
\text { volume }\end{array}$ & $\begin{array}{l}\mathrm{AM} \\
\text { Process }\end{array}$ & $\begin{array}{l}\text { Calculates the average } \\
\text { building volume based on } \\
\text { a previously known } \\
\text { average. }\end{array}$ & $\begin{array}{l}\text { Average building } \\
\text { volume*(Number of batch - } \\
\text { 1)/ Number of batch }+ \\
\text { Building volume per batch/ } \\
\text { Number of batch }\end{array}$ \\
\hline Variable & $\begin{array}{l}\text { Consumed } \\
\text { energy cost }\end{array}$ & $\begin{array}{l}\text { AM } \\
\text { Process }\end{array}$ & $\begin{array}{l}\text { Calculates the consumed } \\
\text { energy cost. }\end{array}$ & $\begin{array}{l}\text { (Material } \\
\text { consumption/1000)*Energy } \\
\text { consumption*Energy cost }\end{array}$ \\
\hline Variable & \begin{tabular}{|l|} 
Consumed \\
material cost
\end{tabular} & $\begin{array}{l}\text { AM } \\
\text { Process }\end{array}$ & $\begin{array}{l}\text { Calculates the consumed } \\
\text { material cost. }\end{array}$ & $\begin{array}{l}((\text { Material } \\
\text { consumption/1000)*7.85/100 } \\
0) * \text { Material cost }\end{array}$ \\
\hline Variable & Cool down & $\begin{array}{l}\mathrm{AM} \\
\text { Process }\end{array}$ & $\begin{array}{l}\text { Required time to cool } \\
\text { down the building space. }\end{array}$ & \\
\hline Variable & $\begin{array}{l}\text { Energy } \\
\text { consumption }\end{array}$ & $\begin{array}{l}\mathrm{AM} \\
\text { Process }\end{array}$ & $\begin{array}{l}\text { Energy consumption on } \\
\text { average production. }\end{array}$ & \\
\hline Variable & Energy cost & $\begin{array}{l}\text { AM } \\
\text { Process }\end{array}$ & $\begin{array}{l}\text { Energy price valid for } \\
\text { production. }\end{array}$ & \\
\hline Attribute & EOQ Part 1 & Part & $\begin{array}{l}\text { Economic order quantity } \\
\text { of part } 1 .\end{array}$ & \\
\hline Attribute & EOQ Part 2 & Part & $\begin{array}{l}\text { Economic order quantity } \\
\text { of part } 2 .\end{array}$ & \\
\hline Attribute & EOQ Part 3 & Part & $\begin{array}{l}\text { Economic order quantity } \\
\text { of part } 3 .\end{array}$ & \\
\hline Variable & \begin{tabular}{|l|} 
Machine \\
depreciation
\end{tabular} & $\begin{array}{l}\mathrm{AM} \\
\text { Process }\end{array}$ & $\begin{array}{l}\text { Calculated machine } \\
\text { depreciation at the } \\
\text { current point in time. }\end{array}$ & $\begin{array}{l}\text { ((Machine purchase } \\
\text { price/Years of } \\
\text { depreciation }) /(365 * 24)) * \mathrm{TN} \\
\text { OW }\end{array}$ \\
\hline
\end{tabular}




\begin{tabular}{|c|c|c|c|c|}
\hline Type & Variable & Reference & Description & Formula \\
\hline Variable & $\begin{array}{l}\text { Machine } \\
\text { purchase } \\
\text { price }\end{array}$ & $\begin{array}{l}\mathrm{AM} \\
\text { Process }\end{array}$ & $\begin{array}{l}\text { Machine price when } \\
\text { purchased. }\end{array}$ & \\
\hline Variable & $\begin{array}{l}\text { Machine } \\
\text { utilization }\end{array}$ & $\begin{array}{l}\text { AM } \\
\text { Process }\end{array}$ & $\begin{array}{l}\text { Calculated average } \\
\text { machine utilization over } \\
\text { time. }\end{array}$ & $\begin{array}{l}\text { (AM Process.VATime / } \\
(\text { TNOW }+0.001))^{*} 100\end{array}$ \\
\hline Variable & \begin{tabular}{|l|} 
Material \\
consumption
\end{tabular} & $\begin{array}{l}\text { AM } \\
\text { Process }\end{array}$ & $\begin{array}{l}\text { Calculates material } \\
\text { consumption by adding } \\
\text { the build volume of each } \\
\text { produced part. }\end{array}$ & $\begin{array}{l}\text { Material consumption + } \\
\text { Building volume }\end{array}$ \\
\hline Variable & $\begin{array}{l}\text { Material } \\
\text { cost }\end{array}$ & $\begin{array}{l}\mathrm{AM} \\
\text { Process }\end{array}$ & $\begin{array}{l}\text { Price of AM-material for } \\
\text { production. }\end{array}$ & \\
\hline Attribute & $\begin{array}{l}\text { Material } \\
\text { type }\end{array}$ & Part & $\begin{array}{l}\text { Material type assignment } \\
\text { by use of integer. }\end{array}$ & \\
\hline Variable & $\begin{array}{l}\text { Number on } \\
\text { stock Part } 1\end{array}$ & Warehouse & $\begin{array}{l}\text { Initiating number of part } \\
1 \text { on stock. }\end{array}$ & \\
\hline Variable & $\begin{array}{l}\text { Number on } \\
\text { stock Part } 2\end{array}$ & Warehouse & $\begin{array}{l}\text { Initiating number of part } \\
2 \text { on stock. }\end{array}$ & \\
\hline Variable & $\begin{array}{l}\text { Number on } \\
\text { stock Part } 3\end{array}$ & Warehouse & $\begin{array}{l}\text { Initiating number of part } \\
3 \text { on stock. }\end{array}$ & \\
\hline Attribute & $\begin{array}{l}\text { Operator } \\
\text { cost }\end{array}$ & Part & $\begin{array}{l}\text { Estimated cost of } \\
\text { required operator. }\end{array}$ & \\
\hline Variable & \begin{tabular}{|l|} 
Operator \\
training cost
\end{tabular} & $\begin{array}{l}\text { AM } \\
\text { Process }\end{array}$ & $\begin{array}{l}\text { Calculates operator } \\
\text { training cost at the } \\
\text { current point in time. }\end{array}$ & $\begin{array}{l}\text { (Operator training } \\
\text { price } /(365 * 24)) * \mathrm{TNOW}\end{array}$ \\
\hline Variable & $\begin{array}{l}\text { Operator } \\
\text { training } \\
\text { price }\end{array}$ & $\begin{array}{l}\mathrm{AM} \\
\text { Process }\end{array}$ & Price of operator training & \\
\hline Variable & $\begin{array}{l}\text { Part } 1 \\
\text { Penalty }\end{array}$ & Warehouse & $\begin{array}{l}\text { Calculated cumulated } \\
\text { penalty of part } 1 .\end{array}$ & $\begin{array}{l}\text { Part } 1 \text { Penalty + Penalty Part } \\
1\end{array}$ \\
\hline Variable & $\begin{array}{l}\text { Part } 2 \\
\text { Penalty }\end{array}$ & Warehouse & $\begin{array}{l}\text { Calculated cumulated } \\
\text { penalty of part } 2 \text {. }\end{array}$ & $\begin{array}{l}\text { Part } 1 \text { Penalty + Penalty Part } \\
1\end{array}$ \\
\hline Variable & $\begin{array}{l}\text { Part } 3 \\
\text { Penalty }\end{array}$ & Warehouse & $\begin{array}{l}\text { Calculated cumulated } \\
\text { penalty of part } 3 \text {. }\end{array}$ & $\begin{array}{l}\text { Part } 1 \text { Penalty + Penalty Part } \\
1\end{array}$ \\
\hline Attribute & \begin{tabular}{|l} 
Part \\
building \\
time
\end{tabular} & Part & $\begin{array}{l}\text { Time that is needed to } \\
\text { build a part with respect } \\
\text { to part volume and } \\
\text { building speed. }\end{array}$ & $\begin{array}{l}\text { (Building } \\
\text { volume/1000)/Building speed } \\
\text { AM Material } 1\end{array}$ \\
\hline Variable & \begin{tabular}{|l|} 
Part value \\
withdrawals
\end{tabular} & Warehouse & $\begin{array}{l}\text { Value of parts taken from } \\
\text { warehouse. }\end{array}$ & $\begin{array}{l}\text { Value consumed Part } \\
\text { 1+Value consumed Part } \\
\text { 2+Value consumed Part } 3\end{array}$ \\
\hline Attribute & $\begin{array}{l}\text { Part value } \\
\text { Part } 1\end{array}$ & Part & Purchase price of part 1. & \\
\hline Attribute & $\begin{array}{l}\text { Part value } \\
\text { Part } 2\end{array}$ & Part & Purchase price of part 2. & \\
\hline Attribute & \begin{tabular}{|l|} 
Part value \\
Part 3
\end{tabular} & Part & Purchase price of part 3. & \\
\hline
\end{tabular}




\begin{tabular}{|c|c|c|c|c|}
\hline Type & Variable & Reference & Description & Formula \\
\hline Variable & $\begin{array}{l}\text { Parts in } \\
\text { queue }\end{array}$ & $\begin{array}{l}\text { AM } \\
\text { Process }\end{array}$ & Counts the parts in queue & Parts in queue +1 \\
\hline Attribute & Penalty & Part & $\begin{array}{l}\text { Receives the penalty } \\
\text { value of each part. }\end{array}$ & \\
\hline Attribute & $\begin{array}{l}\text { Penalty Part } \\
1\end{array}$ & Part & $\begin{array}{l}\text { Penalty when part } 1 \text { is not } \\
\text { delivered in time. }\end{array}$ & \\
\hline Attribute & $\begin{array}{l}\text { Penalty Part } \\
2\end{array}$ & Part & $\begin{array}{l}\text { Penalty when part } 2 \text { is not } \\
\text { delivered in time. }\end{array}$ & \\
\hline Attribute & \begin{tabular}{|l|} 
Penalty Part \\
3
\end{tabular} & Part & $\begin{array}{l}\text { Penalty when part } 3 \text { is not } \\
\text { delivered in time. }\end{array}$ & \\
\hline Attribute & Priority & Part & $\begin{array}{l}\text { Pre-assigned priority of } \\
\text { part as production order } \\
\text { basis. }\end{array}$ & \\
\hline Attribute & $\begin{array}{l}\text { Production } \\
\text { priority }\end{array}$ & Part & $\begin{array}{l}\text { Priority which is used for } \\
\text { production order, } \\
\text { dependent on several } \\
\text { attributes. }\end{array}$ & $\begin{array}{l}\text { Priority*Times in } \\
\text { queue/(Time to } \\
\text { manufacture/(TNOW- } \\
\text { Arrival)) }\end{array}$ \\
\hline Attribute & $\begin{array}{l}\text { Reorder } \\
\text { point part 1 }\end{array}$ & Part & Reorder point of part 1. & \\
\hline Attribute & $\begin{array}{l}\text { Reorder } \\
\text { point part } 2\end{array}$ & Part & Reorder point of part 2. & \\
\hline Attribute & $\begin{array}{l}\text { Reorder } \\
\text { point part } 3\end{array}$ & Part & Reorder point of part 3. & \\
\hline Variable & $\begin{array}{l}\text { Stock value } \\
\text { Part } 1\end{array}$ & Warehouse & $\begin{array}{l}\text { Represents the stock } \\
\text { value of part } 1 \text { in the } \\
\text { warehouse. }\end{array}$ & $\begin{array}{l}\text { Number on stock Part } 1 * \\
\text { Part value Part } 1\end{array}$ \\
\hline Variable & $\begin{array}{l}\text { Stock value } \\
\text { Part } 2\end{array}$ & Warehouse & $\begin{array}{l}\text { Represents the stock } \\
\text { value of part } 2 \text { in the } \\
\text { warehouse. }\end{array}$ & $\begin{array}{l}\text { Number on stock Part } 2 * \\
\text { Part value Part } 2\end{array}$ \\
\hline Variable & $\begin{array}{l}\text { Stock value } \\
\text { Part } 3\end{array}$ & Warehouse & $\begin{array}{l}\text { Represents the stock } \\
\text { value of part } 3 \text { in the } \\
\text { warehouse. }\end{array}$ & $\begin{array}{l}\text { Number on stock Part } 3 * \\
\text { Part value Part } 3\end{array}$ \\
\hline Variable & Storage cost & Warehouse & Storage cost in $\%$. & \\
\hline Variable & $\begin{array}{l}\text { Storage cost } \\
\text { at time }\end{array}$ & Warehouse & $\begin{array}{l}\text { Calculates storage cost at } \\
\text { the current time. }\end{array}$ & $\begin{array}{l}\text { Total stock value*Storage } \\
\text { cost }\end{array}$ \\
\hline Attribute & \begin{tabular}{|l|} 
Time to \\
manufacture
\end{tabular} & Part & $\begin{array}{l}\text { Allowed time to deliver a } \\
\text { part. Exceeding this time } \\
\text { leads to a penalty. }\end{array}$ & \\
\hline Attribute & $\begin{array}{l}\text { Times in } \\
\text { queue }\end{array}$ & Part & $\begin{array}{l}\text { Number of times a part } \\
\text { entered the queue. This } \\
\text { influences the production } \\
\text { priority. }\end{array}$ & Times in queue +1 \\
\hline Variable & $\begin{array}{l}\text { Total AM } \\
\text { cost }\end{array}$ & $\begin{array}{l}\mathrm{AM} \\
\text { Process }\end{array}$ & $\begin{array}{l}\text { Sums up all cost related } \\
\text { to AM. }\end{array}$ & $\begin{array}{l}\text { Consumed material cost }+ \\
\text { Consumed energy cost }+ \\
\text { Total operator cost }+ \text { Total } \\
\text { maintenance cost }+ \text { Operator } \\
\text { training cost }+ \text { Machine } \\
\text { depreciation }+ \text { Total penalty }\end{array}$ \\
\hline
\end{tabular}




\begin{tabular}{|c|c|c|c|c|}
\hline Type & Variable & Reference & Description & Formula \\
\hline Variable & $\begin{array}{l}\text { Total } \\
\text { maintenance } \\
\text { cost }\end{array}$ & $\begin{array}{l}\text { AM } \\
\text { Process }\end{array}$ & $\begin{array}{l}\text { Calculates total } \\
\text { maintenance cost at the } \\
\text { current point in time. }\end{array}$ & $\begin{array}{l}\text { (AM maintenance } \\
\left.\operatorname{cost} /\left(365^{*} 24\right)\right) * \text { TNOW }\end{array}$ \\
\hline Variable & $\begin{array}{l}\text { Total } \\
\text { operator } \\
\text { cost }\end{array}$ & $\begin{array}{l}\mathrm{AM} \\
\text { Process }\end{array}$ & $\begin{array}{l}\text { Calculates total operator } \\
\text { cost at the current point } \\
\text { in time. }\end{array}$ & $\begin{array}{l}\text { Total operator cost }+ \\
\text { Operator cost }\end{array}$ \\
\hline Variable & $\begin{array}{l}\text { Total } \\
\text { penalty }\end{array}$ & $\begin{array}{l}\text { AM } \\
\text { Process }\end{array}$ & $\begin{array}{l}\text { Calculates total penalty } \\
\text { cost at the current point } \\
\text { in time. }\end{array}$ & Total penalty + Penalty \\
\hline Variable & $\begin{array}{l}\text { Total stock } \\
\text { value }\end{array}$ & Warehouse & $\begin{array}{l}\text { Calculates total stock } \\
\text { value at the current point } \\
\text { in time. }\end{array}$ & $\begin{array}{l}\text { Stock value Part } 1+\text { Stock } \\
\text { value Part } 2+\text { Stock value } \\
\text { Part } 3\end{array}$ \\
\hline Variable & $\begin{array}{l}\text { Total } \\
\text { warehousing } \\
\text { cost }\end{array}$ & Warehouse & $\begin{array}{l}\text { Calculates total } \\
\text { warehousing cost at the } \\
\text { current point in time. }\end{array}$ & $\begin{array}{l}\text { Part value consumed + } \\
\text { Storage cost }\end{array}$ \\
\hline Variable & $\begin{array}{l}\text { Value } \\
\text { withdrawals } \\
\text { Part } 1\end{array}$ & Warehouse & $\begin{array}{l}\text { Calculates the value of } \\
\text { consumed part } 1 \text { at the } \\
\text { current point in time. }\end{array}$ & $\begin{array}{l}\text { Value consumed Part } 1+\text { Part } \\
\text { value Part } 1\end{array}$ \\
\hline Variable & $\begin{array}{l}\text { Value } \\
\text { withdrawals } \\
\text { Part } 2\end{array}$ & Warehouse & $\begin{array}{l}\text { Calculates the value of } \\
\text { consumed part } 2 \text { at the } \\
\text { current point in time. }\end{array}$ & $\begin{array}{l}\text { Value consumed Part } 1+\text { Part } \\
\text { value Part } 1\end{array}$ \\
\hline Variable & $\begin{array}{l}\text { Value } \\
\text { withdrawals } \\
\text { Part } 3\end{array}$ & Warehouse & $\begin{array}{l}\text { Calculates the value of } \\
\text { consumed part } 3 \text { at the } \\
\text { current point in time. }\end{array}$ & $\begin{array}{l}\text { Value consumed Part } 1+\text { Part } \\
\text { value Part } 1\end{array}$ \\
\hline Variable & $\begin{array}{l}\text { Years of } \\
\text { depreciation }\end{array}$ & $\begin{array}{l}\text { AM } \\
\text { Process }\end{array}$ & $\begin{array}{l}\text { Planned depreciation time } \\
\text { for AM machine. }\end{array}$ & \\
\hline
\end{tabular}




\subsection{NUMBER OF REPLICATIONS}

The number of replications is important to ensure a robust evaluation from discrete event simulation, and we estimated the number of replication in our simulations with the framework proposed by Kelton et. al (2010). It follows a t-distribution based on the half width.

$$
h=t_{n-1,1-\alpha / 2} \frac{s}{\sqrt{n}}
$$

$\mathrm{h}$

Half width

$\mathrm{t}_{\mathrm{n}-1,1-\alpha / 2}$

t-distribution critical value

s

Standard deviation

$\mathrm{n}$

Number of replications

The error of the average is calculated by dividing $h$ by the average.

Equation (2) is then solved for $\mathrm{s}$ to calculate the standard deviation. The parameter $\mathrm{n}$ and $\mathrm{t}_{\mathrm{n}-1,1-\alpha / 2}$ are known. Arena's output after a simulation run is the average and $\mathrm{h}$, dependent on $\mathrm{n}$. Based on this $s$ is calculated according to equation (3).

$$
s=\frac{h * \sqrt{n}}{t_{n-1,1-\alpha / 2}}
$$

After solving the equation for $\mathrm{n}$, it is possible to estimate the required replications to reach a satisfactory confidence interval.

$$
n=t_{n-1,1-\alpha / 2}{ }^{2} \frac{s^{2}}{h^{2}}
$$


A difficulty occurs when using equation (4) is to calculate the new $n$. The standard deviation is not known, because the new $\mathrm{s}$ is dependent on the new $\mathrm{n}$. To solve this, it is assumed that $\mathrm{s}$ is equal for the scenarios with the old and new $\mathrm{n}$. The failure will be significantly reduced with an increasing number of replications.

Table 4-3 shows how the number of replications influences the quality of the results. Particularly, the table is created according to the following proceeding:

- $\quad$ set the initial number of replications ( $\left.\mathrm{n}_{\text {Basis }}\right)$

- run the simulation model

- fill in the values of average, half width, $\mathrm{n}$ and set the $\mathrm{t}$-value for the confidence interval

- the new $\mathrm{n}$ for the next simulation run is calculated and set as $\mathrm{n}_{\text {Basis }}$ for the next run

For demonstration purposes $\mathrm{n}$ is set to a low value of 10 in the first run. The number of estimation steps can be reduced when the initial $\mathrm{n}$ is set to a more appropriate value directly.

For this dissertation, an error in the point estimate of less than $5 \%$ is the target. Table 4-3 shows the results for the model basic setup, described in the proposal. The "average" value is the total AM cost described in the model (point estimate).

It was decided to use 150 replications for a simulation run. More than 122 replications would be sufficient in order for the error to be below the target of $5 \%$. On the other hand, the time estimate shows that the simulation time is short and a conservative number of 150 replications is acceptable and reduces $\mathrm{h}$ down to $\sim 4.28 \%$. For every model modification, it will be checked if $\mathrm{n}$ is still in the range of a maximum error of $5 \%$. If possible, the number of replications will be reduced to safe calculation time, but the maximum error of $5 \%$ will never be exceeded. 
Table 4-3: Effects of the number of replications

\begin{tabular}{|c|c|c|c|c|c|c|c|c|c|c|c|c|c|c|c|}
\hline & & \multicolumn{14}{|c|}{ Estimate } \\
\hline & & 1 & 2 & 3 & 4 & 5 & 6 & 7 & 8 & 9 & 10 & 11 & 12 & 13 & 14 \\
\hline Average & $\bar{\epsilon}$ & 47354 & 42275 & 42453 & 41563 & 42315 & 41830 & 42245 & 42067 & 42231 & 42013 & 42148 & 42041 & 42127 & 42057 \\
\hline Half width & $€$ & 17435 & 845 & 2939 & 1606 & 2579 & 1789 & 2354 & 1969 & 2195 & 2047 & 2142 & 2076 & 2125 & 2093 \\
\hline$n_{\text {besis }}$ & & 10 & 542 & 87 & 167 & 100 & 149 & 109 & 135 & 118 & 127 & 121 & 125 & 122 & 124 \\
\hline$t_{m-1,1-\alpha / 2}[95 \%]$ & & 2,262 & 2,262 & 2,262 & 2,262 & 2,262 & 2,262 & 2,262 & 2,262 & 2,262 & 2,262 & 2,262 & 2,262 & 2,262 & 2,262 \\
\hline stdDev $_{\text {Basis }}$ & $€$ & 24374 & 8699 & 12118 & 9173 & 11403 & 9657 & 10864 & 10113 & 10540 & 10197 & 10418 & 10263 & 10377 & 10304 \\
\hline Error in pointestimate & $\%$ & 36,82 & 2,00 & 6,92 & 3,86 & 6,10 & 4,28 & 5,57 & 4,68 & 5,20 & 4,87 & 5,08 & 4,94 & 5,04 & 4,98 \\
\hline \multicolumn{16}{|l|}{ Next estimate } \\
\hline Half width & $€$ & 2368 & 2114 & 2123 & 2078 & 2116 & 2092 & 2112 & 2103 & 2112 & 2101 & 2107 & 2102 & 2106 & 2103 \\
\hline Target of error in poinest. & $\%$ & 5,00 & 5,00 & 5,00 & 5,00 & 5,00 & 5,00 & 5,00 & 5,00 & 5,00 & 5,00 & 5,00 & 5,00 & 5,00 & 5,00 \\
\hline Number of replications & & 542 & 87 & 167 & 100 & 149 & 109 & 135 & 118 & 127 & 121 & 125 & 122 & 124 & 123 \\
\hline \multicolumn{16}{|l|}{ Run time of current series } \\
\hline Run time & 5 & 5 & 244 & 39 & 75 & 45 & 67 & 49 & 61 & 53 & 57 & 54 & 56 & 55 & 56 \\
\hline Run time & $\min$ & 0,1 & 4,1 & 0,7 & 1,3 & 0,8 & 1,1 & 0,8 & 1,0 & 0,9 & 1,0 & 0,9 & 0,9 & 0,9 & 0,9 \\
\hline
\end{tabular}

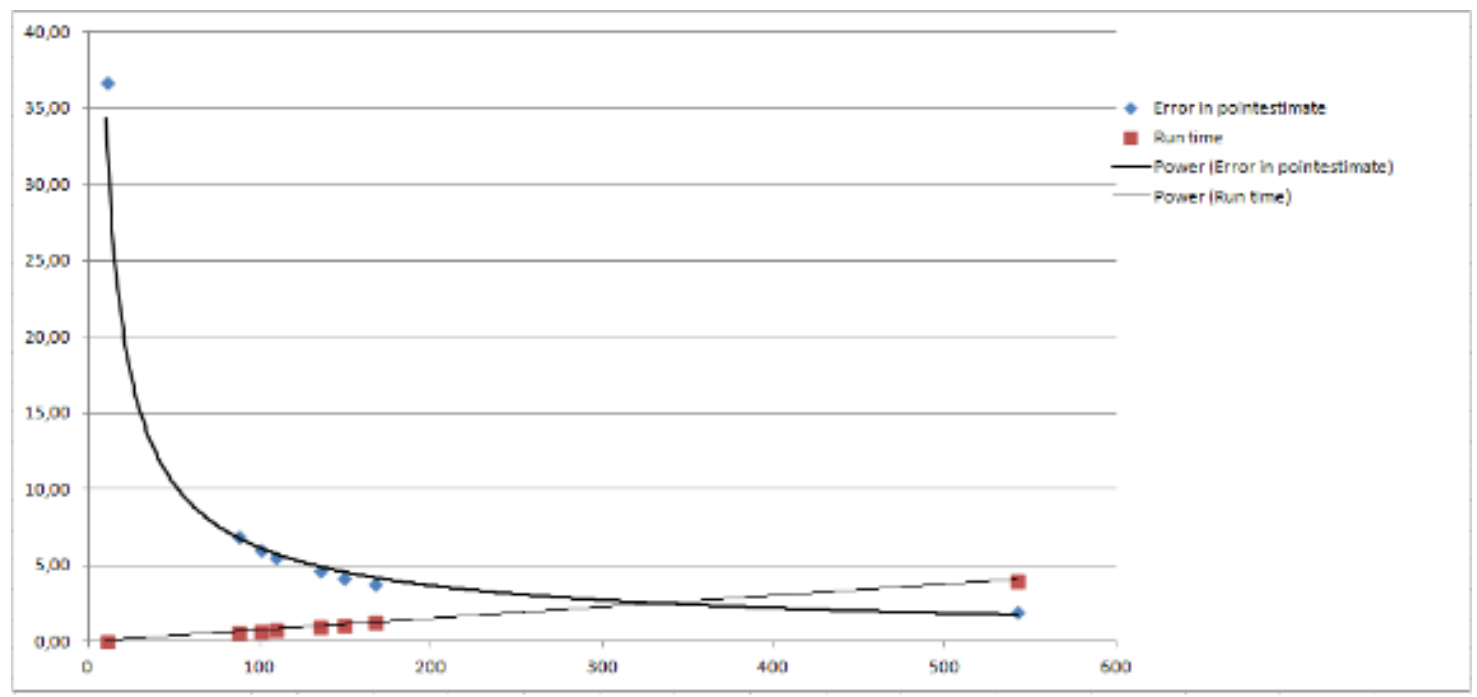




\subsection{SELECTED SPARE PART SET}

Another issue of the work is to define a set of spare parts used for simulation. We did not find any useful set of spare parts used in the literature, thus decided to design such a set in the current dissertation. The goal is to ensure the set of spare parts represents the average mix of a typical warehouse. A big plant, located in Neuss (Germany), agreed to provide warehouse data of one operational area out of three operational areas. The warehouse data contains $\sim 2600$ different kinds of spare parts and the related information for each spare part type.

The data was analyzed in several steps. First, each of the 2600 parts was evaluated to see if it may be possible to be manufactured by AM. If so, the part was marked and selected for further analysis. Evaluation was based on the available listed description of the part, material and part size. Figure 4-1 illustrates the data we were provided pertaining to several spare parts.

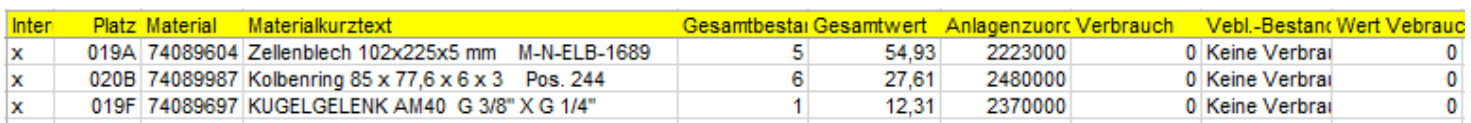

Figure 4-1: Illustrative sample of warehouse data

It was found that among the 2600 parts, 630 can be manufactured by AM. Next, an ABC analysis was executed on the value of the parts. The results are displayed in Table 4-4. Low value parts with an average value of $50 €$ represent $75 \%$, middle value parts (average $200 €$ ) represent $20 \%$ and high value parts (average $1000 €) 5 \%$ of the stock.

Table 4-4: Spare part parameter set

\begin{tabular}{|c|c|c|c|c|c|c|c|c|c|c|c|}
\hline \multicolumn{3}{|c|}{$\begin{array}{c}\text { Value } \\
{[€]}\end{array}$} & \multicolumn{3}{c|}{$\begin{array}{c}\text { Allowed time to } \\
\text { manufacture } \\
{[\mathbf{h r}]}\end{array}$} & \multicolumn{3}{c|}{$\begin{array}{c}\text { Penalty } \\
{[€]}\end{array}$} & \multicolumn{3}{c|}{$\begin{array}{c}\text { Volume } \\
\text { [\% of machine's } \\
\text { building volume] }\end{array}$} \\
\hline low & 50 & $75 \%$ & low & 48 & $5 \%$ & low & 2500 & $75 \%$ & low & 0,005 & $75 \%$ \\
\hline mid & 200 & $20 \%$ & mid & 72 & $20 \%$ & mid & 5000 & $20 \%$ & mid & 0,05 & $20 \%$ \\
\hline high & 1000 & $5 \%$ & high & 192 & $75 \%$ & high & 10000 & $5 \%$ & high & 0,15 & $5 \%$ \\
\hline
\end{tabular}


In the next step boundaries were set during discussions with experts of the plant, based on operational observations. If AM can be applied for a part, the allowed time to manufacture is set to low (48 h) for $5 \%$, middle $(72 \mathrm{~h})$ for $20 \%$ and high ( $192 \mathrm{~h})$ for $75 \%$ of the parts. Allowed time to manufacture describes the maximum allowed time in which a spare part must be produced and delivered. If it is not possible to deliver the spare part, a penalty will be charged. Penalty is therefore an indicator of the system performance.

Also the values for the different penalties were set. Observations and analysis of operation allowed to estimate operational losses on a monetary basis. It was agreed to use $2,500 €$ as low, $5,000 €$ as mid and $10,000 €$ as high average penalty for simulation. The fact of penalties makes preventive maintenance scenarios an interesting field for future research since it will allow for scheduling part production runs, which can certainly improve the AM situation. The presented model is not set up to simulate preventive maintenance strategies upfront the AM performance simulation. The spare part requests are created randomly, which also represents a typical behavior for spare parts with low turnover rates. Furthermore, if regular intervals for part replacements are planned, parts can be ordered on time and do not need to be stocked. This can also be true if parts simply need to be reworked.

The building volume values are estimated by the available machine data and the allowed time to manufacture. In our estimation, the machine Eosint M 280 (400 Watt Laser) was used. For example, the allowed time to manufacture (mid - $72 \mathrm{hr}$ ) multiplied with the average building speed of the machine $\left(23 \mathrm{~cm}^{3} / \mathrm{hr}\right)$ results in a product, representing the maximum build volume of the part $\left(1380 \mathrm{~cm}^{3}\right)$, which is $\sim 6.7 \%$ of the total building volume of the machine. To have a time buffer, the value is reduced to a more practical value, $5 \%$ in this example. The distribution ( 75 $\%, 20 \%, 5 \%)$ was set. 
Table 4-5: Extract of machine data of Eosint M 280 (400 Watt Laser)

\begin{tabular}{|l|l|r|}
\hline \multirow{3}{*}{} & Part size max. length $[\mathrm{mm}]$ & 250 \\
\cline { 2 - 3 } & Part size max. width $[\mathrm{mm}]$ & 250 \\
\cline { 2 - 3 } & Part size max. height $[\mathrm{mm}]$ & 325 \\
\cline { 2 - 3 } & Average building speed $\left[\mathrm{cm}^{3} / \mathrm{hr}\right]$ & 23 \\
\cline { 2 - 3 } & Building volume $\left[\mathrm{cm}^{3}\right]$ & 20312,5 \\
\hline
\end{tabular}

The values used in these tables can be different since they are based on the available warehouse data and the related operational observations.

With the set values in Table 4-4 it is possible to list all possible combinations of low, mid, and high values. To illustrate, Table 4-6 outlines the first 7 of 81 possible combinations. Based on these combinations, further assumptions are possible. For each combination the probability can be assigned and calculated. This is done by multiplying each individual probability.

For example for part $1: 0.75 * 0.05 * 0.75 * 0.75=0.02109$

Table 4-6: Logical combinations (first 7 of 81 )

\begin{tabular}{|c|c|c|c|c|r|r|r|r|r|}
\cline { 2 - 11 } \multicolumn{1}{c|}{ Logic } & \multicolumn{5}{c|}{ Probability } \\
\hline $\begin{array}{c}\text { Part } \\
\text { No. }\end{array}$ & Value & $\begin{array}{c}\text { Allowed } \\
\text { time to } \\
\text { manufacture }\end{array}$ & Penalty & Volume & Value & $\begin{array}{c}\text { Allowed } \\
\text { time to } \\
\text { manufacture }\end{array}$ & Penalty & Volume & \multicolumn{2}{l|}{$\begin{array}{l}\text { Total } \\
\text { Probability = }\end{array}$} \\
\hline 1 & low & low & low & low & 0.75 & 0.05 & 0.75 & 0.75 & 0.02109 \\
\hline 2 & low & low & low & mid & 0.75 & 0.05 & 0.75 & 0.20 & 0.00562 \\
\hline 3 & low & low & low & high & 0.75 & 0.05 & 0.75 & 0.05 & 0.00141 \\
\hline 4 & low & low & mid & low & 0.75 & 0.05 & 0.20 & 0.75 & 0.00563 \\
\hline 5 & low & low & mid & mid & 0.75 & 0.05 & 0.20 & 0.20 & 0.00150 \\
\hline 6 & low & low & mid & high & 0.75 & 0.05 & 0.20 & 0.05 & 0.00038 \\
\hline 7 & low & low & high & low & 0.75 & 0.05 & 0.05 & 0.75 & 0.00141 \\
\hline
\end{tabular}


When this is done for each part, the table can be sorted by the individual values of the total probability. The individual probability value represents the probability that this specific part will be requested and must be delivered. When the probabilities are sorted and cumulated, they can be displayed. It becomes obvious that the first 30 part types represent $95 \%$ of all requests. The other 51 types represent only $5 \%$ of all requests. Even if $95 \%$ of the system utilization can be displayed by 30 kinds of spare parts, it was decided to keep all 81 kinds of spare parts in the model. This is because these parts will block storage space, whether they are being used or not, and therefore contribute to inventory cost. It is our belief that these low probability part types might significantly impact the spare part simulation, and therefore represent a real world situation where rare failures occur.

Table 4-7: Spare parts with sorted probability (first 9 of 81)

\begin{tabular}{|c|c|c|c|c|c|c|c|c|c|c|}
\hline & \multicolumn{4}{|c|}{ Logic } & \multicolumn{4}{|c|}{ Probability } & \multicolumn{2}{|c|}{ Calculations } \\
\hline $\begin{array}{c}\text { Part } \\
\text { No. } \\
\text { sorted }\end{array}$ & Value & $\begin{array}{l}\text { Allowed } \\
\text { time to } \\
\text { manu- } \\
\text { facture }\end{array}$ & Penalty & Volume & Value & $\begin{array}{l}\text { Allowed } \\
\text { time to } \\
\text { manu- } \\
\text { facture }\end{array}$ & $\begin{array}{c}\text { Penalt } \\
\mathrm{y}\end{array}$ & Volume & $\begin{array}{l}\text { Total } \\
\text { Probability } \\
=1\end{array}$ & $\begin{array}{l}\text { Probability } \\
\text { cumulated }\end{array}$ \\
\hline 1 & low & high & low & low & 0.75 & 0.75 & 0.75 & 0.75 & 0.31641 & 0.316406 \\
\hline 2 & low & mid & low & low & 0.75 & 0.20 & 0.75 & 0.75 & 0.08438 & 0.400781 \\
\hline 3 & low & high & low & mid & 0.75 & 0.75 & 0.75 & 0.20 & 0.08438 & 0.485156 \\
\hline 4 & low & high & mid & low & 0.75 & 0.75 & 0.20 & 0.75 & 0.08438 & 0.569531 \\
\hline 5 & mid & high & low & low & 0.20 & 0.75 & 0.75 & 0.75 & 0.08438 & 0.653906 \\
\hline 6 & low & mid & low & mid & 0.75 & 0.20 & 0.75 & 0.20 & 0.02250 & 0.676406 \\
\hline 7 & low & mid & mid & low & 0.75 & 0.20 & 0.20 & 0.75 & 0.02250 & 0.698906 \\
\hline
\end{tabular}




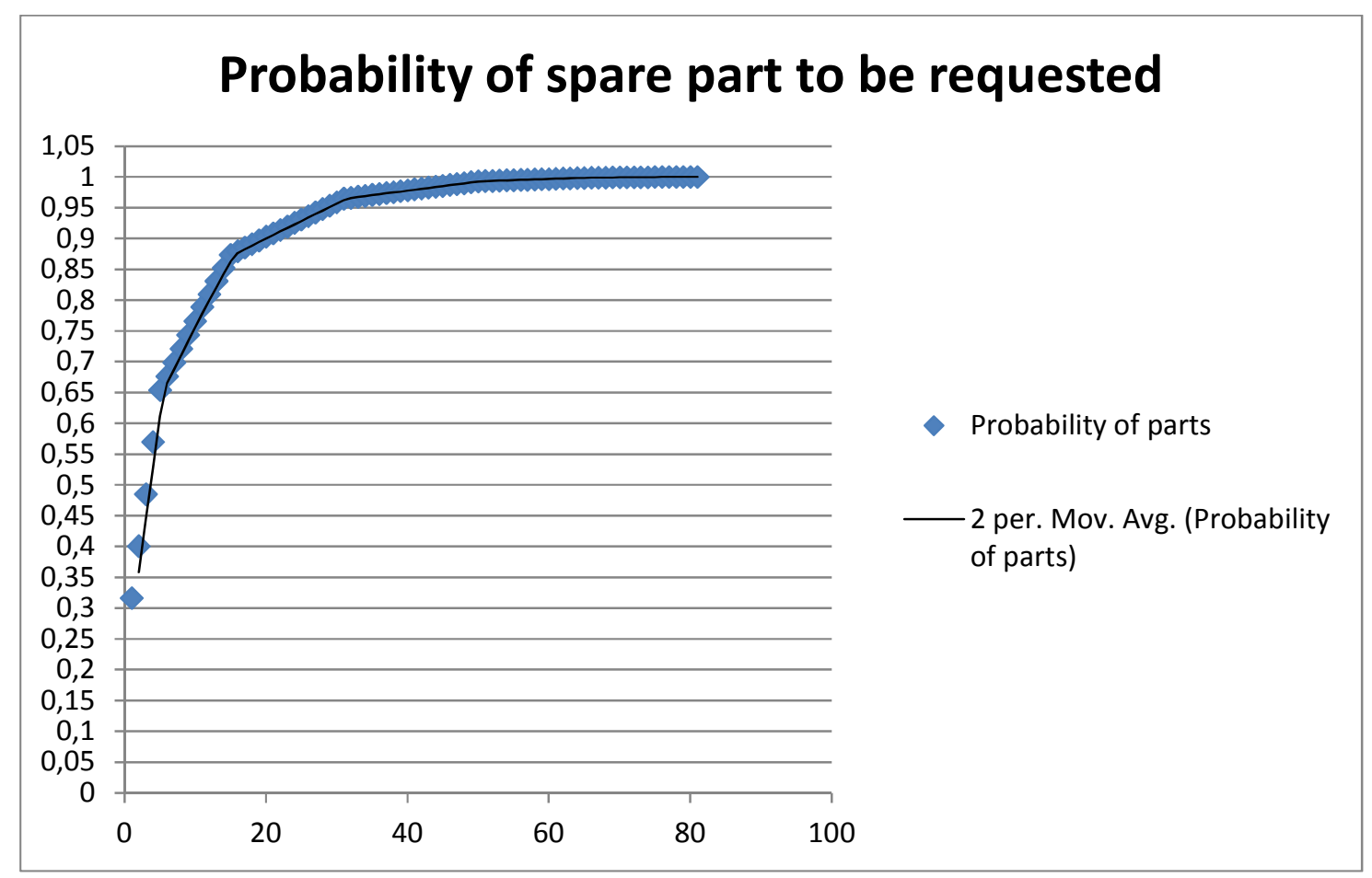

Figure 4-2: Probability of spare part to be requested

Next a priority is assigned to each kind of part by use of a pairwise importance matrix and comparison thereafter. In the pairwise importance matrix, each attribute is compared with all other attributes, stating which attribute should be prioritized or if the importance of two is equal. For the resulting three cases, the following values are used:

- Attribute is less important than the other attribute: 1

- Attribute is equal to the other attribute: 2

- Attribute is more important the other attribute: 3

For example:

Value is less important than Penalty $\rightarrow 1$ or Volume is more important than Penalty $\rightarrow 3$ ) 
When all combinations are evaluated, the values of the each column are summed up, which represents the weight of the attribute in the relevant column. The weight can be normalized and used for further calculations. Table 4-8 shows the set preferences including the weight and normalized weight of each attribute.

Table 4-8: Paired comparison

\begin{tabular}{|c|c|c|c|c|c|c|}
\hline & Value & $\begin{array}{c}\text { Allowed } \\
\text { time to } \\
\text { manufacture }\end{array}$ & Penalty & Volume & Weight & $\begin{array}{c}\text { Normalized } \\
\text { weigth }\end{array}$ \\
\hline Value & & 1 & 1 & 1 & 3 & 0.125 \\
\hline Allowed time to deliver & 3 & & 3 & 3 & 9 & 0.375 \\
\hline Penalty & 3 & 1 & . & 1 & 5 & 0.208333 \\
\hline Volume & 3 & 1 & 3 & & 7 & 0.291667 \\
\hline
\end{tabular}

For each attribute a basic priority can be assigned. For value, penalty and volume, it is assumed that a low value in the logic part has a basic priority of 1 . Consequently, mid has a value of 2 and high a value of 3 . While for example a low penalty does not need a high priority, it is the opposite for the allowed time to manufacture. Here, low represents a high time pressure and therefore a high priority. The setting is - low equals 3 , mid equals 2 , high equals 1 . When the values are assigned, the weighted priority can be calculated by multiplying the basic priority of each attribute with the normalized weight of the attribute. For example for part type 1:

$$
1 * 0.125+3 * 0.375+1 * 0.208333+1 * 0.291667=1.7500
$$

Then the actual priority is assigned accordingly:

$\begin{array}{llll}\text { Priority }=1 & 1< & \text { weighted priority }< & 1.66667 \\ \text { Priority }=2 & 1.66667<= & \text { weighted priority }< & 2.333337 \\ \text { Priority }=3 & 2.333337<= & \text { weighted priority }< & 3\end{array}$


Table 4-9: Priority calculation

\begin{tabular}{|c|c|c|c|c|c|c|c|c|c|c|}
\hline \multirow[b]{2}{*}{ No. } & \multicolumn{4}{|c|}{ Logic } & \multicolumn{6}{|c|}{ Priority } \\
\hline & Value & $\begin{array}{l}\text { Allowed time } \\
\text { to } \\
\text { manufacture }\end{array}$ & Penalty & Volume & Value & $\begin{array}{c}\text { Allowed } \\
\text { time to } \\
\text { manufacture }\end{array}$ & Penalty & Volume & $\begin{array}{l}\text { Weighted } \\
\text { priority }\end{array}$ & Priority \\
\hline 1 & low & low & low & low & 1 & 3 & 1 & 1 & 1.7500 & 2 \\
\hline 2 & low & low & low & mid & 1 & 3 & 1 & 2 & 2.0417 & 2 \\
\hline 3 & low & low & low & high & 1 & 3 & 1 & 3 & 2.3333 & 2 \\
\hline 4 & low & low & mid & low & 1 & 3 & 2 & 1 & 1.9583 & 2 \\
\hline 5 & low & low & mid & mid & 1 & 3 & 2 & 2 & 2.2500 & 2 \\
\hline 6 & low & low & mid & high & 1 & 3 & 2 & 3 & 2.5417 & 3 \\
\hline 7 & low & low & high & low & 1 & 3 & 3 & 1 & 2.1667 & 2 \\
\hline 8 & low & low & high & mid & 1 & 3 & 3 & 2 & 2.4583 & 3 \\
\hline 9 & low & low & high & high & 1 & 3 & 3 & 3 & 2.7500 & 3 \\
\hline
\end{tabular}

In the last step the table must be cleared of combinations which are not possible. This means that combinations where a high volume and a mid or low allowed time to manufacture occur, are deleted from the spare part set. It will never be possible to produce a high volume part in mid or low "Allowed time to manufacture". The same is also true for mid volume parts and low "Allowed time to manufacture". After clearing the table, $81-27=54$ spare part types remain. The probabilities must then be corrected (Total probability must sum up to 1) since the eliminated parts are no longer part of the spare part set.

Table 4-10 was prepared in accordance with the previously described proceeding and lists the 54 spare part types, relevant for simulation, and sorted by probability. Only results are presented. 
Table 4-10: Spare part types for simulation

\begin{tabular}{|c|c|c|c|c|c|c|c|c|c|c|}
\hline \multirow[b]{2}{*}{$\begin{array}{l}\vec{D} \\
\stackrel{0}{0} \\
0 \\
\mathscr{C}\end{array}$} & \multirow[b]{2}{*}{ No. } & \multicolumn{4}{|c|}{ Logic } & \multicolumn{2}{|c|}{ Priority } & \multicolumn{3}{|c|}{ Calculations } \\
\hline & & Value & $\begin{array}{l}\text { Allowed } \\
\text { time to } \\
\text { deliver }\end{array}$ & Penalty & Volume & $\begin{array}{l}\text { Weighted } \\
\text { priority }\end{array}$ & Priority & $\begin{array}{l}\text { Corrected } \\
\text { Total } \\
\text { Probability = } \\
1 \\
\end{array}$ & $\begin{array}{l}\text { Production } \\
\text { time [hr] }\end{array}$ & $\begin{array}{l}\text { Corrected } \\
\text { Probability } \\
\text { cumulated }\end{array}$ \\
\hline 1 & 19 & low & high & low & low & 1,0000 & 1 & 0,323689 & 4 & 0,323689 \\
\hline 2 & 10 & low & mid & low & low & 1,3750 & 1 & 0,086317 & 4 & 0,410006 \\
\hline 3 & 20 & low & high & low & mid & 1,2917 & 1 & 0,086317 & 44 & 0,496324 \\
\hline 4 & 22 & low & high & mid & low & 1,2083 & 1 & 0,086317 & 4 & 0,582641 \\
\hline 5 & 46 & mid & high & low & low & 1,1250 & 1 & 0,086317 & 4 & 0,668958 \\
\hline 6 & 11 & low & mid & low & mid & 1,6667 & 1 & 0,023018 & 44 & 0,691976 \\
\hline 7 & 13 & low & mid & mid & low & 1,5833 & 1 & 0,023018 & 4 & 0,714994 \\
\hline 8 & 37 & mid & mid & low & low & 1,5000 & 1 & 0,023018 & 4 & 0,738012 \\
\hline 9 & 47 & mid & high & low & mid & 1,4167 & 1 & 0,023018 & 44 & 0,761029 \\
\hline 10 & 49 & mid & high & mid & low & 1,3333 & 1 & 0,023018 & 4 & 0,784047 \\
\hline 11 & 23 & low & high & mid & mid & 1,5000 & 1 & 0,023018 & 44 & 0,807065 \\
\hline 12 & 1 & low & low & low & low & 1,7500 & 2 & 0,021579 & 4 & 0,828645 \\
\hline 13 & 21 & low & high & low & high & 1,5833 & 1 & 0,021579 & 132 & 0,850224 \\
\hline 14 & 25 & low & high & high & low & 1,4167 & 1 & 0,021579 & 4 & 0,871803 \\
\hline 15 & 73 & high & high & low & low & 1,2500 & 1 & 0,021579 & 4 & 0,893382 \\
\hline 16 & 14 & low & mid & mid & mid & 1,8750 & 2 & 0,006138 & 44 & 0,899520 \\
\hline 17 & 38 & mid & mid & low & mid & 1,7917 & 2 & 0,006138 & 44 & 0,905659 \\
\hline 18 & 40 & mid & mid & mid & low & 1,7083 & 2 & 0,006138 & 4 & 0,911797 \\
\hline 19 & 50 & mid & high & mid & mid & 1,6250 & 1 & 0,006138 & 44 & 0,917935 \\
\hline 20 & 4 & low & low & mid & low & 1,9583 & 2 & 0,005754 & 4 & 0,923689 \\
\hline 21 & 16 & low & mid & high & low & 1,7917 & 2 & 0,005754 & 4 & 0,929444 \\
\hline 22 & 28 & mid & low & low & low & 1,8750 & 2 & 0,005754 & 4 & 0,935198 \\
\hline 23 & 48 & mid & high & low & high & 1,7083 & 2 & 0,005754 & 132 & 0,940953 \\
\hline 24 & 52 & mid & high & high & low & 1,5417 & 1 & 0,005754 & 4 & 0,946707 \\
\hline 25 & 64 & high & mid & low & low & 1,6250 & 1 & 0,005754 & 4 & 0,952462 \\
\hline 26 & 74 & high & high & low & mid & 1,5417 & 1 & 0,005754 & 44 & 0,958216 \\
\hline 27 & 76 & high & high & mid & low & 1,4583 & 1 & 0,005754 & 4 & 0,963971 \\
\hline 28 & 24 & low & high & mid & high & 1,7917 & 2 & 0,005754 & 132 & 0,969725 \\
\hline 29 & 26 & low & high & high & mid & 1,7083 & 2 & 0,005754 & 44 & 0,975480 \\
\hline 30 & 41 & mid & mid & mid & mid & 2,0000 & 2 & 0,001637 & 44 & 0,977116 \\
\hline 31 & 17 & low & mid & high & mid & 2,0833 & 2 & 0,001535 & 44 & 0,978651 \\
\hline 32 & 31 & mid & low & mid & low & 2,0833 & 2 & 0,001535 & 4 & 0,980185 \\
\hline 33 & 43 & mid & mid & high & low & 1,9167 & 2 & 0,001535 & 4 & 0,981720 \\
\hline 34 & 51 & mid & high & mid & high & 1,9167 & 2 & 0,001535 & 132 & 0,983254 \\
\hline 35 & 53 & mid & high & high & mid & 1,8333 & 2 & 0,001535 & 44 & 0,984789 \\
\hline 36 & 65 & high & mid & low & mid & 1,9167 & 2 & 0,001535 & 44 & 0,986324 \\
\hline
\end{tabular}




\begin{tabular}{|c|c|c|c|c|c|c|c|c|c|c|}
\hline \multirow[b]{2}{*}{$\begin{array}{l}\overrightarrow{0} \\
\stackrel{0}{0} \\
0 \\
0\end{array}$} & \multirow[b]{2}{*}{ No. } & \multicolumn{4}{|c|}{ Logic } & \multicolumn{2}{|c|}{ Priority } & \multicolumn{3}{|c|}{ Calculations } \\
\hline & & Value & $\begin{array}{l}\text { Allowed } \\
\text { time to } \\
\text { deliver }\end{array}$ & Penalty & Volume & $\begin{array}{l}\text { Weighted } \\
\text { priority }\end{array}$ & Priority & \begin{tabular}{|l} 
Corrected \\
Total \\
Probability = \\
1 \\
\end{tabular} & $\begin{array}{l}\text { Production } \\
\text { time [hr] }\end{array}$ & $\begin{array}{l}\text { Corrected } \\
\text { Probability } \\
\text { cumulated }\end{array}$ \\
\hline 37 & 67 & high & mid & mid & low & 1,8333 & 2 & 0,001535 & 4 & 0,987858 \\
\hline 38 & 77 & high & high & mid & mid & 1,7500 & 2 & 0,001535 & 44 & 0,989393 \\
\hline 39 & 7 & low & low & high & low & 2,1667 & 2 & 0,001439 & 4 & 0,990831 \\
\hline 40 & 55 & high & low & low & low & 2,0000 & 2 & 0,001439 & 4 & 0,992270 \\
\hline 41 & 75 & high & high & low & high & 1,8333 & 2 & 0,001439 & 132 & 0,993708 \\
\hline 42 & 79 & high & high & high & low & 1,6667 & 1 & 0,001439 & 4 & 0,995147 \\
\hline 43 & 27 & low & high & high & high & 2,0000 & 2 & 0,001439 & 132 & 0,996586 \\
\hline 44 & 44 & mid & mid & high & mid & 2,2083 & 2 & 0,000409 & 44 & 0,996995 \\
\hline 45 & 68 & high & mid & mid & mid & 2,1250 & 2 & 0,000409 & 44 & 0,997404 \\
\hline 46 & 34 & mid & low & high & low & 2,2917 & 2 & 0,000384 & 4 & 0,997788 \\
\hline 47 & 54 & mid & high & high & high & 2,1250 & 2 & 0,000384 & 132 & 0,998171 \\
\hline 48 & 58 & high & low & mid & low & 2,2083 & 2 & 0,000384 & 4 & 0,998555 \\
\hline 49 & 70 & high & mid & high & low & 2,0417 & 2 & 0,000384 & 4 & 0,998939 \\
\hline 50 & 78 & high & high & mid & high & 2,0417 & 2 & 0,000384 & 132 & 0,999322 \\
\hline 51 & 80 & high & high & high & mid & 1,9583 & 2 & 0,000384 & 44 & 0,999706 \\
\hline 52 & 71 & high & mid & high & mid & 2,3333 & 2 & 0,000102 & 44 & 0,999808 \\
\hline 53 & 61 & high & low & high & low & 2,4167 & 3 & 0,000096 & 4 & 0,999904 \\
\hline 54 & 81 & high & high & high & high & 2,2500 & 2 & 0,000096 & 132 & 1,000000 \\
\hline
\end{tabular}




\section{BASE CASE SIMULATION}

The base case is a reference case for all further extensions of the model. It is important to evaluate the impact and therefore the significance of changes in the parameter set. The base case enables the direct comparison with respect to changes in the parameter set.

\subsection{MODEL ADJUSTMENT}

The simulation experiments require changes in the basic model described in the previous sections. Recall that Section 4.3 mentions that no individual parts are used, while in fact the simulation uses a set of spare parts with certain characteristics. This is important for the calculation of storage cost. While the base case model calculates the storage cost by summing up the product of the number of parts on stock times price times storage cost, the same is not possible for a general spare part set. For example:

The total spare part set consists of approximately 630 parts and represents a stock value of $285,000 €$. The general spare part set includes 54 parts representing only a fraction of the actual stock value.

The model is corrected to compensate this effect. Compensation is done by using the known stock value, used as average ${ }^{6}$, and breaking it down to an hourly basis. The time related storage cost can then again be calculated by multiplying it with the parameter "storage cost" [\%].

\footnotetext{
${ }^{6}$ Due to the high stock value variations are assumed to be marginal.
} 
Calculation:

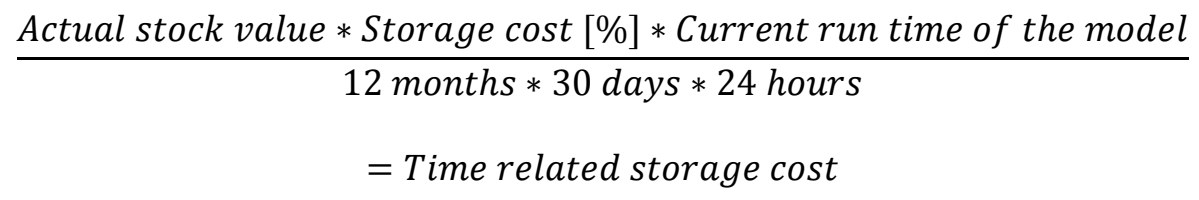

For example after a one year run time of the simulation model the result for the storage cost at this time is calculated:

$$
\frac{285,000 € * 15 \% * 8,760 h}{12 \text { months } * 30 \text { days } * 24 \text { hours }} * 5=42,583 €
$$

The simulation model will always update the storage cost at time according to the present run time.

All items in the selected spare part stock were optimized to the specific EOQ, reorder point and lead time for each spare part type. The target was to have a minimum stock level without creating penalties.

The second adjustment to the base case model is the removal of the depreciation out of the total cost of AM. In the basic model an existing warehouse is assumed where the depreciation time has ended. In this case, depreciation cost of AM are a significant cost factor and should be included in the total AM cost. Since the main focus of this work is comparing the performance of AM to warehousing, depreciation is not considered as a cost factor included in the total cost, neither for the warehouse nor for the AM machine. Further more information about building cost for warehouses was not available, so taking the depreciation of the AM machine into account would only produce misleading results. However, the depreciation of the AM machine will be a result which can be used if further data becomes available. 
Lastly, the general spare part set is included in the model and the replication length was adjusted to 8640 hours, representing 1 year of operation.

The create module was set to create entities according to a Poisson distribution with a mean of $100 \mathrm{hrs}$ as a basic setting. The mean of the distribution represents the mean arrival time of the spare part requests. The mean arrival time is used to stress or relax the system, which allows identifying an "upper limit" at which the system is working stable with maximum utilization, without creating no or minor penalties.For example when the mean inter-arrival time decreases, more part requests will enter the system and the system's stress is increased. When the mean inter-arrival time increases, less part requests will enter the system and the system will be more relaxed. The effect of these changes is displayed best by "AM parts out". This variable describes the number of parts which left the system after they were produced by the AM machine. As long as the system is in a stable state, "AM parts out" is equal to the delivered parts of the warehouse route. The upper limit is defined as the point where cost of the AM option equals that the warehousing option.

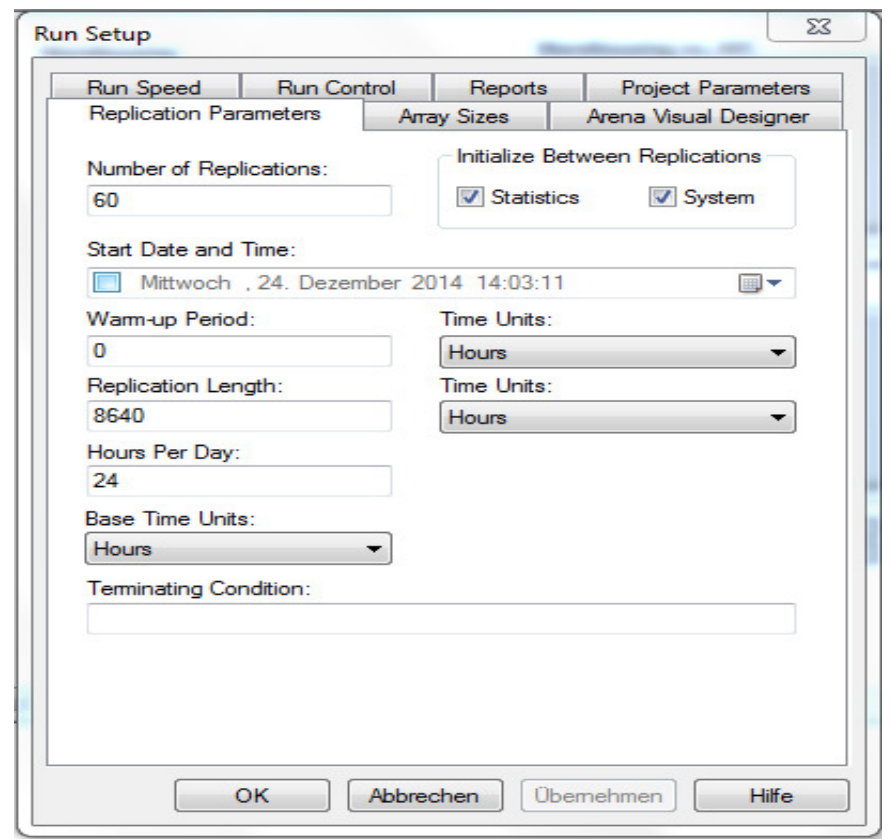

Figure 5-1: Changes in replication parameters 


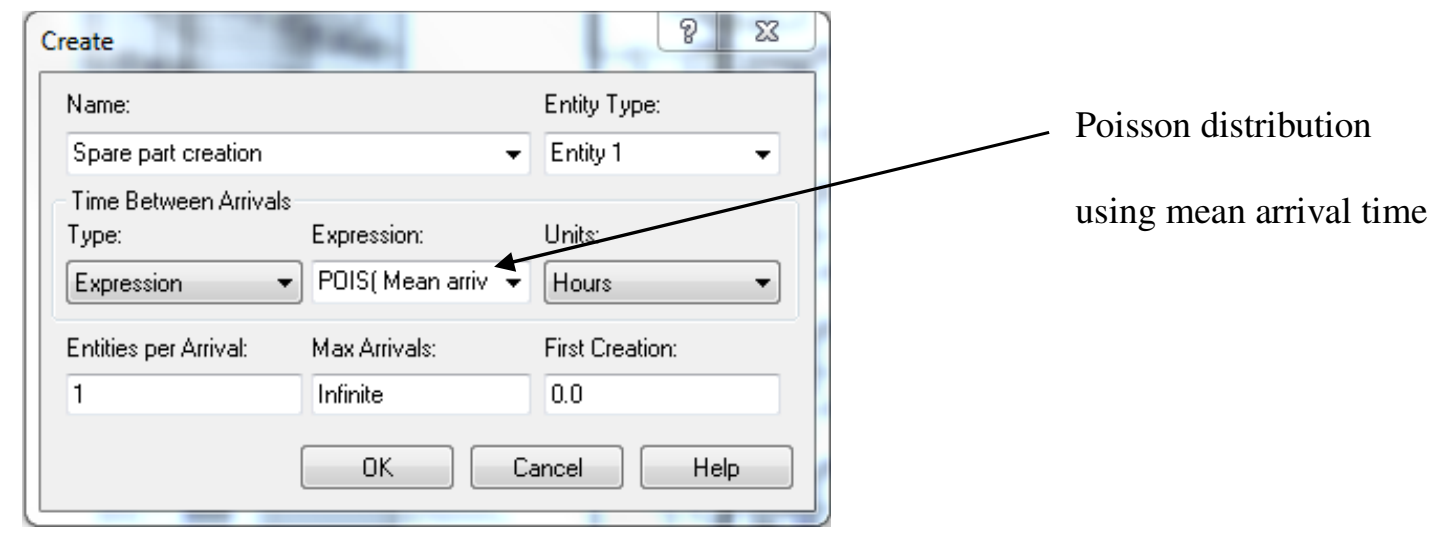

Figure 5-2: Changes in create module

To reach an acceptable half width of less than five percent, 60 replications are used. The half width is checked for every simulation setup and was never bigger than the accepted $5 \%$ (typically around $3 \%$ ).

\begin{tabular}{l|rrrr}
\multicolumn{1}{l}{\begin{tabular}{l} 
Output \\
\multicolumn{1}{l}{ Aversge }
\end{tabular}} & \multicolumn{1}{c}{ Helf Width } & $\begin{array}{r}\text { Minimum } \\
\text { Aversge }\end{array}$ & $\begin{array}{r}\text { Maximum } \\
\text { Aversge }\end{array}$ \\
\hline Total AM cost statistic & 73493.78 & $1.918,33$ & 59415.21 & 91953.46 \\
Total warehousing cost statistic & 74190.58 & 510,59 & 69176.27 & 81680.14
\end{tabular}

Figure 5-3: Verification of half width

\subsection{PROCEEDING}

First of all, an upper limit search is executed to define a limit for the system performance in the base case. An upper limit search stresses the system until the system exits the stable state. This provides a first impression of how the system reacts to changes. The limit search is executed using two independent simulation runs. First a rough and then a detailed limit search. Each scenario (one row is one scenario) will run 60 times to create the accepted half width. 

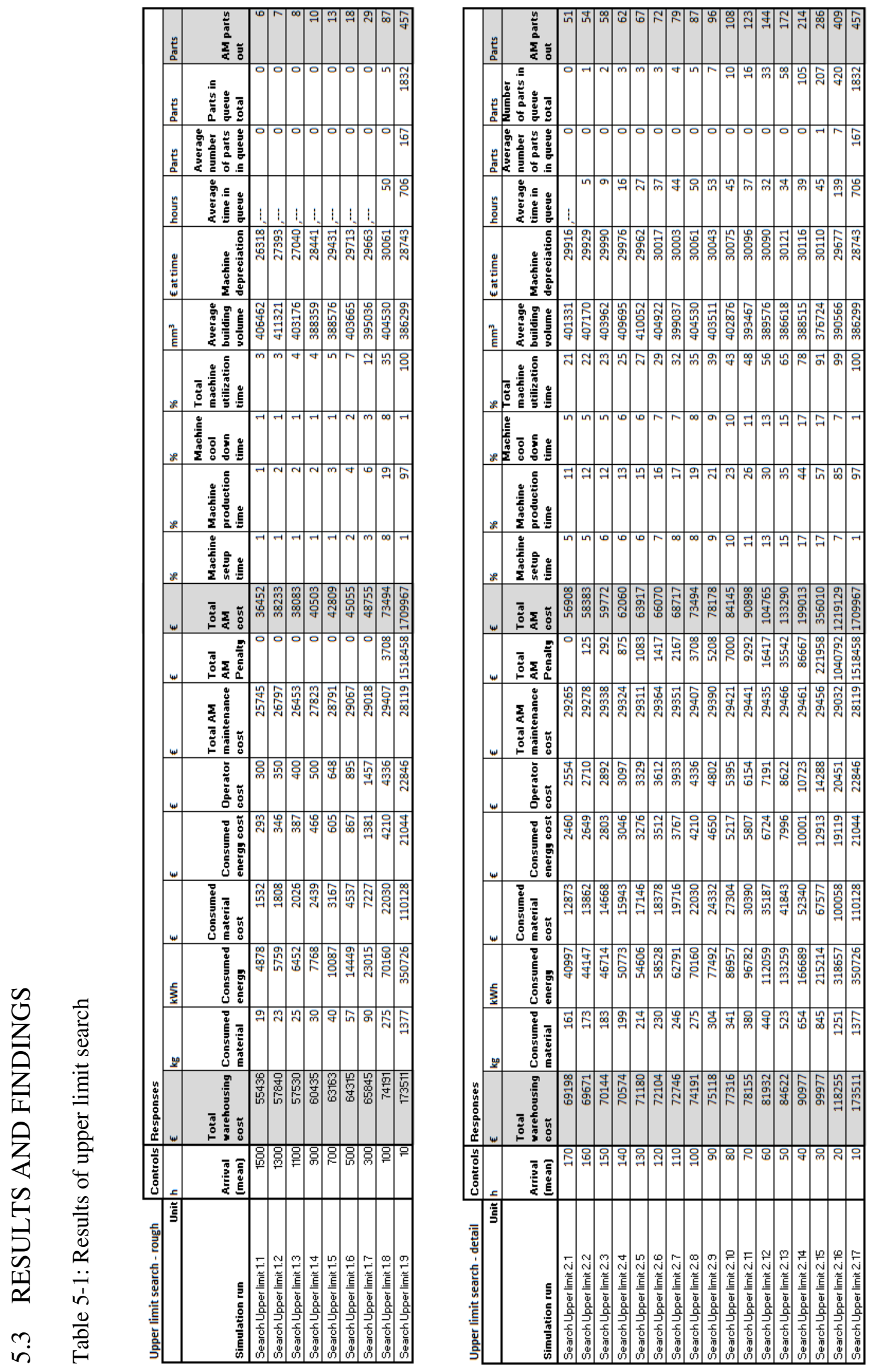

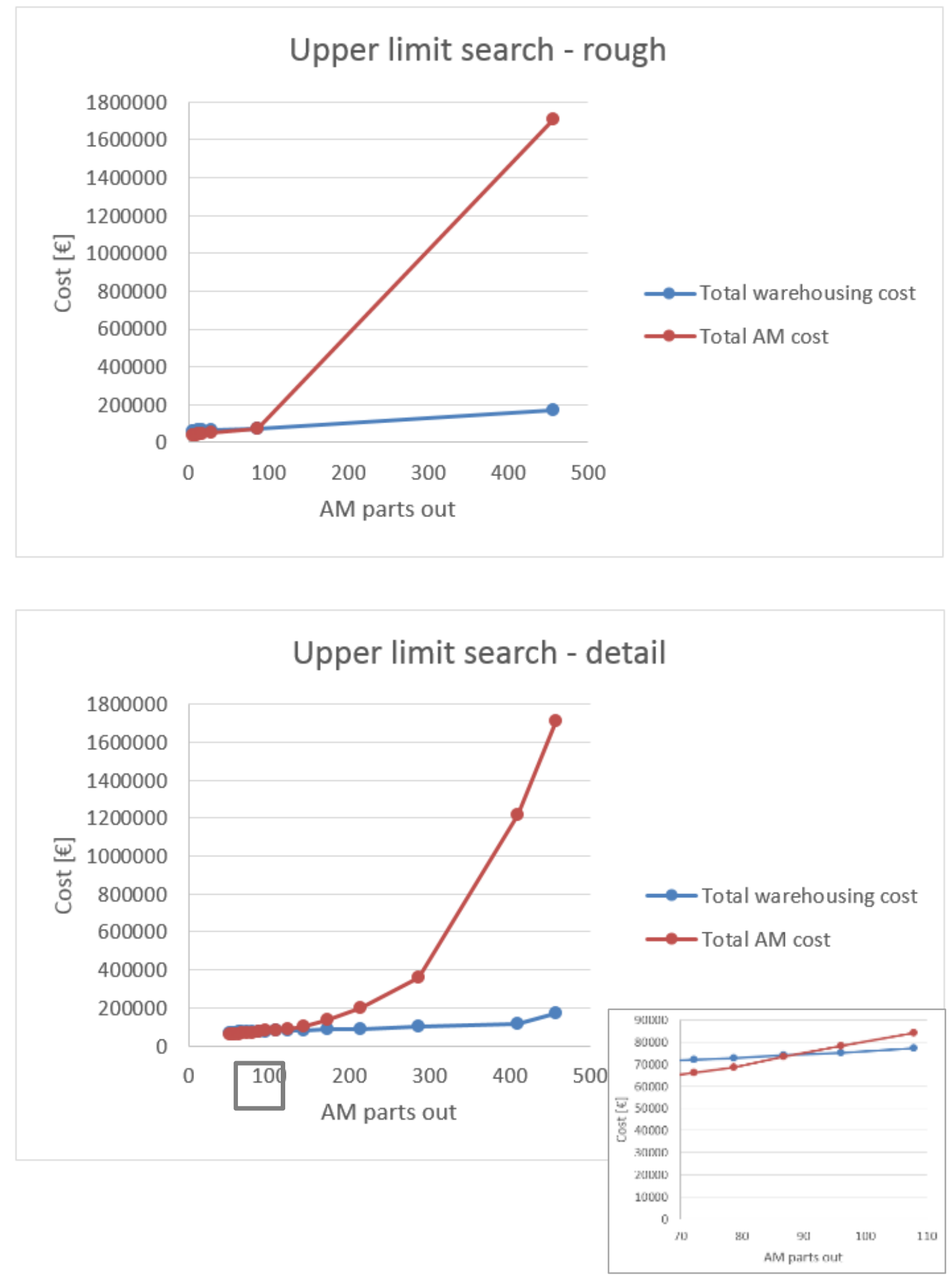

Figure 5-4: Upper limit search 
We now compare further setups (a setup means a set of several scenarios) of the technical investigations against the base case. Also, the base cases of technical extensions can be compared against the given base case with a defined upper limit.

Figure 5-4 summarizes the detailed results of the upper limit search of the base case. The rough overview of upper limit search shows significant cost increase at an output of more than 100 parts, representing an upper limit of $90 \mathrm{hrs}$. This section was analyzed in detail. The cost of AM and warehousing are equal at an output between 90 and 100 parts, representing an upper limit between 90 and 100 hours. 100 hours mean inter-arrival time is therefore the selected standard upper limit for entity creation, since penalties increase strongly at a higher utilization. It must be mentioned that the upper limit correlates strongly with the total machine utilization. An increased total machine utilization of approximately $39 \%$ leads to a strong increase in the total penalty. Consequently the system is no longer interesting for spare part supply on demand if the total AM machine utilization is above an accepted level of penalties, what is equivalent to an insufficient performance of the AM setup.

The upper limit search of the base case showed an important effect. When the machine utilization exceeds a certain level, in the current setup $39 \%$, the system is not able to provide a proper service level with respect to penalties. Observations of the running simulation model lead to the conclusion that the more parts are placed in a production run, the more time the production run will take. This increases the machine utilization, the chance that a new part request must wait in queue for the next production run, and therefore the chance for a higher penalty. Figure 5-5 illustrates this correlation. 


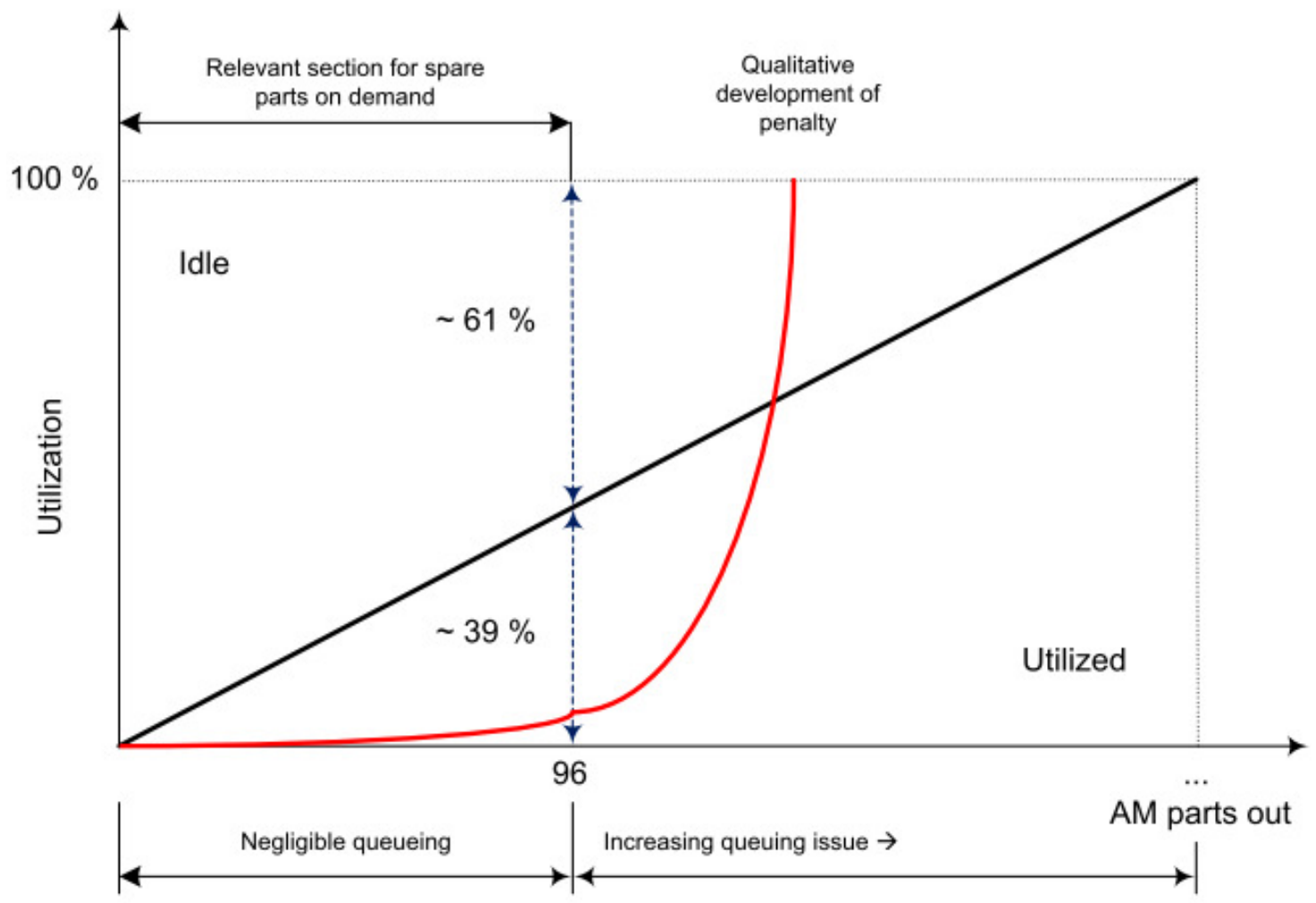

Figure 5-5: Correlation between machine utilization and queuing 


\section{TECHNICAL INVESTIGATIONS}

Technical investigations are conducted mainly for two reasons. First, it can be used as a verification of the simulation model. When results of the planned experiments are predictable even without simulation, these predicted results can help to verify the efficiency and correctness of the simulation model. It is important to have a valid model before performing more complex experiments as discussed in chapter 7. Second, the technical investigations can provide some insights on effects of various parameters on the system. Typically a hypothesis regarding results for a specific setup can be generated through these investigations. The planned experiments allow us to see the actual effect of changes on the complete system and will allow for further conclusions with respect to the relevant hypothesis.

\subsection{BUILDING SPACE VOLUME}

The effect of an increased building space volume with respect to spare parts is not yet clarified. The following hypothesis is investigated for clarification:

- Increased building space volume increases the processing time and delivery time.

The calculations regarding the building space volume use the same simulation model which is used for the base case. To execute the simulation the first scenario of the setup is set to a minimum building space volume which can take only the biggest spare part. For the following scenarios the building space volume is increased stepwise to see if any effects in the responses occur. Effects on the results will be discussed. 

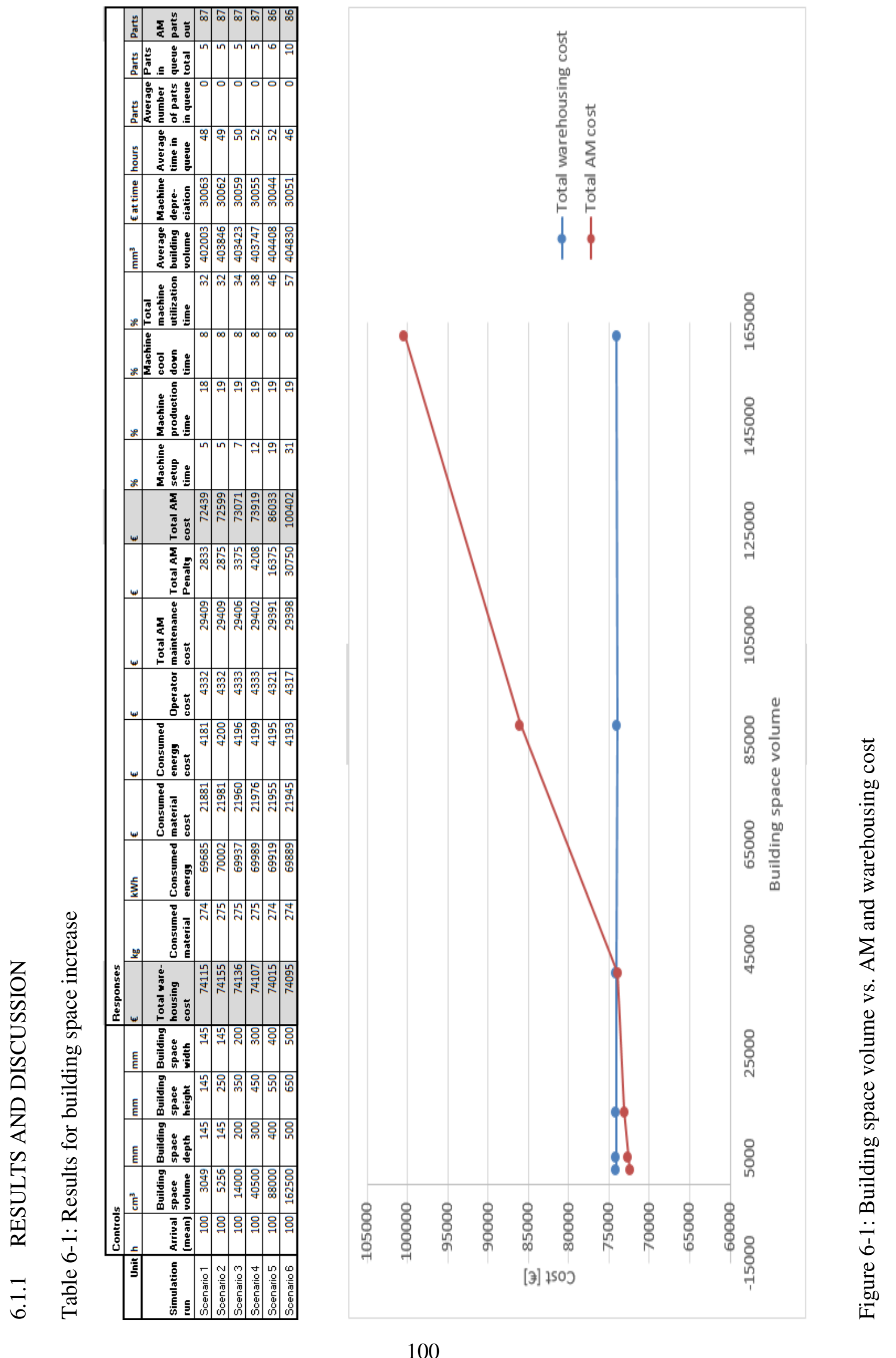
The first experiments show the influence of the building space. It can be confirmed that an increase in the building volume increases also the processing time, and thus enlarges the delivery time for spare parts. Table 6-1 shows the effect of the building space volume to the machine setup time. The machine setup takes longer when the building space volume increases, which leads to a penalty increase. Additionally, a bigger building space allows for bigger parts. Naturally, bigger parts will take more time to be produced, but producing more or bigger parts in the same building space volume is restricted by the total machine utilization.

The above simulated result suggests that compared to the base case no changes occur in the total warehousing cost. The effect of changes in the AM cost can be explained by the machine utilization, especially the machine setup. When the machine is utilized more than $38 \%$, a sufficient service level cannot be reached. At a service level of $38 \%$, only a small number of parts (5 of 87) need to wait in queue and at no point in time was there more than one part produced in the building space. After this limit, queuing occurs and the total processing time increases due to multi part production, which results in longer queue, and creates an unstable system. Therefore, the total machine utilization is an appropriate generic measure to evaluate the effect of changes in the system.

To improve the system performance in a spare part environment the machine setup time should be minimized to allow for higher building space volumes (due to preheating and atmosphere creation). Under the given set of conditions it can be concluded that it is preferable to adjust the building space volume to the maximum part size, instead of generating unused building space volume with the related drawbacks (for example more material must be heated, more unused powder must be scrapped, a bigger machine is necessary, etc.). 


\subsection{BUILDING SPEED}

The following hypotheses are investigated with respect to building speed:

- Increased building speed will lead to faster processing, which has a positive impact on the spare part supply.

The calculations regarding the building speed use the same simulation model, which is used for the base case.

For execution of experiments the mean arrival and building speed are the parameter of variation. Mean arrival is changed from 10 to $150 \mathrm{hr}$ with an increment of $10 \mathrm{hr}$ while the building speed is varied between $10 \mathrm{~cm}^{3} / \mathrm{hr}$ and $100 \mathrm{~cm}^{3} / \mathrm{hr}$ with an increment of $10 \mathrm{~cm}^{3} / \mathrm{hr}$. This results in 150 combinations which allow to analyze the building speed with respect to the upper limit of the system. 


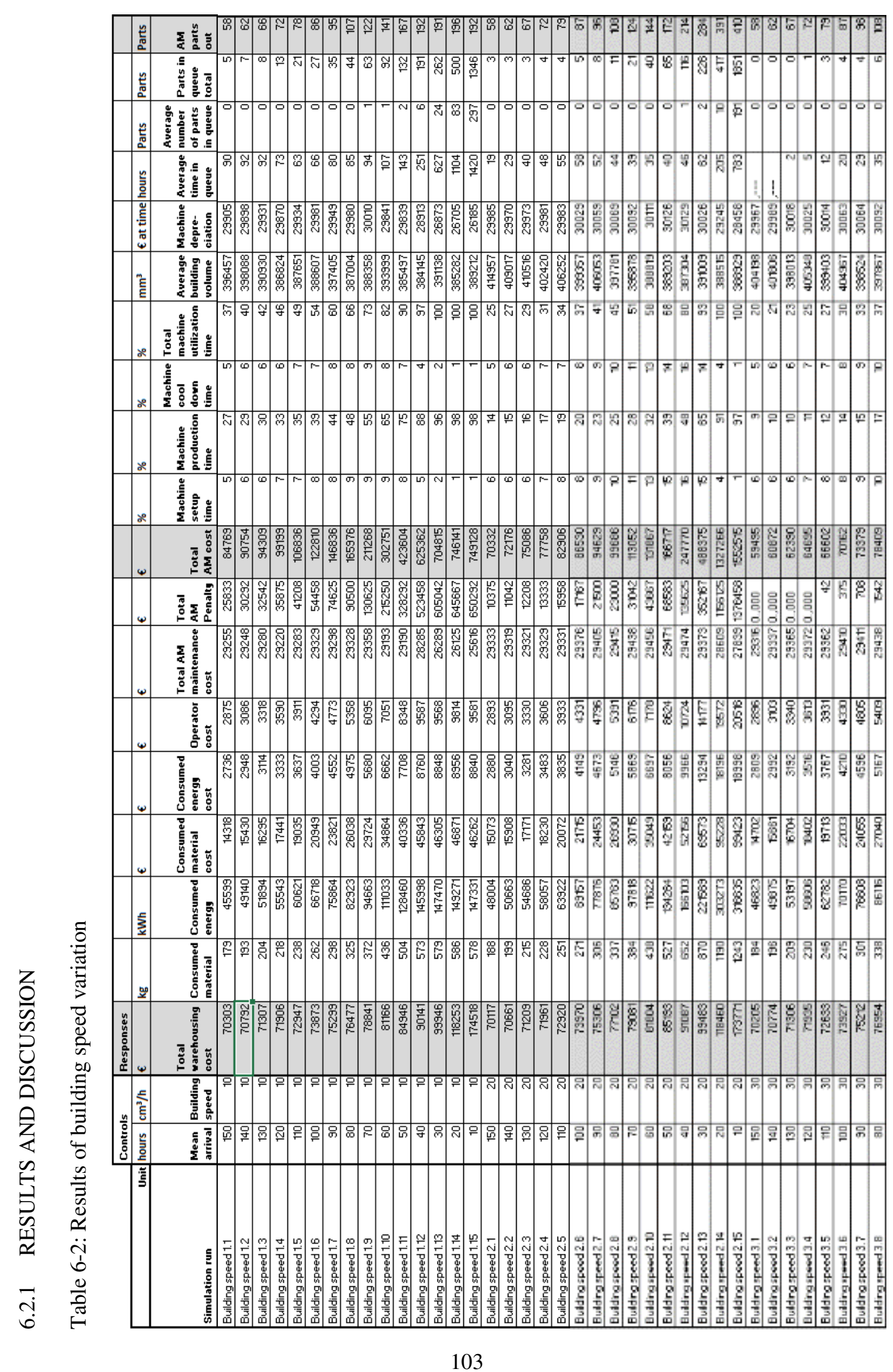




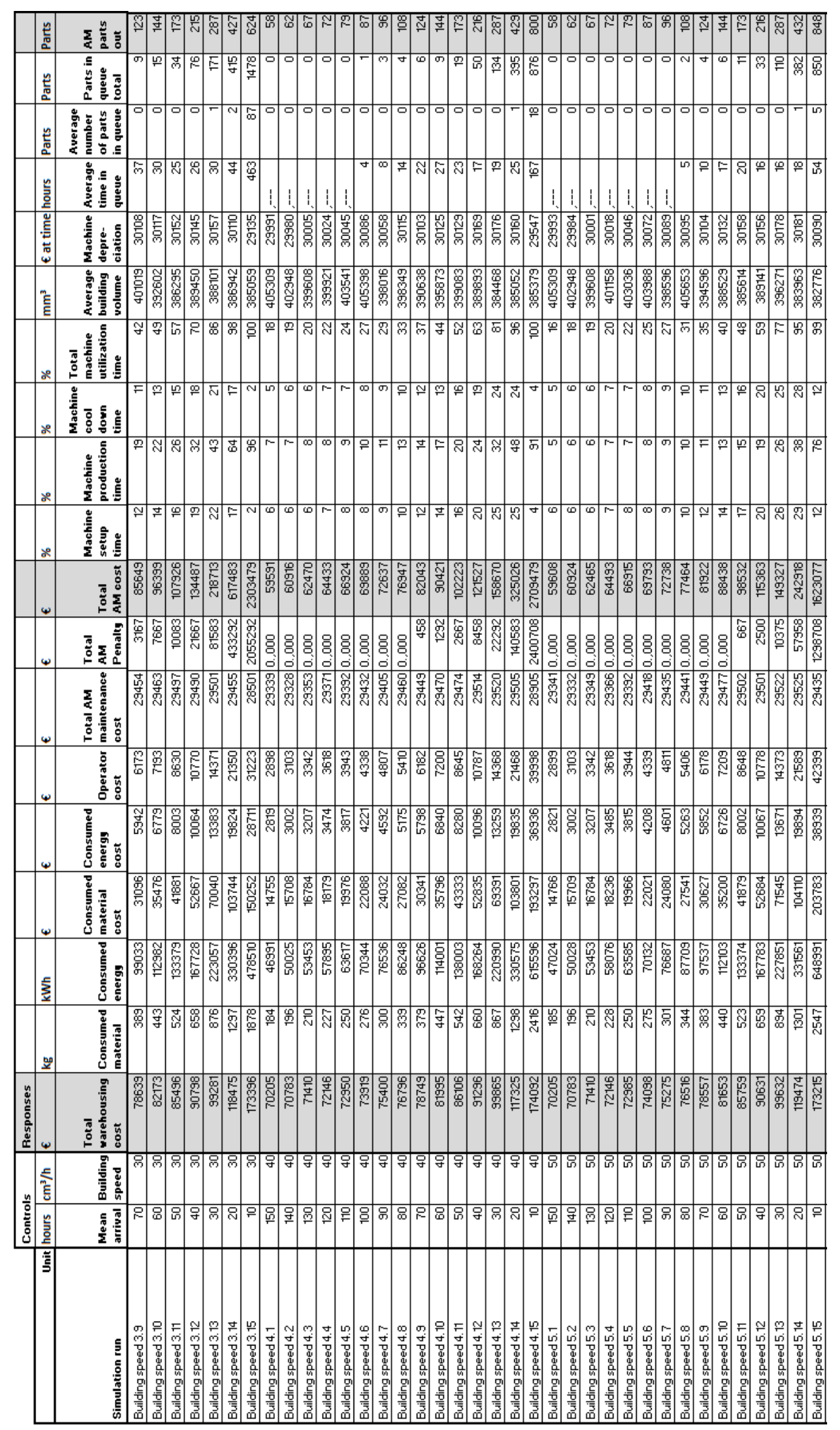




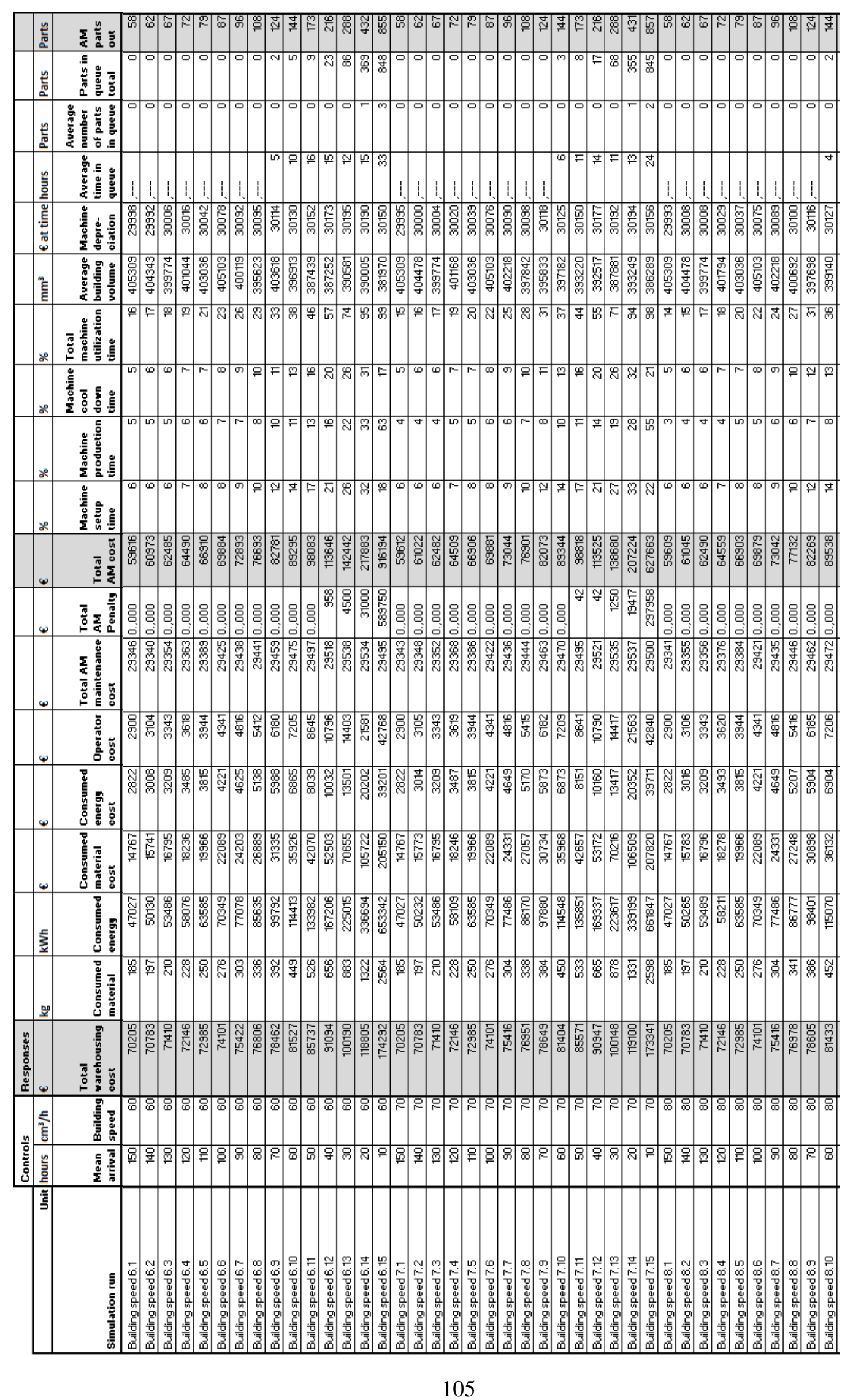




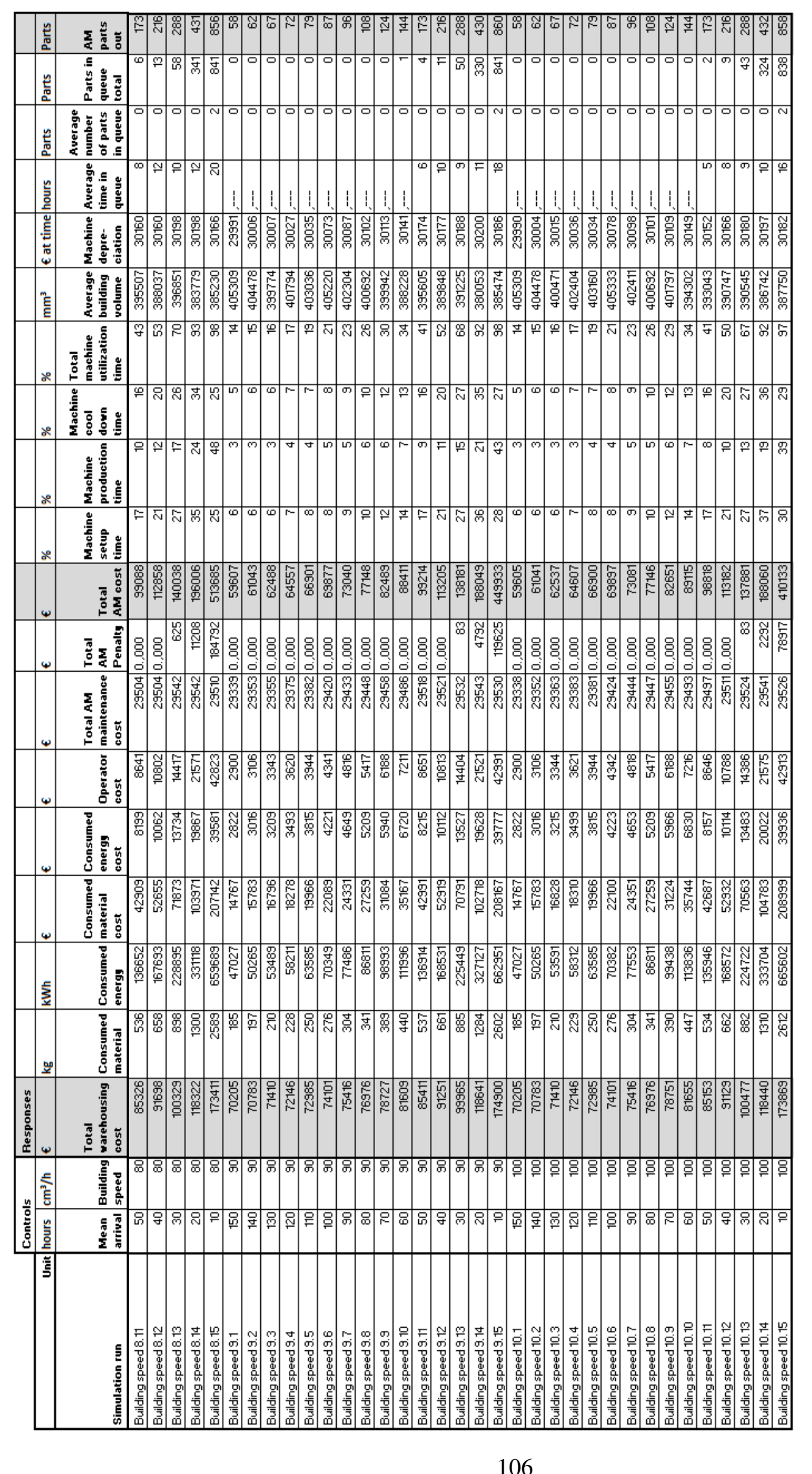


It is confirmed that an increase in building speed has a positive impact on the spare part supply.

However, not that from a cost perspective there is a limit to production expenses. Further, compensation of building space volume increase can be confirmed partly only, since a cost increase can be created.

It can be seen that an increase in building speed leads to a decrease in the total AM penalty until the machine utilization reaches approximately $38 \%$ (similar to the base case setting). These findings are supported by the results of average time in queue, average number of parts in queue, and parts in queue total decrease. For the current base case model setup, no significant cost reduction is generated by a building speed of more than $40 \mathrm{~cm}^{3} / \mathrm{hr}$. Results are displayed in Figure 6-2 and Figure 6-3.

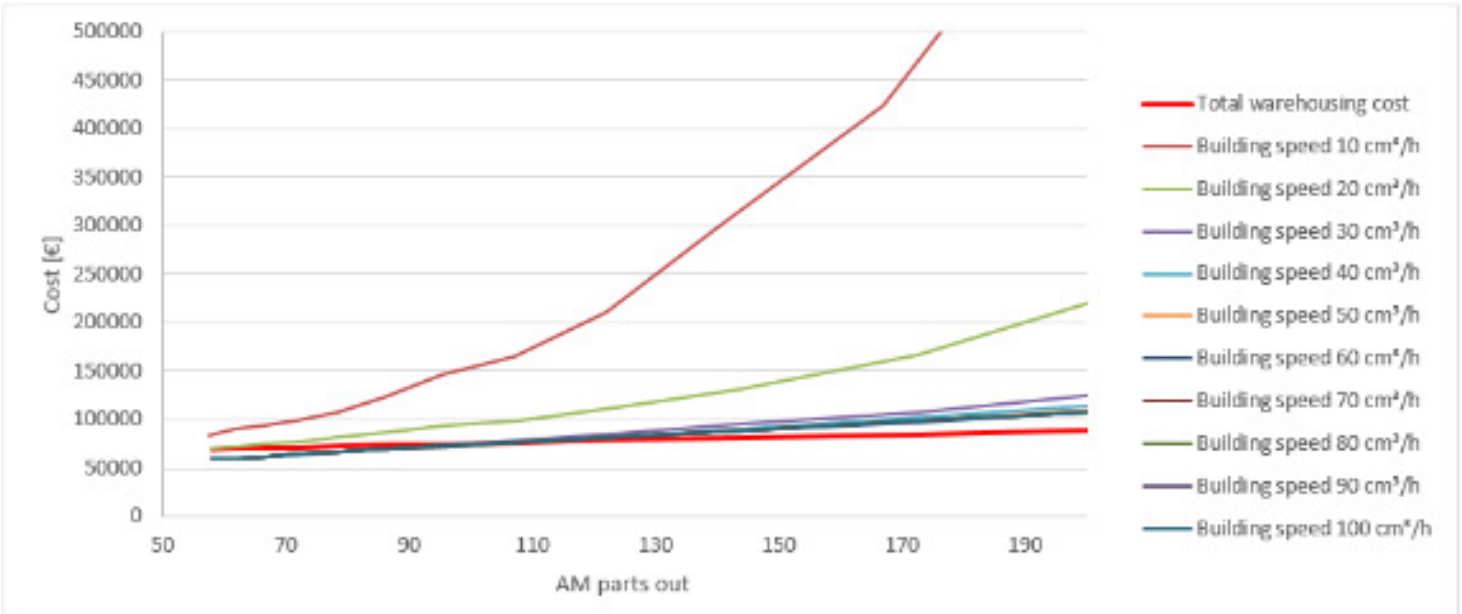

Figure 6-2: Building speed and upper limit search 


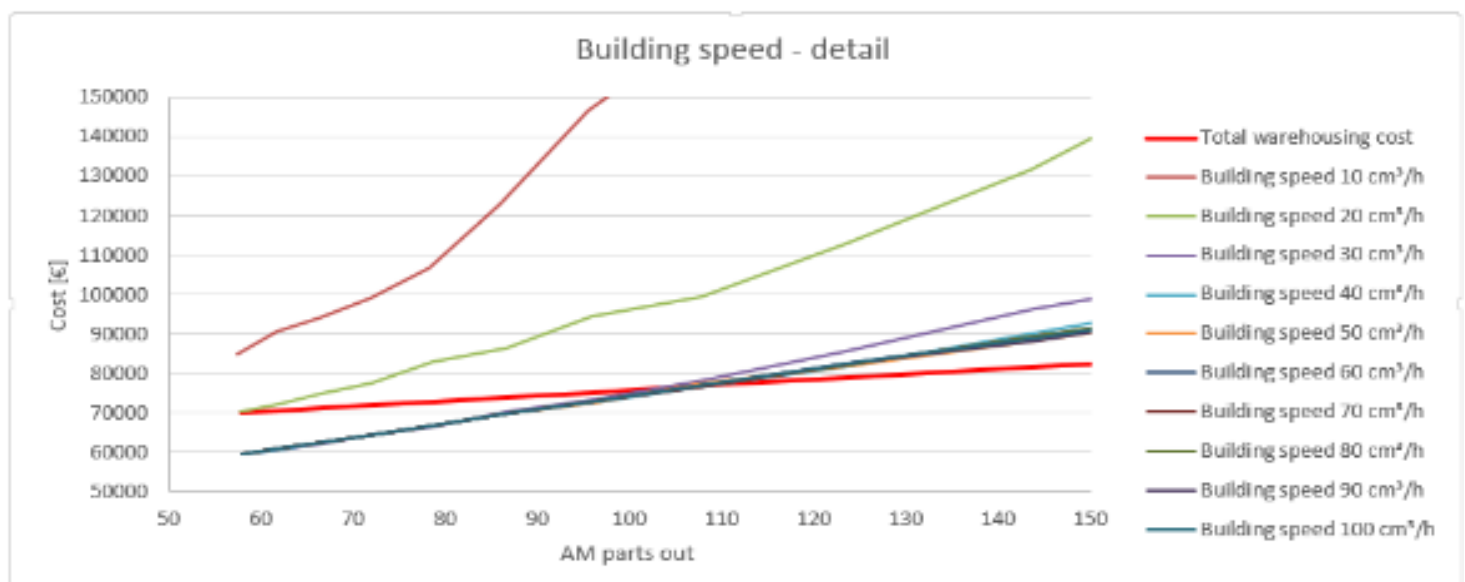

Figure 6-3: Building speed and upper limit search - details

The results can also be analyzed by constant building speed. $40 \mathrm{~cm}^{3} / \mathrm{hr}$ is selected here since no further cost improvement is obvious for the current setup. ${ }^{7}$ By keeping the building speed constant while decreasing the upper limit another interesting effect becomes apparent. At the point where the mean arrival is $70 \mathrm{hr}$ the first penalty occurs but the Total AM cost already exceeded the Total warehousing cost. Compared to the base setting this means that at a high enough building speed the penalty is no longer an issue, but the production related variable operation, material and energy consumption cost are. This is also supported by the fact that the Total machine utilization can increase significantly when the building speed increases. The building machine utilization can therefore be increased as long as the level of penalty is within the accepted range.

This leads to the finding that increasing the building speed strongly increases the production capacity, which seems to be a logical conclusion ${ }^{8}$. In consequence, production cost and service level related factors need to be evaluated to find an acceptable balance.

\footnotetext{
${ }^{7}$ The effect of the building speed variation is assumed to be very specific for the presented case. Another case can show significant effects to changes in the building speed.

${ }^{8}$ Doubling the production speed approximately doubled the production capability in this case.
} 
Another interesting issue occurs in the context of the machine utilization and process speed. As can be seen in Table 6-2 there is a change in machine time results. At lower building speeds the machine production time takes the major part of the total machine utilization time, while machine setup and cool-down time are less significant. When the building speed increases the machine setup and cool-down time become more significant, since both are assumed to be constant for simulation. This observation can be justified by the fixed building space volume. When the simulation model is running the building space volume will be filled and a certain average building volume will occur. Since the machine production time is dependent upon the building speed, the actual machine production time will decrease while setup and cool-down time are constant. When the building space volume is completely filled, it is not possible to place one more part in the production run and arriving spare part requests need to wait in queue. At these high utilizations the effect can be observed best. But in general queuing should be avoided to achieve fast delivery times for the spare parts, since spare parts on demand should be delivered as fast as possible in the allowed time (there lies the difference between optimization for production and spare parts on demand).

Another interesting aspect here is that the building space fill up is executed as a volumetric approach. Since typically no more than one part should be in production in order to have a stable system this assumption fits the purpose. It is also possible to align the process times, depending on the part height instead of the part volume. This change of philosophy can then allow a placement of two parts next to each other while the building time will be defined by the total building height of the entire batch. This case will be analyzed during the technical extensions. 


\subsection{MATERIAL PRICE}

Since it is commonly agreed that the material price is a key factor and limits the application of AM in industry, the following is investigated:

- The price a company would be willing to pay for material.

The calculations regarding the material price use the same simulation model which was used for the base case.

In this experiment the material price is increased stepwise starting at $10 € / \mathrm{kg}$, up to the maximum price of $150 € / \mathrm{kg}$. Effects on the responses will be discussed. 


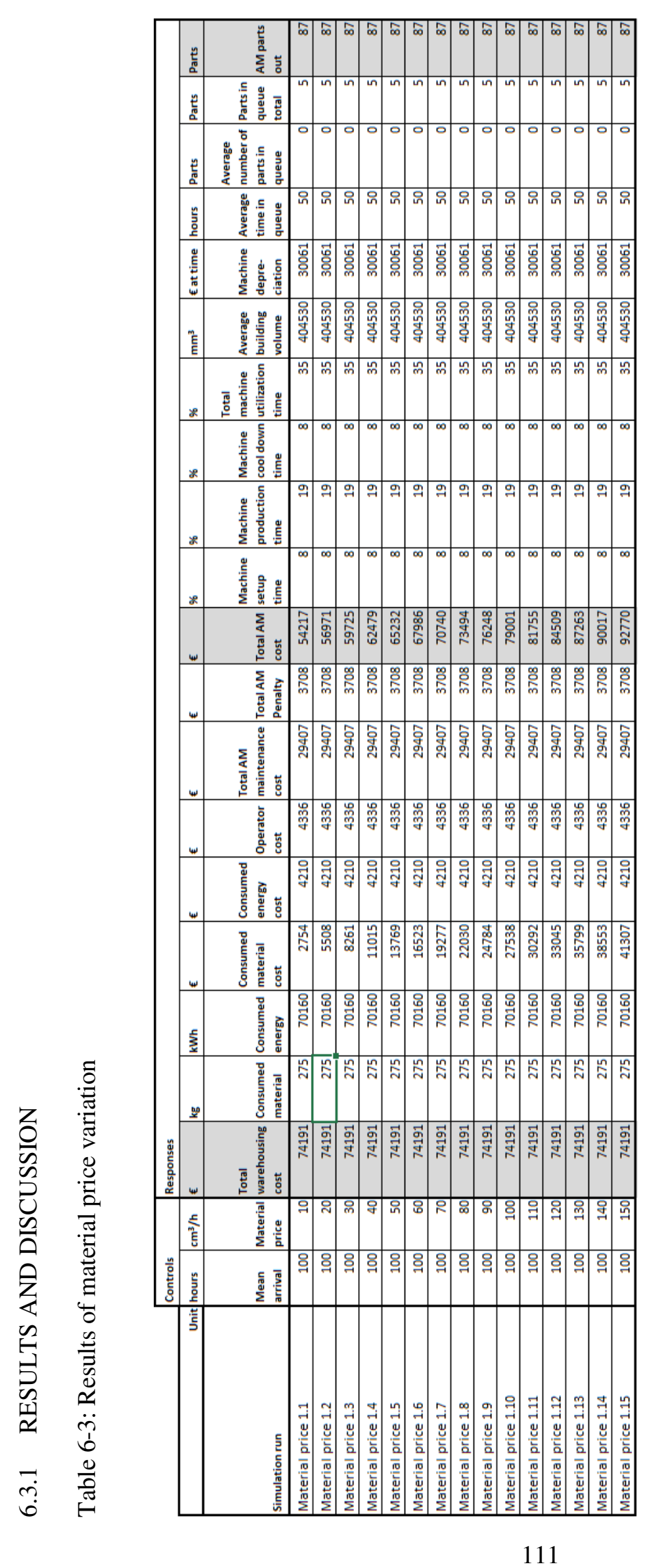




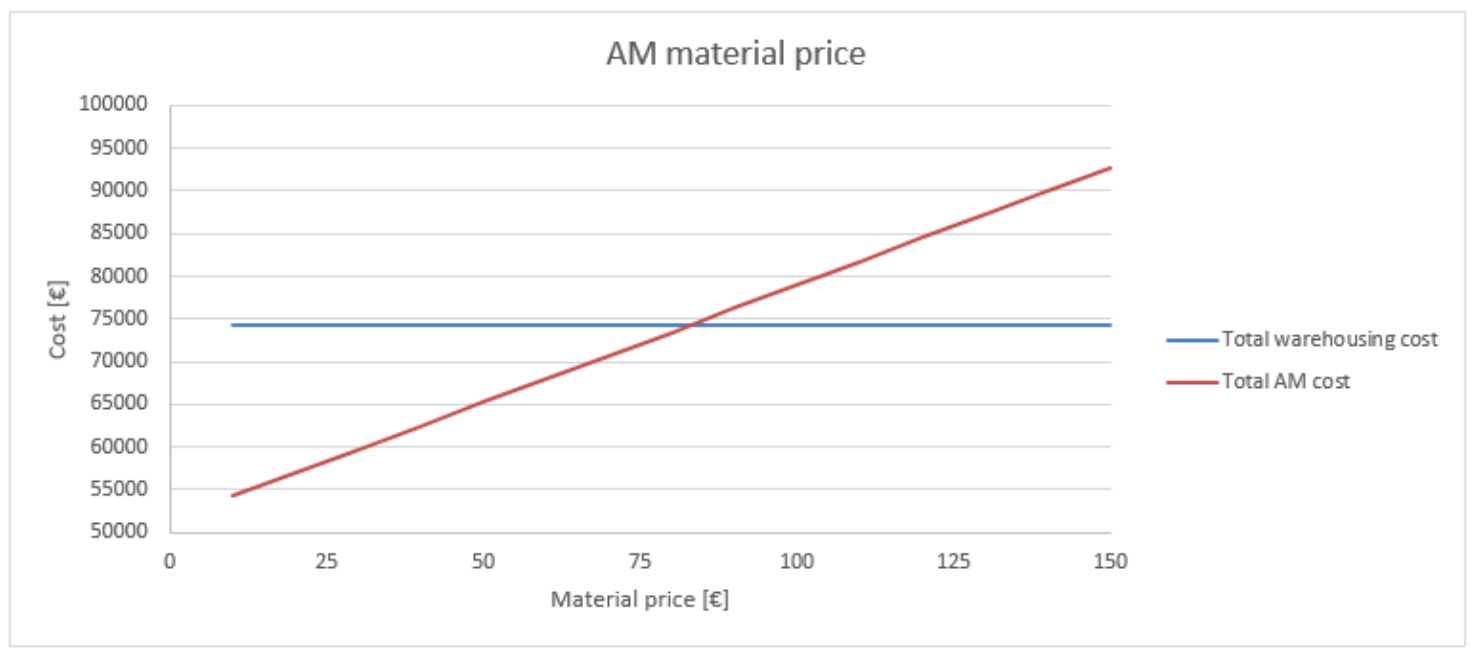

Figure 6-4: Cost compared to building material price

Generally, the price a company is willing to pay must be as low as possible. But the calculation shows that even a higher price can be reasonable for the given set of conditions.

It is obvious that the material price related costs follow a linear function which influences the total AM cost. Based on the model setup, this is not surprising since the material cost is the product of consumed material and the material price. Therefore a decreasing material price will directly improve the Total AM cost. At the current Total AM cost (material price: $80 € / \mathrm{kg}$ ) the material price makes consumed material cost/ Total $\mathrm{AM}$ cost $=22030 € / 73494 € \approx 30 \%$ of the Total AM cost. Since the material cost follows a linear function, it can be concluded that each $2.67 €$ decrease in the material price will lower the Total AM cost by $1 \%$ for the current model setup.

To estimate an acceptable price for the material the real warehouse data can be taken into account, since there is a difference between the actual spare part requests of the real warehouse and the possible spare part requests of the simulation model. The real warehouse got 50 spare part requests, while the simulation goes for an upper limit which allows for 87 spare part requests as a 
limit to work economical (see Chapter 8.2.1 for details). With this information an acceptable price for the material can be estimated due to the linear behavior of the results in the simulation. Taking the simulation results as a basis, the price can be scaled to the acceptable price for the actual number of spare parts delivered.

$$
\begin{aligned}
& \text { Material price } * \frac{\text { Max. \# of parts }}{\text { Actual number of parts }} \\
& =\text { Max. Material Price } \\
& 80 € / \mathrm{kg} /\left(\frac{87}{57}\right)=122 € / \mathrm{kg}
\end{aligned}
$$

For the assumed situation, 57\% of the actual required parts are needed. Consequently, as long as the material price does not exceed $122 € / \mathrm{kg}, \mathrm{AM}$ is economical for the current situation.

This approximation can be corrected further by considering energy and operator cost. Less material will need less material and operator cost, which will also allow a further material price increase.

Calculations are only valid as long as only the material price is varied, as no other variables are changed for this analysis. 


\subsection{MACHINE PURCHASE PRICE}

For the machine price, literature indicates that the machine purchase price is a key factor and limits the application of AM in industry. The following is investigated:

- Influence of the machine purchase price regarding the decision for AM.

- Indication of a useful depreciation time for an AM machine.

The calculations regarding the machine purchase price use the same simulation model which was used for the base case.

The experiment is executed in two steps. As a first step the machine purchase price is increased stepwise from $100,000 €$ to $1,000,000 €$. The depreciation time is kept constant. In a second step the machine purchase price will be kept constant and the years of depreciation will be changed from 2 to 20 years. Responses will be analyzed to check how the machine purchase price and the depreciation time influence the results. 

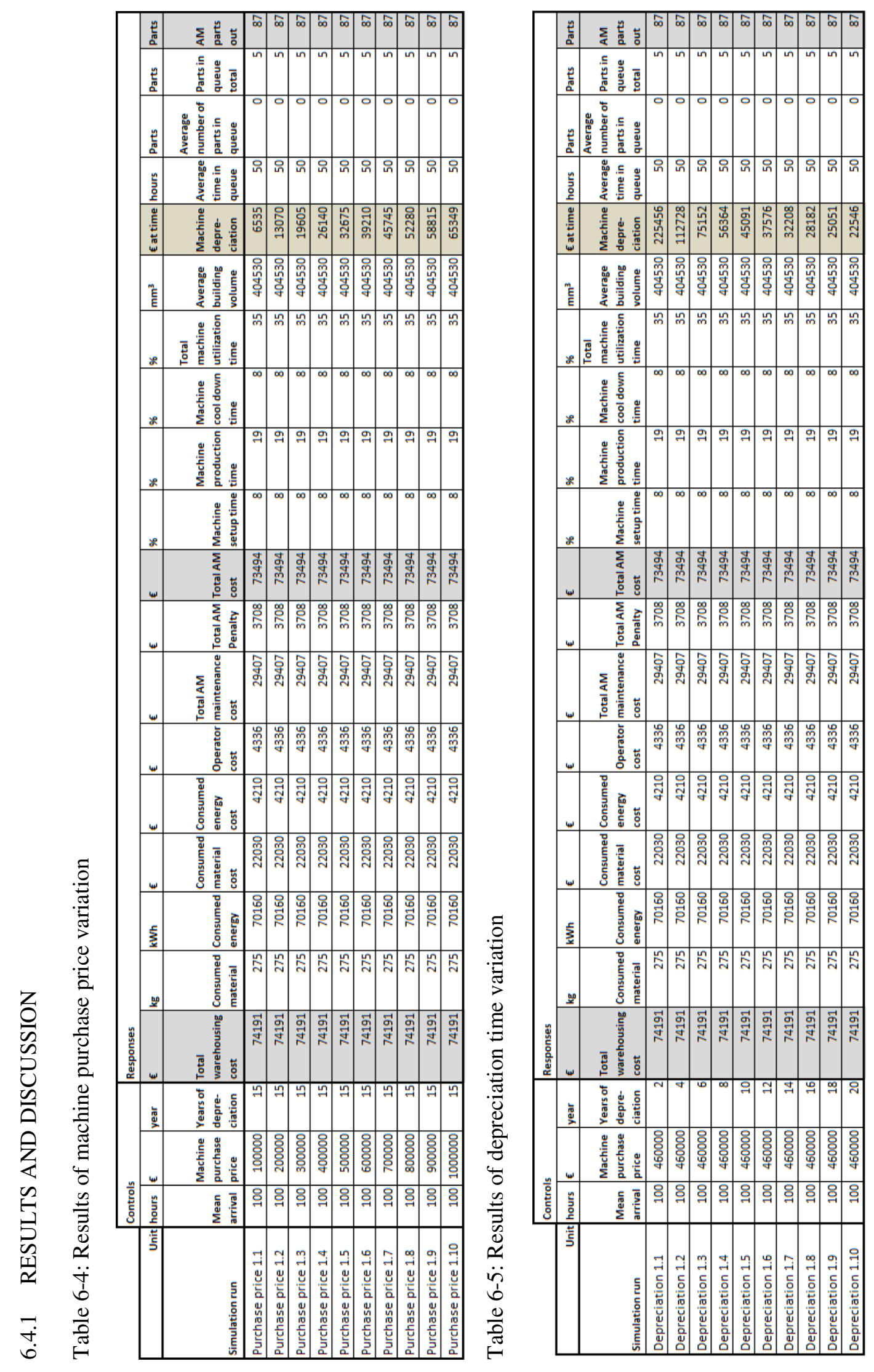


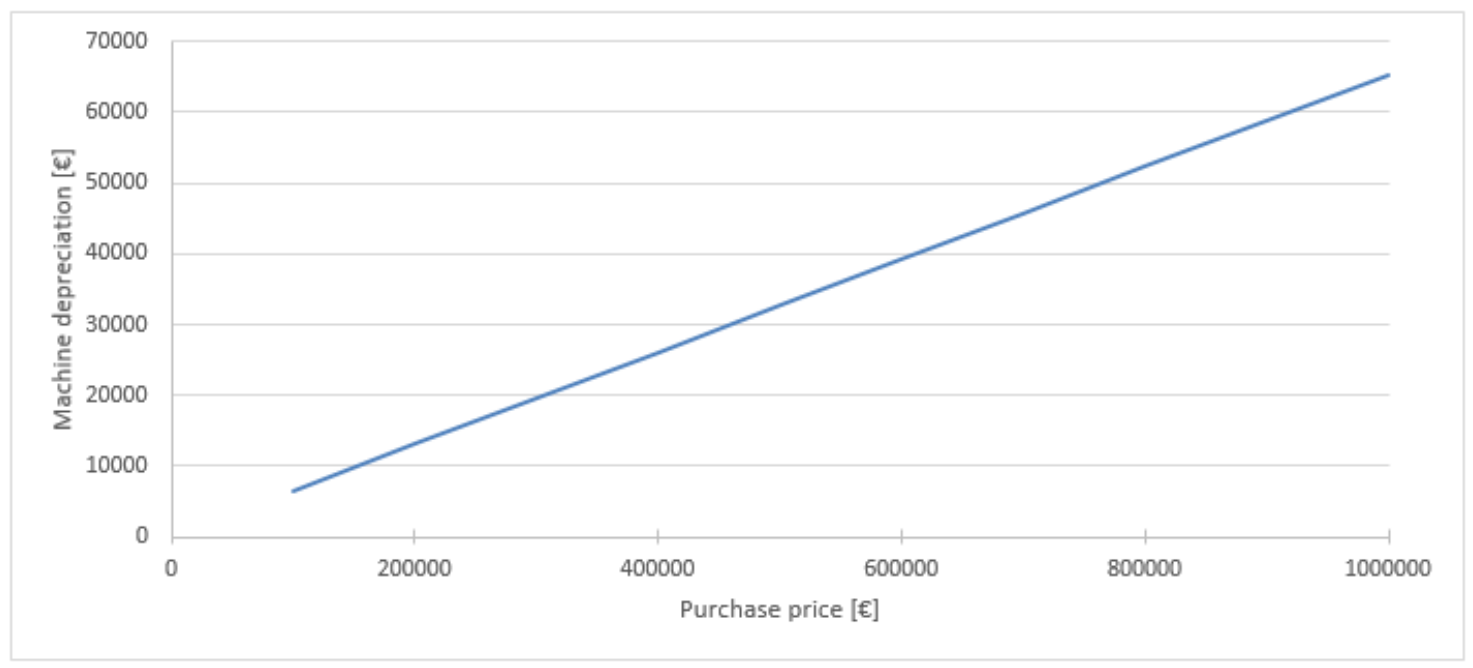

Figure 6-5: Machine depreciation vs. purchase price

Figure 6-5 illustrates the linear relation between the machine purchase price and the machine depreciation. It must be mentioned that no depreciation factors of warehousing are included in calculations of the warehousing route (for example depreciation of the building - it must be individually evaluated if it is better to buy an AM machine or build up more storage space, which also creates cost. This is especially true when storage space is strongly limited and therefore valuable). The depreciation factors of warehousing and AM need to be compared directly for the specific case to reach a valuable response. Therefore the depreciation of the AM machine is excluded from the Total AM cost. A maximum price limit for an AM machine cannot be defined on this basis. However, the lower the price of the AM machine will be, the more the cost will improve. 


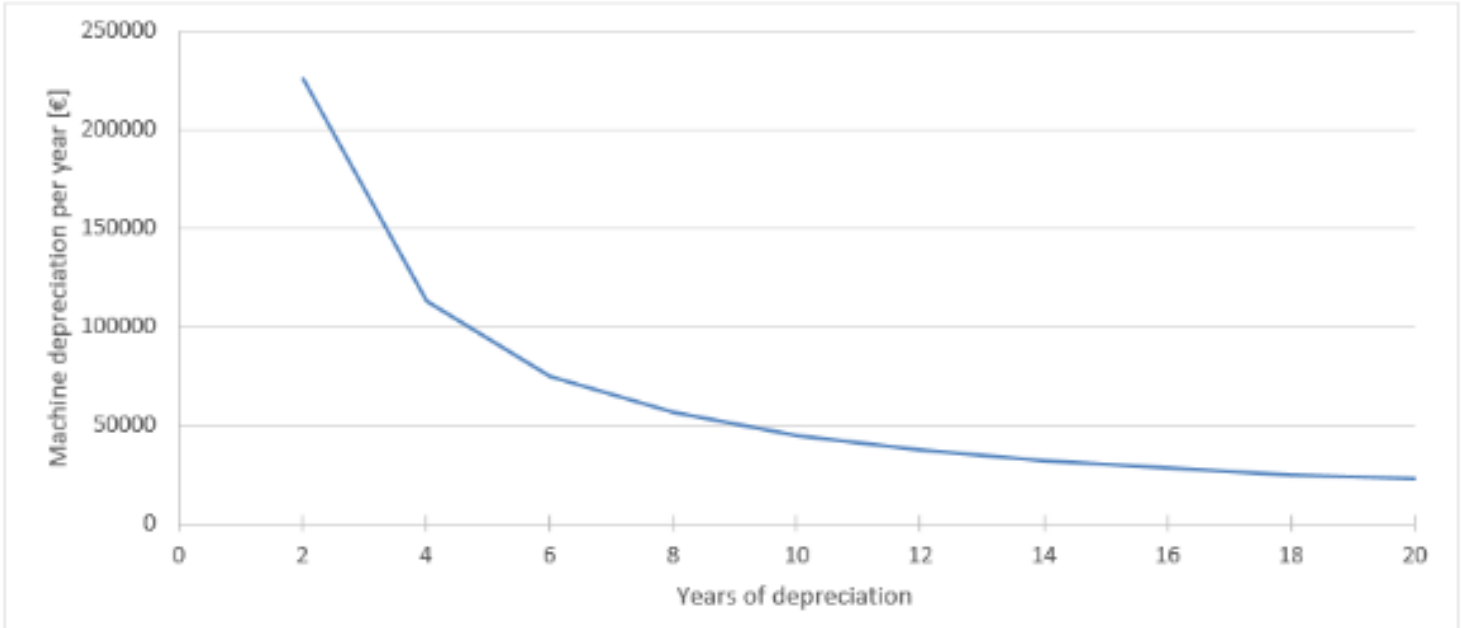

Figure 6-6: Years of depreciation vs. machine depreciation

Figure 6-7 shows the influence of depreciation time. The biggest cost impact occurs at a depreciation time between 2 and 8 years. In consequence this means if the depreciation time is bigger than 8 years the effect on the yearly depreciation tends to stabilize at a certain level. 


\subsection{COOL DOWN TIME}

The following hypotheses is investigated with respect to cool down time:

- A decrease of cool down time leads to faster processing and improved spare part supply.

The calculations regarding the cool down time use the same simulation model which was used for the base case.

To analyze the influence of the cool down time, it is varied stepwise from $1 \mathrm{hr}$ to $12 \mathrm{hr}$. For each cool down time the upper limit is decreased from $150 \mathrm{hr}$ to $10 \mathrm{hr}$ to stress the system at several levels and reach a clear response in the total AM cost. 


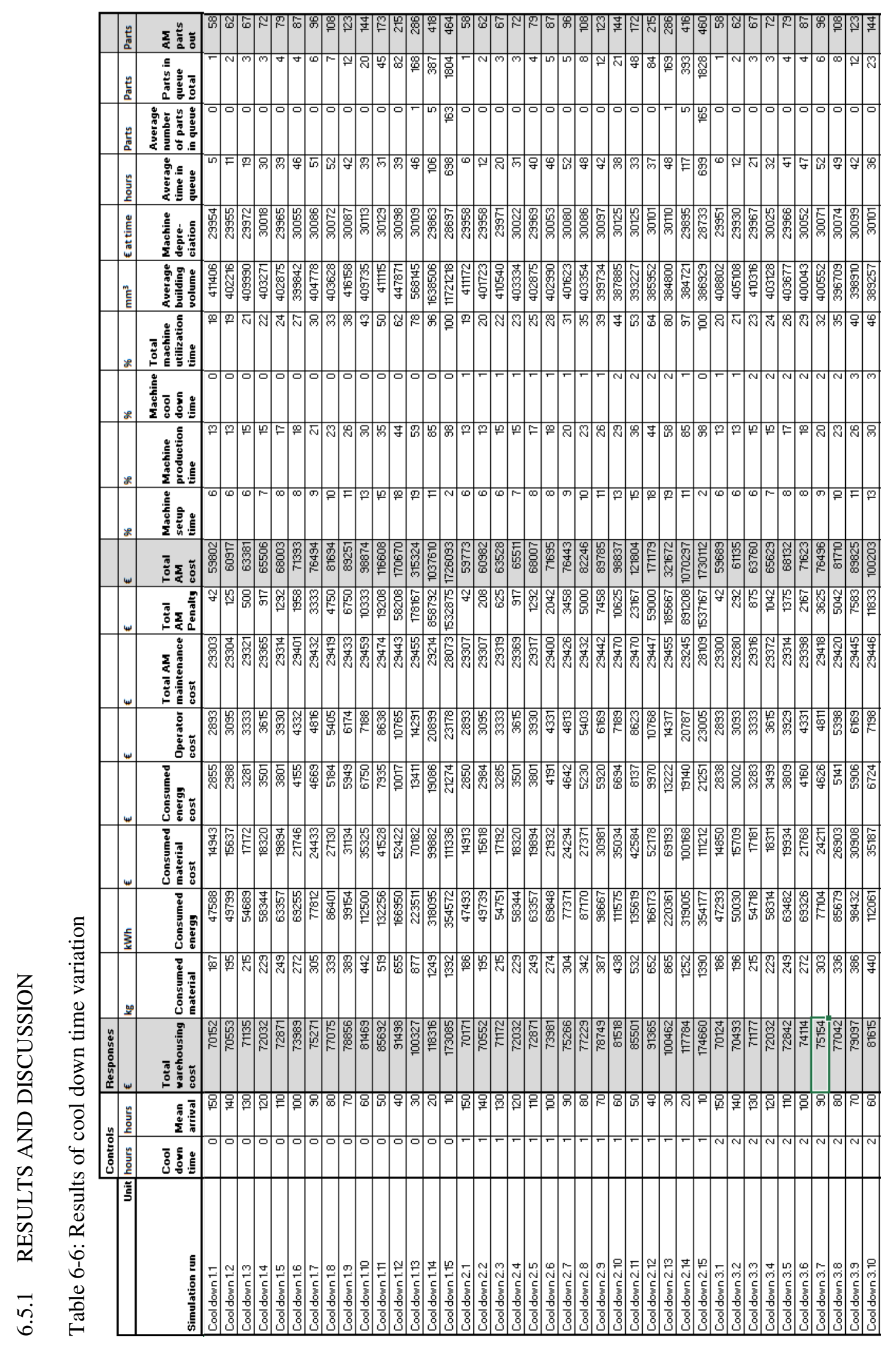




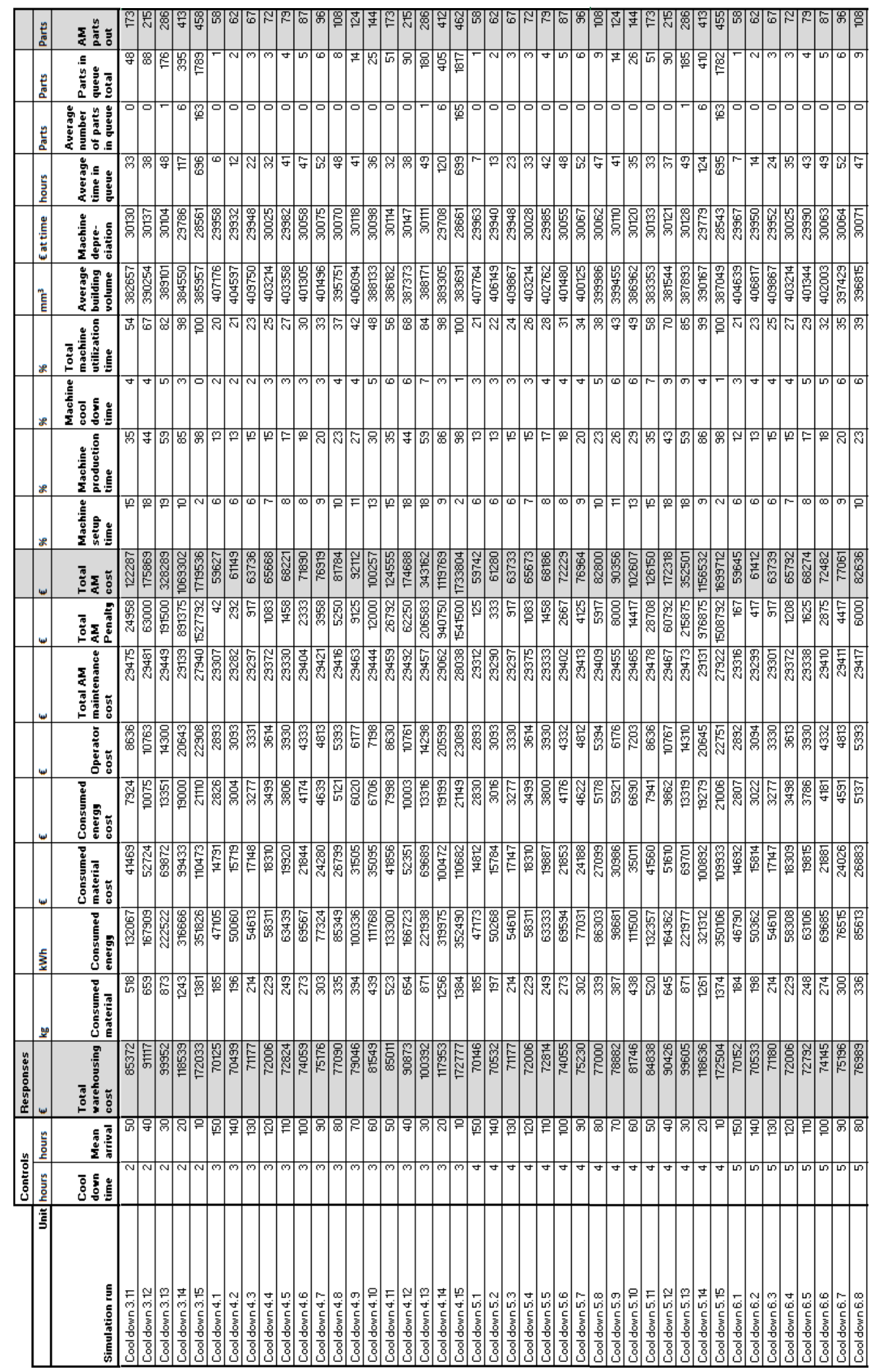




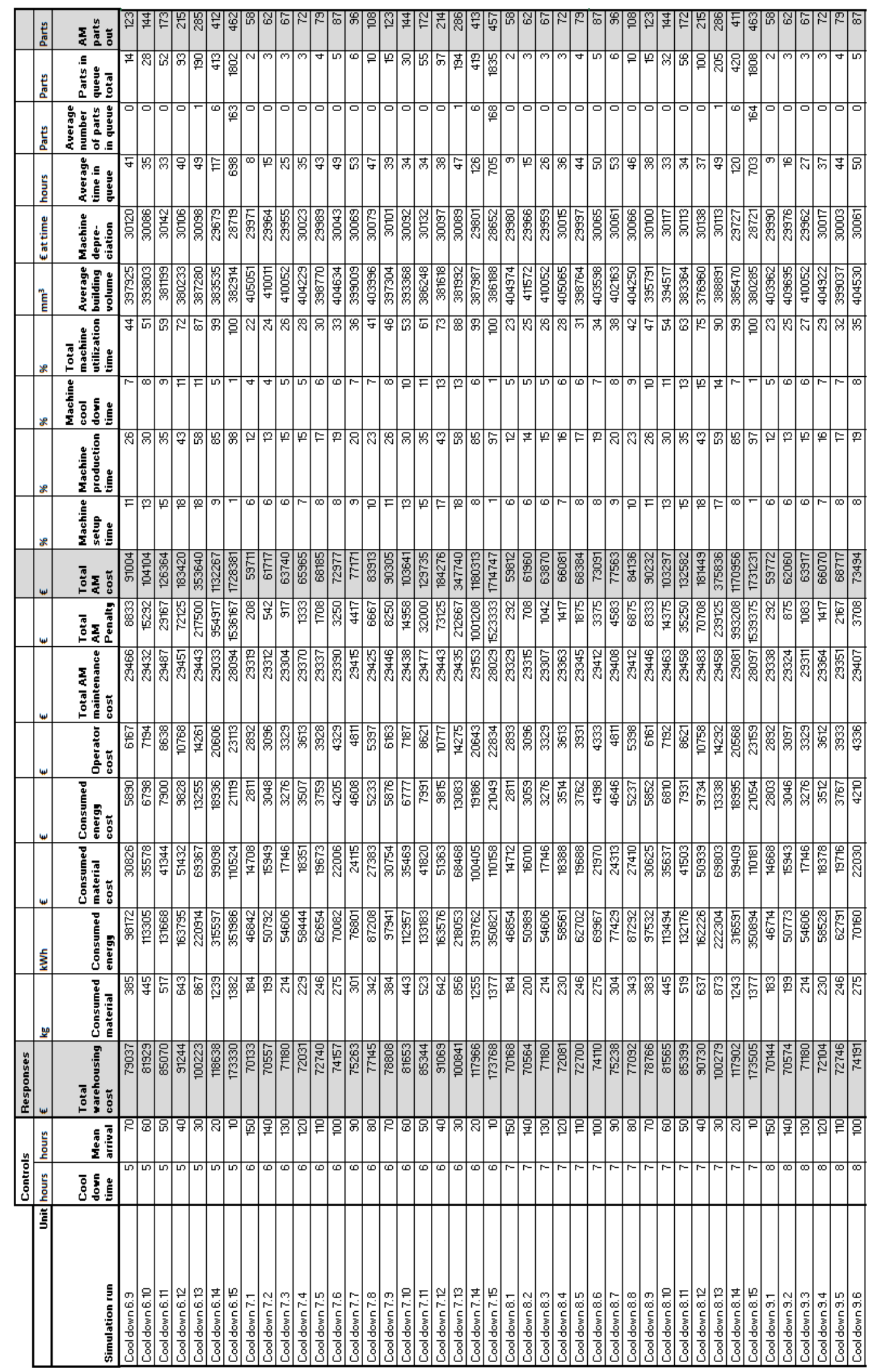




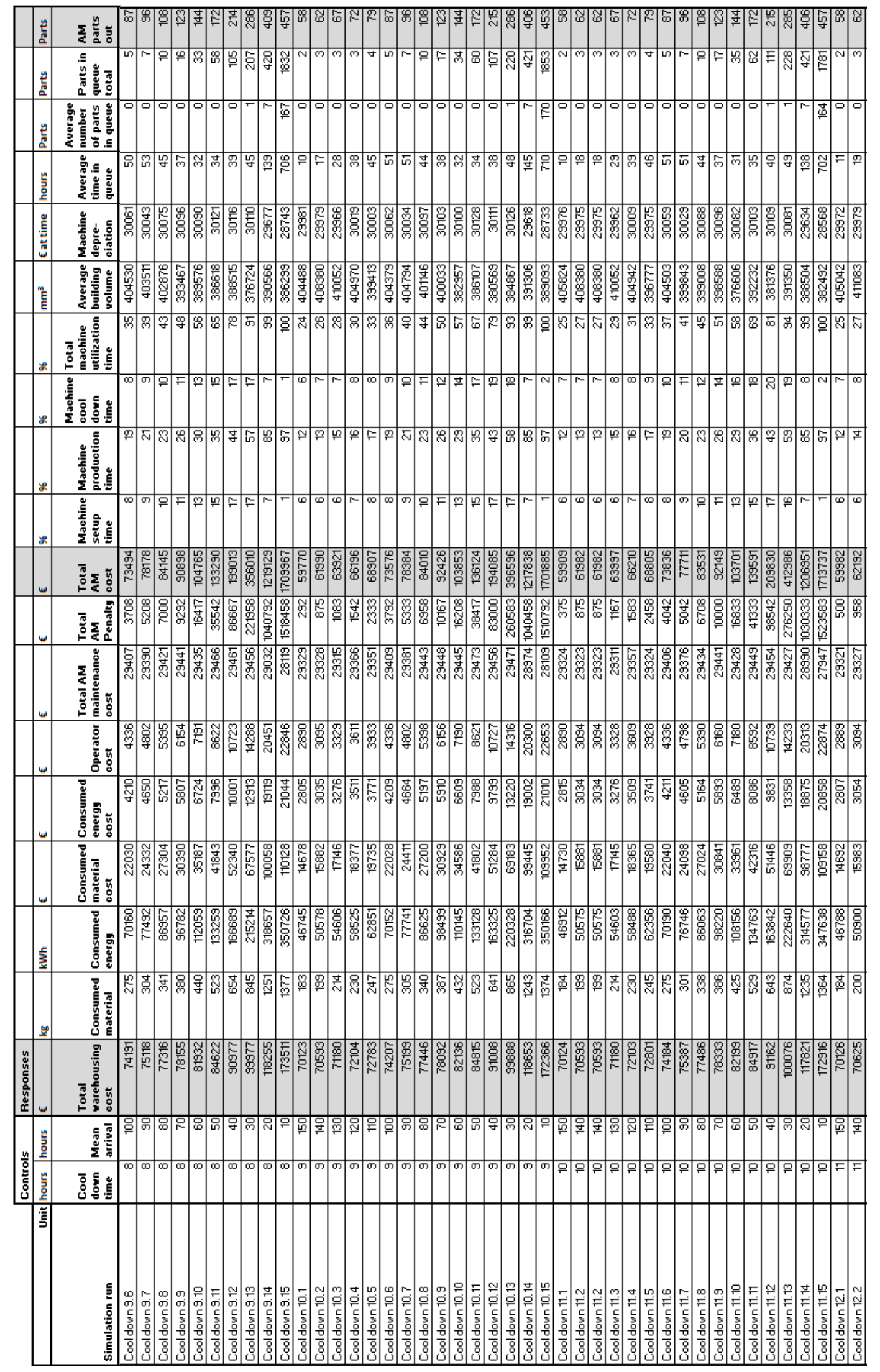




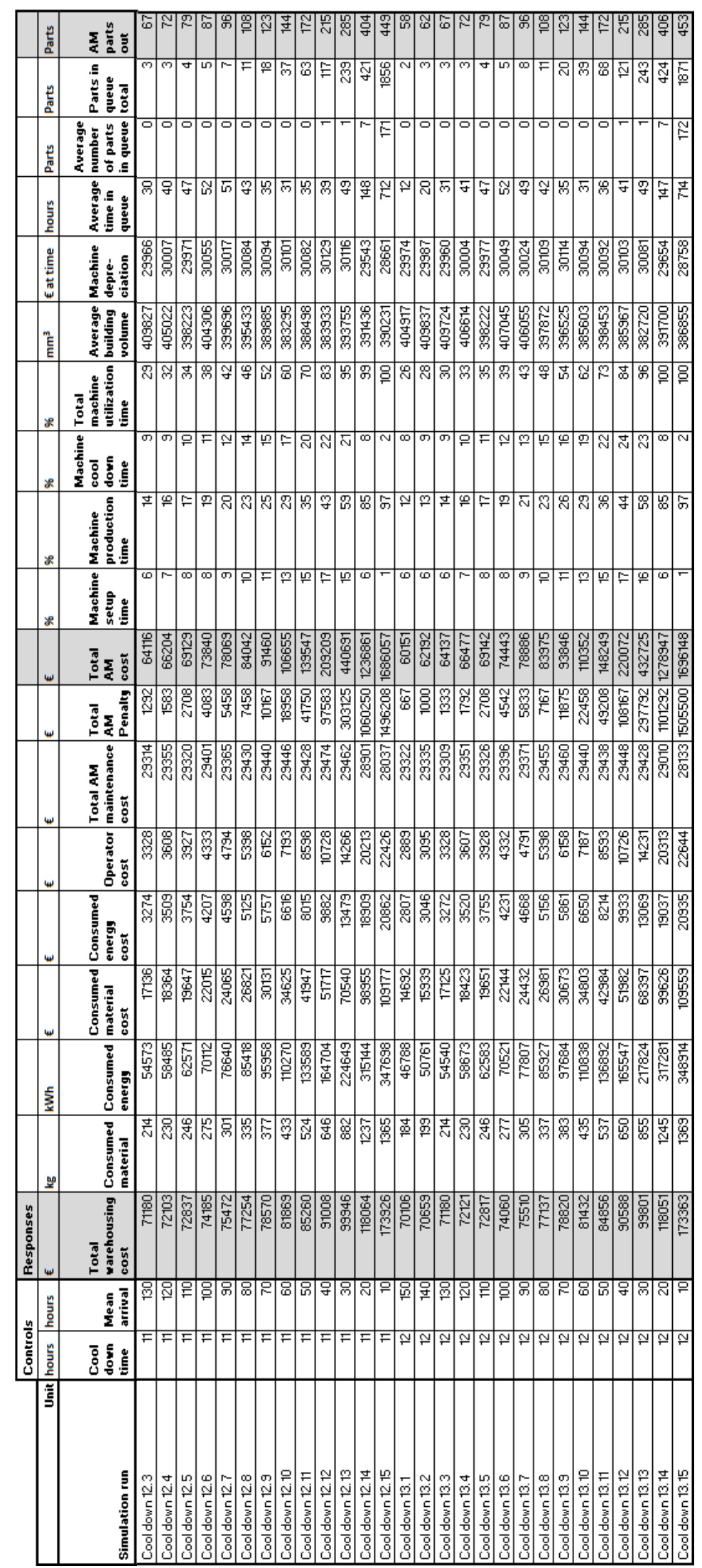


It can be confirmed that a reduced cool down time leads to faster processing and improved spare part supply. However, from a cost perspective the potential is limited.

The results show that cool down time has only a slight influence on the results as long as the system is in a stable state below $\sim 38 \%$ total machine utilization. The lower the utilization is, the smaller the effect is on the total AM cost. When $~ 38 \%$ total machine utilization is exceeded the penalties start to increase significantly, so it is no longer possible to maintain a proper service level. Figure 6-7 and Figure 6-8 show the tolerance of the presented system with respect to cool down time. Allowing a cool down time of $12 \mathrm{hrs}$ has a significant impact on the overall system performance, represented by the Total AM cost. A limit for the system performance is found at this point since an allowed cool down time of $12 \mathrm{hr}$ has a significant impact on the Total AM cost. The cool down times between 2 and 11 hrs cause only small variations in the Total AM cost and the delivered parts. The more the system is stressed the stronger the system will react on variations of the cool down time, especially when the found limit of $12 \mathrm{hrs}$ is exceeded.

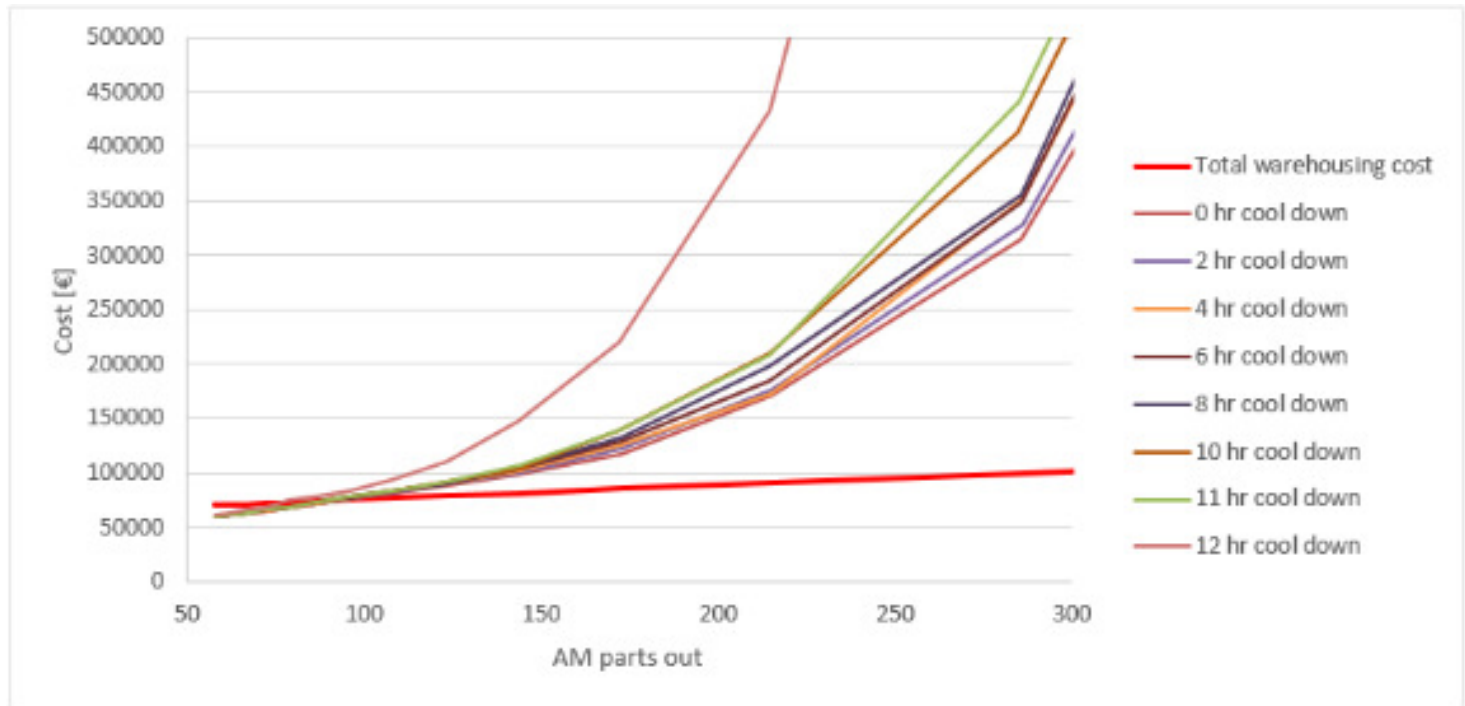

Figure 6-7: Cool down time variation 


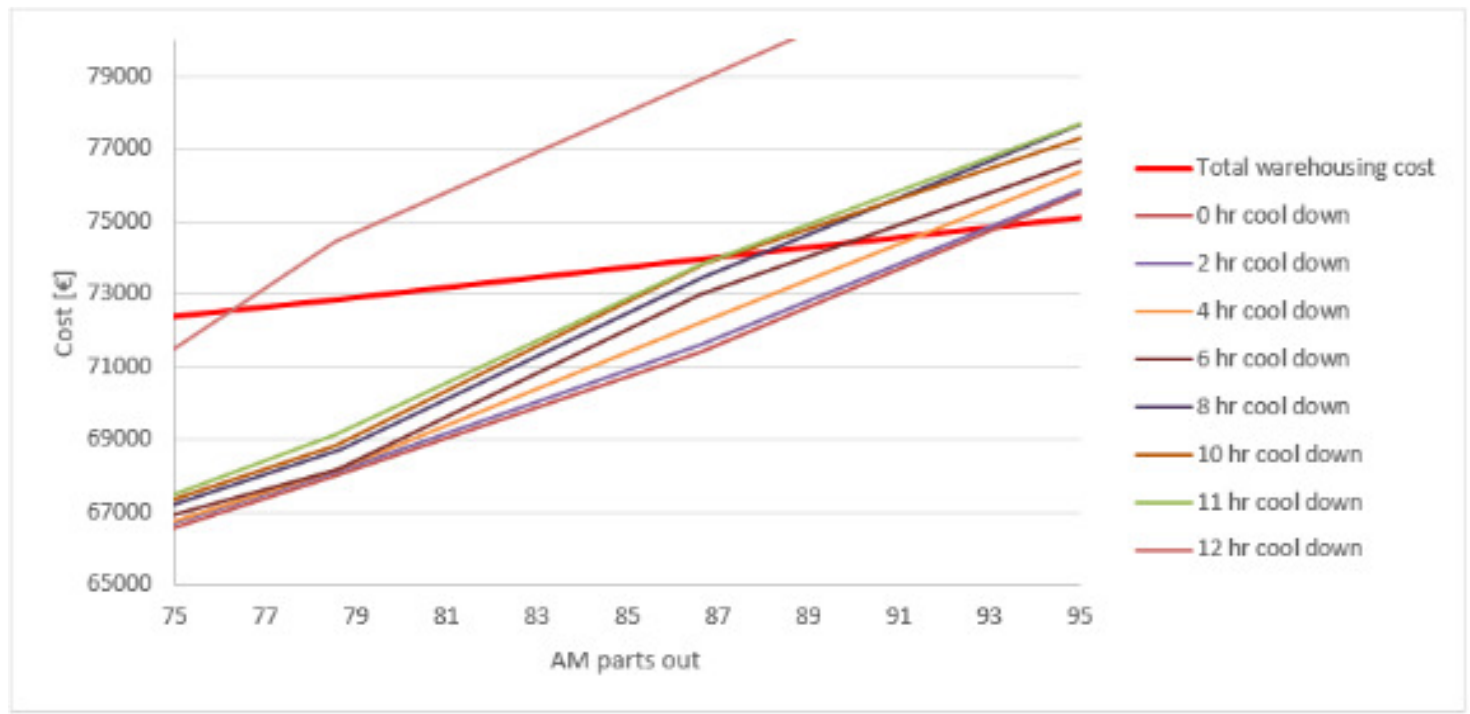

Figure 6-8: Cool down time variation - detail

As for the machine setup and building speed, a faster cool down will create a higher system output which can increase the variable production cost. The system must need to be balanced. 


\section{ADDITIVE STRATEGY INVESTIGATION}

Based on the results from the basic model analysis, further investigations were made for various AM strategies. These strategies were designed to simulate multiple potential real-world strategies for AM spare part services, such as multiple machines and combination of queuing scenarios. In addition, since part size appears to have significant influence on the performance of the AM system. In order to evaluate the sensitivity of strategies to the average size distribution of the spare parts, part sets will vary size distributions and perform simulations. Since the simulation model requires specific information as input parameters the results of calculation can only be valid for the specific case. However, for the presented setup it will be possible to see trends or specific system behavior. For the multi-machine strategy study, details of each scenarios are briefly described below:

1. Two machines with fixed material assignments - Each machine will be dedicated to fabricate only one fixed type of material. One of the two possible materials will be assigned to each new spare part request. The spare part requests will then be assigned to the corresponding machines accordingly.

2. Two machines with flexible material assignments - Each machine will be able to switch to either of the two materials for a new production run. Similar to the first strategy, one of the two possible materials will be assigned to each new spare part request. The spare part requests will be assigned to the machines according to their availability. If material switch occurred between builds for either machine, additional setup time will be included for that particular machine. 
3. Three machines with a fixed material assignment - Each machine will be dedicated to fabricate only one fixed type of material. One of three possible materials will be assigned to each spare part request. The spare part requests will be assigned to the corresponding machines accordingly.

4. Three machines with flexible material assignment - Each machine will be able to switch to either of the three materials for a new production run. One of the three possible materials will be assigned to each spare part request. The spare part requests will be assigned to the machines according to their availability. If material switch occurred between builds for either machine, additional setup time will be included for that particular machine.

For each of these four strategies, two modes were evaluated for individual AM systems:

(a) No-waiting - In this mode arriving spare part requests will be forwarded to production immediately if a machine is idle. If no machine is idle, arriving spare part requests are sent to a queue. When a machine becomes idle again the parts in queue will be prioritized and sent to production directly.

(b) Waiting - Similar to the no-waiting mode, spare part requests will be sent to production directly, however the production will not start for a specific duration or until a certain building space volume is filled. This could potentially increase the chance that multiple parts can enter the production run without the need to wait in the queues.

For the part size distribution study, the simulated scenario was defined as below:

5. Part size distribution - A two-machine strategy with one type of material was set up. Several distribution models of part sizes, such as big parts only or an equally distributed mix of small, mid and big parts were analyzed. In addition, both waiting and no-waiting mode as described previously were also investigated for each part size distribution models. 
For each of those strategies the following input and performance parameters were investigated:

- Upper limit/Mean part arrival

- Setup and cool down time

- Elapsed time (only for setups in waiting mode)

- Production Start volume (only for setups in waiting mode)

- Material changeover time (for flexible material strategies)

The mean part arrival time is an important control parameter and is used in all simulations to vary the mean arrival rate of spare part requests. Therefore it is an entire approach adopted in all simulations. The mean arrival time has the ability to find specific performance levels of the system. Finding these specific performance levels is described as upper limit search.Upper limit search - An upper limit search is intended to stress the system until a certain limit is reached by decreasing the mean arrival time of spare part requests that increases the actual arrival of spare part requests. In the following investigations three different stress levels were of interest.

- Low arrival rate - none to minor penalties occur until this point (marked green).

- Upper limit - a penalty of less than $5000 €$ is charged. The system runs stably with a defined penalty. The upper limit is the standard indicator for the system performance. (marked yellow).

- High arrival rate - The system is still able to handle the spare part request, but a heavy penalty occurs. Typically the average number of parts in queue is below one. If the average number of parts in queue is larger than one the system is assumed to be unstable. As later results will show the spare part requests arrive in a higher frequency than the system can deliver (marked red). This is at least true for the current sytem setup and can be different in other cases. This effect is related to the total production time of the parts. 
Investigations of setup and cool down time, elapse time, start volume and material change over time were relatively straightforward and since these parameter created a direct in- or decrease in the cost results of the simulations.

The general proceeding for all investigated strategies to be investigated will run in the no waiting and waiting mode, in the following setups:

- Upper limit search - 10 to $150 \mathrm{hrs}$

- Setup and cool down time - 3 to 36 hrs at low, upper limit and high arrival rate

- Start volume - 0 to $100 \%$ at upper limit

- Elapse time - 0 to $12 \mathrm{hrs}$ at upper limit

- Material changeover time -1 to $10 \mathrm{hrs}$ at low, upper limit and high arrival rate

The described values are varied during simulations. Each variation is named and numbered accordingly. The material changeover time is investigated only when a material changeover is applied in the according strategy.

Results and findings will be discussed for each strategy individually in this section. Selected results are presented in this chapter. The tables containing all results of simulation runs are available in the appendix. 


\subsection{TWO MACHINES WITH FIXED MATERIAL ASSIGNMENTS}

As described earlier, two machines with a fixed material assignment is to be modeled. Each machine will be dedicated to fabricate only one fixed type of material. One of the two possible materials will be assigned to each spare part request. The spare part requests will be assigned to the machines accordingly. Changes with respect to the upper limit, setup and cool down time, elapse time and start volume were investigated.

\subsubsection{MODEL ADJUSTMENTS}

The model for this strategy as shown in Figure 7-1 is a modification of the base case. The main change was the arrival and queueing logic of the AM route.

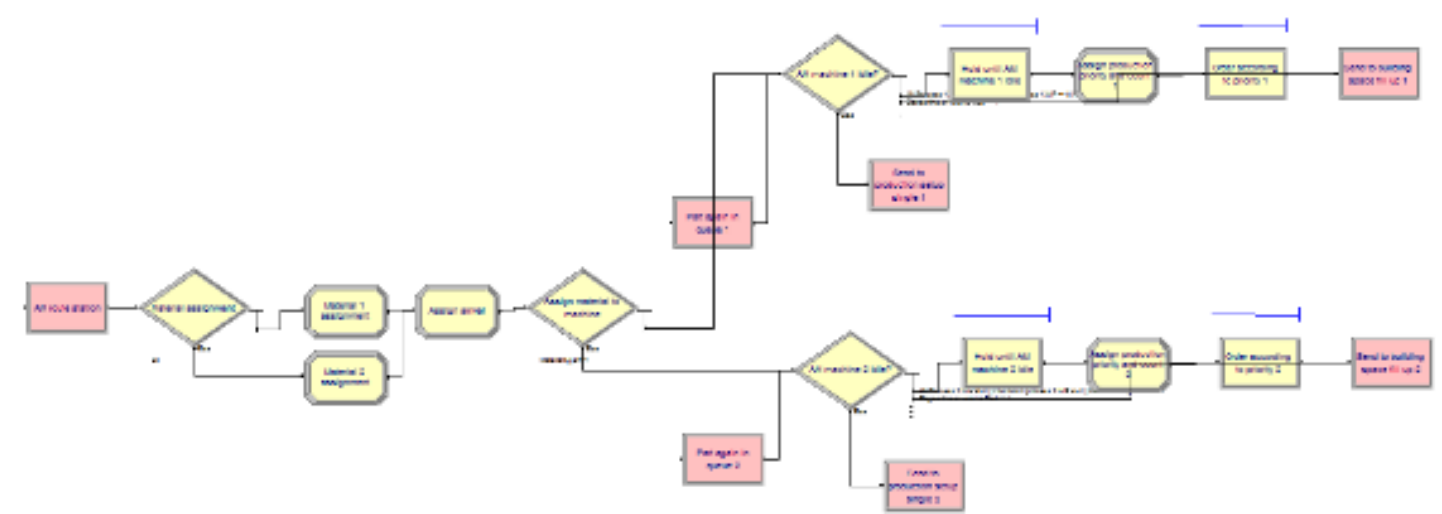

Figure 7-1: Adjusted AM rout arrival and queueing logic

Each of the two machines is dedicated to produce one of the two materials as oppose to the basic setup, in which only one material is assigned to the spare parts. Therefore the material type assignment must be added to the model. This is done by a decide module which assigns the two material with a $50 \%$ chance each. ${ }^{9}$ After that the arrival time is assigned to the part the same way as in the basic model.

\footnotetext{
${ }^{9}$ It is assumed that an equal distribution of materials will represent the best setup to allow for further conclusions, based on a similar stress level of both machines. Another distribution would make one machine a bottleneck, creating a reduced system performance, what would also reduce the generality of the model when the results are compared with other strategies which can react better to different materials.
} 


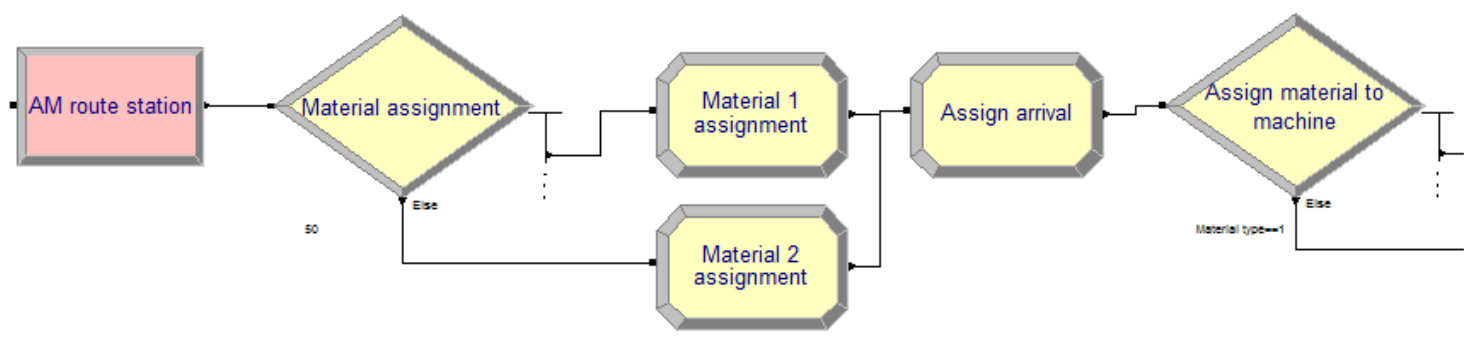

Figure 7-2: Material assignment

After the assignment of the arrival time the spare part request enters a decide module which checks for the assigned material. Spare part requests with assigned material type 1 will follow path one, those with material type 2 will follow path two. Paths one and two are copies of the basic setup and are adjusted to be independent of each other until the finished parts leave the system.

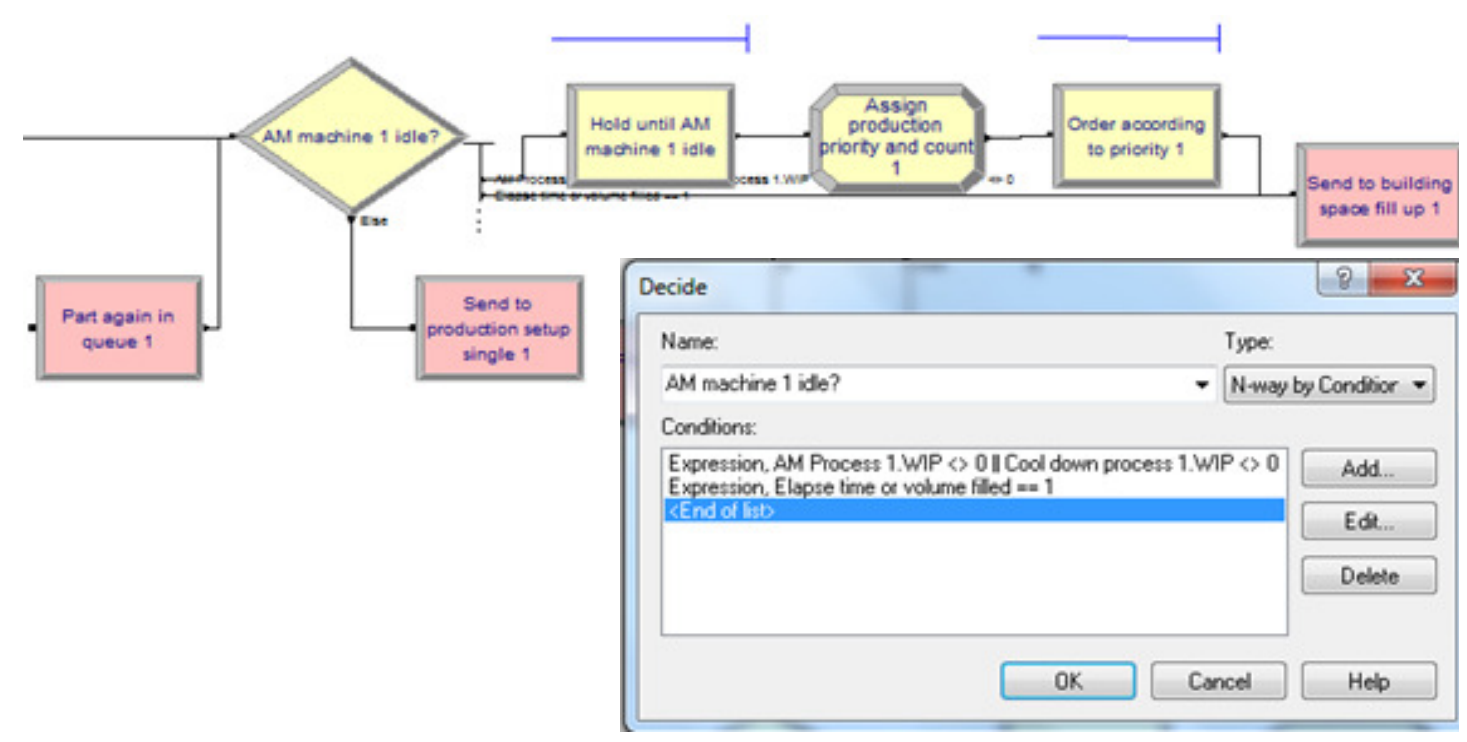

Figure 7-3: Modification of queueing logic

For each queuing logic an additional check function was added to the decide module of AM idle status checking, which determines whether the model should run in the waiting or no-waiting mode. This works as a switch during simulation runs. If the variable "Elapse time or volume filled" is 0 , the model logic will follow the established mode as previously described. If "Elapse time or volume filled" is set to 1, the newly generated part arrivals will enter the "Building 
volume counter logic" module, where a separate "waiting logic" is integrated. The rest of the logic has the same functionality as the setup in the base case.
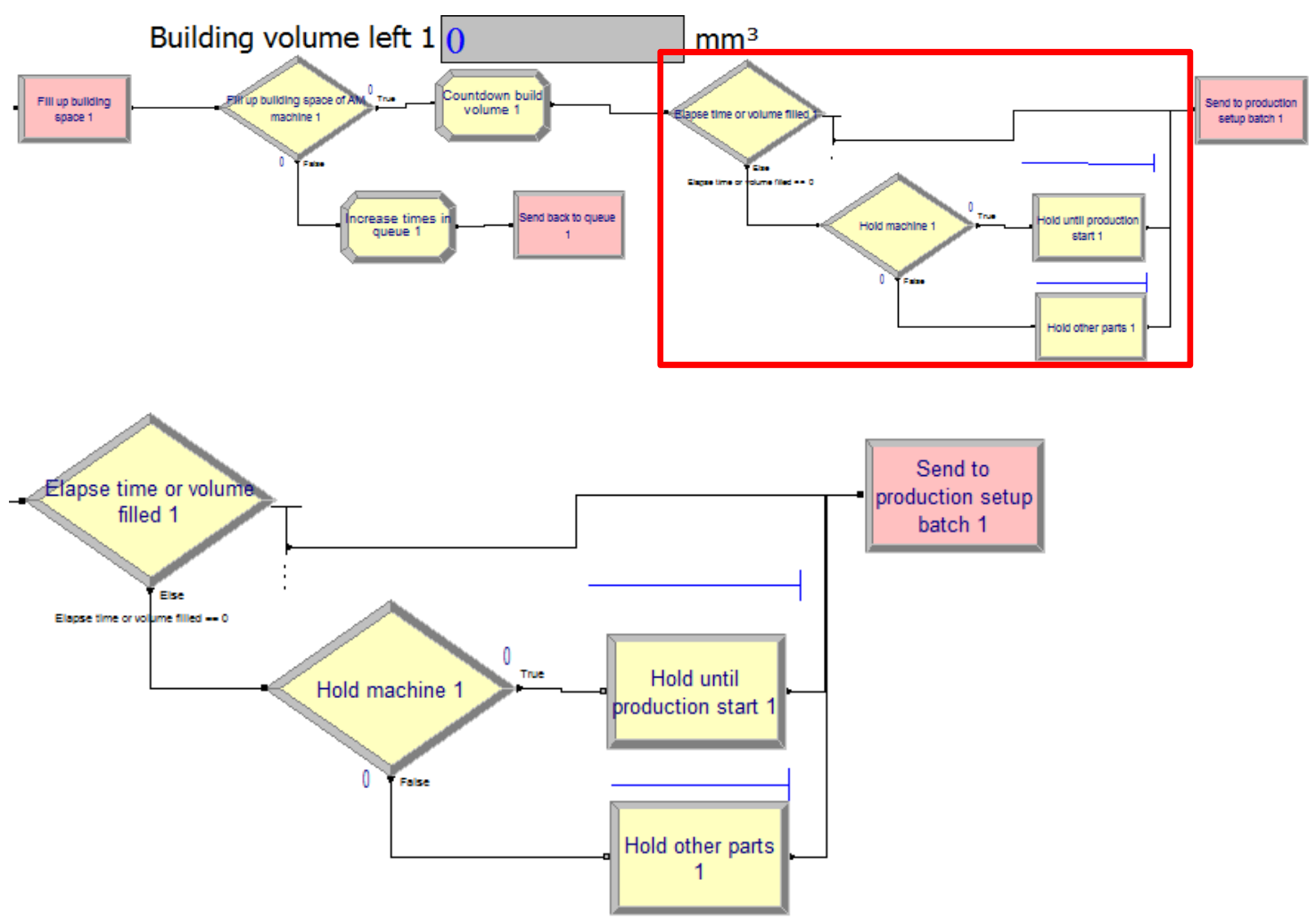

Figure 7-4: Changes in building volume counter logic

When a part enters in the building volume counter logic it flows downstream in the model following the path according to the basic model until it enters at the decide module "Elapse time or volume filled 1". When the model is set to the waiting mode the spare part request bypasses the normal queue and setup logic and begins the waiting until a specific time elapsed or a specific volume is filled. When either time elapsed or a "production start volume" is reached, the spare part request will be forwarded back to the basic model to continue the standard production setup. All other variables and settings are adjusted according to these changes of the model. 


\subsubsection{RESULTS AND DISCUSSION}

The results of the upper limit search are presented in Table 7-1, Figure 7-5 and Figure 7-6. In comparison to the base case (chapter 5) the performance of the system improves as expected.

Compared to the base case the upper limit improved by $40 \%$, AM parts out by $66 \%$ and the system utilization is reduced by $19 \%$. The highest possible arrival rate is at a mean arrival of 20 hrs. When high penalties are accepted the system can deliver up to 429 parts applying the highest arrival rate. Looking at the AM parts out, the system output did not double due to the second machine. This is due to the fixed material setup. If for example two parts of the same material arrive, the system will behave like a one machine strategy, with the results that one part request must wait in queue, while the other machine must wait idle. This decreases also the total system utilization at the upper limit.

Table 7-1: Results of two machines with fixed material assignment- Upper limit No-waiting/

\begin{tabular}{|c|c|c|c|c|c|c|c|c|c|c|}
\hline \multirow{4}{*}{\multicolumn{2}{|c|}{ C }} & \multirow{4}{*}{\begin{tabular}{|c|} 
Base case \\
\\
Upper \\
Iimit \\
\end{tabular}} & \multirow{2}{*}{\multicolumn{6}{|c|}{ Two machines with fixed material assignment }} & \multirow{3}{*}{\multicolumn{2}{|c|}{$\begin{array}{l}\text { Upper limit - } \\
\text { changes compared } \\
\text { to base case [\%] }\end{array}$}} \\
\hline & & & & & & & & & & \\
\hline & & & \multicolumn{3}{|c|}{ No wating } & \multicolumn{3}{|c|}{ Waiting } & & \\
\hline & & & \begin{tabular}{|l|} 
Low \\
arival \\
rate
\end{tabular} & \begin{tabular}{|l} 
Upper \\
limit
\end{tabular} & \begin{tabular}{|l|} 
High \\
arrival \\
rate
\end{tabular} & $\begin{array}{l}\text { Low } \\
\text { arrival } \\
\text { rate }\end{array}$ & $\begin{array}{l}\text { Upper } \\
\operatorname{limit}\end{array}$ & \begin{tabular}{|l|} 
High \\
arrival \\
rate
\end{tabular} & $\begin{array}{l}\text { No } \\
\text { wating }\end{array}$ & Waiting \\
\hline Mean arrival & $\mathrm{hr}$ & 100 & 130 & 60 & 20 & 130 & 70 & 20 & $60 \%$ & $70 \%$ \\
\hline \multicolumn{11}{|l|}{ Cost related responses } \\
\hline Total warehousing cost & f & 55436 & 70873 & 81403 & 117856 & 70873 & 78402 & 117891 & $147 \%$ & $141 \%$ \\
\hline Total AM cost & $\varepsilon$ & 73494 & 98913 & 131635 & 482313 & 99006 & 122822 & 508942 & $179 \%$ & $167 \%$ \\
\hline Consumed mater ial cost & $\varepsilon$ & 22030 & 15465 & 34664 & 105093 & 15451 & 29487 & 105102 & $157 \%$ & $134 \%$ \\
\hline Consumed energy cost & E & 4210 & 2955 & 6623 & 20081 & 2952 & 5634 & 20083 & $157 \%$ & $134 \%$ \\
\hline Operator cost & E & 4336 & 3332 & 7206 & 21470 & 3329 & 6172 & 21489 & $166 \%$ & $142 \%$ \\
\hline Total maintenance cost & $\varepsilon$ & 29407 & 57745 & 58573 & 58907 & 57705 & 58396 & 58825 & $199 \%$ & $199 \%$ \\
\hline Total AM penalty & E & 3708 & 166 & 5041 & 257125 & 333 & 3666 & 283833 & $136 \%$ & $99 \%$ \\
\hline \multicolumn{11}{|l|}{ AM process related responses } \\
\hline Consumed mater ial & $\mathrm{kg}$ & 275 & 193 & 433 & 1313 & 193 & 368 & 1313 & $157 \%$ & $134 \%$ \\
\hline Consumed energy & $\mathrm{kWh}$ & 70160 & 49251 & 110396 & 334693 & 49208 & 93907 & 334720 & $157 \%$ & $134 \%$ \\
\hline System setuptime & $\%$ & 8 & 3 & 7 & 15 & 3 & 6 & 15 & $86 \%$ & $74 \%$ \\
\hline System utilization time & $\%$ & 19 & 7 & 15 & 44 & 7 & 13 & 44 & $77 \%$ & $66 \%$ \\
\hline Systen cool down time & $\%$ & 8 & 3 & 7 & 15 & 3 & 6 & 14 & $83 \%$ & $72 \%$ \\
\hline Total system utilization & $\%$ & 35 & 13 & 28 & 74 & 13 & 24 & 73 & $81 \%$ & $69 \%$ \\
\hline Average building volume & $\mathrm{mm}^{2}$ & 404530 & 369511 & 382907 & 389408 & 369507 & 380333 & 389230 & $95 \%$ & $94 \%$ \\
\hline Machine depreciation & f & 30061 & 59028 & 59875 & 60216 & 58987 & 59694 & 60133 & $199 \%$ & $199 \%$ \\
\hline Average time in queue & $\mathrm{hr}$ & 50 & - & 30 & 39 & - & 27 & 38 & $60 \%$ & $54 \%$ \\
\hline Average number of parts in queue & pcs. & 0,001 & 0,002 & 0,027 & 0,642 & 0,003 & 0,017 & 0,725 & $2700 \%$ & $1700 \%$ \\
\hline Number of parts in queue total & pcs. & 5 & 1 & 15 & 285 & 1 & 10 & 317 & $300 \%$ & $200 \%$ \\
\hline AM parts out & pcs. & 87 & 67 & 144 & 429 & 67 & 123 & 430 & $166 \%$ & $141 \%$ \\
\hline
\end{tabular}



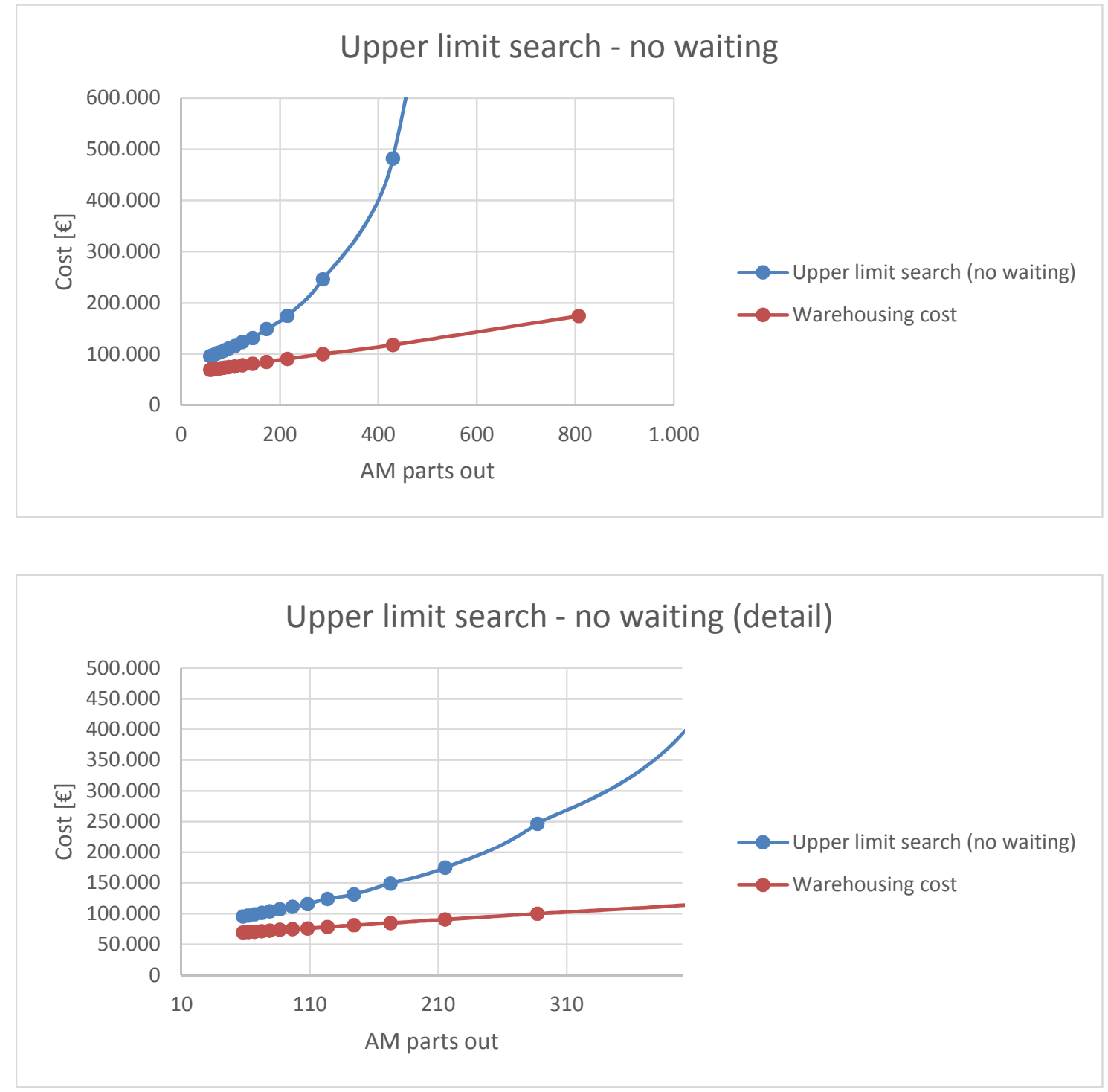

Figure 7-5: Two machines with fixed material - Upper limit search - No waiting 

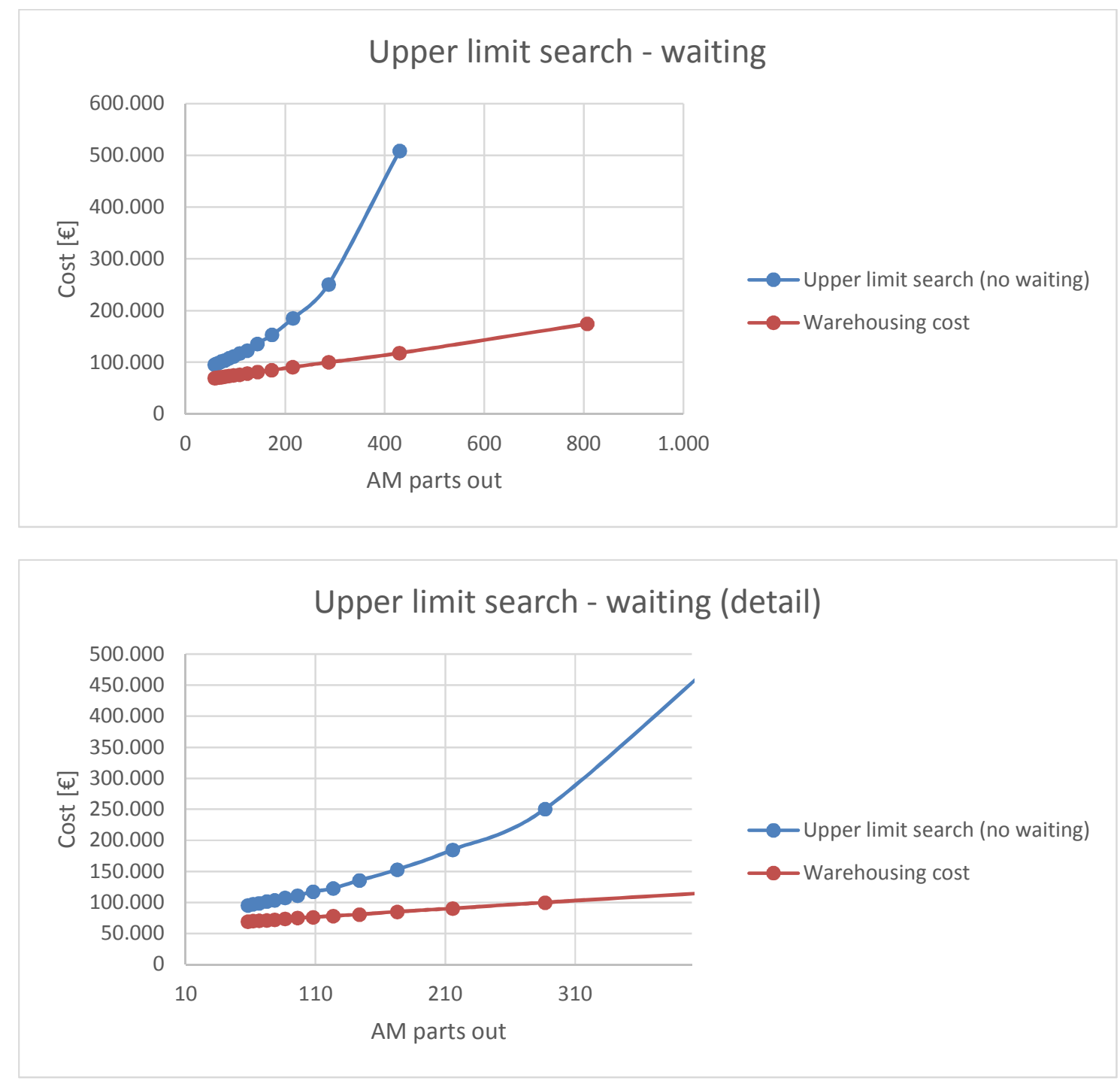

Figure 7-6: Two machines with fixed material - Upper limit search - Waiting

When the waiting mode is applied to the model, the upper limit is reduced, indicating a less efficient performance from the system. This results in a mean arrival time of $70 \mathrm{hrs}$ with a part output of 123 parts. Consequently the machine utilization decreased to $24 \%$, since less parts can be produced due to waiting. 
It was found that for all the simulated scenarios waiting is generally an unfavorable option. This is expected to be caused primarily by the current part set designs. For all the scenarios the part set was setup to have the maximum mean arrival time to be $20 \mathrm{hrs}$ which ensures the stable operation of the system as discussed in previous chapters. However, since the maximum waiting time before a production run starts is set to $12 \mathrm{hrs,} \mathrm{it} \mathrm{became} \mathrm{unlikely} \mathrm{that} \mathrm{a} \mathrm{second} \mathrm{part} \mathrm{will} \mathrm{enter} \mathrm{the}$ production before the waiting period is over, which result in a net delay for the production part in the machines and increases the probability to create additional penalties. It is now in question if a generic scenario where waiting is advantageous exists. An advantageous scenario setup was found in section 7.5.

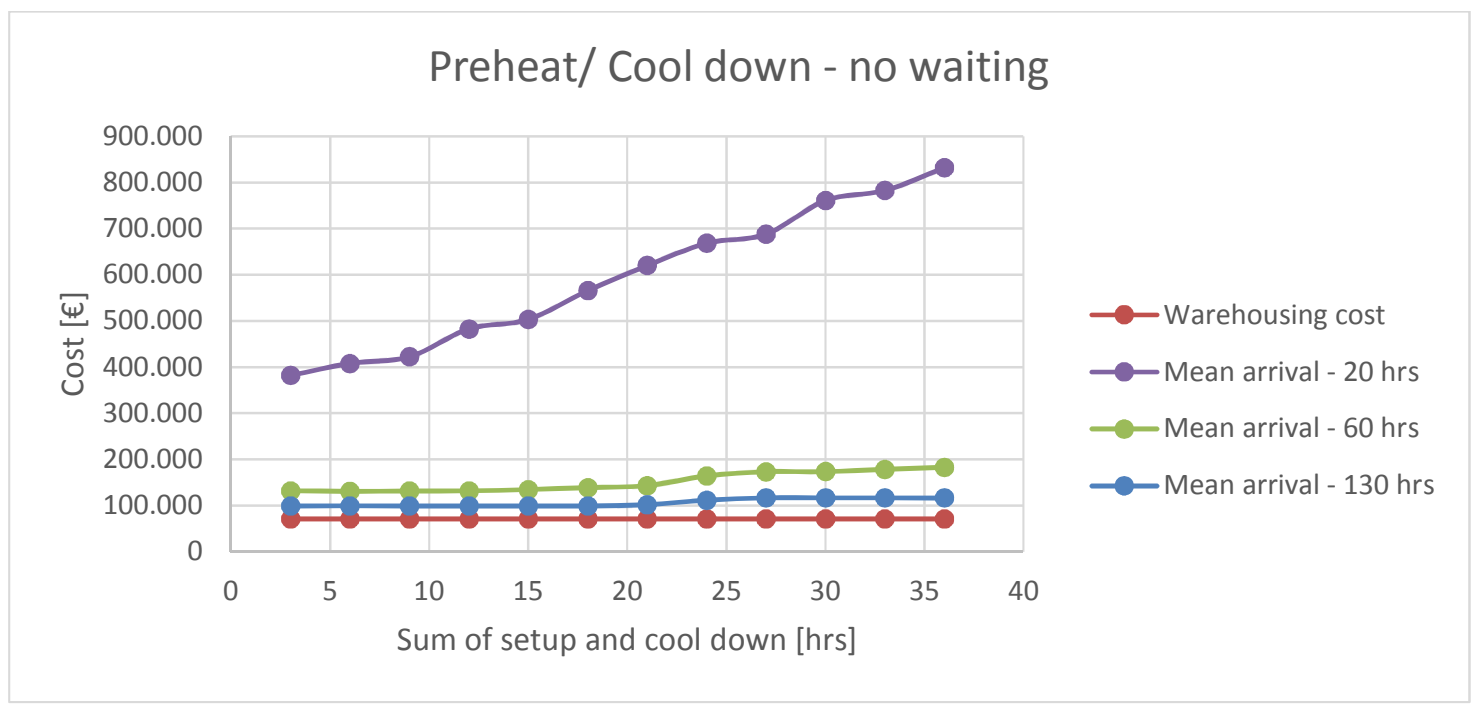

Figure 7-7: Two machines with fixed material - Setup \& cool down time - No waiting 


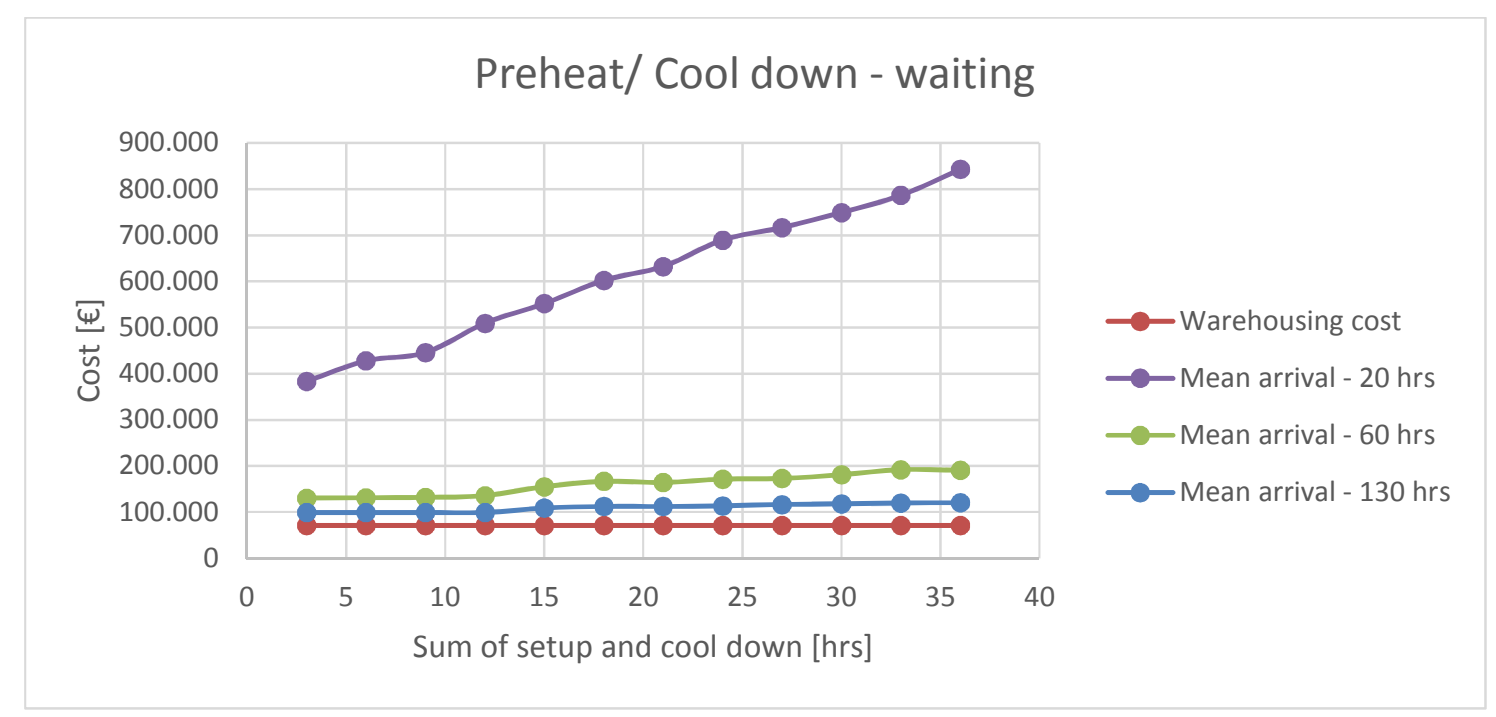

Figure 7-8: Two machines with fixed material - Setup \& cool down time - Waiting

The effect of preheat and cool down is illustrated by Figure 7-7 Figure 7-8. The results clearly showed that the faster parts arrive, the more sensitive the system becomes with respect to setup and cool down times (simulated with high, medium and low inter-arrival times). This is reasonable since longer setup and cool down time will reduce the productivity of the system. Also, the no-waiting mode was found to be more efficient than the waiting mode in these cases since the same part set design was used. 


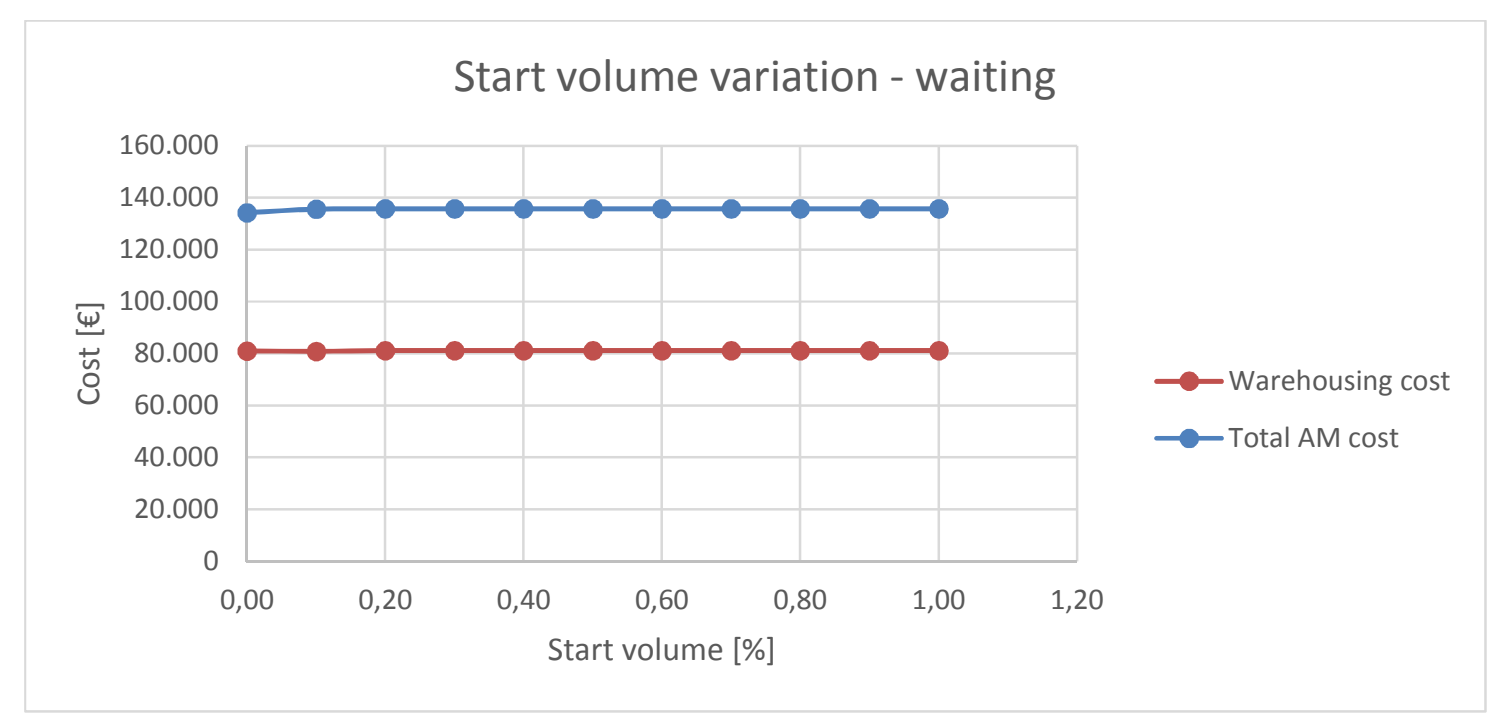

Figure 7-9: Two machines with fixed material - Start volume - Waiting

Figure 7-9 shows that the start volume variation does not have an effect of the system performance. With the part set designs used in the simulations there is never a second part arrival during waiting as long as the system is in a stable state. As described before this is due to the fact that the waiting time is shorter than the inter-arrival time of new spare part requests. The results might be different when the properties of the specific spare part set change. If for example the allowed time to manufacture is much longer, penalties are negligible or the overall production times change the situation might change. 


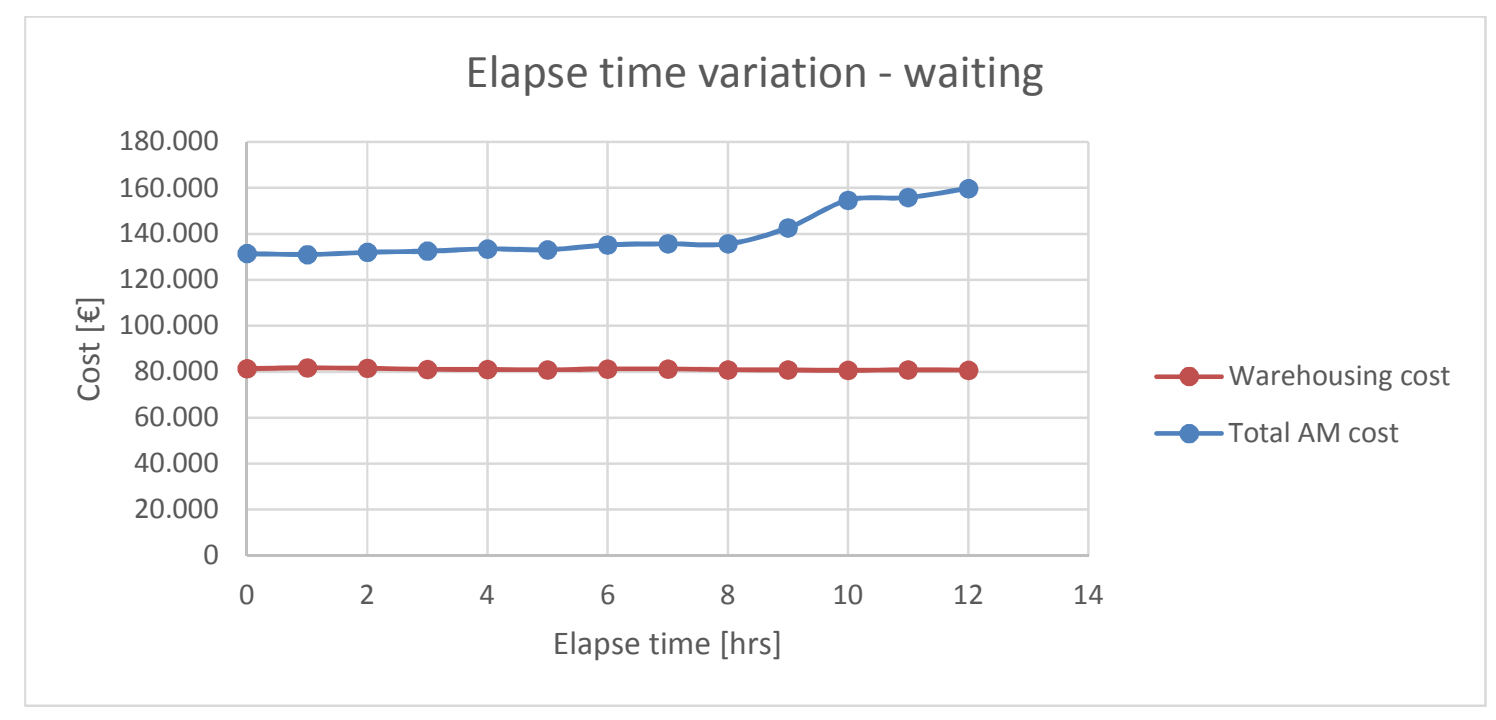

Figure 7-10: Two machines with fixed material - Elapse time - Waiting

Changes in the elapse time have an effect on the system, since an increased elapse time decreases the overall system availability, which is not assumed to be beneficial. This is due to the fact that a production start is postponed without adding a second part into the production run. 


\subsection{TWO MACHINES WITH FLEXIBLE MATERIAL ASSIGNMENT}

In this strategy each machines is able to switch to either of the two materials for a new production run. One of the two possible materials will be assigned to each spare part request. The spare part requests will be assigned to the machines according to their availability. Since thorough machine cleaning is needed in operation whenever a change of material is needed, additional setup time will be needed for the system, which was modeled for this strategy.

Changes with respect to the upper limit, setup and cool down time, elapse time and start volume, and material change over time were investigated.

\subsubsection{MODEL ADJUSTMENT}

The modifications with the base model were mostly focused on the AM route arrival and queueing logic as shown in Figure 7-11.

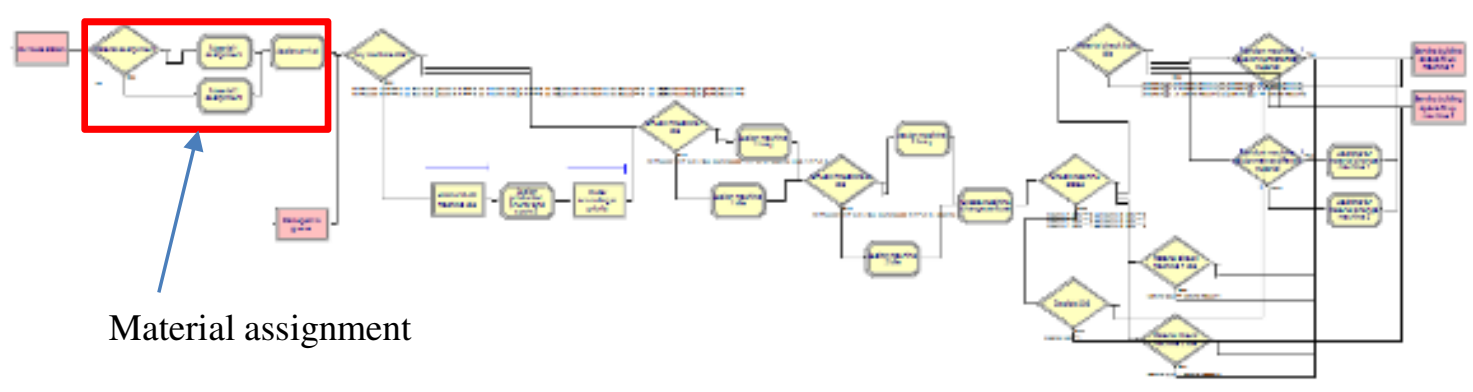

Figure 7-11: Adjusted AM route arrival and queueing logic

In the basic setup only one material is assigned to the spare parts. Therefore the material type must be reassigned. Similar to the strategies of two machines with a fixed material assignment, this was done by a decide module which assigns the two material with a $50 \%$ chance each. The arrival time is assigned to the part the same way as in the basic model. In addition, the downstream part queuing logics remain identical to the two-machine strategies with fixed material assignment as described previously. 


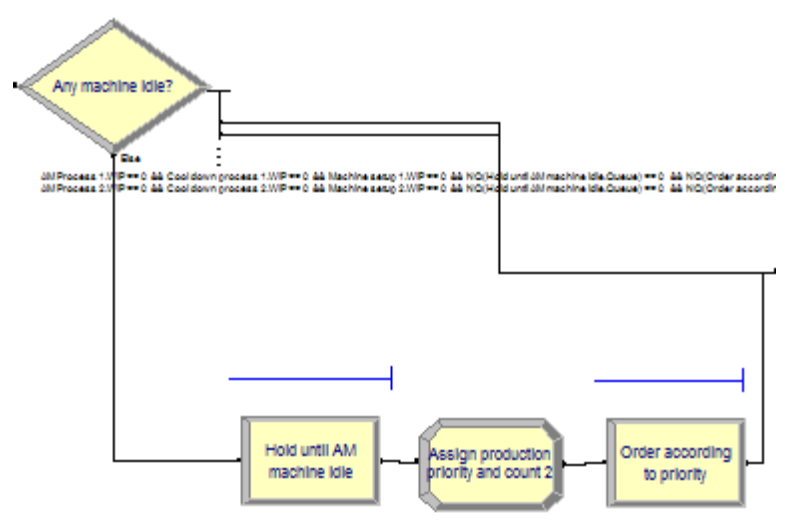

Figure 7-12: Check for idle machine

In order to facilitate the machine assignment in the model, machine states were assigned to the spare part requests as additional attributes. The states are 0 for an idle machine and 1 for a busy machine. In addition, a new attribute is created for each part called "material change", which is set to 0 by default which stands for no material change. It will be changed to 1 if a material change for a production run takes place.

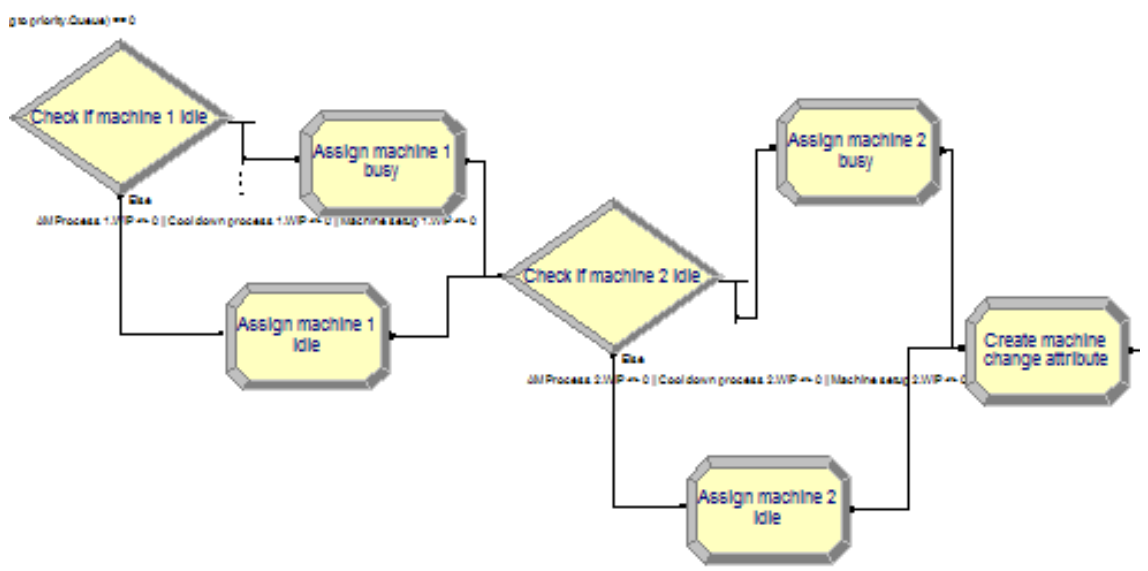

Figure 7-13: Machine states follow up by part attributes 


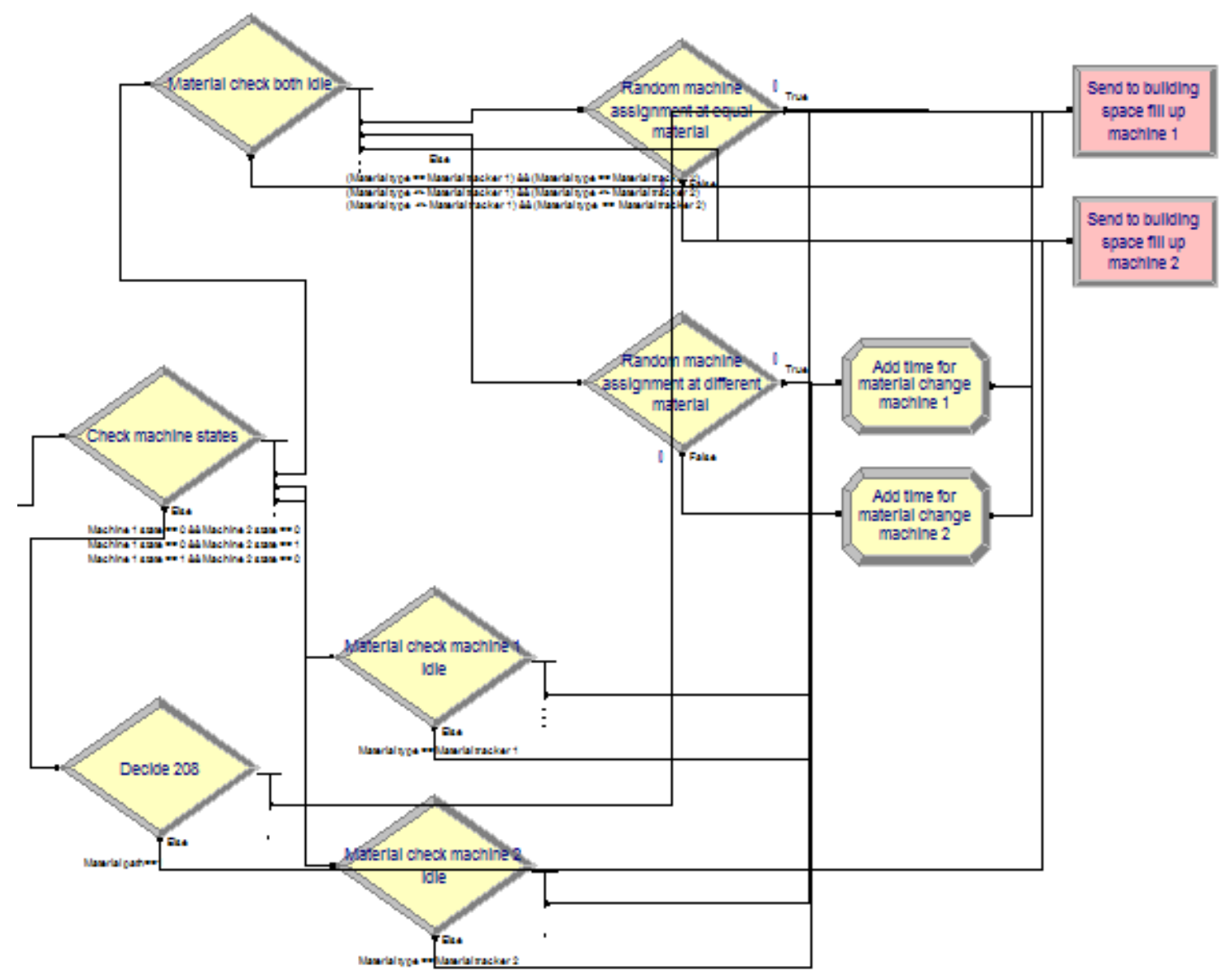

Figure 7-14: Machine assignment and material changeover logic

The new attributes were used in the machine assignment and material changeover logics. In the first step it was checked which machine is idle or busy. In a two machine setup this leads to four possible combinations. Table 7-2 illustrates these combinations in the "check for idle machine" section. Each combination of the consequent step is dependent upon the material of the requested part and the currently applied material of the machine. Each of the possible material combinations requires different actions, which are also listed in Table 7-2. After this step an independent downstream logic path is setup for each machine in the model. 


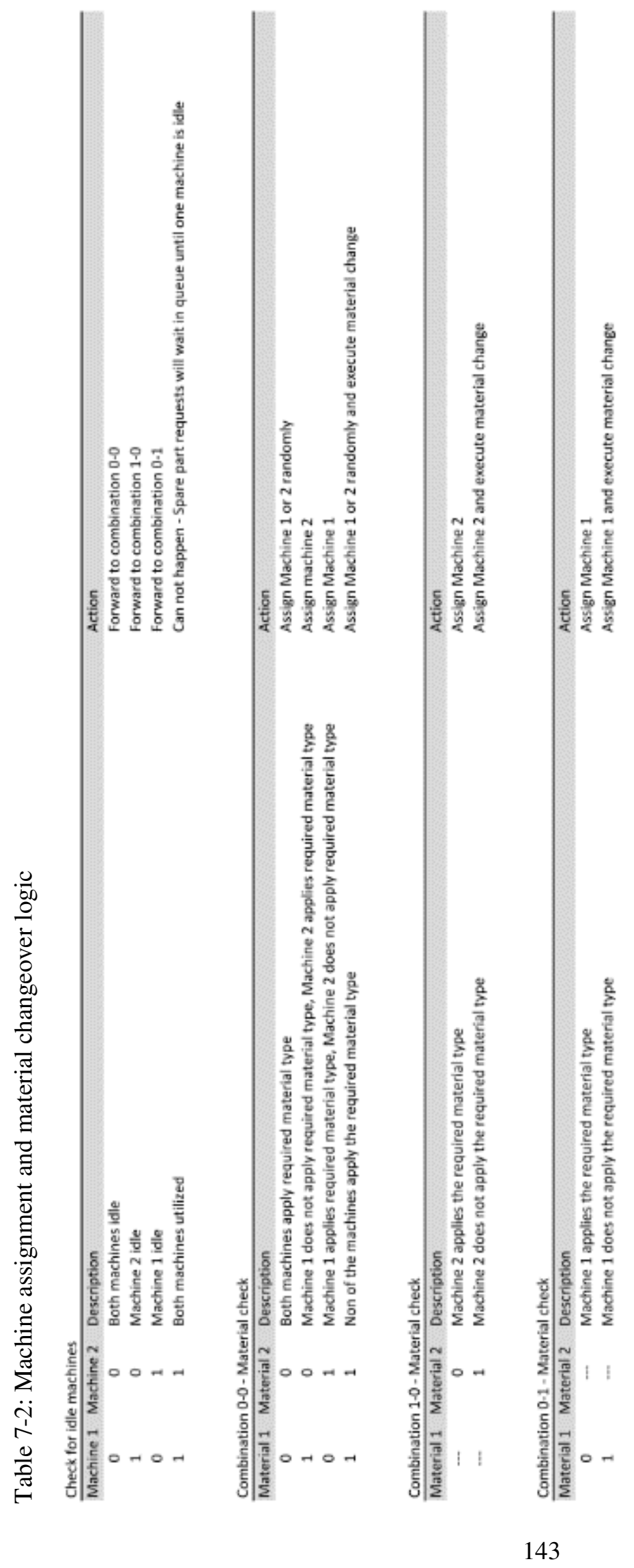


The rest of the model is identical to the base case setup or the two machines with fixed material setup, with the only exception that the material changeover time is added to the production setup time when material change takes place. 


\subsubsection{RESULTS AND DISCUSSION}

The results of the upper limit search are presented in Table 7-3. In comparison to the one machine setup the performance of the system improved as expected. When only one machine is applied AM parts out is 86 parts at the upper limit. In the two machine setup with flexible material assignment the machine utilization equals out at $44 \%$. The highest possible arrival rate is at a mean arrival of $20 \mathrm{hrs,} \mathrm{creating} \mathrm{significant} \mathrm{penalties} \mathrm{at} \mathrm{a} \mathrm{part} \mathrm{output} \mathrm{of} 430$ parts. Compared to the two machines with a fixed material assignment the results for mean arrival, AM parts out and total system utilization improved. A more detailed comparison of all strategies will follow in chapter 8 .

Table 7-3: Two machines with flexible material assignment - Upper limit No waiting/ Waiting

\begin{tabular}{|c|c|c|c|c|c|c|c|c|c|c|}
\hline \multirow[b]{3}{*}{ Control } & & \multirow{3}{*}{\begin{tabular}{|c|} 
Base case \\
\\
Upper \\
Iimit
\end{tabular}} & \multicolumn{6}{|c|}{ Two machines with flex ble material assignment } & \multirow{2}{*}{\multicolumn{2}{|c|}{$\begin{array}{c}\text { Upper limit - } \\
\text { changes compared } \\
\text { to base case [\%] }\end{array}$}} \\
\hline & & & \multicolumn{3}{|c|}{$\begin{array}{l}\text { Mean arival } \\
\text { No wating }\end{array}$} & \multicolumn{3}{|c|}{$\begin{array}{c}\text { Mean arival } \\
\text { Wating }\end{array}$} & & \\
\hline & & & $\begin{array}{l}\text { Low } \\
\text { arival } \\
\text { rate }\end{array}$ & \begin{tabular}{|l} 
Upper \\
limit
\end{tabular} & \begin{tabular}{|l} 
High \\
arrival \\
rate \\
\end{tabular} & $\begin{array}{l}\text { Low } \\
\text { arrival } \\
\text { rate } \\
\end{array}$ & $\begin{array}{l}\text { Upper } \\
\operatorname{limit}\end{array}$ & \begin{tabular}{|l|} 
High \\
arrival \\
rate \\
\end{tabular} & $\begin{array}{l}\text { No } \\
\text { wating }\end{array}$ & Waiting \\
\hline Mean arrival & $\mathrm{hr}$ & 100 & & & & 120 & 70 & 20 & $0 \%$ & $70 \%$ \\
\hline \multicolumn{11}{|l|}{ Cost related responses } \\
\hline Total warehousing cost & 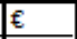 & 55436 & 60 & 40 & 10 & 72062 & 78751 & 117681 & $0 \%$ & $142 \%$ \\
\hline Total AM cost & $€$ & 73494 & 81601 & 90498 & 173380 & 102295 & 120773 & 378359 & $123 \%$ & $164 \%$ \\
\hline Consumed mater ial cost & $\varepsilon$ & 22030 & 34688 & 53087 & 201068 & 17058 & 28534 & 102863 & $241 \%$ & $130 \%$ \\
\hline Consumed energy cost & $\varepsilon$ & 4210 & 6628 & 10144 & 38420 & 3259 & 5452 & 19655 & $241 \%$ & $130 \%$ \\
\hline Operator cost & E & 4336 & 7208 & 10778 & 41495 & 3615 & 6163 & 21474 & $249 \%$ & $142 \%$ \\
\hline Total maintenance cost & $€$ & 29407 & 58673 & 58777 & 58304 & 57990 & 58498 & 58931 & $200 \%$ & $199 \%$ \\
\hline Total AM penalty & $\varepsilon$ & 3708 & 291 & 2583 & $2 \mathrm{E}+06$ & 1041 & 2625 & 155791 & $70 \%$ & $71 \%$ \\
\hline \multicolumn{11}{|l|}{ AM process related responses } \\
\hline Consumed mater ial & $\mathrm{kg}$ & 275 & 433 & 663 & 2513 & 213 & 356 & 1285 & $241 \%$ & $129 \%$ \\
\hline Consumed energy & kWh & 70160 & 110473 & 169069 & 640346 & 54326 & 90874 & 327590 & $241 \%$ & $130 \%$ \\
\hline System setup time & $\%$ & 8 & 8 & 12 & 8 & 4 & 6 & 23 & $147 \%$ & $81 \%$ \\
\hline System utilization time & $\%$ & 19 & 15 & 22 & 85 & 7 & 12 & 43 & $118 \%$ & $64 \%$ \\
\hline Systen cool down time & $\%$ & 8 & 7 & 10 & 6 & 3 & 6 & 17 & $125 \%$ & $72 \%$ \\
\hline Total system utilization & $\%$ & 35 & 29 & 44 & 99 & 14 & 24 & 83 & $126 \%$ & $70 \%$ \\
\hline Average building volume & $\mathrm{mm}^{2}$ & 404530 & 384452 & 393624 & 386716 & 377651 & 370109 & 382680 & $97 \%$ & $91 \%$ \\
\hline Machine depreciation & $\varepsilon$ & 30061 & 59977 & 60083 & 59600 & 59279 & 59798 & 60240 & $200 \%$ & $199 \%$ \\
\hline Average time in queue & $\mathrm{hr}$ & 50 & - & 19,264 & 78,027 & - & - & 18,353 & $39 \%$ & $\cdots$ \\
\hline Average number of parts in queue & pcs. & 0,001 & 0,002 & 0,023 & 1,566 & 0 & 0,001 & 0,718 & $2300 \%$ & $100 \%$ \\
\hline Number of parts in queue total & pcs. & 5 & 1 & 9 & 1268 & 0 & 1 & 335 & $186 \%$ & $20 \%$ \\
\hline AM parts out & pcs. & 87 & 144 & 216 & 830 & 72 & 123 & 430 & $248 \%$ & $142 \%$ \\
\hline
\end{tabular}



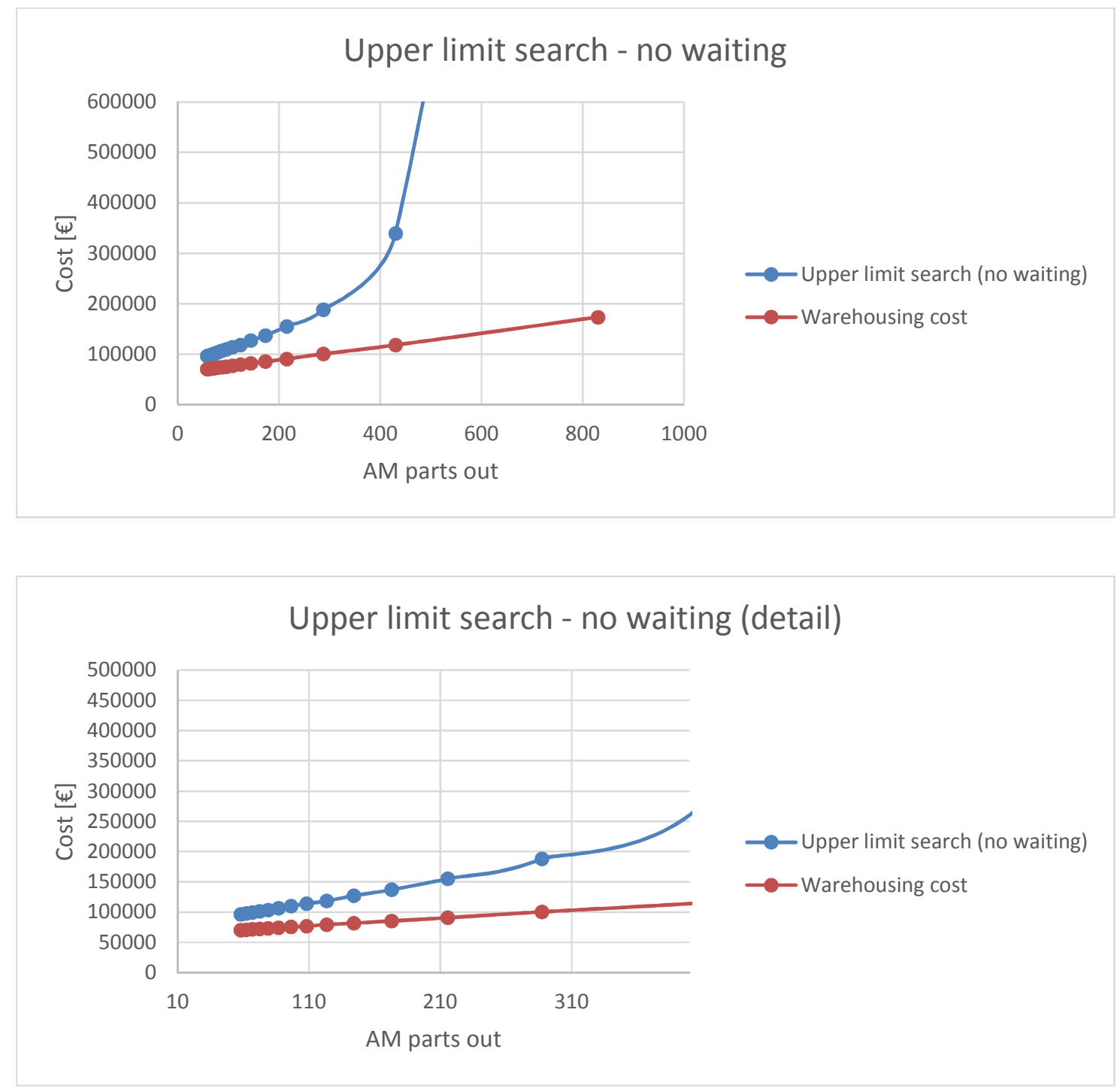

Figure 7-15: Two machines with flexible material - Upper limit search - No waiting 


\section{Upper limit search - waiting}
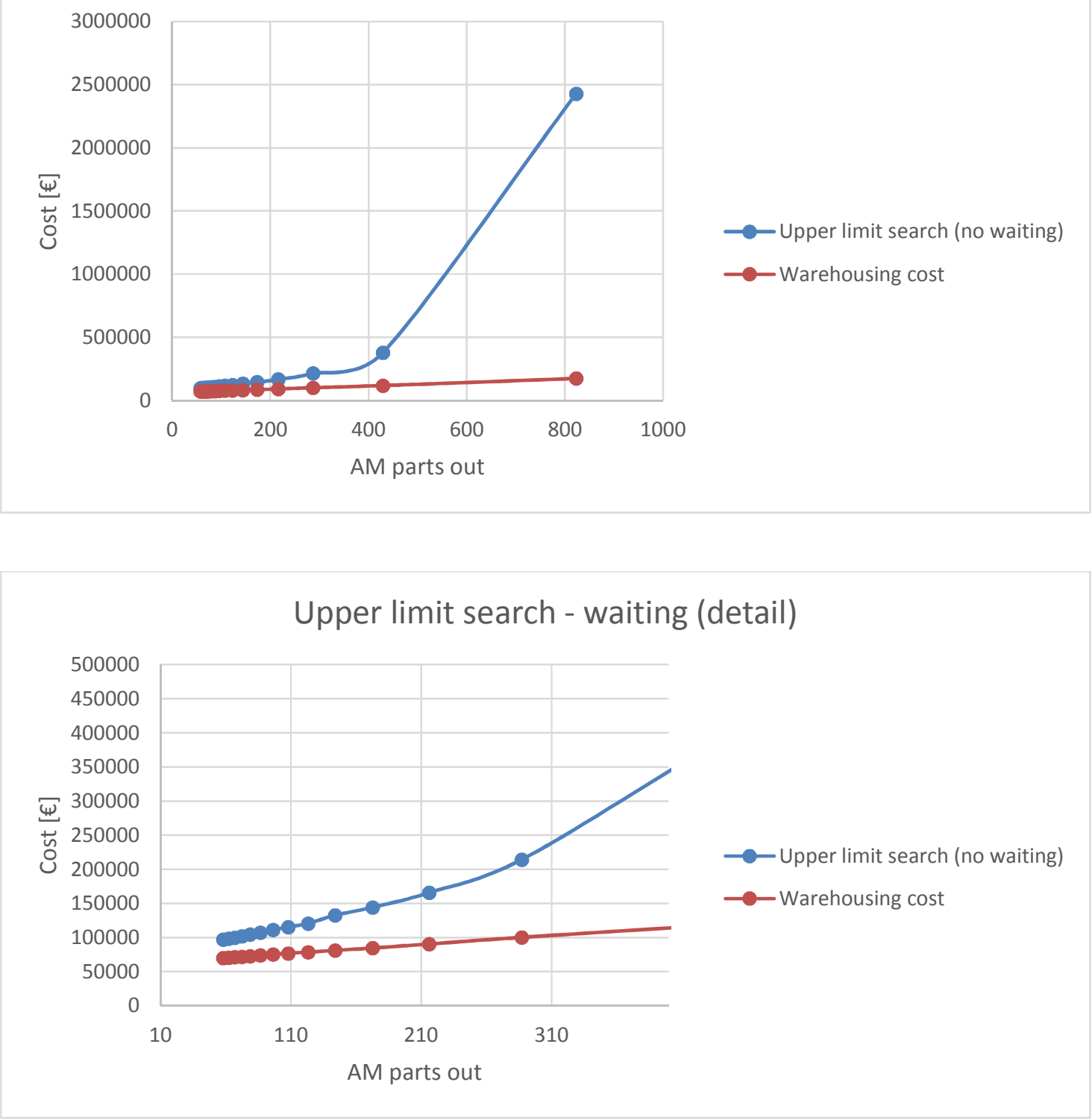

Figure 7-16: Two machines with flexible material - Upper limit search - Waiting

For the two-machine with flexible material assignment, the performance deterioration appears to be considerably more significant when the waiting mode is applied, which resulted in a near $45 \%$ reduction of the maximum system utilization as shown in Table 7-3. Comparing Table 7-1 and Table 7-3 it can be seen that under this condition the flexible strategy does not appear to add any 
benefits to the system when waiting. Also, in this case machine utilization decreases to $24 \%$, since less parts can be produced due to waiting. This seems very similar compared the two machines with the fixed material assignment, but the average number of parts in queue decreased, which is indicates a well-performing system.

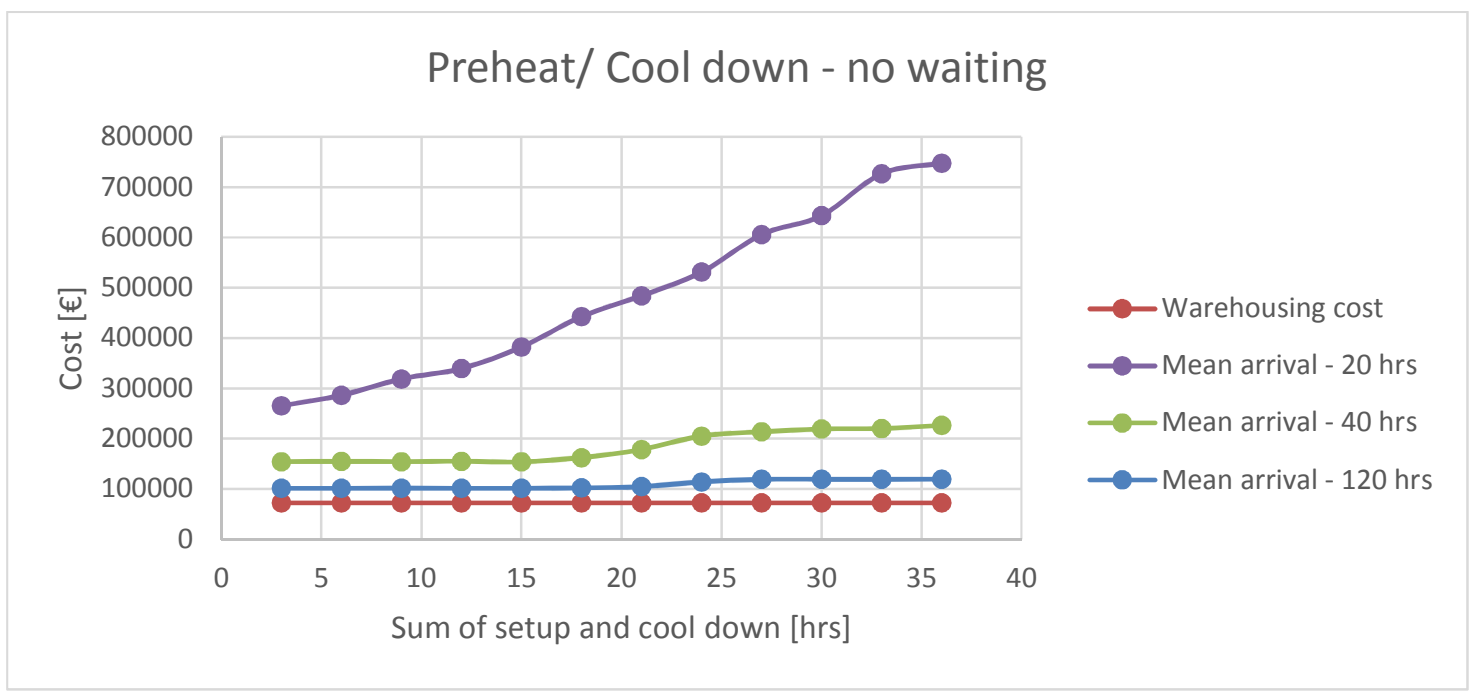

Figure 7-17: Two machines with flexible material - Preheat and cool down - No waiting

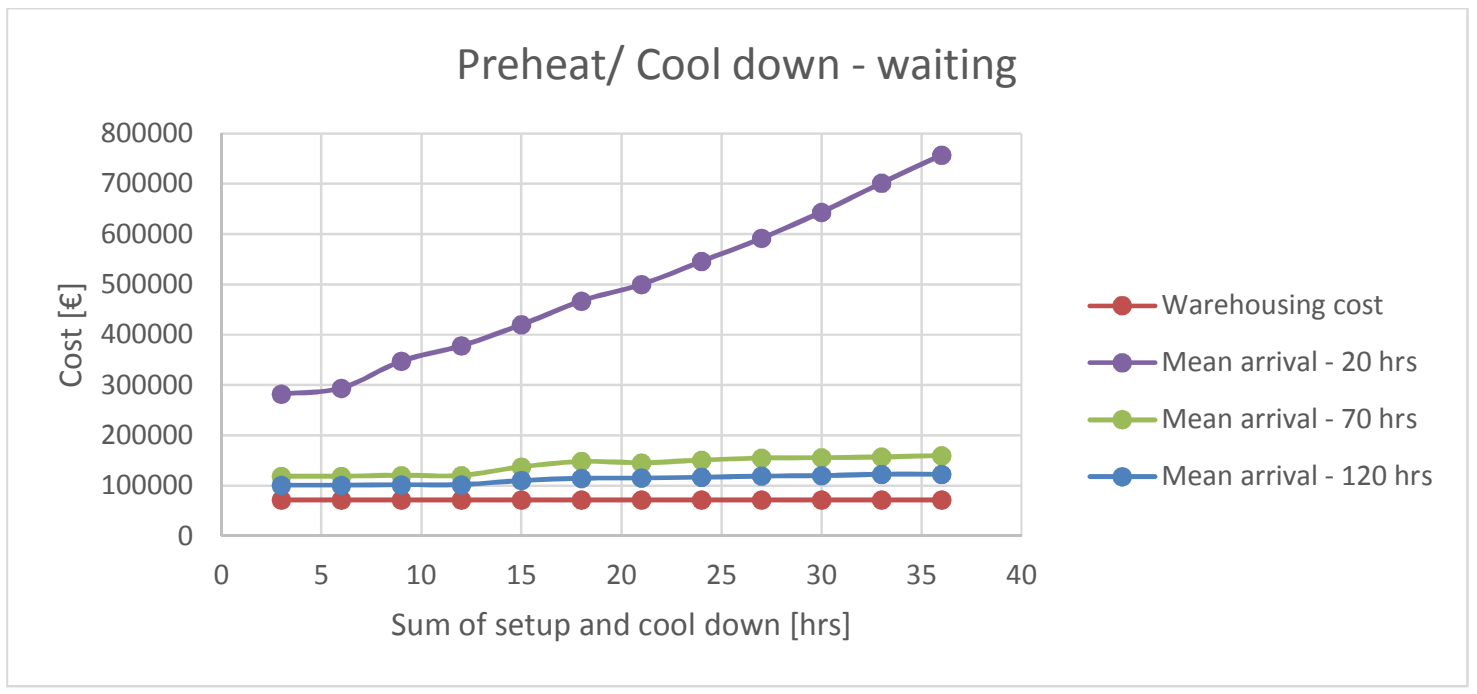

Figure 7-18: Two machines with flexible material - Preheat and cool down - Waiting 


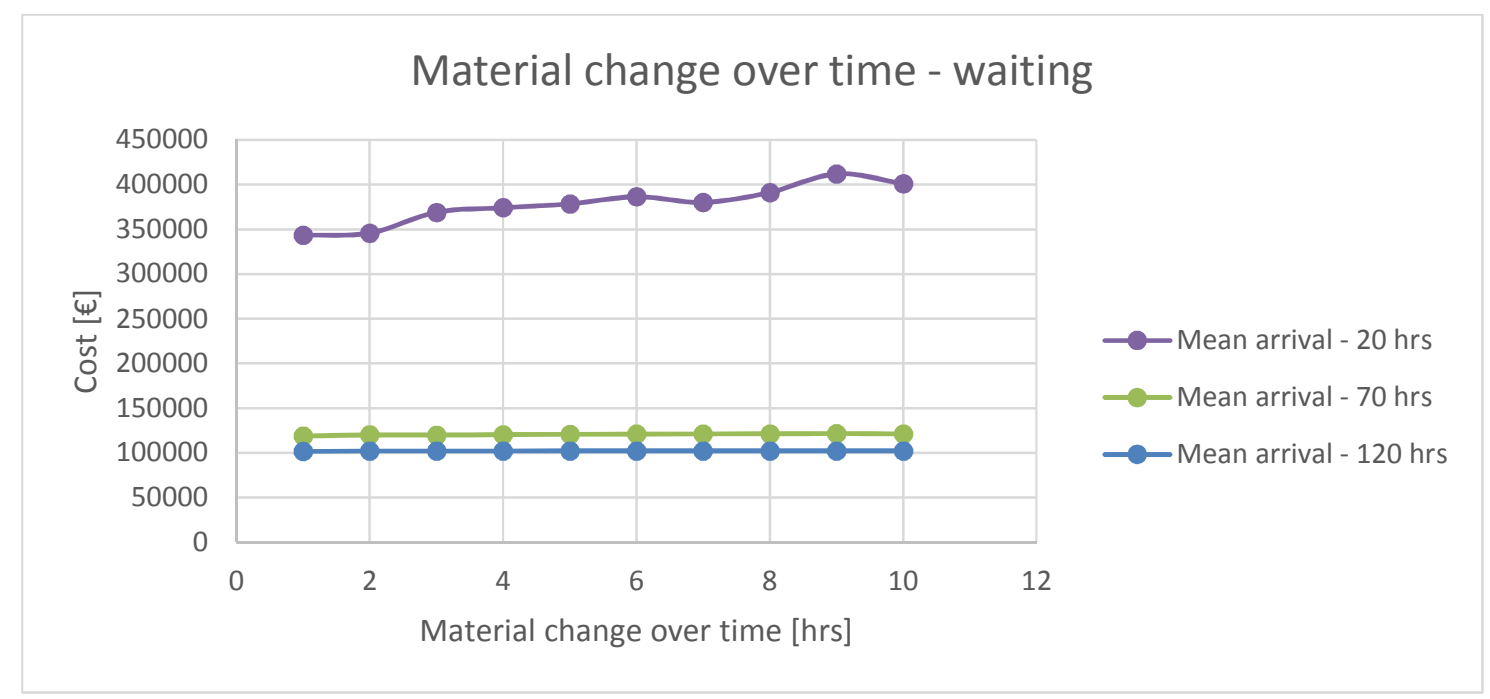

Figure 7-19: Two machines with flexible material - Material change over time - Waiting

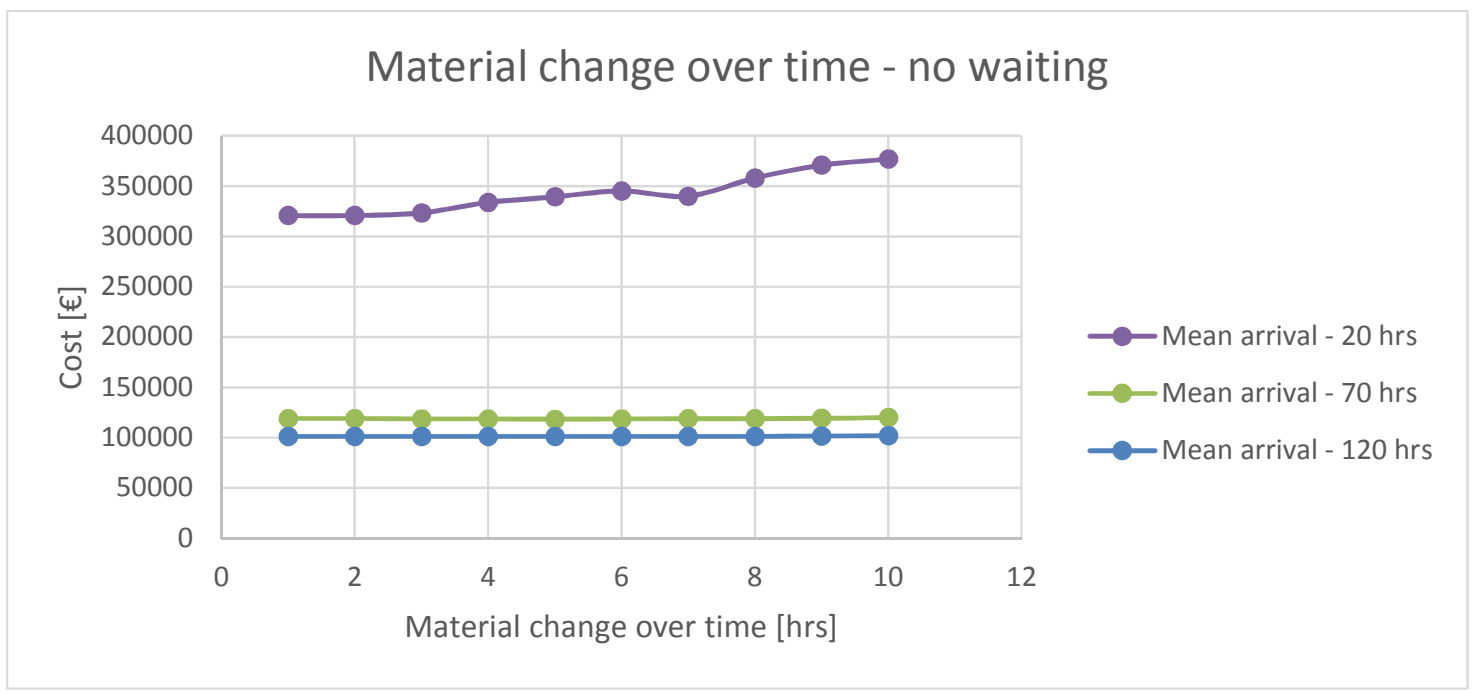

Figure 7-20: Two machines with flexible material - Material change over time - No waiting

The influences of material changeover, preheat and cool down are similar to the two-machine with fixed material assignment, with the no-waiting mode outperforming the waiting mode. 


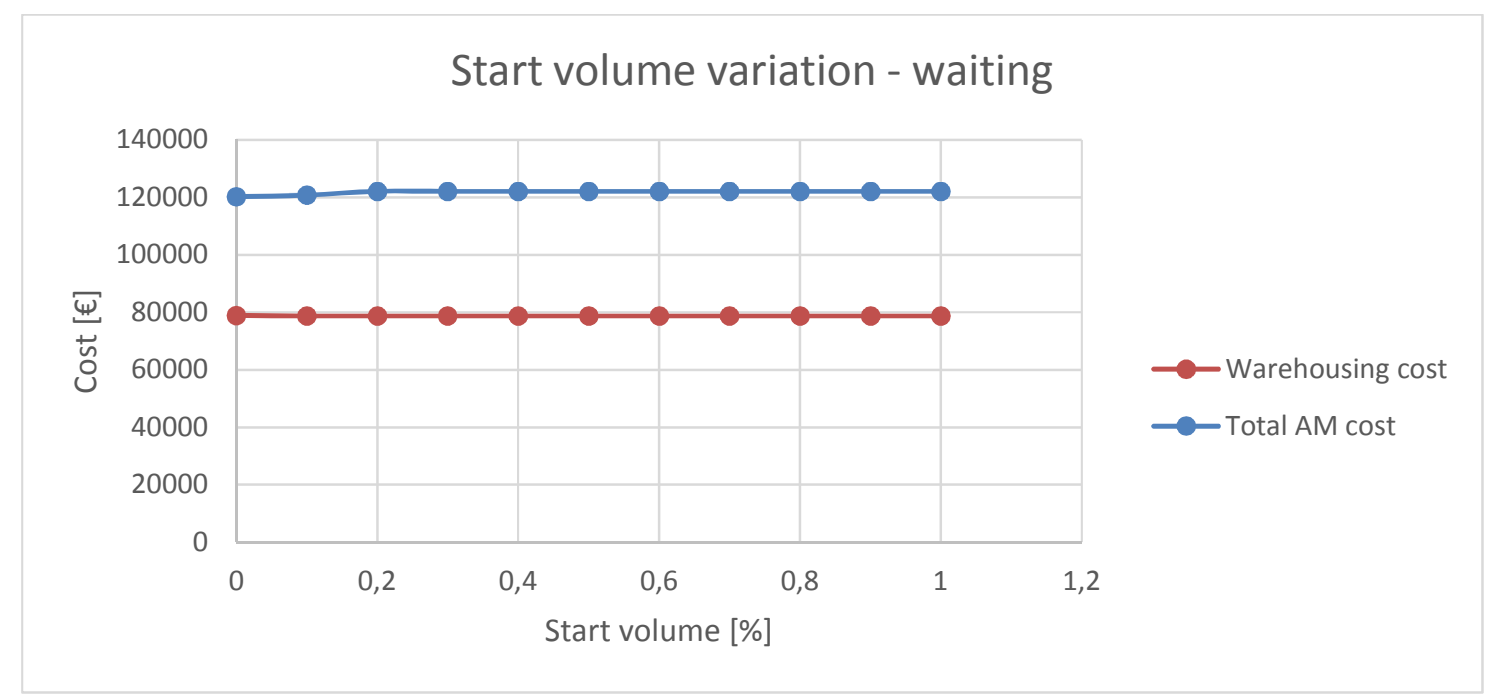

Figure 7-21: Two machines with flexible material - Start volume - Waiting

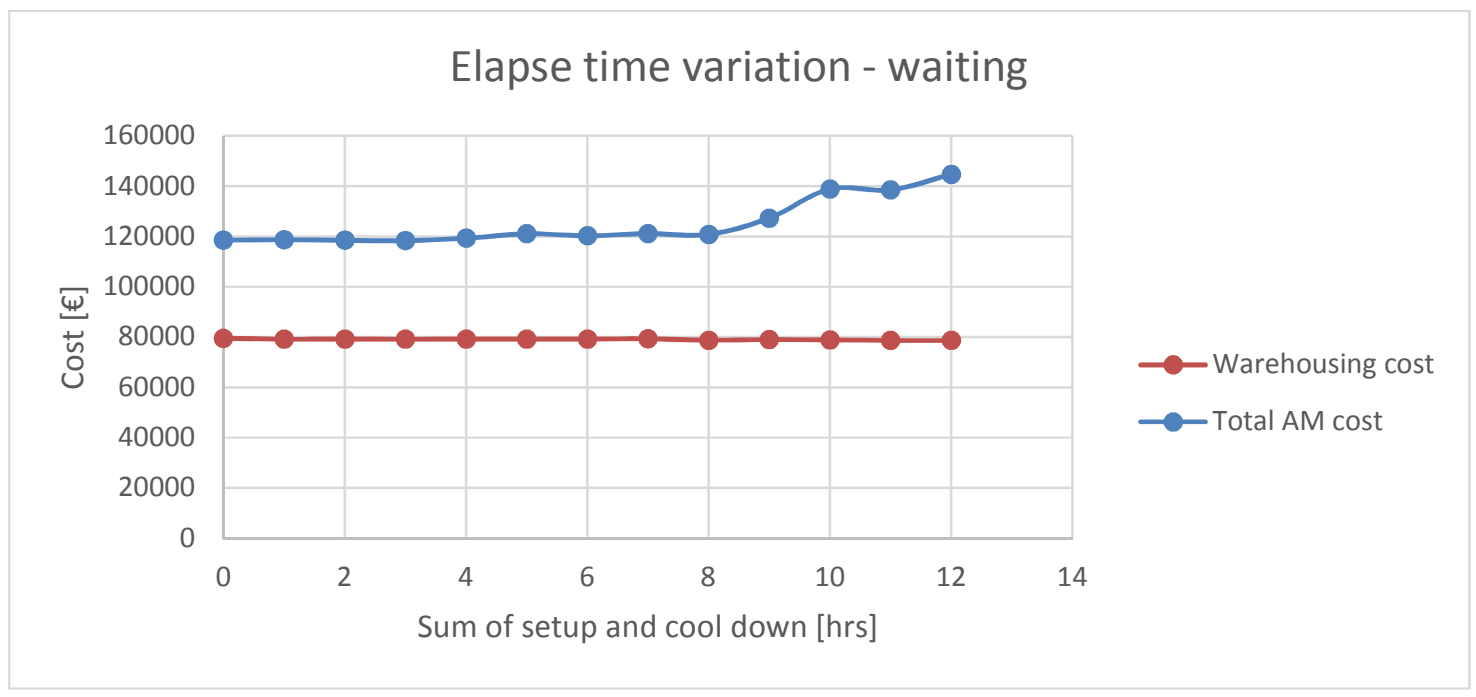

Figure 7-22: Two machines with flexible material - Elapse time - Waiting

Also, the start volume and elapse time variation show almost identical effects to the total cost compared to the fixed material strategy with the current part set designs as discussed previously. 


\subsubsection{THREE MACHINES WITH FIXED MATERIAL ASSIGNMENT}

In this section the strategy of three-machine with fixed material assignments was modeled and analyzed. Each machine was dedicated to fabricate only one fixed type of material. One of the three possible materials was assigned to each spare part request, and the treatment of the model followed the same approach as that used in two-machine with fixed material assignment strategy. Again, changes with respect to the upper limit, setup and cool down time, elapse time and start volume were investigated.

\subsubsection{MODEL ADJUSTMENT}

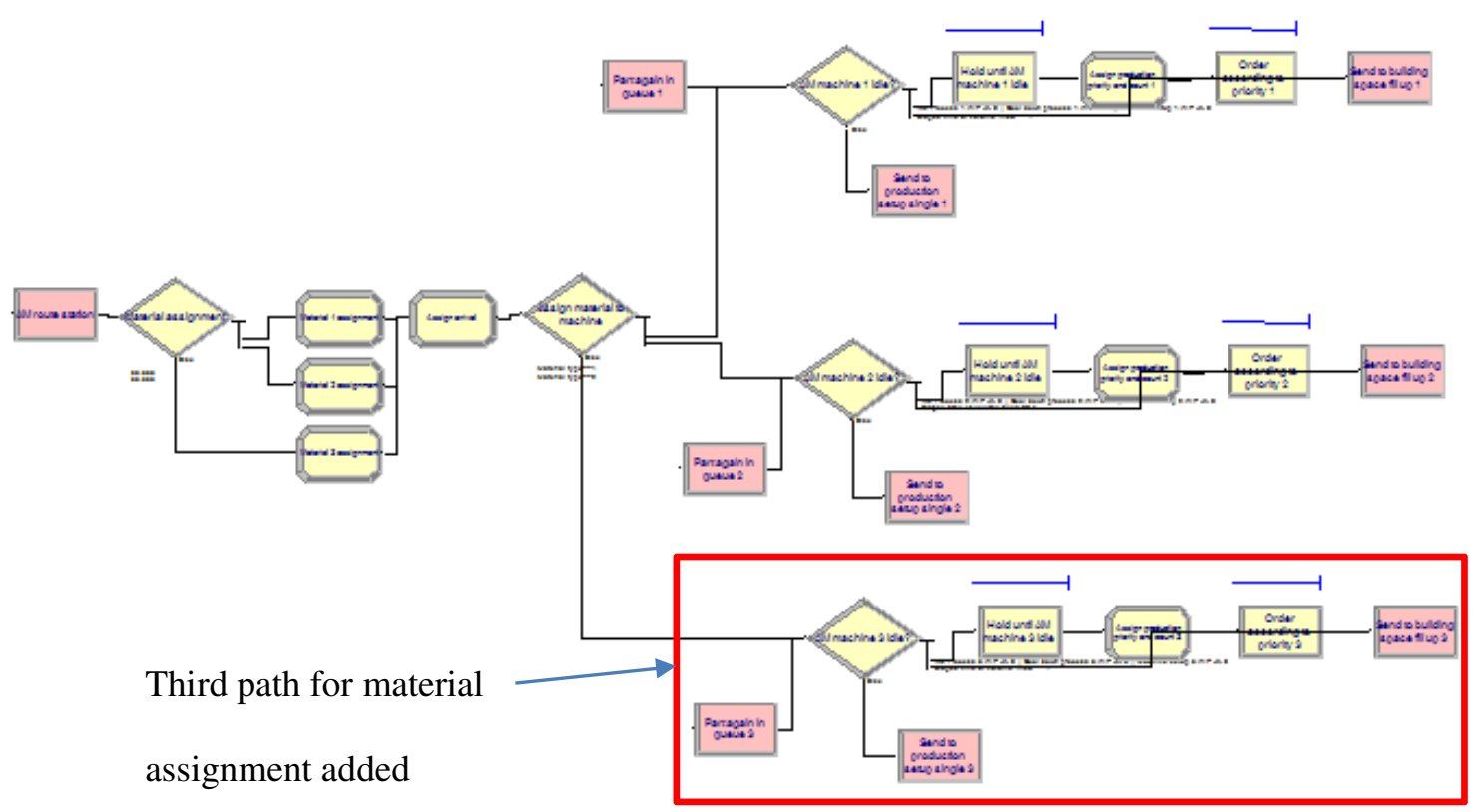

Figure 7-23: Main adjustment of the model

The Three machines with fixed material model is an extension of the two machines with fixed material model. A third path is added which allows assignment of a third material type. The rest of the model is adjusted accordingly. 


\subsubsection{RESULTS AND DISCUSSION}

The result of the upper limit search is presented in Table 7-4

Table 7-4: Three machines with fixed material - Upper limit No waiting/ Waiting

\begin{tabular}{|c|c|c|c|c|c|c|c|c|c|c|}
\hline \multirow[b]{3}{*}{ Control } & & \multirow{3}{*}{\begin{tabular}{|c|} 
Base case \\
\\
\\
Upper \\
limit \\
\end{tabular}} & \multicolumn{6}{|c|}{ Three machines w th fixed material assignment } & \multirow{2}{*}{\multicolumn{2}{|c|}{$\begin{array}{c}\text { Upper limit - } \\
\text { changes compared } \\
\text { to base case [\%] }\end{array}$}} \\
\hline & & & \multicolumn{3}{|c|}{$\begin{array}{l}\text { Mean arival } \\
\text { No wating }\end{array}$} & \multicolumn{3}{|c|}{$\begin{array}{l}\text { Mean arival } \\
\text { Wating }\end{array}$} & & \\
\hline & & & $\begin{array}{l}\text { Low } \\
\text { arival } \\
\text { rate } \\
\end{array}$ & \begin{tabular}{|l} 
Upper \\
limit
\end{tabular} & \begin{tabular}{|l}
$\begin{array}{l}\text { High } \\
\text { arival } \\
\text { rate }\end{array}$ \\
\end{tabular} & $\begin{array}{l}\text { Low } \\
\text { arrival } \\
\text { rate } \\
\end{array}$ & \begin{tabular}{|l} 
Upper \\
$\operatorname{limit}$
\end{tabular} & \begin{tabular}{|l|} 
High \\
arrival \\
rate
\end{tabular} & $\begin{array}{l}\text { No } \\
\text { wating }\end{array}$ & Waiting \\
\hline Mean arrival & $\mathrm{hr}$ & 100 & 130 & 60 & 20 & 130 & 60 & 20 & $60 \%$ & $60 \%$ \\
\hline \multicolumn{11}{|l|}{ Cost related responses } \\
\hline Total warehousing cost & $E$ & 55436 & 70873 & 81454 & 117537 & 70873 & 80950 & 120076 & $147 \%$ & $146 \%$ \\
\hline Total AM cost & $€$ & 73494 & 136044 & 169974 & 380022 & 136172 & 169690 & 409459 & $231 \%$ & $231 \%$ \\
\hline Consumed mater ial cost & $€$ & 22030 & 15475 & 35687 & 103204 & 15461 & 35114 & 103328 & $162 \%$ & $159 \%$ \\
\hline Consumed energy cost & $€$ & 4210 & 2957 & 6819 & 19720 & 2954 & 6709 & 19744 & $162 \%$ & $159 \%$ \\
\hline Operator cost & $€$ & 4336 & 3333 & 7211 & 21558 & 3330 & 7186 & 21483 & $166 \%$ & $166 \%$ \\
\hline Total maintenance cost & $€$ & 29407 & 85584 & 87285 & 88122 & 85632 & 87228 & 88208 & $297 \%$ & $297 \%$ \\
\hline Total AM penalty & $€$ & 3708 & 166 & 3875 & 118041 & 250 & 4375 & 147291 & $105 \%$ & $118 \%$ \\
\hline \multicolumn{11}{|l|}{ AM process related responses } \\
\hline Consumed mater ial & $\mathrm{kg}$ & 275 & 193 & 446 & 1290 & 193 & 438 & 1291 & $162 \%$ & $159 \%$ \\
\hline Consumed energy & kWh & 70160 & 49284 & 113655 & 328677 & 49241 & 111829 & 329071 & $162 \%$ & $159 \%$ \\
\hline System setuptime & $\%$ & 8 & 2 & 5 & 12 & 2 & 5 & 12. & $58 \%$ & $58 \%$ \\
\hline System utilization time & $\%$ & 19 & 4 & 10 & 29 & 4 & 10 & 29 & $53 \%$ & $53 \%$ \\
\hline Systen cool down time & $\%$ & 8 & 2 & 5 & 12 & 2 & 4 & 11 & $56 \%$ & $56 \%$ \\
\hline Total s/stem utilization & $\%$ & 35 & 9 & 19 & 53 & 9 & 19 & 52 & $55 \%$ & $55 \%$ \\
\hline Average building volume & $\mathrm{mm}^{2}$ & 404530 & 366354 & \begin{tabular}{|l|l|}
393399 \\
\end{tabular} & 90080 & 366389 & \begin{tabular}{|c|}
389143 \\
\end{tabular} & 383055 & $97 \%$ & $96 \%$ \\
\hline Machine depreciation & $€$ & 30061 & 87485 & 89225 & 90080 & 87534 & 89166 & 90168 & $297 \%$ & $297 \%$ \\
\hline Average time in quese & $\mathrm{hr}$ & 50 & 1,285 & 28,122 & 31,795 & 1,61 & \begin{tabular}{|l|}
18,224 \\
\end{tabular} & 31,623 & $56 \%$ & $36 \%$ \\
\hline Average number of parts in queue & pcs. & 0,001 & 0,001 & 0,013 & 0,236 & 0,001 & \begin{tabular}{|l|}
0,014 \\
\end{tabular} & 0,279 & $1300 \%$ & $1400 \%$ \\
\hline Number of parts in queue total & pcs. & 5 & 1 & 10 & 190 & 1 & 13 & 226 & $200 \%$ & $260 \%$ \\
\hline AM parts out & pcs. & 87 & $67 \mid$ & 144 & 431 & 67 & 144 & 430 & $166 \%$ & $166 \%$ \\
\hline
\end{tabular}

From the previous results, the two-machine setup exhibited significantly higher total number of parts out and system utilization compared to the one-machine setup. Therefore, it would appear logical that a three-machine setup would further improve the system efficiency. However, from Table 7-4 the three-machine setup did not achieve any performance gain compared to the twomachine setup. The overall queuing is slightly reduced, but parts still has to wait in queue if two parts of the same material arrive in a row between short intervals. Therefore, with the current part set design the three-machine setup can be essentially treated as a scaled-up version of the twomachine setup. It can be reasonably concluded that the same observation can be made for four- or more-machine setups with the same part set design. 
When the waiting mode was applied to the system, the upper limit is reduced slightly. However, a nearly identical system performance was observed for the three-machine strategy. On the other hand, the queuing situation for the no waiting mode is favorable.
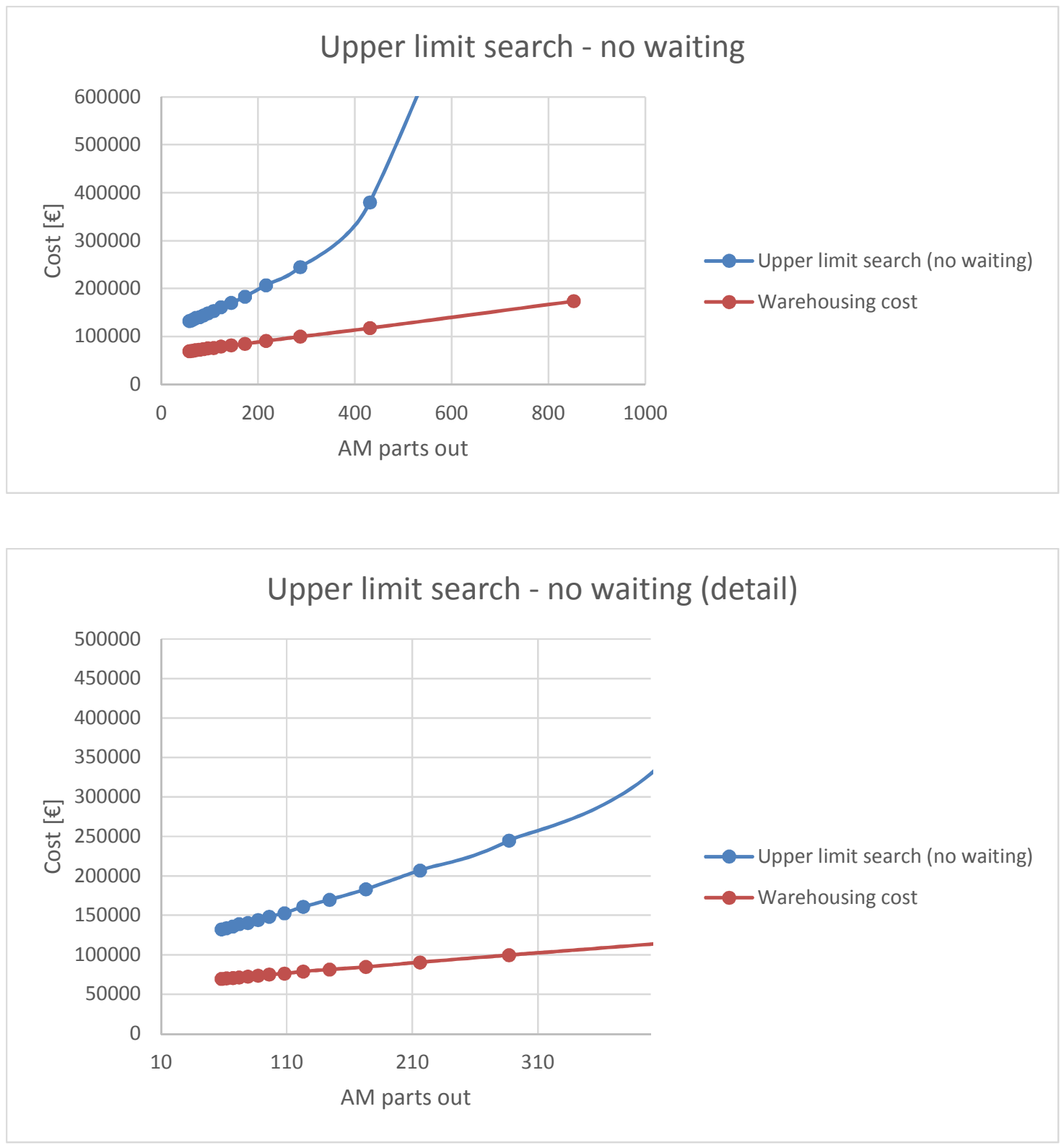

Figure 7-24: Three machines with fixed material - Upper limit search - No waiting 

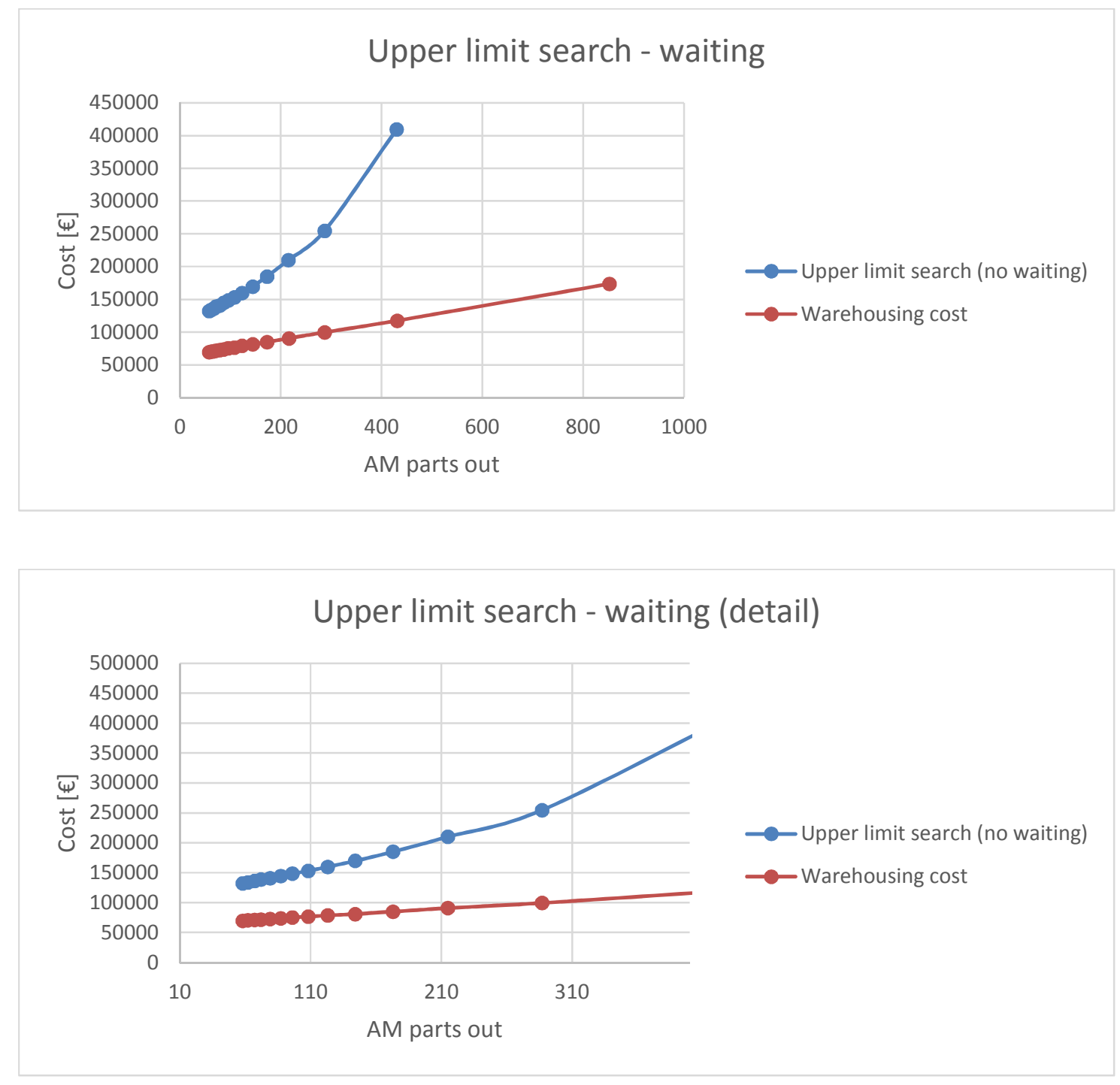

Figure 7-25: Three machines with fixed material - Upper limit search - Waiting 


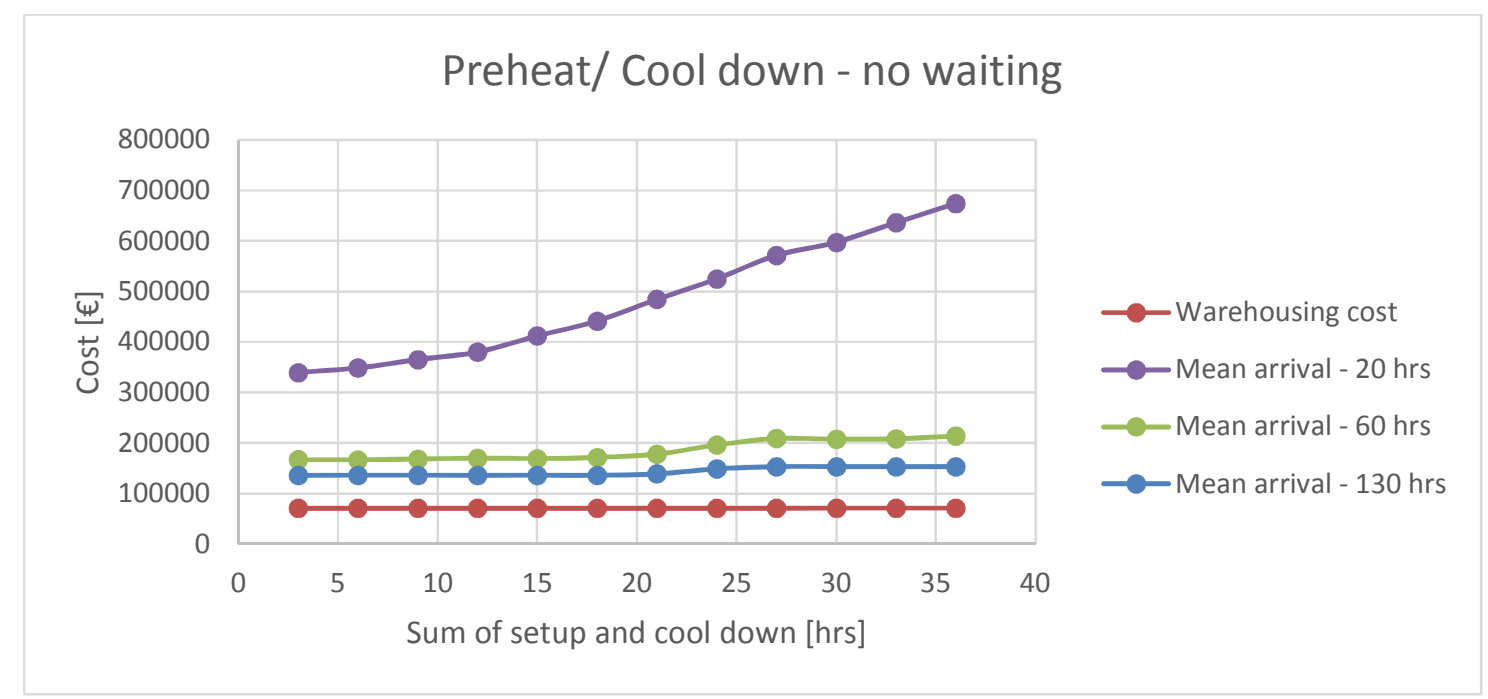

Figure 7-26: Three machines with fixed material - Preheat and cool down - No waiting

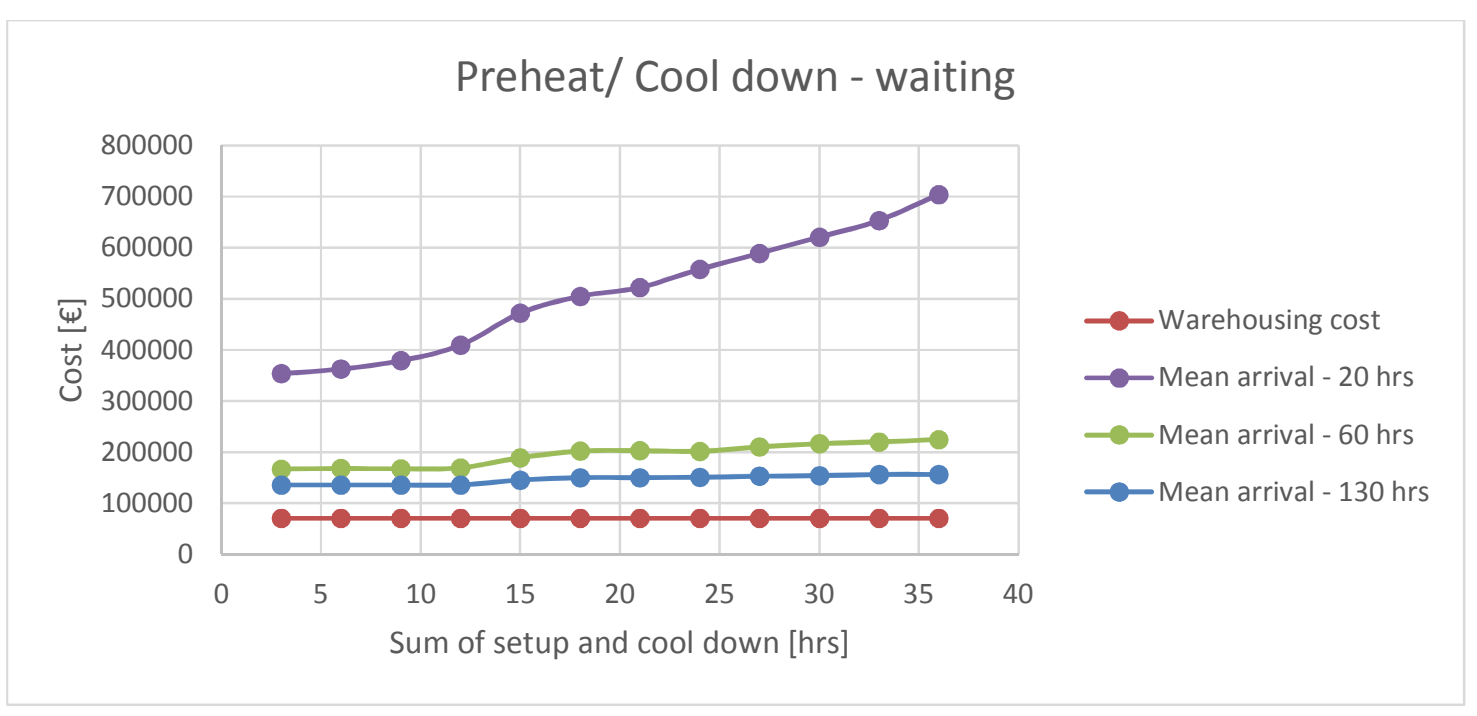

Figure 7-27: Three machines with fixed material - Preheat and cool down - Waiting

The influence of preheat and cool down is similar to the two-machine with fixed material assignment strategy. The no-waiting mode performed better compared to the waiting mode, and the start volume and elapse time variation show almost identical characteristics to the twomachine setups, which again could be readily explained by treating the three-machine system as a scaled-up two-machine system. 


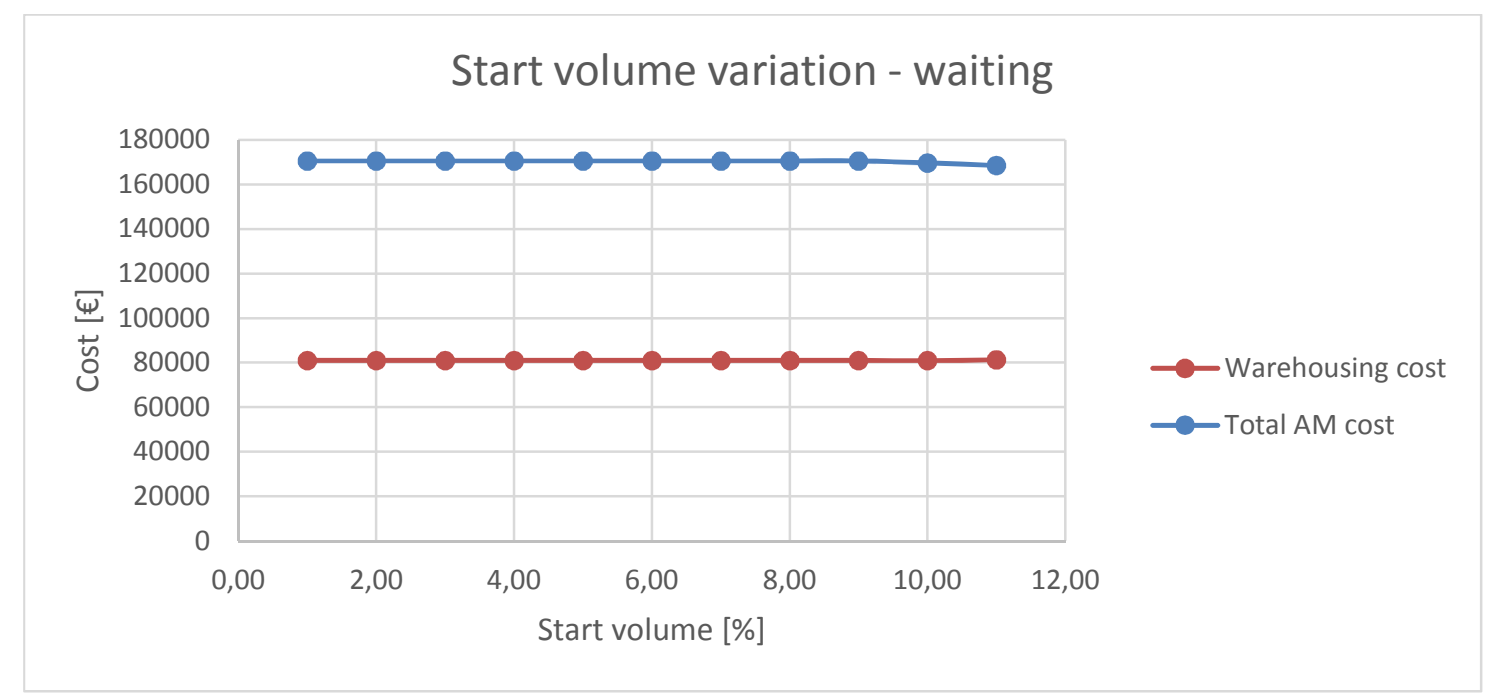

Figure 7-28: Three machines with fixed material - Start volume - Waiting

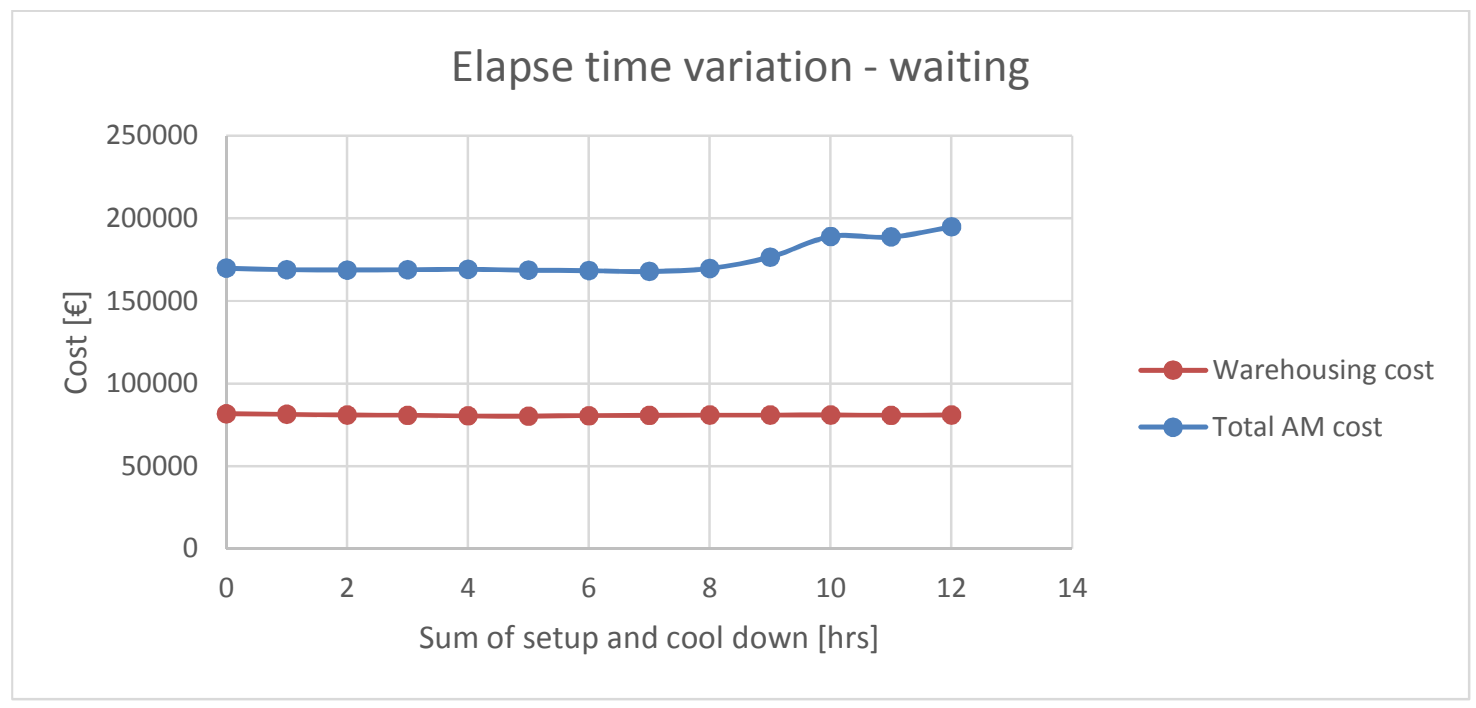

Figure 7-29: Three machines with fixed material - Elapse time - Waiting 


\subsection{THREE MACHINES WITH FLEXIBEL MATERIAL ASSIGNMENT}

The three-machine with flexible material assignment strategy was modeled similarly to the twomachine with flexible material strategy, with the only difference being the number of material types. System performance with respect to the upper limit, setup and cool down time, elapse time, start volume and material changeover time were investigated.

\subsubsection{MODEL ADJUSTMENT}

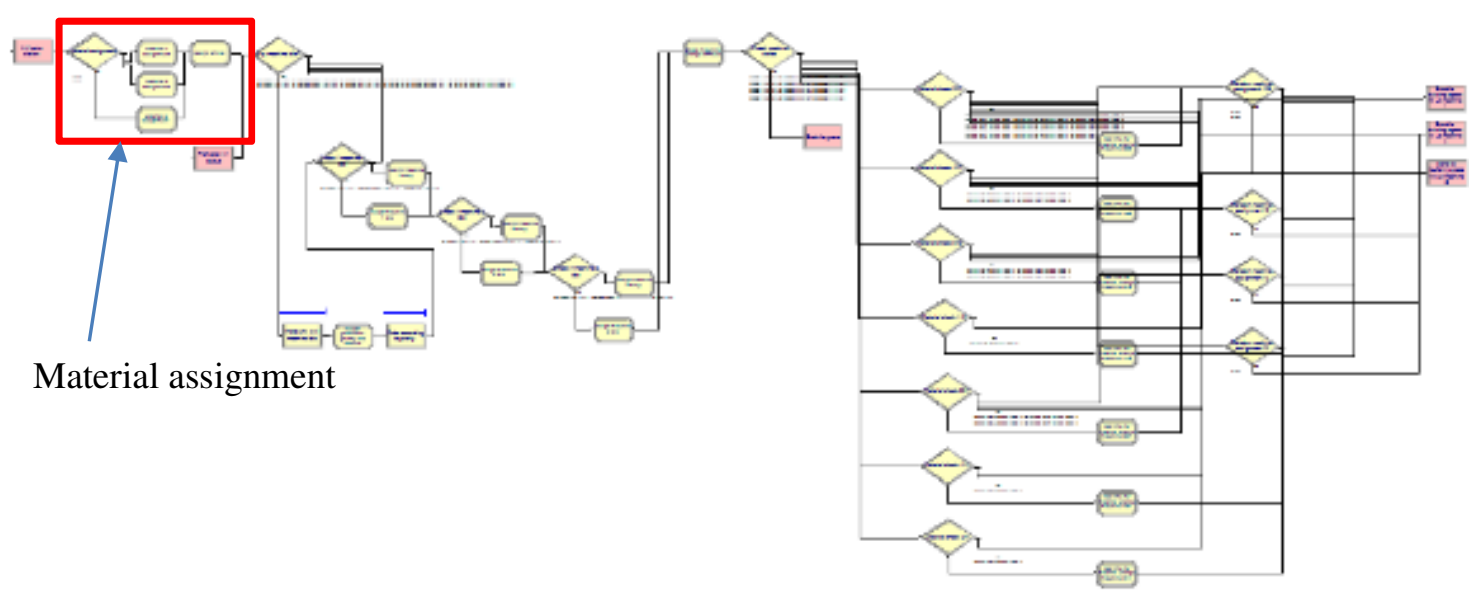

Figure 7-30: Adjusted AM route arrival and queueing logic

The model for three-machine with flexible material is a further expansion of the two-machine with flexible material model with a third machine added. Changes of the setup were made in the AM route and queueing logic. Similar to the two-machine with flexible material setup, the material assignment starts with a decide module, which forwards the part request to three material type assign modules with a $33 \%$ chance each. 


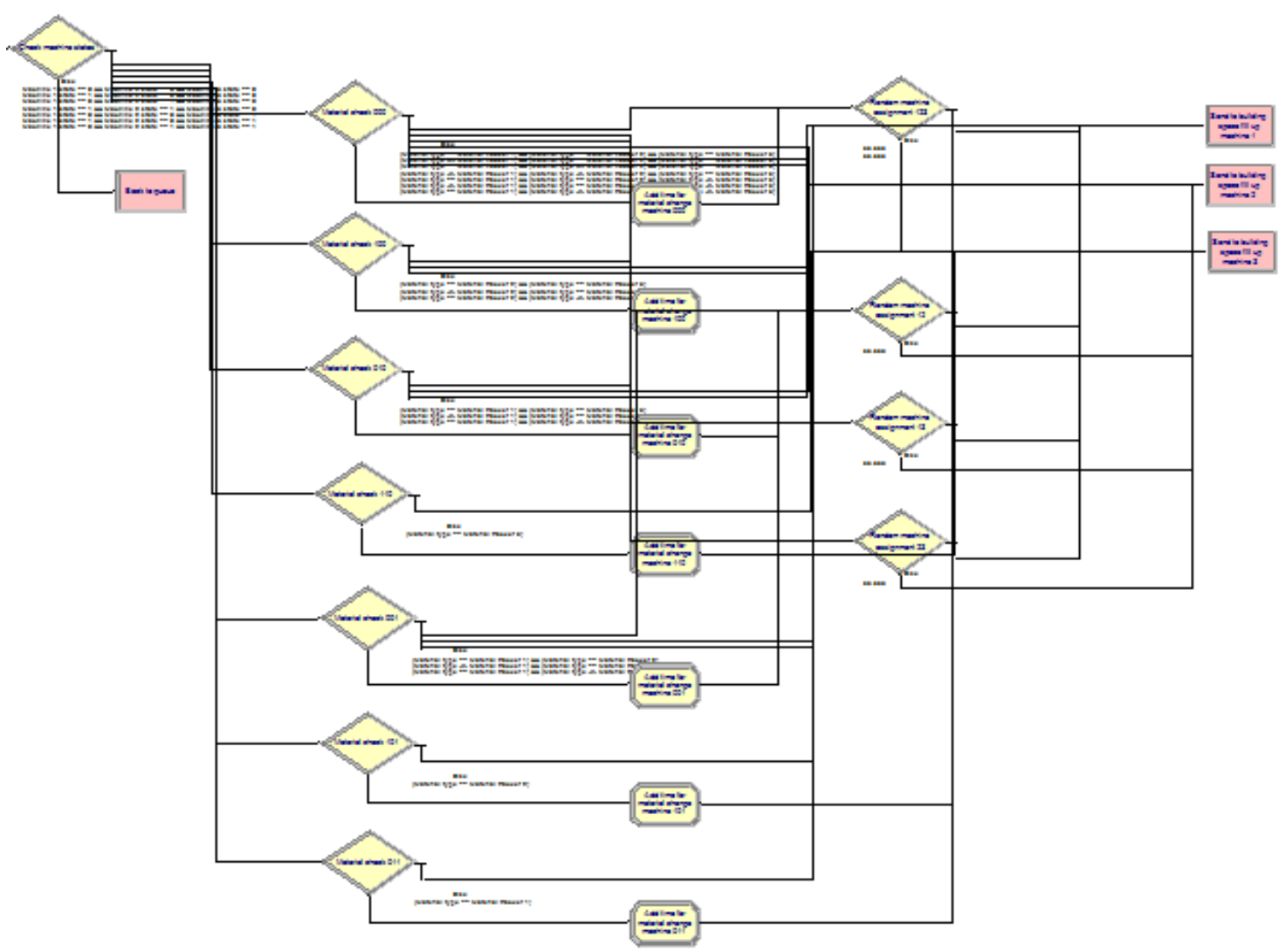

Figure 7-31: Machine assignment and material changeover logic - three machines

Similar to the two machine setup, machine assignment and material changeover setups were specified based on individual conditions of the machine status. Table 7-5 shows the overview of combinations and actions. After this step in the model an independent path is set up for each machine. 


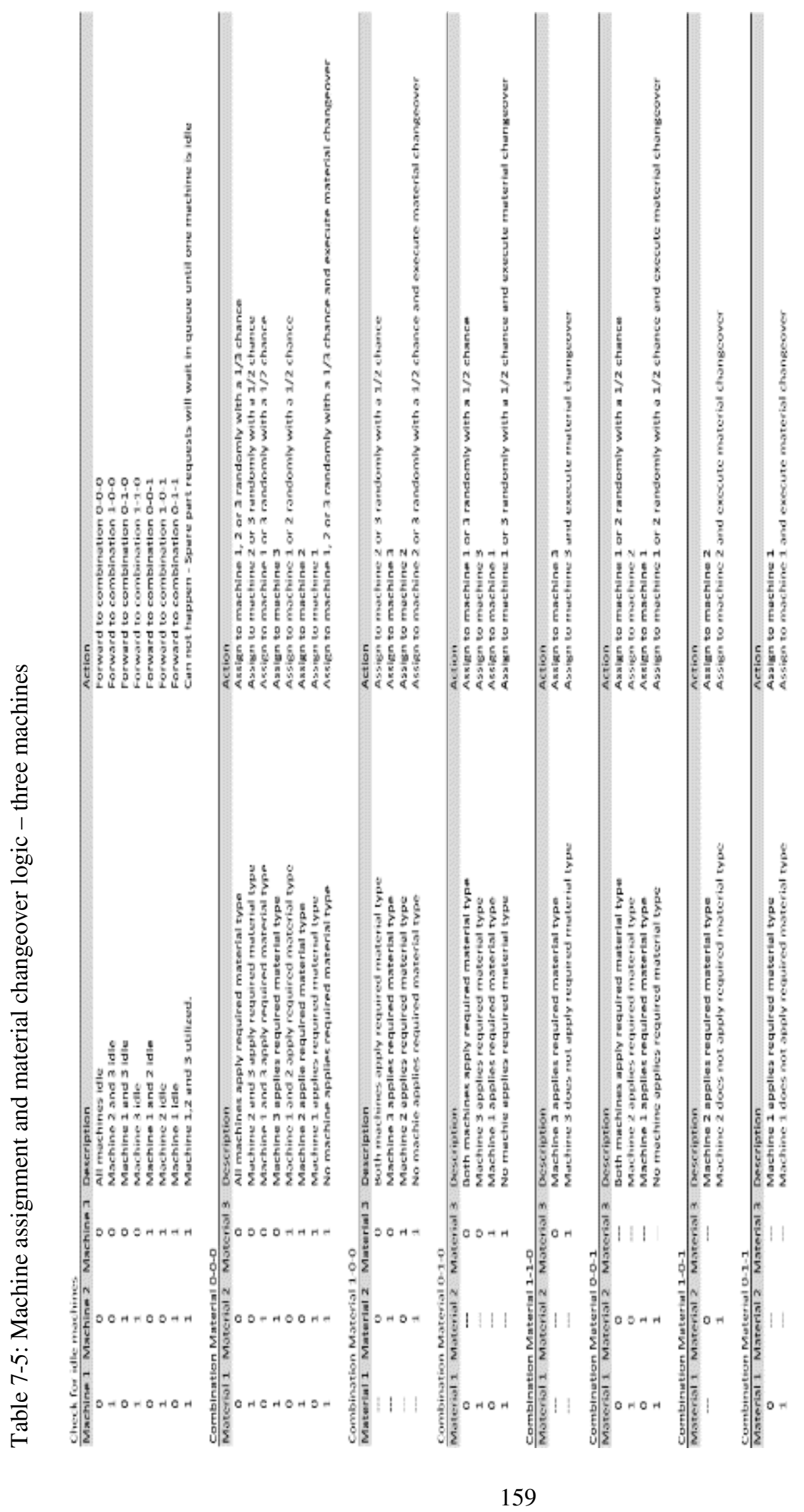




\subsubsection{RESULTS AND DISCUSSION}

The result of the upper limit search is presented in Table 7-6:

Table 7-6: Three machines with flexible material assignment - Upper limit No waiting/ Waiting

\begin{tabular}{|c|c|c|c|c|c|c|c|c|c|c|}
\hline \multirow[b]{3}{*}{ Control } & & \multirow{3}{*}{\begin{tabular}{|c|} 
Base case \\
\\
Upper \\
limit \\
\end{tabular}} & \multicolumn{6}{|c|}{ Three machines with flex ble material assignment } & \multirow{2}{*}{\multicolumn{2}{|c|}{$\begin{array}{c}\text { Upper limit - } \\
\text { changes compared } \\
\text { to base case [\%] }\end{array}$}} \\
\hline & & & \multicolumn{3}{|c|}{$\begin{array}{l}\text { Mean arrival } \\
\text { No waiting }\end{array}$} & \multicolumn{3}{|c|}{$\begin{array}{l}\text { Mean arrival } \\
\text { Waiting }\end{array}$} & & \\
\hline & & & $\begin{array}{l}\text { Low } \\
\text { arival } \\
\text { rate } \\
\end{array}$ & $\begin{array}{l}\text { Upper } \\
\text { Iimit }\end{array}$ & \begin{tabular}{|l} 
High \\
arival \\
rate \\
\end{tabular} & $\begin{array}{l}\text { Low } \\
\text { arinal } \\
\text { rate } \\
\end{array}$ & $\begin{array}{l}\text { Upper } \\
\text { Iimit }\end{array}$ & \begin{tabular}{|l} 
High \\
arrival \\
rate \\
\end{tabular} & $\begin{array}{l}\text { No } \\
\text { waiting }\end{array}$ & Waiting \\
\hline Mean arrival & $\mathrm{hr}$ & 100 & 40 & 20 & 10 & 100 & 60 & 20 & $20 \%$ & $60 \%$ \\
\hline \multicolumn{11}{|l|}{ Cost related responses } \\
\hline Total warehousing cost & $\hat{\epsilon}$ & 55436 & 90275 & 117594 & 174999 & 74119 & 81248 & 118375 & $212 \%$ & $147 \%$ \\
\hline Total AM cost & $\varepsilon$ & 73494 & 190719 & 274890 & 2471954 & 145352 & 169015 & 313436 & $374 \%$ & $230 \%$ \\
\hline Consumed material cost & $€$ & 22030 & 52633 & 103858 & 164495 & 20851 & 34054 & 102195 & $471 \%$ & $155 \%$ \\
\hline Consumed energy cost & $€$ & 4210 & 10057 & 19845 & 31432 & 3984 & 6507 & 19527 & $471 \%$ & $155 \%$ \\
\hline Operator cost & $\varepsilon$ & 4336 & 10775 & 21550 & 33762 & 4318 & 7186 & 21538 & $497 \%$ & $166 \%$ \\
\hline Total maintenance cost & $\varepsilon$ & 29407 & 87814 & 88351 & 88448 & 86368 & 87356 & 88349 & $300 \%$ & $297 \%$ \\
\hline Total AM penalty & E & 3708 & 166 & 11833 & 2124333 & 1041 & 4791 & 52375 & $319 \%$ & $129 \%$ \\
\hline \multicolumn{11}{|l|}{ AM process related responses } \\
\hline Consumed material & $\mathrm{kg}$ & 275 & 657 & 1298 & 2056 & 260 & 425 & 1277 & $472 \%$ & $155 \%$ \\
\hline Consumed energy & kWh & 70160 & 167623 & 330758 & 523870 & 66404 & 108452 & 325464 & $471 \%$ & $155 \%$ \\
\hline System setup time & $\%$ & 8 & 8 & 18 & 30 & 3 & 5 & 18 & $224 \%$ & $65 \%$ \\
\hline System utilization time & $\%$ & 19 & 15 & 29 & 46 & 6 & 10 & 29 & $153 \%$ & $51 \%$ \\
\hline Systen cool down time & $\%$ & 8 & 7 & 13 & 21 & 3 & 5 & 13 & $167 \%$ & $56 \%$ \\
\hline Total system utilization & $\%$ & 35 & 29 & 60 & 97 & 12 & 19 & 60 & $173 \%$ & $55 \%$ \\
\hline Average building volume & $\mathrm{mm}^{2}$ & 404530 & 391011 & 386009 & 390217 & 386701 & 378199 & 379486 & $95 \%$ & $93 \%$ \\
\hline Machine depreciation & 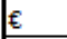 & 30061 & 89766 & 90315 & 90413 & 88287 & 89298 & 90313 & $300 \%$ & $297 \%$ \\
\hline Averagetime in queue & $\mathrm{hr}$ & 50 & - & 10,62 & 12,45 & 0 & 0 & 10,744 & $21 \%$ & $0 \%$ \\
\hline Average number of parts in queue & pcs. & 0,001 & 0,001 & 0,094 & 8,806 & 0 & 0 & 0,139 & $9400 \%$ & $0 \%$ \\
\hline Number of parts in queue total & pcs. & 5 & 0 & 73 & 58618 & 0 & 0 & 108 & $1469 \%$ & $0 \%$ \\
\hline AM parts out & pcs. & 87 & 216 & 431 & 675 & 86 & 144 & 431 & $495 \%$ & $166 \%$ \\
\hline
\end{tabular}

When compared to the base case, the three-machine setup appears to bring about further

improvements. The maximum parts out exhibited an approximately $400 \%$ increase with the mean arrival rate of 20 hours. Also, the possible total system utilization increased by almost $73 \%$. The high system utilization is due to the fact that each machine can start production at arrival of a spare part request. No unnecessary idle times, as in the fixed material setups, must be compensated by the system. On the other hand, when the waiting mode is applied to the system, the upper limit is significantly reduced to a level similar to the two-machine setup with the same waiting mode. In addition, the total system utilization was even further lowered compared to the two-machine setup. 

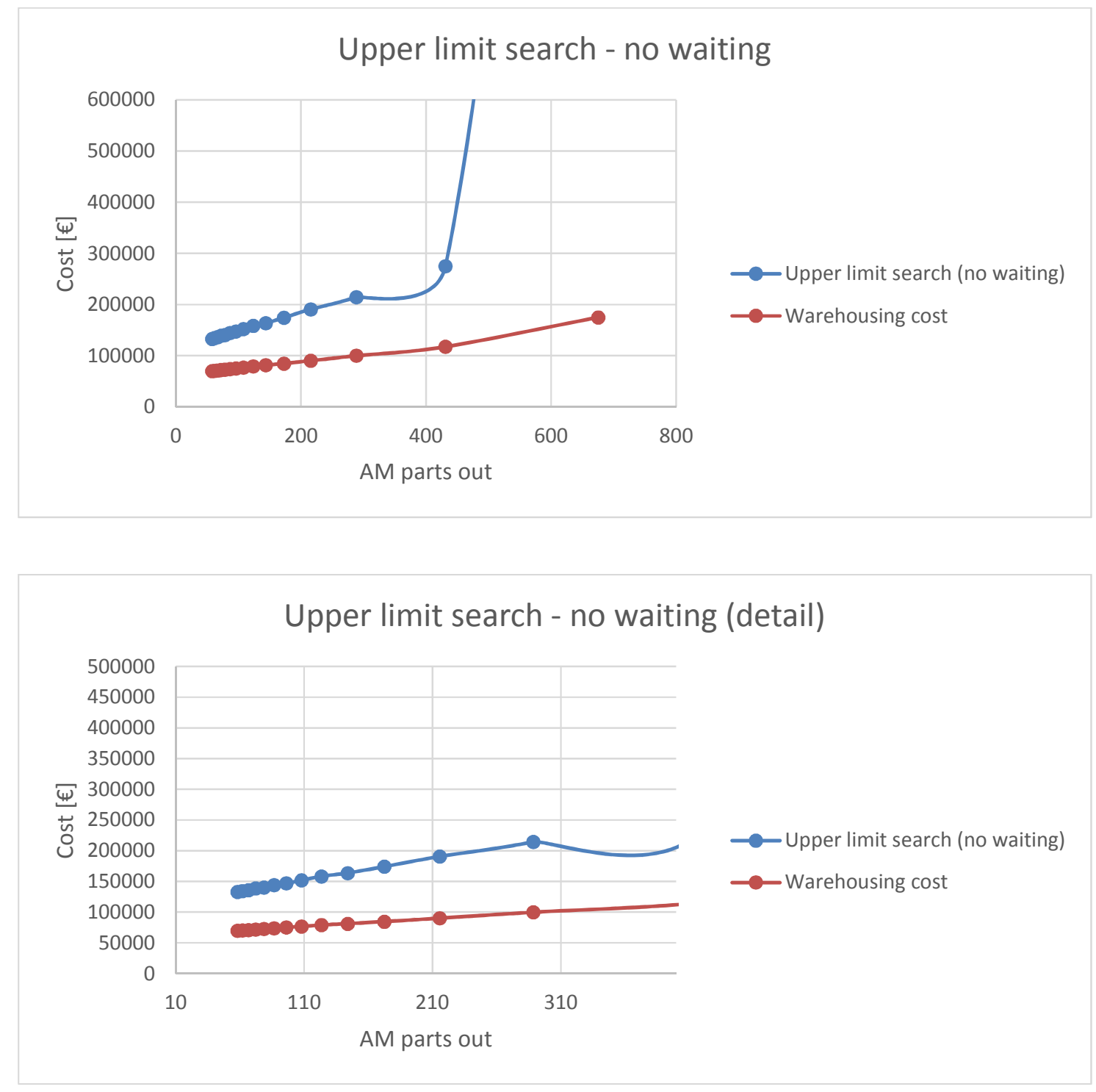

Figure 7-32: Three machines with flexible material - Upper limit search - No waiting 


\section{Upper limit search - waiting}
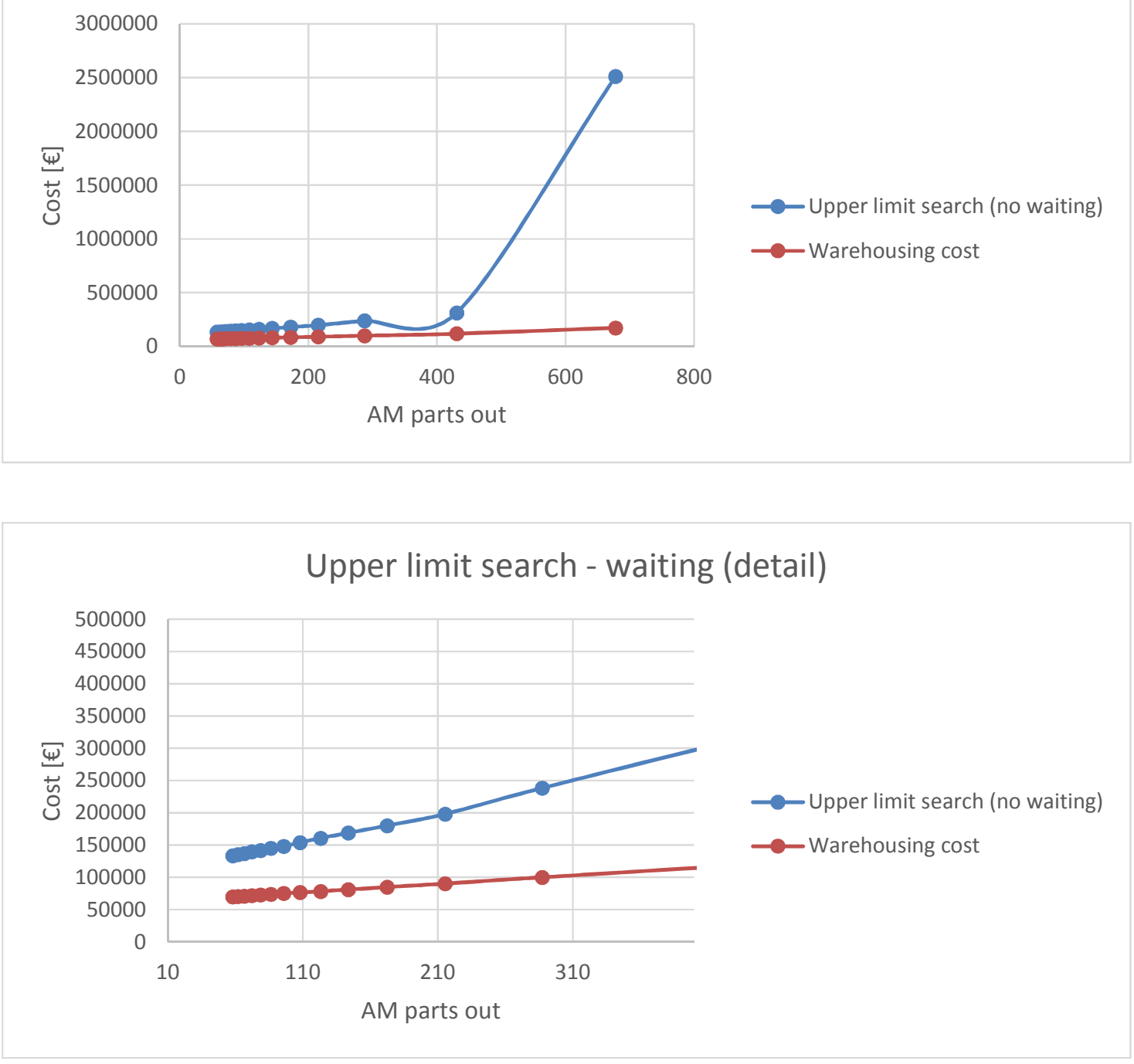

Figure 7-33: Three machines with flexible material - Upper limit search - Waiting

The influences of material changeover, preheat and cool down are similar to the two-machine with fixed material assignment strategy. Again, the no-waiting mode significantly more efficient compared to the waiting mode. The start volume and elapse time variation still show identical characteristics compared to the fixed material setup. On the other hand, the effect of preheat and cool down time on the total system cost exhibited a different pattern as shown in Figure 7-36. 
When the sum of preheat and cool down time exceeds a certain level (approx. $24 \mathrm{hrs)} \mathrm{the} \mathrm{total}$ AM cost decreases. This result is seemingly counterintuitive and is actually artificial effects due to the modelling. Cost related factors are updated when a part leaves the system. In other words, the more parts leave the system, the more cost and/ or penalties are charged. As a result, when preheat and cool down time becomes significantly elongated, the number of parts leaving the system will be largely controlled by this time delay, which contributed to the reduction of the AM costs over the fixed period of time. Therefore, after taking the artificial effects into account, the system output is actually expected to exhibit decrease due to the increasing overall process time.

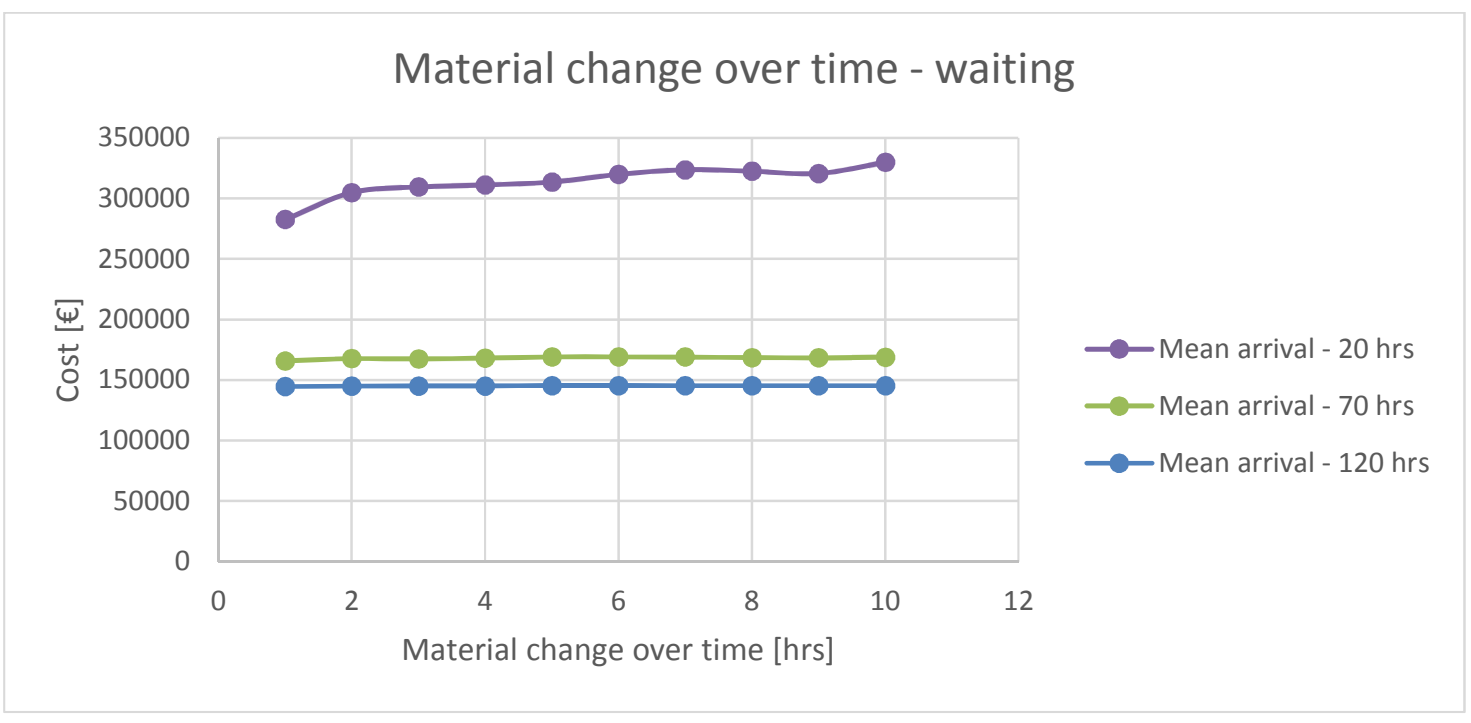

Figure 7-34: Three machines with flexible material - Material change over time - Waiting 


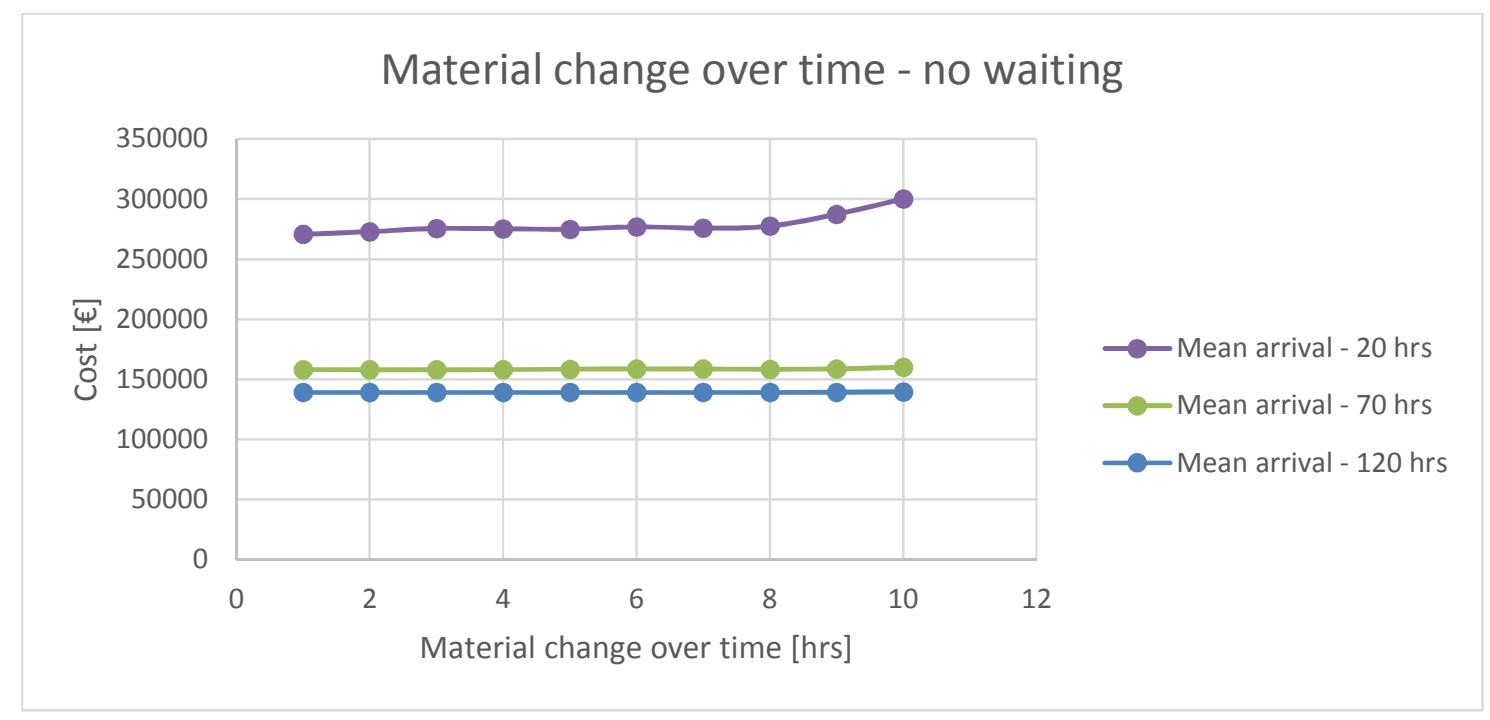

Figure 7-35: Three machines with flexible material - Start volume - No waiting

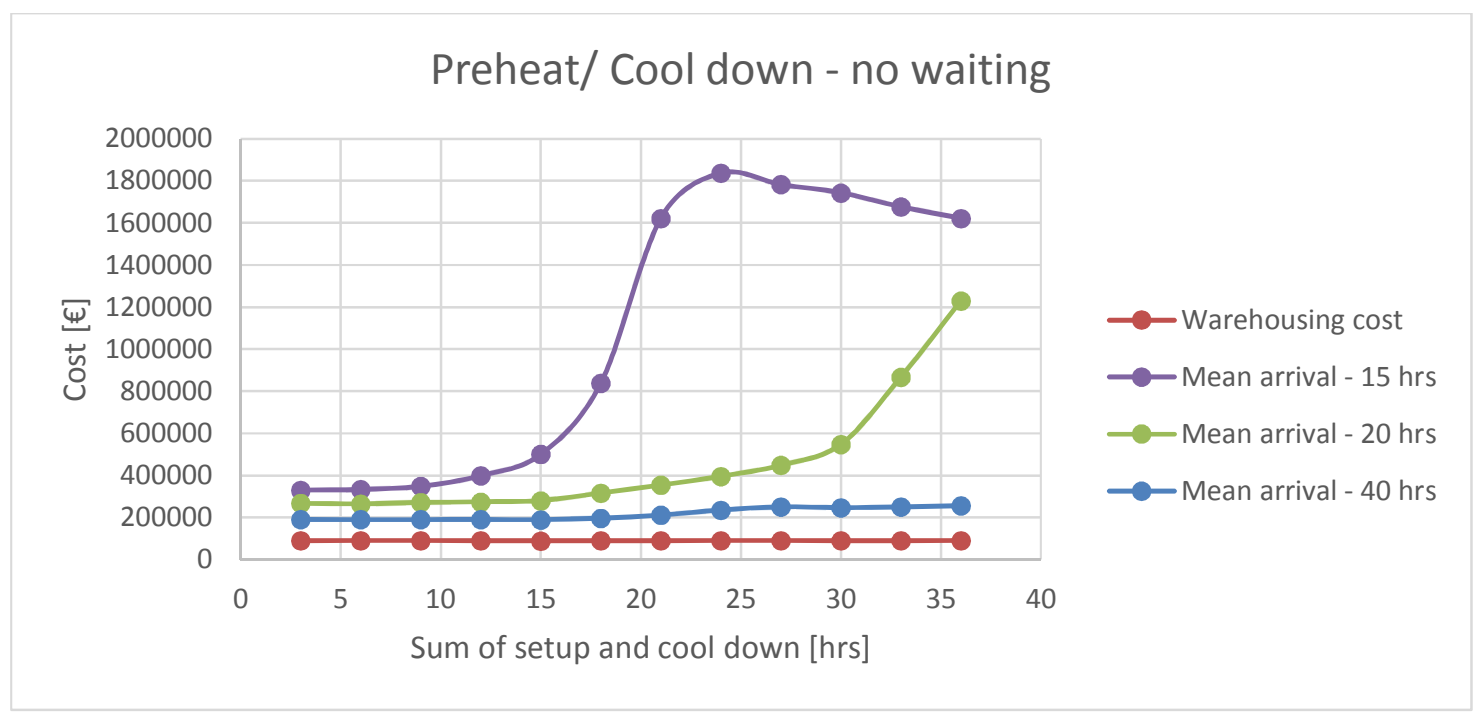

Figure 7-36: Three machines with flexible material - Preheat and cool down - No waiting 


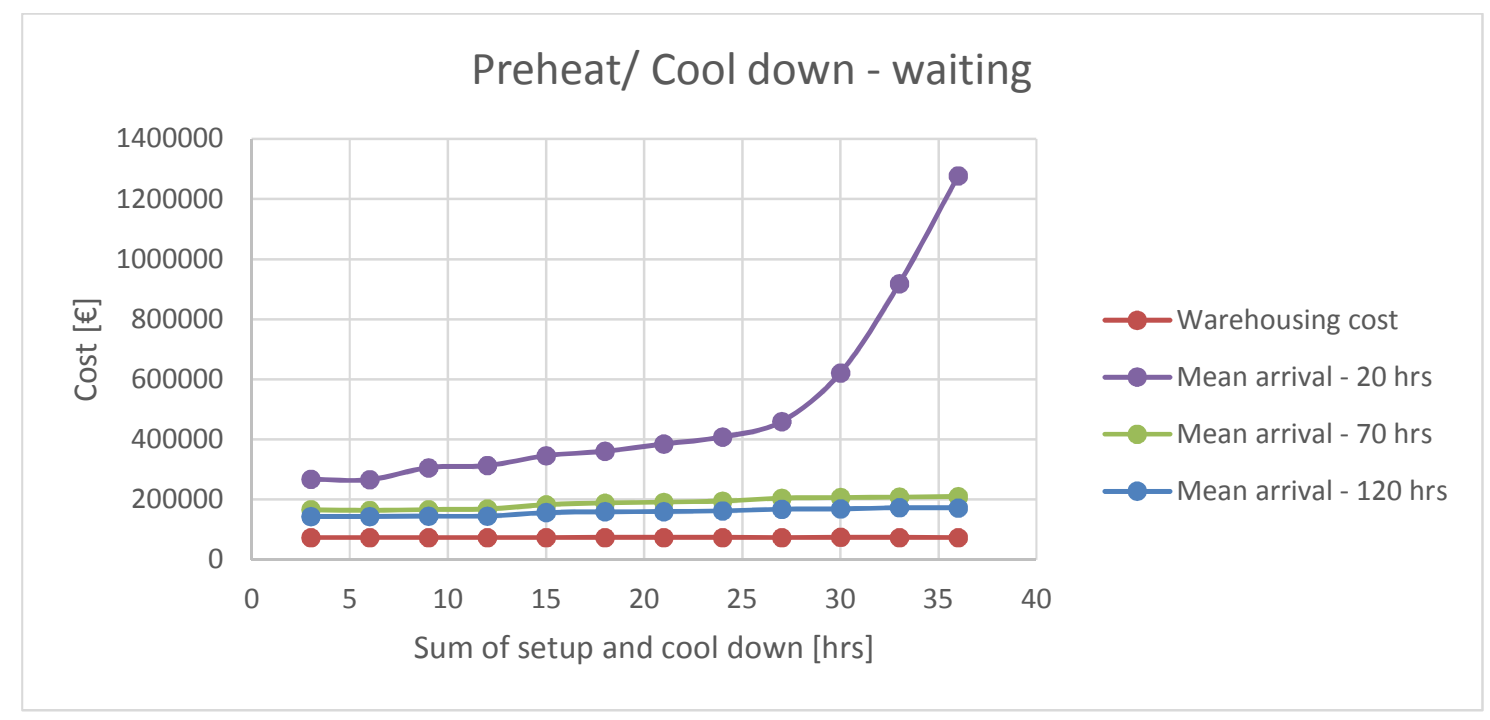

Figure 7-37: Three machines with flexible material - Preheat and cool down - Waiting

The start volume variation and elapse time shows the same properties like in the two machines with flexible material experiment.

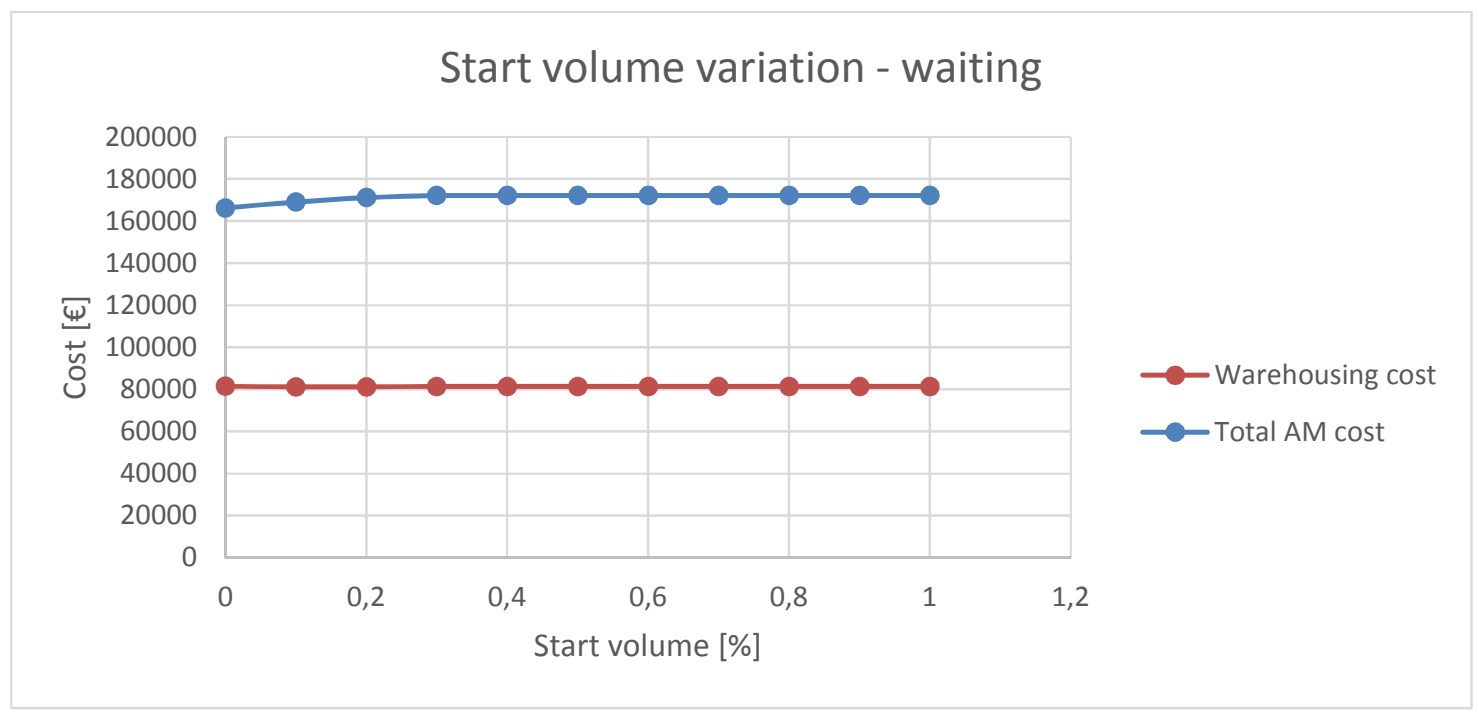

Figure 7-38: Three machines with flexible material - Start volume - Waiting 


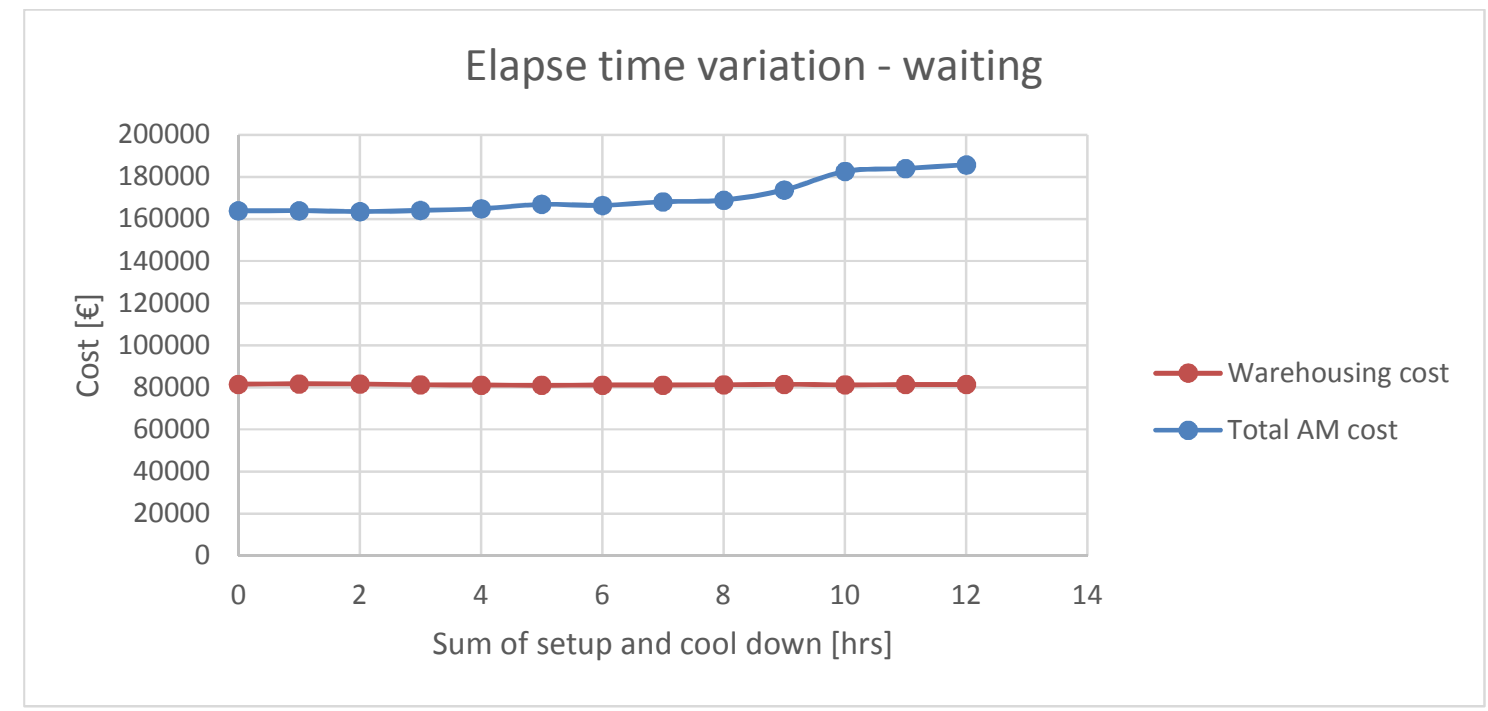

Figure 7-39: Three machines with flexible material - Elapse time - Waiting 


\subsection{PART SIZE DISTRIBUTION}

The part size distribution setups are based on the two-machine system with flexible material assignment strategy with the part size distribution being the only variable. In this experiment the spare parts requests require only one material in order to focus the investigation on the part size effects. Several distributions of part sizes such big parts only or an equally distributed mix of small, mid and big parts were analyzed. The setup were also simulated in both a waiting and no waiting mode.

\subsubsection{MODEL ADJUSTMENT}

The part size simulation model was created based on the two-machine with flexible material setup. The main changes were made in the AM rout arrival and queuing logic.

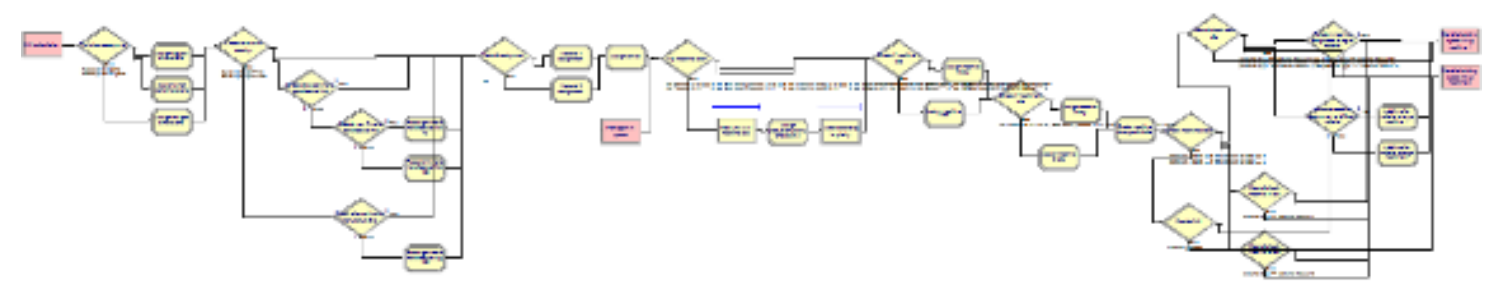

Figure 7-40: Adjusted AM rout arrival and queueing logic

Firstly, the spare part sizes attributes were re-defined (see Figure 7-41). The original spare part set consisted of $75 \%$ small, $20 \%$ medium size and $5 \%$ big parts, which were modified for this study. Three new variables "Reassign small parts", "Reassign mid parts" and "Reassign big parts" were introduced. The values represent the percentage of the occurring spare part size on random basis, with the only restriction that the sum of those three needed to equal 100 . The variables were then used in a decide module to control the assignment of the spare part size. 


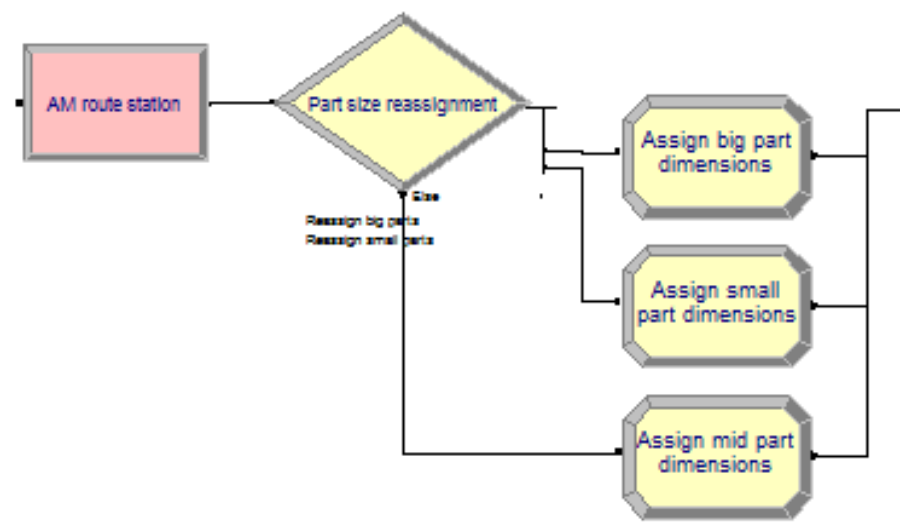

Figure 7-41: New part size assignment

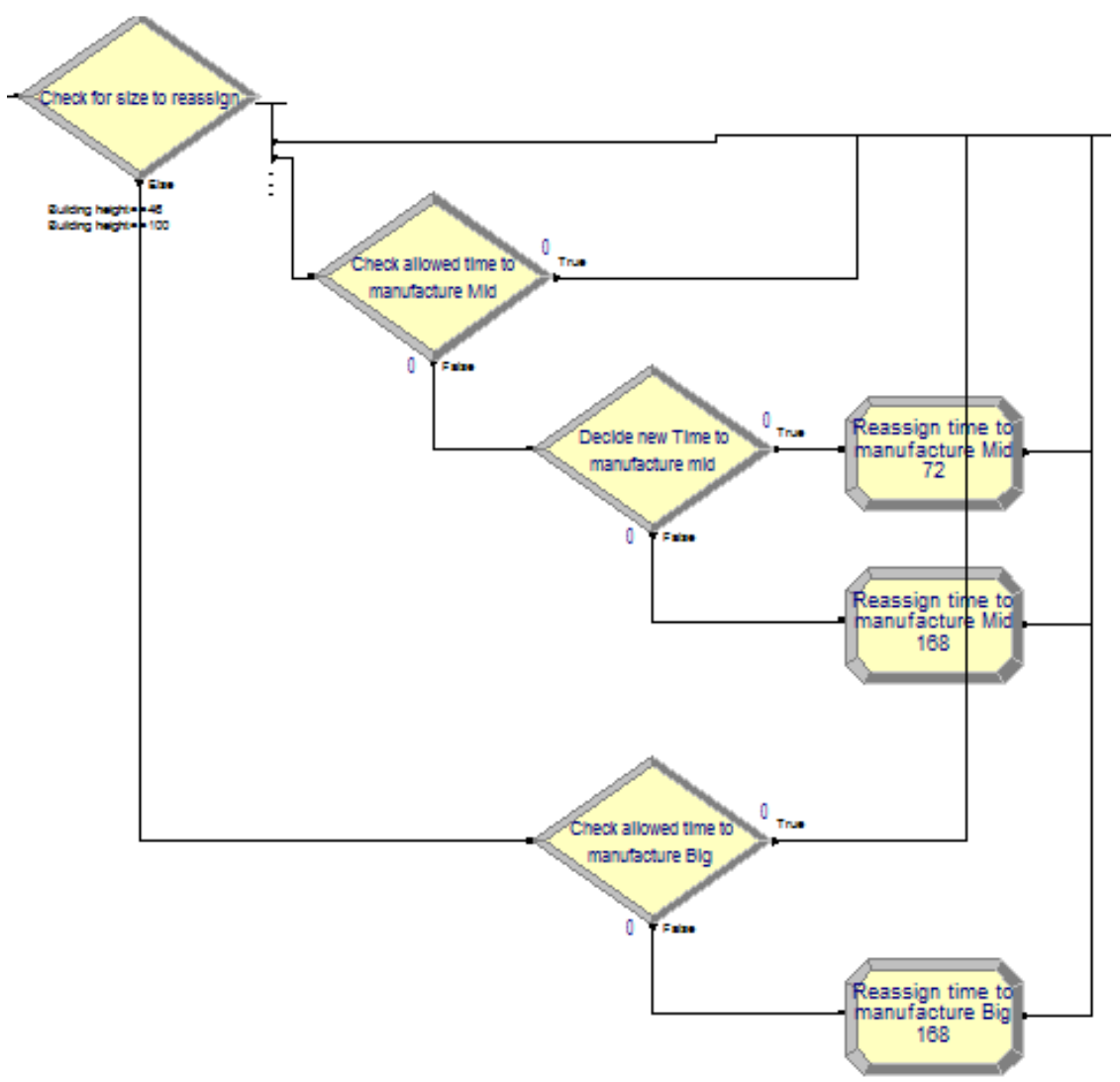

Figure 7-42: Check for allowed time to manufacture 
Due to the part size reassignment it is necessary to recheck the allowed time to manufacture. For example a big part cannot be produced in the originally defined allowance time which was $46 \mathrm{hrs}$.

First, the reassigned part size was checked to ensure that it meets the following criteria:

- Small parts work with all times to manufacture.

- Medium size parts work with medium time to manufacture and long time to manufacture.

- Big parts work with the long time to manufacture only.

The parts will follow a specific path according to part size which works according to the following logics:

- Small parts are simply forwarded to the next material assignment section.

- Medium size parts are assigned with medium or long allowance time (50/50 chance)

- Large size parts are assigned with long allowed time to manufacture.

After that the parts are sent to the material assignment. The rest of the model is identical to the two-machines with flexible material setup.

\subsubsection{PROCEEDING}

The percentages of big, medium and small parts were varied at several levels. These variations allow for multiple combinations. In order to limit the simulations to only the most representative setups, combinations with extreme settings were selected for simulations as listed in Table 7-7. For the purpose of comparison, the basic setup was included as the baseline reference. 
Table 7-7: Selected variations of part size distributions

\begin{tabular}{|l|c|c|c|}
\cline { 2 - 4 } \multicolumn{1}{c|}{} & \multicolumn{3}{c|}{ Selected spare part size setups } \\
\cline { 2 - 4 } \multicolumn{1}{c|}{} & Big & Mid & Small \\
\cline { 2 - 4 } \multicolumn{1}{c|}{} & $\%$ & $\%$ & $\%$ \\
\hline Case 1 & 5 & 20 & 75 \\
\hline Case 2 & 33 & 33 & 33 \\
\hline Case 3 & 50 & 50 & 0 \\
\hline Case 4 & 50 & 0 & 50 \\
\hline Case 5 & 100 & 0 & 0 \\
\hline Case 6 & 0 & 50 & 50 \\
\hline Case 7 & 0 & 100 & 0 \\
\hline Case 8 & 0 & 0 & 100 \\
\hline
\end{tabular}

The applied tool for calculation is the integrated process analyzer of Arena.

Following simulations will run in the no waiting and waiting mode:

- Upper limit search 


\subsubsection{RESULTS AND DISCUSSION}

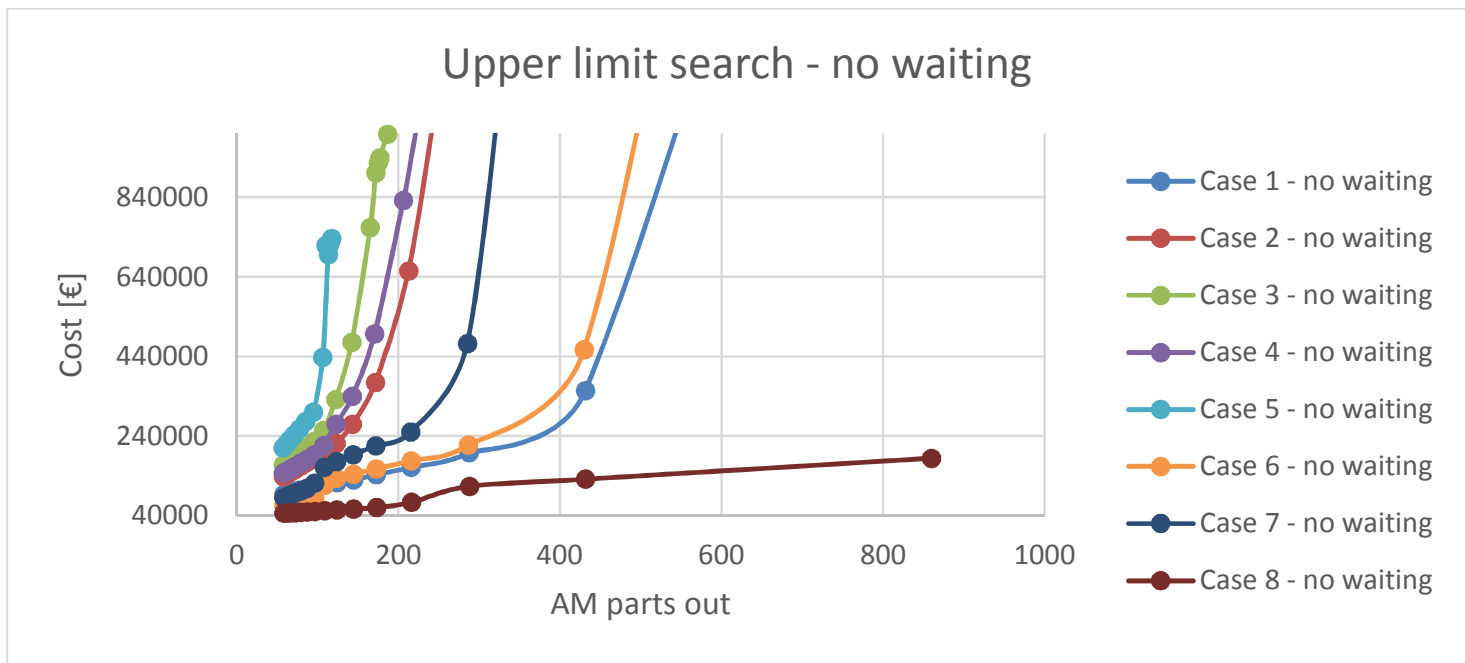

Figure 7-43: Results of part size simulations - Upper limit - No waiting

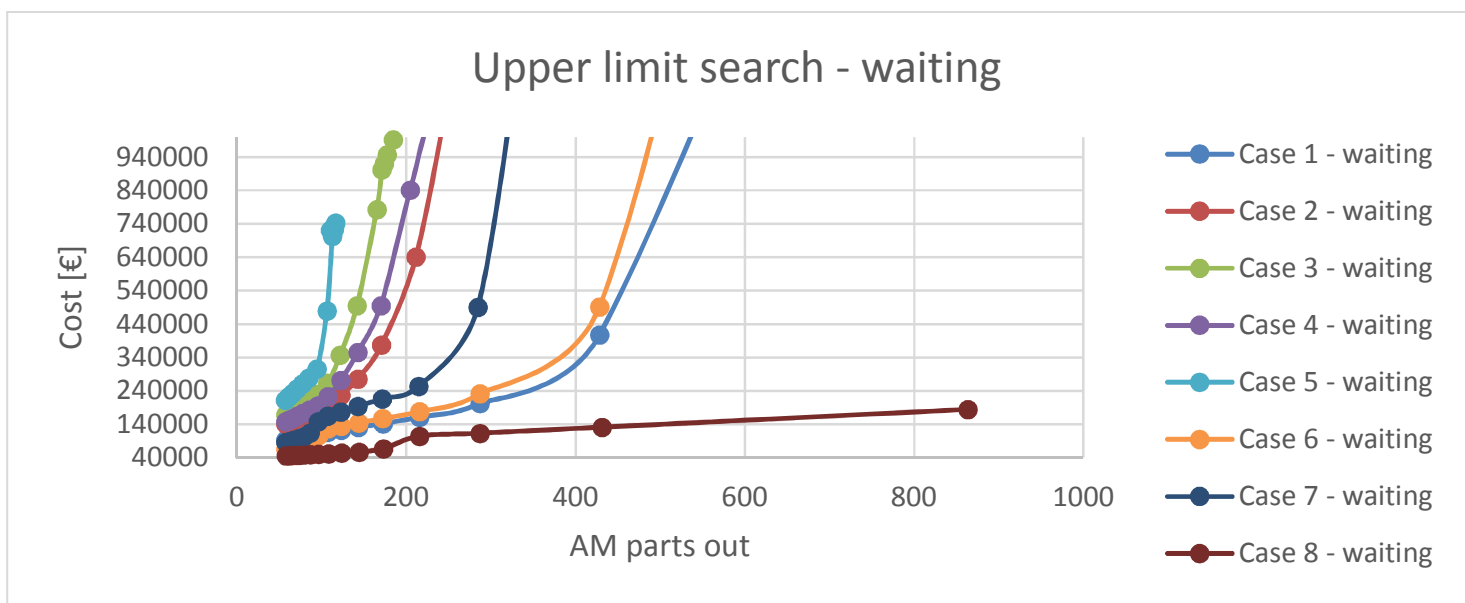

Figure 7-44: Results of part size simulations - Upper limit - Waiting

Figure 7-43 and Figure 7-44 show the results of the upper limit search for each setup in the waiting and no-waiting mode. The cases show a clear trend. The smaller the average size of the requested spare parts, the better the system can react to arriving spare part requests. This seems logical since producing small parts allows to produce more parts in the same time frame. 
Table 7-8: Upper limit results of spare part size variation - No waiting and waiting

\begin{tabular}{l}
\cline { 3 - 10 } \\
\cline { 3 - 11 } \\
\cline { 3 - 11 }
\end{tabular}

\begin{tabular}{|c|c|c|c|c|c|c|c|c|c|}
\hline \multirow[b]{3}{*}{ Control } & & \multicolumn{8}{|c|}{ Part sizevariation } \\
\hline & & \multicolumn{8}{|c|}{ Mean arrival- Waiting } \\
\hline & & Case1 & Cæe2 & Case 3 & Case 4 & Case 5 & Case 6 & Case 7 & Case 8 \\
\hline Mean arrival & $\mathrm{hr}$ & 40 & 80 & 90 & 90 & 100 & 40 & 40 & 7 \\
\hline Big parts & $\%$ & 5 & 33 & 50 & 50 & 100 & 0 & 0 & 0 \\
\hline Medium parts & $\%$ & 20 & 33 & 50 & 0 & 0 & 50 & 100 & 0 \\
\hline Small parts & $\%$ & 75 & 33 & 0 & 50 & 0 & 50 & 0 & 100 \\
\hline \multicolumn{10}{|l|}{ Cost related responses } \\
\hline Total warehousing cost & $E$ & 90648 & 76489 & 74836 & 75039 & 73685 & 90860 & 90886 & 219627 \\
\hline Total AM cost & $€$ & 161905 & 198649 & 230666 & 195556 & 279998 & 178438 & 254449 & 233128 \\
\hline Consumed material cost & $\varepsilon$ & 57149 & 92622 & 121559 & 92866 & 163182 & 74156 & 134988 & 75166 \\
\hline Consumed energy cost & $€$ & 10920 & 17698 & 23227 & 17745 & 31181 & 14170 & 25794 & 14363 \\
\hline Operator cost & $€$ & 10783 & 5373 & 4765 & 4784 & 4261 & 10780 & 10747 & 61484 \\
\hline Total maintenance cost & $\varepsilon$ & 58758 & 58497 & 58429 & 58433 & 58498 & 58841 & 58907 & 59085 \\
\hline Total AM penalty & $\varepsilon$ & 4708 & 4958 & 3208 & 2250 & 3375 & 875 & 4375 & 3333 \\
\hline \multicolumn{10}{|l|}{ AM process related responses } \\
\hline Consumed material & $\mathrm{kg}$ & 714 & 1157 & 1519 & 1160 & 2039 & 926 & 1687 & 939 \\
\hline Consumed energy & kWh & 182003 & 294975 & 387131 & 295752 & 519688 & 236167 & 429900 & 239384 \\
\hline System setup time & $\%$ & 10 & 5 & 5 & 5 & 4 & 10 & 10 & 30 \\
\hline System utilization time & $\%$ & 24 & 39 & 52 & 39 & 69 & 31 & 57 & 32 \\
\hline Systen cool down time & $\%$ & 10 & 5 & 4 & 4 & 4 & 10 & 10 & 29 \\
\hline Total system utilization & $\%$ & 44 & 50 & 61 & 49 & 77 & 52 & 77 & 91 \\
\hline Average building volume & $\mathrm{mm}^{2}$ & 423489 & 1378738 & 2033402 & 1550195 & 3048625 & 548455 & 1000000 & 97336 \\
\hline Machine depreciation & $€$ & 60064 & 59797 & 59728 & 59731 & 59798 & 60149 & 60217 & 60398 \\
\hline Average time in queue & $\mathrm{hr}$ & 19,772 & 8,853 & 4,405 & 3,125 & - & 3,968 & 4,591 & 6,974 \\
\hline Average number of parts in queue & pcs. & 0,031 & 0,009 & 0,001 & 0,001 & 0 & 0,004 & 0,015 & 0,822 \\
\hline Number of parts in queue total & pcs. & 13 & 8 & 2 & 2 & 0 & 8 & 28 & 1017 \\
\hline AM parts out & pcs. & 216 & 107 & 95 & 96 & 85 & 216 & 215 & 1230 \\
\hline
\end{tabular}


Even if this is an important finding it must be extenuated. The spare part size distribution has an effect on the system's performance. But if the system's overall performance is better than the required system performance there is no argument for limiting the spare part sizes to an unnecessarily small size. For example in case 7 - no waiting only medium size parts are produced and 95 spare parts can leave the system. When the actual system would require less parts to be delivered in this time the setup is sufficient to meet the demand.

Results also allow to conclude that a smaller the part size results in a higher machine utilization. For example small parts only allows for a system utilization of $94 \%$ at an upper limit of $8 \mathrm{hrs,}$ while big parts allow for a system utilization of $86 \%$ at an upper limit of $90 \mathrm{hrs}$. A mix of two types of spare parts strongly reduces the system performance. A 50/ 50 mix of small and big size spare parts reaches a $49 \%$ total system utilization at an upper limit of $90 \mathrm{hrs}$.

$90 \mathrm{hrs}$ is the upper limit for both, big parts only and the 50/50 mix of small and big parts, but the utilization is $49 \%$ instead $86 \%$ for the small and big size mix. To explain this gap it can be assumed that several big parts are requested in a row. Then the situation is equal to the big parts only case. In consequence, if penalties should be avoided, the system must be designed to handle big parts only. If again small parts arrive again the total system utilization must decrease, due to the fact that the total production time for small parts is shorter, while the system is designed for longer production times.

The effect is also recognizable when the upper limits of the other cases are taken into account. Small parts only have an upper limit of 8 hours, medium size parts have an upper limit of $40 \mathrm{hrs}$ and big parts only $100 \mathrm{hrs}$. If other part sizes are mixed in the upper limit of the bigger spare part type decreases only slightly. For example in case $175 \%$ of parts are small, $20 \%$ are medium size and $5 \%$ are big. The upper limit is at 40 hrs. Compared to the small only case with an upper limit of $8 \mathrm{hrs}$ the system performance decreased by the factor 5 . Further medium size parts are the 
second relevant group of requested spare parts and $40 \mathrm{hrs}$ is the upper limit of the medium parts only setup. Since a certain penalty is accepted it can be created by arriving big part requests. Also the system utilization decreased by approx. $50 \%$. It can be assumed that the biggest part type will influence the upper limit of a system most. The utilization will be a result of the produced amount of smaller parts. Consequently for a high utilization a uniform part size is advantageous.

The waiting setup decreases the system performance in most cases. But things change at the point where only small parts are produced. Table 7-8 shows that the waiting mode performs better than the no waiting mode in case 8 (More AM parts out at an equivalent cost level). This seems logical, since setup and cool down is only applied once if one, two or more parts are placed in the building space, while the production time is relatively short and the allowed time to manufacture is relatively long. If the parts would become even smaller, waiting is assumed to become a more beneficial strategy. Consequently this means that the advantage of waiting can improve when the typical part size is decreases.

Table 7-9: Possibility of simultaneous production

\begin{tabular}{|c|c|c|c|c|c|c|c|c|c|c|c|c|c|}
\hline \multirow[t]{2}{*}{ Part size } & \begin{tabular}{|l|} 
Allowed \\
time to \\
manufac- \\
ture
\end{tabular} & $\begin{array}{l}\text { Manufac- } \\
\text { turing }\end{array}$ & $\begin{array}{l}\text { Preheat \& } \\
\text { cool down }\end{array}$ & $\begin{array}{l}\text { Max } \\
\text { waiting } \\
\text { time }\end{array}$ & \multicolumn{8}{|c|}{ Production possible if two parts are in building space } & \multirow[b]{2}{*}{ big - 48} \\
\hline & Defined & \begin{tabular}{|l|} 
Part \\
volume/ \\
Building \\
speed \\
\end{tabular} & $\begin{array}{l}\text { Preheat + } \\
\text { cool down }\end{array}$ & \begin{tabular}{|l|} 
(if no \\
other part \\
arrives)
\end{tabular} & $\begin{array}{c}\text { small - } \\
168\end{array}$ & $\begin{array}{c}\text { small - } \\
72\end{array}$ & $\begin{array}{c}\text { small - } \\
48\end{array}$ & mid - 168 & mid -72 & mid - 48 & big - 168 & big - 72 & \\
\hline$\ldots$ & hrs & hrs & hrs & hrs & hrs & hrs & hrs & hrs & hrs & hrs & hrs & hrs & hrs \\
\hline \multirow{2}{*}{ small } & \multirow{2}{*}{168} & \multirow{2}{*}{4,5} & \multirow{2}{*}{12} & \multirow{2}{*}{151,5} & & 51 & 27 & 106,5 & 10,5 & $-13,5$ & 11,5 & $-84,5$ & $-108,5$ \\
\hline & & & & & & 147 & 147 & 106,5 & 106,5 & 106,5 & 11,5 & 11,5 & 11,5 \\
\hline \multirow{2}{*}{ small } & \multirow{2}{*}{72} & \multirow{2}{*}{4,5} & \multirow{2}{*}{12} & \multirow{2}{*}{55,5} & 147 & & 27 & 106,5 & 10,5 & $-13,5$ & 11,5 & $-84,5$ & $-108,5$ \\
\hline & & & & & 51 & & 51 & 10,5 & 10,5 & 10,5 & $-84,5$ & $-84,5$ & $-84,5$ \\
\hline \multirow{2}{*}{ small } & \multirow{2}{*}{48} & \multirow{2}{*}{4,5} & \multirow{2}{*}{12} & \multirow{2}{*}{31,5} & 147 & 51 & & 106,5 & 10,5 & $-13,5$ & 11,5 & $-84,5$ & $-108,5$ \\
\hline & & & & & 27 & 27 & & $-13,5$ & $-13,5$ & $-13,5$ & $-108,5$ & $-108,5$ & $-108,5$ \\
\hline \multirow{2}{*}{ mid } & \multirow{2}{*}{168} & \multirow{2}{*}{45} & \multirow{2}{*}{12} & \multirow{2}{*}{111} & 106,5 & 10,5 & $-13,5$ & & -30 & -54 & -29 & -125 & -149 \\
\hline & & & & & 106,5 & 106,5 & 106,5 & & 66 & 66 & -29 & -29 & -29 \\
\hline \multirow{2}{*}{ mid } & \multirow{2}{*}{72} & \multirow{2}{*}{45} & \multirow{2}{*}{12} & \multirow{2}{*}{15} & 106,5 & 10,5 & $-13,5$ & 66 & & -54 & -29 & -125 & -149 \\
\hline & & & & & 10,5 & 10,5 & 10,5 & -30 & & -30 & -125 & -125 & -125 \\
\hline \multirow{2}{*}{ mid } & \multirow{2}{*}{48} & \multirow{2}{*}{45} & \multirow{2}{*}{12} & -9 & 106,5 & 10,5 & $-13,5$ & 66 & -30 & & -29 & -125 & -149 \\
\hline & & & & -9 & $-13,5$ & $-13,5$ & $-13,5$ & -54 & -54 & & -149 & -149 & -149 \\
\hline big & 168 & 140 & 12 & 16 & 11,5 & $-84,5$ & $-108,5$ & -29 & -125 & -149 & & -220 & -244 \\
\hline Dig & 100 & 140 & 12 & 10 & 11,5 & 11,5 & 11,5 & -29 & -29 & -29 & & -124 & -124 \\
\hline big & 72 & 140 & 12 & -80 & 11,5 & $-84,5$ & $-108,5$ & -29 & -125 & -149 & -124 & & -244 \\
\hline big & $/ 2$ & 140 & 12 & -80 & $-84,5$ & $-84,5$ & $-84,5$ & -125 & -125 & -125 & -220 & & -220 \\
\hline bjg & 48 & 140 & 12 & -104 & 11,5 & $-84,5$ & $-108,5$ & -29 & -125 & -149 & -124 & -220 & \\
\hline & & & & & $-108,5$ & $-108,5$ & $-108,5$ & -149 & -149 & -149 & -244 & -244 & \\
\hline
\end{tabular}


Table 7-9 illustrates this fact. The left part of the table lists the different part size types and their major production related characteristics. Manufacturing allowance time is the driving component from which manufacturing, setup and cool down time are subtracted. This results in the maximum waiting time (values are simplified), which describes the time a spare part request is allowed to wait in queue before a penalty is charged. A negative maximum waiting time indicates that a production of the part is not possible, since a penalty cannot be avoided. Therefore several parts are excluded from further analysis. If the maximum allowed waiting time is bigger than zero, it is checked if a second part can enter the production run without creating a penalty. The production time of the second part is then subtracted from the maximum allowed time to manufacture of the first part. If the result is positive, waiting can be beneficial. The same check is executed on the second part. The production time of the first part is subtracted from the maximum allowed time to manufacture of the second part. If the result is positive, waiting can be beneficial. If one of those two checks is negative waiting is not an option since a penalty will be charged for the part with the negative results.

The same check can be done for third part which might enter the production run, but introducing a third part would not lead to new system behaviors. But if the calculations are executed for a third part entering the production run the results represent the new maximum waiting time for the two already set parts. This allows to increase the number of parts in the building volume in some situations.

Table 7-9 now shows the possible combinations of part sizes in green and the non-possible combinations in red. This shows that waiting is only possible when small parts are produced. If medium and big parts are introduced penalties will be created. A better control of the spare part set might slightly improve the situation, since a production of exceptionally small/ medium size and small/ big combinations are possible. However, in the current setup this is not an option. For future extensions to this work this may present a new field of study. In a situation in which for no 
part in process a penalty is charged, adding a part to an ongoing production run might become an option to eliminate double setup and cool down times for certain part combinations. For now it is assumed that the more parts are added to a production run the longer the production will take.

This can increase the chance to create a penalty if the system is not balanced accordingly.

The smaller the part size will become, the bigger the influence of setup and cool down times will be. This can lead to the conclusion that reducing setup and cool down times might again lead to further improvements. It can be assumed that the waiting mode can become less beneficial for the small parts only production if setup and cool down times decrease significantly. 


\section{SUMMARY OF FINDINGS}

The individual findings have been presented in the previous chapters. This chapter focuses on the comparison between different strategies directly. The following tables summarize findings when parameter such as setup and cool down are varied for one-, two- or three machine setups in no waiting and waiting mode.

If relevant, the most representative results are added according to the specific purpose.

The following tables are presented:

Table 8-1: Discussion of base case simulation

Table 8-2: Discussion of AM strategy investigations

Table 8-3: Comparison of different strategies - Upper limit - No waiting

Table 8-4: Comparison of different strategies - Upper limit - Waiting

Table 8-5: Comparison of different strategies - Preheat and cool down - No waiting

Table 8-6: Comparison of different strategies - Preheat and cool down - Waiting

Table 8-7: Comparison of different part size setups - No waiting

Table 8-8: Comparison of different part size setups - Waiting 

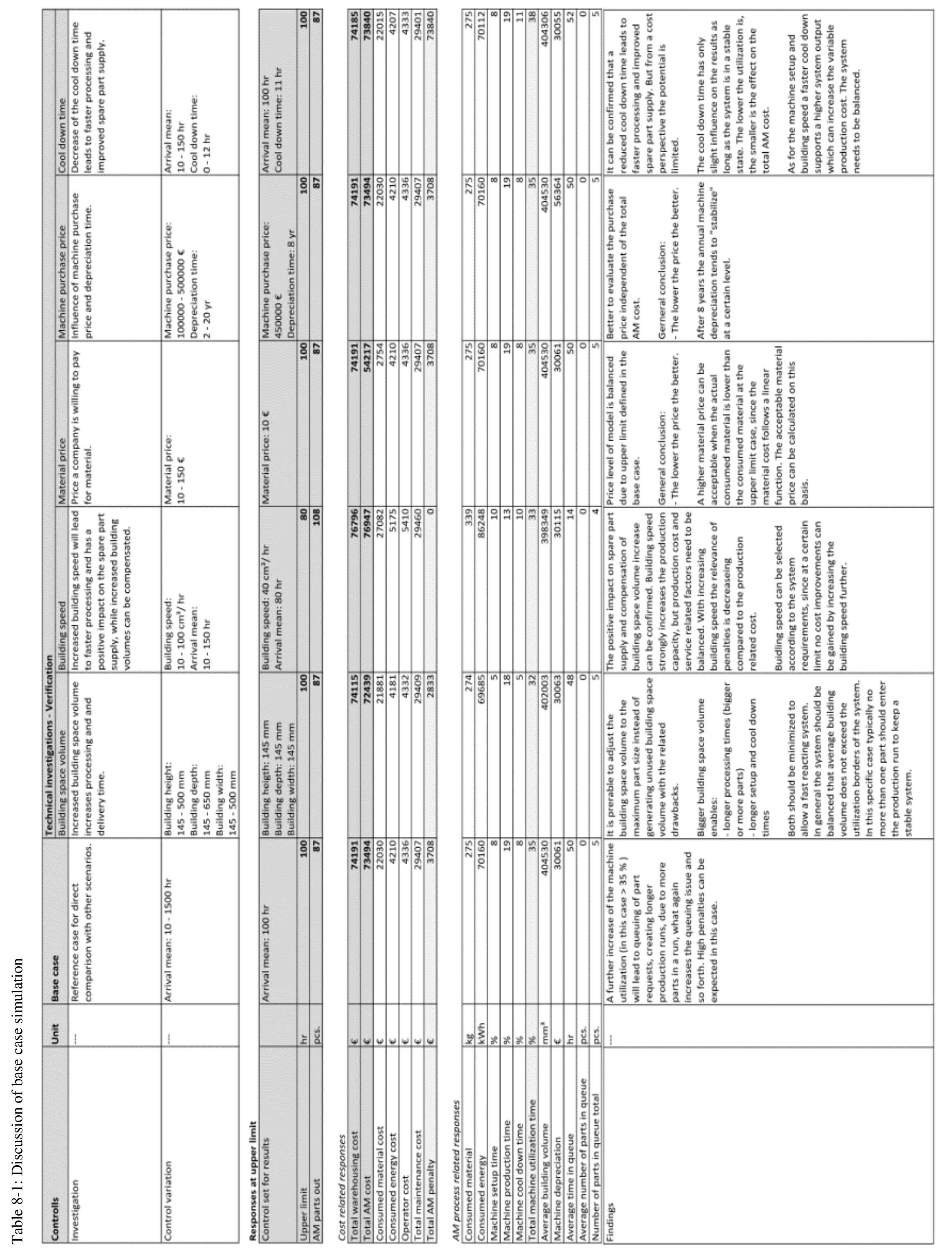

$\pm$
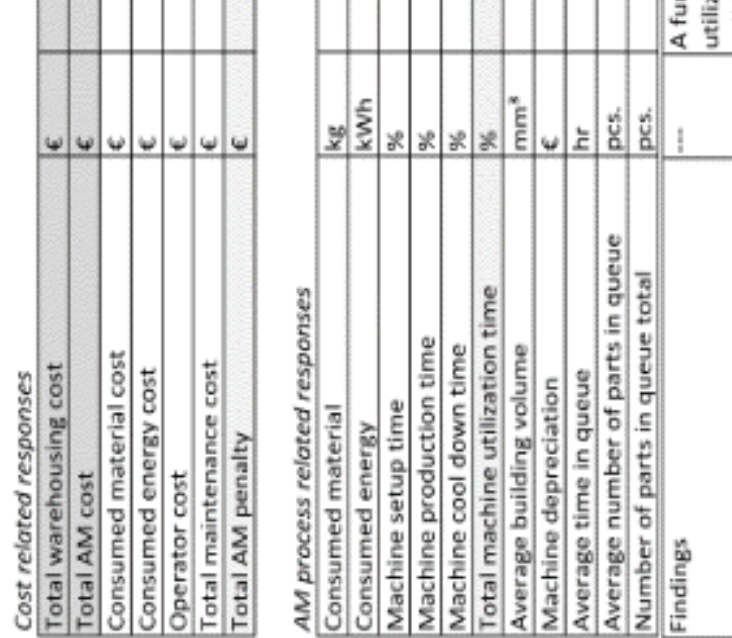

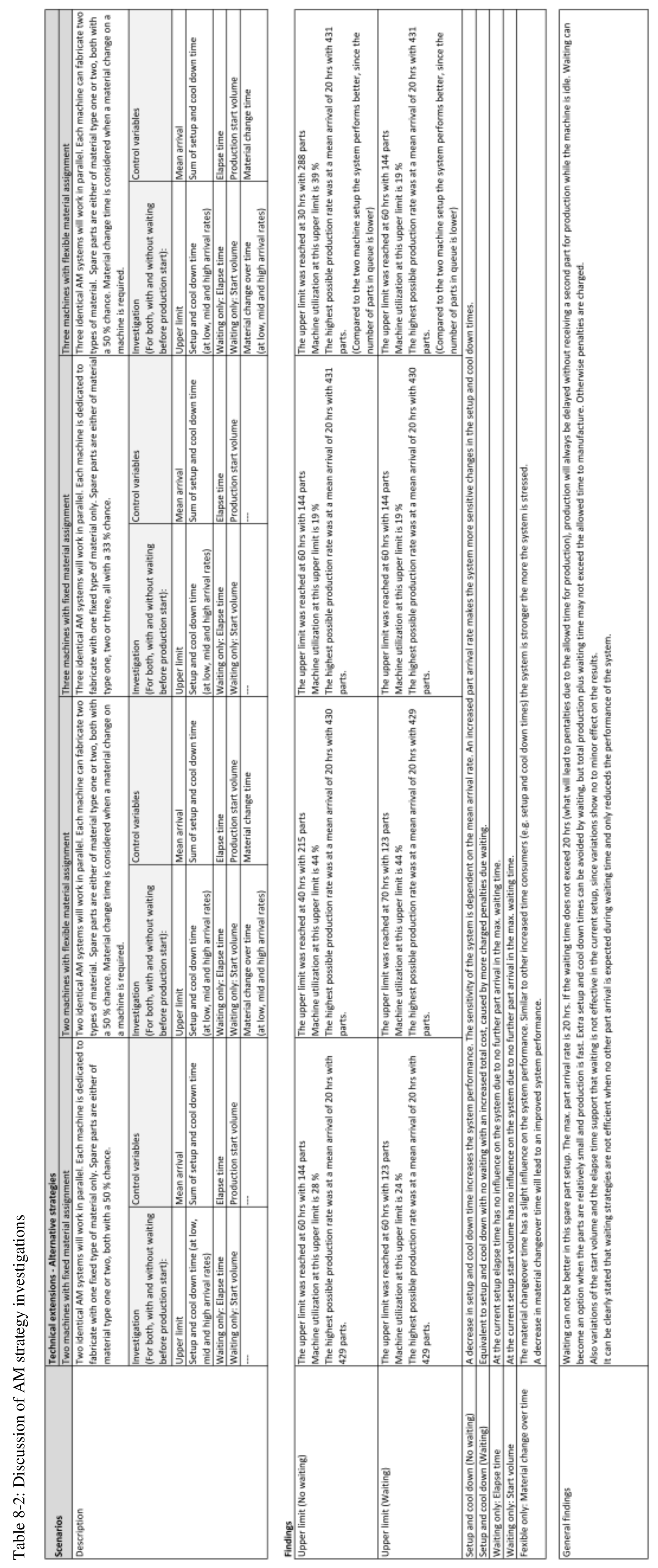

179 
Table 8-3: Comparison of different strategies - Upper limit - No waiting

\begin{tabular}{|c|c|c|c|c|c|}
\hline \multirow[b]{2}{*}{ Setting - No waiting } & \multirow[b]{2}{*}{ Unit } & \multicolumn{4}{|l|}{ Investigation: Upper limit } \\
\hline & & $\begin{array}{c}\text { Two machines with foxed } \\
\text { material assignment }\end{array}$ & $\begin{array}{l}\text { Two machines with } \\
\text { flexible material } \\
\text { assignment }\end{array}$ & $\begin{array}{l}\text { Three machines with } \\
\text { foxed material } \\
\text { assignment }\end{array}$ & $\begin{array}{l}\text { Three machines with } \\
\text { flexible material } \\
\text { assignment }\end{array}$ \\
\hline Investigation & $-\cdots$ & $\begin{array}{l}\text { Two identical AM } \\
\text { systems will work in } \\
\text { parallel. Each machine is } \\
\text { dedicated to fabricate } \\
\text { with one fixed type of } \\
\text { material only. Spare } \\
\text { parts are either of } \\
\text { material type one or } \\
\text { two, both with a } 50 \% \\
\text { chance. }\end{array}$ & $\begin{array}{l}\text { Two identical AM } \\
\text { systems will work in } \\
\text { parallel. Each machine } \\
\text { can fabricate two types } \\
\text { of material. Spare parts } \\
\text { are vither of material } \\
\text { type one or two, both } \\
\text { with a } 50 \% \text { chance. } \\
\text { Material change time is } \\
\text { considered when a } \\
\text { material change on a } \\
\text { machine is required. }\end{array}$ & $\begin{array}{l}\text { Three identical AM } \\
\text { systems will work in } \\
\text { parallel. Each machine is } \\
\text { dedicated to fabricate } \\
\text { with one fixed type of } \\
\text { material only. Spare } \\
\text { parts are either of } \\
\text { material type one, two } \\
\text { or three, all with a } 33 \% \\
\text { chance. }\end{array}$ & $\begin{array}{l}\text { Three identical AM } \\
\text { srstems will work in } \\
\text { parallel. Each machine } \\
\text { can fabricate two types } \\
\text { of material. Spare parts } \\
\text { are cither of material } \\
\text { type one or two, both } \\
\text { with a } 50 \text { \% chance. } \\
\text { Material change time is } \\
\text { considered when a } \\
\text { material change on a } \\
\text { machine is required. }\end{array}$ \\
\hline Control variation & - & Upper limit & Upper limit & Upper limit & Upper limit \\
\hline
\end{tabular}

Responses at upper limit

\begin{tabular}{|l|l|r|r|r|r|}
\hline Upper limit & hr & 60 & 40 & 60 & 30 \\
\hline AM parts out & pcs. & 144 & 216 & 144 & 288 \\
\hline
\end{tabular}

Cost related responses

\begin{tabular}{|c|c|c|c|c|c|}
\hline Total warehousing cost & $\epsilon$ & 81403 & 90498 & 81454 & 99982 \\
\hline Total AM cost & $\epsilon$ & 131635 & 154963 & 169974 & 214494 \\
\hline Consumed material cost & $\epsilon$ & 34664 & 53087 & 35687 & 68923 \\
\hline Consumed energy cost & $E$ & 6623 & 10144 & 6819 & 13170 \\
\hline Operatof cost & $\epsilon$ & 7206 & 10778 & 7211 & 14424 \\
\hline Total maintenance cost & $\epsilon$ & 58573 & 5877 & 87285 & 88138 \\
\hline Total AM penalty & $\epsilon$ & 5041 & 2583 & 3875 & 458 \\
\hline
\end{tabular}

\begin{tabular}{|c|c|c|c|c|c|}
\hline Consumed material & $\mathrm{kg}$ & 433 & 663 & 446 & 861 \\
\hline Consumed energy & kWh & 110396 & 169069 & 113655 & 219501 \\
\hline System setup time & $\%$ & 6,88 & 11,786 & 4,65 & 10,876 \\
\hline System utilization time & $\%$ & 14,67 & 22,387 & 10,13 & 19,383 \\
\hline Systen cool down time & $\%$ & 6,67 & 10,022 & 4,51 & 8,968 \\
\hline Total system utilization & $\%$ & 28,22 & 44,194 & 19,3 & 39,226 \\
\hline Average building volume & $\mathrm{mm}^{3}$ & 382907 & 393624 & 393399 & 382545 \\
\hline Machine depreciation & $\epsilon$ & 59875 & 60083 & B9225 & 90097 \\
\hline Average time in queue & hr & 30 & 19,264 & 28,123 & 6,191 \\
\hline Average number of parts in queve & pcs. & 0,027 & 0,023 & 0,012 & 0,003 \\
\hline Number of parts in queue total & pcs. & 15 & 9,3 & 10 & 3,217 \\
\hline
\end{tabular}

\begin{tabular}{|l|l|}
\hline Findings & $\begin{array}{l}\text { The results show a clear trend with respect to system performance. } \\
\text { The foxed material systems perform on a similar level with respect to AM parts out. The overall peformance of } \\
\text { the three machine setup can even be evaluated as worse compared to the two machine setup, since the total } \\
\text { system utilization is only } 19 \% \text { compared to } 28 \% \text { using two machines only. }\end{array}$ \\
$\begin{array}{l}\text { The flexible material systems improve significantly with respect to system perfomance. The number of AM } \\
\text { parts out is increased by } 33 \% \text { while the upper limit improved by } 25 \% \text { when a third machine is added. Also the } \\
\text { two machine setup shows clearly better results compared to the foxed material setup. } \\
\text { With respect to a performance evaluation of fixed vs. flexible material systems, the flexible material system is } \\
\text { preferable for the current system setup. }\end{array}$ \\
\hline
\end{tabular}


Table 8-4: Comparison of different strategies - Upper limit - Waiting

\begin{tabular}{|c|c|c|c|c|c|}
\hline \multirow[b]{2}{*}{ Setting - Waiting } & \multirow[b]{2}{*}{ Unit } & \multicolumn{4}{|l|}{ Investigation: Upper limit } \\
\hline & & $\begin{array}{c}\text { Two machines with fixed } \\
\text { material assignment }\end{array}$ & $\begin{array}{l}\text { Two machines with } \\
\text { flexible material } \\
\text { assignment }\end{array}$ & $\begin{array}{l}\text { Three machines with } \\
\text { fixed material } \\
\text { assignment }\end{array}$ & $\begin{array}{l}\text { Three machines with } \\
\text { flexible material } \\
\text { assignment }\end{array}$ \\
\hline Investigation & - & $\begin{array}{l}\text { Two identical AM } \\
\text { systems will work in } \\
\text { parallel. Each machine is } \\
\text { dedicated to fabricate } \\
\text { with one fixed type of } \\
\text { material cnly- Spare } \\
\text { parts are vither of } \\
\text { material type one or } \\
\text { two, both with a } 50 \% \\
\text { chance. }\end{array}$ & $\begin{array}{l}\text { Two identical AM } \\
\text { systems will work in } \\
\text { parallel. Each machine } \\
\text { can fabricate two types } \\
\text { of material. Spare parts } \\
\text { are either of material } \\
\text { type one or two, both } \\
\text { with a } 50 \% \text { chance. } \\
\text { Material change time is } \\
\text { considered when a } \\
\text { material change on a } \\
\text { machine is required. }\end{array}$ & $\begin{array}{l}\text { Three identical AM } \\
\text { systems will work in } \\
\text { parallel. Each machine is } \\
\text { dedicated to fabricate } \\
\text { with one fixed type of } \\
\text { material anly. Spare } \\
\text { parts are either of } \\
\text { material type one, two } \\
\text { or three, all with a } 33 \% \\
\text { chance. }\end{array}$ & $\begin{array}{l}\text { Three identical AM } \\
\text { systems will work in } \\
\text { parallel. Each machine } \\
\text { can fabricate two types } \\
\text { of material. Spare parts } \\
\text { are either af material } \\
\text { type one or two, both } \\
\text { with a } 50 \% \text { chance. } \\
\text { Material change time is } \\
\text { considered when a } \\
\text { material change on a } \\
\text { machine is required. }\end{array}$ \\
\hline Control variation & -- & Upper limit & Upaer limit & Upper limit & Upper limit \\
\hline
\end{tabular}

Responses at upper limit

\begin{tabular}{|l|l|r|r|r|r|}
\hline Upper limit & hr & 70 & 70 & 60 & 123 \\
\hline AM parts out & pCs. & 123 & 123 & 144 & 144 \\
\hline
\end{tabular}

Cost reloted responses

\begin{tabular}{|c|c|c|c|c|c|}
\hline Total warehousing cost & $\epsilon$ & 78402 & 78751 & 80950 & 81248 \\
\hline Total AM cost & $E$ & 122822 & 120773 & 169690 & 169015 \\
\hline Consumed material cost & $\varepsilon$ & 29487 & 28534 & 35114 & 34054 \\
\hline Consumed energy cost & $\epsilon$ & 5634 & 5452 & 6709 & 6507 \\
\hline Operator cost & $E$ & 6172 & 6163 & 7185 & 7186 \\
\hline Total maintenance cost & $\varepsilon$ & 58396 & 58498 & 87228 & 87356 \\
\hline Total AM penalty & $\varepsilon$ & 3656 & 2625 & 4375 & 4791 \\
\hline
\end{tabular}

AM process related responses

\begin{tabular}{|c|c|c|c|c|c|}
\hline Consumed material & $\mathrm{kg}$ & 368 & 356 & 438 & 425 \\
\hline Consumed energy & kWh & 93907 & 90874 & 111829 & 108452 \\
\hline System setup time & $\%$ & 5,93 & 6,473 & 4,64 & 5,174 \\
\hline System utilization time & $\%$ & 12,52 & 12,095 & 9,98 & 9,661 \\
\hline Systen cool down time & $\%$ & 5,74 & 5,773 & 4,49 & 4,508 \\
\hline Total system utilization & $\%$ & 24,19 & 24,341 & 19,11 & 19,342 \\
\hline Average building volume & $\mathrm{mm}^{3}$ & 380333 & 370109 & 389143 & 378199 \\
\hline Machine depreciation & $\epsilon$ & 59694 & 59798 & 89166 & 89298 \\
\hline Average time in queue & hr & 27 & 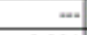 & 27,336 & $\ldots$ \\
\hline Average number of parts in queue & pes. & 0,017 & 0,001 & 0,015 & 0 \\
\hline Number of parts in queue total & pCs. & 10 & 1 & 13 & 0 \\
\hline
\end{tabular}

\begin{tabular}{|l|l|}
\hline Findings & $\begin{array}{l}\text { The upper limit search in the "waiting" setting shows similar results to the "no waiting" setting. The flexible } \\
\text { material setup performs better than the fixed material setup. While the upper limit and the number of parts } \\
\text { out are equal for both setups with an equivalent penalty, the queing behaviour is different. While queueing } \\
\text { occurs for the fixed material setup, no queving ocrurs for the flexible material setup. That indicates that the } \\
\text { system performs better. }\end{array}$ \\
\hline
\end{tabular}


Table 8-5: Comparison of different strategies - Preheat and cool down - No waiting

\begin{tabular}{|c|c|c|c|c|c|}
\hline \multirow[b]{2}{*}{ Setting - No waiting } & \multirow[b]{2}{*}{ Unit } & \multicolumn{4}{|c|}{ Investigation: Preheat/ Cool down variation } \\
\hline & & $\begin{array}{c}\text { Two machines with fixed } \\
\text { material assignment }\end{array}$ & $\begin{array}{l}\text { Two machines with } \\
\text { flexible material } \\
\text { assignment }\end{array}$ & $\begin{array}{l}\text { Throe machines with } \\
\text { fixed material } \\
\text { assignment }\end{array}$ & \begin{tabular}{|l} 
Three machines with \\
flexible material \\
assignment
\end{tabular} \\
\hline Investigation & - & $\begin{array}{l}\text { Two identical AM } \\
\text { svstems will work in } \\
\text { parallel. Each machine is } \\
\text { dedicated to fabricate } \\
\text { with one fixed type of } \\
\text { material only. Spare } \\
\text { parts are either of } \\
\text { material type one or } \\
\text { two, both with a } 50 \% \\
\text { chance. }\end{array}$ & $\begin{array}{l}\text { Two identical AM } \\
\text { systems will work in } \\
\text { parallel. Each machine } \\
\text { can fabricate two types } \\
\text { of material. Spare parts } \\
\text { are either of material } \\
\text { type one or two, both } \\
\text { with a } 50 \% \text { chance. } \\
\text { Material change time is } \\
\text { considered when a } \\
\text { material change on a } \\
\text { machine is required. }\end{array}$ & $\begin{array}{l}\text { Three identical AM } \\
\text { systems will work in } \\
\text { parallel. Each machine is } \\
\text { dedicated to fabricate } \\
\text { with one fixed type of } \\
\text { material only. Spare } \\
\text { parts are either of } \\
\text { material type one, two } \\
\text { or three, all with a } 33 \% \\
\text { chance. }\end{array}$ & $\begin{array}{l}\text { Three identical AM } \\
\text { systems will work in } \\
\text { parallel. Each machine } \\
\text { can fabricate two types } \\
\text { of material. Spare parts } \\
\text { are either of material } \\
\text { type one or two, both } \\
\text { with a } 50 \text { \% chance. } \\
\text { Material change time is } \\
\text { considered when a } \\
\text { material change on a } \\
\text { machine is required. }\end{array}$ \\
\hline Control variation & - & $\begin{array}{c}\text { Sum of setup and cool } \\
\text { down }\end{array}$ & $\begin{array}{c}\text { Sum of setup and cool } \\
\text { down }\end{array}$ & $\begin{array}{l}\text { Sum of setup and cool } \\
\text { down }\end{array}$ & $\begin{array}{c}\text { Sum of setup and cool } \\
\text { dewn }\end{array}$ \\
\hline
\end{tabular}

Setting

\begin{tabular}{|l|l|r|r|r|r|}
\hline Mean arrival & hr & 60 & 40 & 60 & 15 \\
\hline Sum of setup and cool down & hr & 9 & 15 & 15 & 4 \\
\hline
\end{tabular}

Cost reioted responses

\begin{tabular}{|c|c|c|c|c|c|}
\hline Total warehousing cost & E & 81203 & 90533 & 80609 & 117901 \\
\hline Total AM cost & E & 131289 & 153721 & 169277 & 265106 \\
\hline Consumed material cost & E & 35080 & 51965 & 34289 & 103701 \\
\hline Consumed energy cost & $\mathrm{c}$ & 6703 & 9929 & 6552 & 19815 \\
\hline Operator cost & 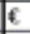 & 7201 & 10772 & 7191 & 21535 \\
\hline Total maintenance cost & $e$ & 58478 & 58758 & 87214 & 88259 \\
\hline Total AM penalty & $\varepsilon$ & 4333 & 2708 & 4958 & 2375 \\
\hline
\end{tabular}

AM process reíted responses

\begin{tabular}{|c|c|c|c|c|c|}
\hline Consumed material & $\mathrm{kg}$ & 438 & 649 & 428 & 1296 \\
\hline Consumed energy & kWh & 111721 & 165494 & 109202 & 330259 \\
\hline System sotup time & $\approx$ & 6,06 & 13,05 & 5,2 & 13,667 \\
\hline System utilization time & $\%$ & 14,87 & 21,925 & 9,74 & 29,123 \\
\hline Systen cool down time & $\%$ & 5,01 & 12,51 & 5,62 & 6,685 \\
\hline Total system utilization & $\%$ & 25,93 & 47,486 & 20,56 & 49,474 \\
\hline Average bulding wolume & $\mathrm{mm}^{2}$ & 387570 & 386087 & 378971 & 385188 \\
\hline Machine depreciation & e & 59777 & 60064 & 89152 & 90220 \\
\hline Average time in queue & hr & 32 & 18,368 & 29,296 & 8,988 \\
\hline Average number of parts in queue & pes. & 0,025 & 0,024 & 0,013 & 0,038 \\
\hline Number of parts in queue total & pcs. & 12 & 10,23 & 11 & 32,783 \\
\hline AM parts out & pes. & 144 & 215 & 144 & 431 \\
\hline
\end{tabular}

\begin{tabular}{|l|l|}
\hline Findings & $\begin{array}{l}\text { With respect to setup and cool down times the flexble material systems perform better than the fixed material } \\
\text { systems. } \\
\text { (Results show the middle upper limit of the upper limit search. The systems where stressed by increasing the } \\
\text { sum of setup and cool down times.] } \\
\text { The three machine setup with flexible material very eood results with respect to the mean arrival rate of part } \\
\text { requests, but needs extremely low setup/ cool down times to perform with an acceptable penalty. This means } \\
\text { that the more part request arrive the faster the setup and changeover should be, since the sum of setup and } \\
\text { cool down become significant. This effect is not as significant as long as the mean arrival rate is in a more } \\
\text { relaxed state. }\end{array}$ \\
\hline
\end{tabular}


Table 8-6: Comparison of different strategies - Preheat and cool down - Waiting

\begin{tabular}{|c|c|c|c|c|c|}
\hline \multirow[b]{2}{*}{ Setting - Waiting } & \multirow[b]{2}{*}{ Unit } & \multicolumn{4}{|l|}{ Investigation: Upper limit } \\
\hline & & $\begin{array}{c}\text { Two machines with fixed } \\
\text { material assignment }\end{array}$ & $\begin{array}{l}\text { Two machines with } \\
\text { flexible material } \\
\text { assignment }\end{array}$ & $\begin{array}{l}\text { Three machines with } \\
\text { fixed material } \\
\text { assignment }\end{array}$ & $\begin{array}{l}\text { Three machines with } \\
\text { flexible material } \\
\text { assignment }\end{array}$ \\
\hline Investigation & -- & \begin{tabular}{|l|} 
Two identical AM \\
systems will work in \\
parallel. Each machine is \\
dedicated to fabricate \\
with one fixed type of \\
material cnly-Spare \\
parts are either of \\
material type one or \\
two, both with a $50 \%$ \\
chance.
\end{tabular} & $\begin{array}{l}\text { Two identical AM } \\
\text { systems will wark in } \\
\text { parallel. Each machine } \\
\text { can fabricate two types } \\
\text { of material. Spare parts } \\
\text { are either of material } \\
\text { type one or two, both } \\
\text { with a } 50 \% \text { chance. } \\
\text { Material change time is } \\
\text { considered when a } \\
\text { material change on a } \\
\text { machine is required. }\end{array}$ & $\begin{array}{l}\text { Three identical AM } \\
\text { systems will work in } \\
\text { parallel. Each machine is } \\
\text { dedicated to fabricate } \\
\text { with one fixod type of } \\
\text { material only. Spare } \\
\text { parts are either of } \\
\text { material type one, two } \\
\text { or three, all with a } 33 \% \\
\text { chance. }\end{array}$ & $\begin{array}{l}\text { Three identical AM } \\
\text { systems will work in } \\
\text { parallel. Each machine } \\
\text { can fabricate two types } \\
\text { of material. Spare parts } \\
\text { are either of material } \\
\text { type one or two, both } \\
\text { with a } 50 \% \text { chance. } \\
\text { Material change time is } \\
\text { considered when a } \\
\text { material change on a } \\
\text { machine is required. }\end{array}$ \\
\hline Control variation & - & Upper limit & Upper limit & Upper limit & Upper limit \\
\hline
\end{tabular}

\section{Responses at upper limit}

\begin{tabular}{|l|l|r|r|r|r|}
\hline Upper limit & hr & 70 & 70 & 60 & 60 \\
\hline
\end{tabular}

\begin{tabular}{|l|l|r|r|r|r|}
\hline AM parts out & DCS. & 123 & 123 & 144 & 144 \\
\hline
\end{tabular}

Cost related responses

\begin{tabular}{|c|c|c|c|c|c|}
\hline Total warehousing cost & $\epsilon$ & 78402 & 78751 & 80950 & 81248 \\
\hline Total AM cost & $\varepsilon$ & 122822 & 120773 & 169690 & 169015 \\
\hline Consumed material cost & $\epsilon$ & 29487 & 28534 & 35114 & 34054 \\
\hline Consumed energy cDst & $\epsilon$ & 56.34 & 5452 & 6709 & 6507 \\
\hline Operator cost & $\epsilon$ & 6172 & 6163 & 7186 & 7186 \\
\hline Total maintenance cost & $\epsilon$ & 58396 & 58498 & 87228 & 87356 \\
\hline Total AM penality & $\epsilon$ & 3666 & 2625 & 4375 & 4791 \\
\hline
\end{tabular}

AM process related responses

\begin{tabular}{|c|c|c|c|c|c|}
\hline Consumed material & $\mathrm{kg}$ & 368 & 356 & 438 & 425 \\
\hline Consumed enerzy & kWh & 93907 & 90874 & 111829 & 108452 \\
\hline System setup time & $\%$ & 5,93 & 6,473 & 4,64 & 5,174 \\
\hline System utilization time & $\%$ & 12,52 & 12,095 & 9,98 & 9,661 \\
\hline Systen cool down time & $\%$ & 5,74 & 5,773 & 4,49 & 4,508 \\
\hline Total system utilization & $\%$ & 24,19 & 24,341 & 19,11 & 19,342 \\
\hline Average building volume & $\mathrm{mm}^{2}$ & 380333 & 370109 & 399143 & 378199 \\
\hline Machine depreciation & $\varepsilon$ & 59694 & 59798 & 89166 & 89298 \\
\hline Average time in queve & her & 27 & -- & 27,336 & $\ldots$ \\
\hline Average number of parts in queve & pCs. & 0,017 & 0,001 & 0,015 & 0 \\
\hline Number of parts in queue total & pes. & 10 & 1 & 13 & 0 \\
\hline
\end{tabular}

\begin{tabular}{|l|l|}
\hline Findings & $\begin{array}{l}\text { The upper limit search in the "waiting" setting shows similar results to the "no waiting" setting. The flexible } \\
\text { material setup performs better than the foxed material setup. While the upper limit and the number of parts } \\
\text { out are equal for both setups with an equivalent penalty, the queing behaviour is different. While queuring } \\
\text { occurs for the fixed material setup, no queuing accurs for the flexible material setup. That indicates that the } \\
\text { system performs better. }\end{array}$ \\
\hline
\end{tabular}


Table 8-7: Comparison of different part size setups - No waiting

\begin{tabular}{|c|c|c|}
\hline \multirow{2}{*}{ Setting - No waiting } & \multirow{2}{*}{ Unit } & Investigation: Part size variation \\
\hline & & Two machines producing several part size combinations \\
\hline Investigation & - & $\begin{array}{l}\text { Two identical AM systems will work in parallel. Each machine is dedicated to fabricate with } \\
\text { one fixed type of material only. Standard cases and extreme spare part size setup are } \\
\text { investigated. }\end{array}$ \\
\hline Part size - small & & $46 \times 46 \times 46 \mathrm{~mm}^{3}$ \\
\hline Part size - mid & & $100 \times 100 \times 100 \mathrm{~mm}^{3}$ \\
\hline Part size - big & - & $145 \times 145 \times 145 \mathrm{~mm}^{3}$ \\
\hline
\end{tabular}

Setting

\begin{tabular}{|c|c|c|c|c|c|c|c|c|c|}
\hline Percentage small parts & $\%$ & 75 & 33 & 0 & 50 & 0 & 50 & 0 & 100 \\
\hline Percentage mid parts & $\%$ & 20 & 33 & 50 & 0 & 0 & 50 & 100 & 0 \\
\hline Percentage big marts & $\%$ & 5 & 33 & 50 & 50 & 100 & 0 & 0 & 0 \\
\hline
\end{tabular}

\begin{tabular}{|c|c|c|c|c|c|c|c|c|c|}
\hline Total warehousing cost & $\epsilon$ & 90275 & 76559 & 75075 & 75201 & 75056 & 90227 & 90697 & 201283 \\
\hline Total AM cost & $\epsilon$ & 161281 & 195676 & 226837 & 193128 & 300524 & 178079 & 250516 & 213543 \\
\hline Consumed material cost & $\epsilon$ & 58101 & 92354 & 120589 & 92386 & 181434 & 74446 & 135040 & 65914 \\
\hline Consumed energy cost & $\epsilon$ & 11102 & 17647 & 23042 & 17653 & 34668 & 14225 & 25804 & 12595 \\
\hline Operator cost & $€$ & 10780 & 5389 & 4781 & 4795 & 4738 & 10794 & 10751 & 53915 \\
\hline Total maintenance cost & $\epsilon$ & 58816 & 58433 & 58536 & 58438 & 58575 & 58897 & 58908 & 59088 \\
\hline Total AM penalty & $€$ & 2875 & 2375 & 375 & 375 & 1583 & 83 & 375 & 2333 \\
\hline
\end{tabular}

AM process related responses

\begin{tabular}{|c|c|c|c|c|c|c|c|c|c|}
\hline Consumed material & $\mathrm{kg}$ & 726 & 1154 & 1507 & 1154 & 2267 & 930 & 1688 & 823 \\
\hline Consumed energy & kWh & 185036 & 294123 & 384042 & 294224 & 577816 & 237092 & 430066 & 209918 \\
\hline System setup time & $\%$ & 10,361 & 5,279 & 4,682 & 4,705 & 4,636 & 10,432 & 10,388 & 33,958 \\
\hline System utilization time & $\%$ & 24,486 & 39,17 & 51,062 & 39,19 & 76,779 & 31,33 & 56,823 & 27,651 \\
\hline Systen cool down time & $\%$ & 9,975 & 5,054 & 4,476 & 4.497 & 4,433 & 10,042 & 10,001 & 32,827 \\
\hline Total system utilization & $\%$ & 44,822 & 49,503 & 60,22 & 48,391 & 85,848 & 51,804 & 77,212 & 94,437 \\
\hline Average building volume & $\mathrm{mm}^{3}$ & 431063 & 1368484 & 2011654 & 1538840 & 3048625 & 550032 & 1000000 & 97336 \\
\hline Machine depreciation & $€$ & 60123 & 59731 & 59837 & 59736 & 59876 & 60206 & 60217 & 60401 \\
\hline Average time in queue & hr & 21,271 & 8,648 & 1,989 & 1,823 & $\ldots$ & 1,806 & 3,401 & 8,269 \\
\hline Average number of parts in queue & pes. & 0,027 & 0,005 & 0,001 & 이 & 0,002 & 0 & 0,002 & 0,905 \\
\hline Number of parts in queve total & pcs. & 10,333 & 5,033 & 0,867 & 0,75 & 3,1 & 1,083 & 4,267 & 944,6 \\
\hline AM parts out & pes. & 215,617 & 107,783 & 95,633 & 95,917 & 94,767 & 215,883 & 215,033 & 1078,317 \\
\hline
\end{tabular}

\begin{tabular}{|l|l|}
\hline Findings & $\begin{array}{l}\text { The smaller the parts in the spare part mix are, the better the system can react on part requests. But if } \\
\text { the frequency of the real life spare part request is lower than the upper limit it should not be a } \\
\text { problem, since the system is able to handle the spare part requests. }\end{array}$ \\
\hline
\end{tabular}


Table 8-8: Comparison of different part size setups - Waiting

\begin{tabular}{|l|l|l|}
\hline Setting - Walting & Unit & Investigation: Part size variation \\
\cline { 3 - 4 } & - & $\begin{array}{l}\text { Two machines producing seweral part size combinations } \\
\text { Investigal AM systems will work in parallel. Each machine is dedicated to fabricate with one }\end{array}$ \\
\hline Part size - small & & \\
\hline Part size - mid & & $46 \times 46 \times 46 \mathrm{~mm}^{3}$ \\
\hline Part size - big & & $100 \times 100 \times 100 \mathrm{~mm}^{3}$ \\
\hline
\end{tabular}

Setting
\begin{tabular}{|l|r|r|r|r|r|r|r|r|r|}
\hline Percentage small parts & $\%$ & 75 & 33 & 0 & 50 & 0 & 50 & 0 & 100 \\
\hline Percentage mid parts & $\%$ & 20 & 33 & 50 & 0 & 0 & 50 & 100 & 0 \\
\hline Percentage big marts & $\%$ & 5 & 33 & 50 & 50 & 100 & 0 & 0 & 0 \\
\hline
\end{tabular}

\begin{tabular}{|c|c|c|c|c|c|c|c|c|c|}
\hline Total warehousing cost & $\varepsilon$ & 90648 & 76489 & 74836 & 75039 & 73685 & 90860 & 90886 & 219627 \\
\hline Total AM cost & $E$ & 161905 & 198649 & 230666 & 195556 & 279998 & 178438 & 254449 & 233128 \\
\hline Consumed material cost & $E$ & 57149 & 92622 & 121559 & $928 \mathrm{6} 6$ & 163182 & 74156 & 134988 & 75166 \\
\hline Consumed energy cost & $\epsilon$ & 10920 & 17698 & 23227 & 17745 & 31181 & 14170 & 25794 & 14363 \\
\hline Operator cost & $E$ & 10783 & 5373 & 4765 & 4784 & 4261 & 10780 & 10747 & 61484 \\
\hline Total maintenance cost & E. & 58758 & 58497 & 58429 & 58433 & 58498 & 58841 & 58907 & 59085 \\
\hline Total AM penalty & 6 & 4708 & 4958 & 3208 & 2250 & 3375 & 875 & 4375 & 3333 \\
\hline
\end{tabular}

\section{AM process reloted responses}

\begin{tabular}{|c|c|c|c|c|c|c|c|c|c|}
\hline Consumed material & $\mathrm{kg}$ & 714 & 1157 & 1519 & 1160 & 2039 & 926 & 1637 & 939 \\
\hline Consumed enerzy & kWh & 182003 & 294975 & 387131 & 295752 & 519688 & 236167 & 429900 & 239384 \\
\hline System setup time & $\%$ & 10,362 & 5,256 & 4,673 & 4,692 & 4,181 & 10,42 & 10,381 & 30,124 \\
\hline Srstem utilization time & $\%$ & 24,107 & 39,241 & 51,564 & 39,397 & 69,146 & 31,238 & 56,801 & 31,534 \\
\hline Systen cool down time & $\%$ & 9,978 & 5,033 & 4,468 & 4,486 & 3,992 & 10,039 & 9,997 & 29,113 \\
\hline Total system utilization & $\%$ & 44,447 & 49,53 & 60,705 & 48,575 & 77,318 & 51,697 & 77,179 & 90,772 \\
\hline Awerage building volume & $\mathrm{mm}^{2}$ & 423489 & 1378738 & 2033402 & 1550195 & 3048625 & 548455 & 1000000 & 97336 \\
\hline Machine depreciation & $\epsilon$ & 60064 & 59797 & 59728 & 59731 & 59798 & 60149 & 60217 & 60398 \\
\hline Average time in queve & hr & 19,772 & 8,853 & 4,405 & 3,125 & - & 3,968 & 4,591 & 6,974 \\
\hline Average number of parts in queue & pcs. & 0,031 & 0,009 & 0,001 & 0,001 & 0 & 0,004 & 0,015 & 0,822 \\
\hline Number of parts in queue total & pcs. & 13,233 & 7,75 & 1,9 & 1,517 & 0,25 & 8,267 & 27,817 & 1017,057 \\
\hline AM parts out & pes. & 215,667 & 107,467 & 95,3 & 95,683 & 85,233 & 215,617 & 214,95 & 1229,683 \\
\hline
\end{tabular}

\begin{tabular}{|l|l|}
\hline Findings & $\begin{array}{l}\text { For most scenarias the waiting setup is worse that the no waiting setup under the given set af conditions. } \\
\text { deviation occurs when only small parts are produced. Here a sligth advantage of the waiting strategy } \\
\text { occurs. A smaller part size means realtively long setup and cool down times compared to the actual } \\
\text { production time. In consequence the smaller the part size the more interisting becomes batching of spare } \\
\text { part request. }\end{array}$ \\
\hline
\end{tabular}




\subsection{COMPARISON OF TOTAL AM COST}

One advantage of the established model is to enable direct comparisons between various setup and strategies against certain performance criteria efficiently, such as the relationship between part arrival rate and system operating cost. The total AM cost of all strategies with various mean arrival time are listed in Table 8-9. The high arrival times, low arrival times and the upper limit of the spare part requests are marked in red, green and yellow respectively. Waiting generally results in additional costs and lower efficiencies in the current setup and is not discussed in this section.

Looking at the fixed material strategies, the system performance does not improve with the number of machines. This is due to the previously described effects. More interesting to note is the flexible material strategy. Overall the system performance of this strategy improves with increasing number of machines. Further it can be said that the higher the number of machines, the closer the lower, and higher limit shift to the upper limit. This can mean that the more machines are used the better the system can react, since more machines are sharing the jobs. For example it is more likely to have a machine idle for direct production when three machines are used compared to using one machine. Then the system does not need to compensate for this uncertainty, what allows the system to work stable when the upper or lower is not exceeded. On the other hand, due to the high arrival rate of spare part request, a queue is created fast if no machine is idle for a while since spare part requests keep arriving and will most likely create penalties. But below the upper limit the system can be operated very stable. 
Table 8-9: Overview of different strategies - Upper limit search - No waiting

\begin{tabular}{|c|r|r|r|r|r|}
\hline \multirow{2}{*}{$\begin{array}{c}\text { Mean } \\
\text { arrival }\end{array}$} & \multicolumn{5}{|c|}{ Total AM cost } \\
\cline { 2 - 6 } & Base case & $\begin{array}{c}\text { Two } \\
\text { machines } \\
\text { fixed }\end{array}$ & $\begin{array}{c}\text { Two } \\
\text { machines } \\
\text { flexible }\end{array}$ & $\begin{array}{c}\text { Three } \\
\text { machines } \\
\text { fixed }\end{array}$ & $\begin{array}{c}\text { Three } \\
\text { machines } \\
\text { flexible }\end{array}$ \\
\hline hrs & \multicolumn{5}{|c|}{$€$} \\
\hline 150 & 59772 & 95.849 & 96146 & 132381 & 133019 \\
\hline 140 & 62060 & 97.270 & 97749 & 133786 & 134876 \\
\hline 130 & 63917 & 98.913 & 99234 & 136044 & 136234 \\
\hline 120 & 66070 & 101.718 & 101237 & 138861 & 139073 \\
\hline 110 & 68717 & 103.993 & 103396 & 140477 & 140697 \\
\hline 100 & 73494 & 107.410 & 106276 & 144249 & 144310 \\
\hline 90 & 78178 & 111.450 & 109770 & 148389 & 147166 \\
\hline 80 & 84145 & 116.021 & 113943 & 152922 & 151932 \\
\hline 70 & 90898 & 124.050 & 118266 & 160813 & 158433 \\
\hline 60 & 104765 & 131.635 & 127048 & 169974 & 163877 \\
\hline 50 & 133290 & 149.389 & 136911 & 183340 & 174260 \\
\hline 40 & 199013 & 175.122 & 154963 & 207051 & 190719 \\
\hline 30 & 356010 & 246.337 & 188196 & 244715 & 214494 \\
\hline 20 & 1219129 & 482.313 & 339234 & 380022 & 274890 \\
\hline 10 & 1709967 & 2.461 .622 & 2537724 & 1405475 & 2471954 \\
\hline
\end{tabular}

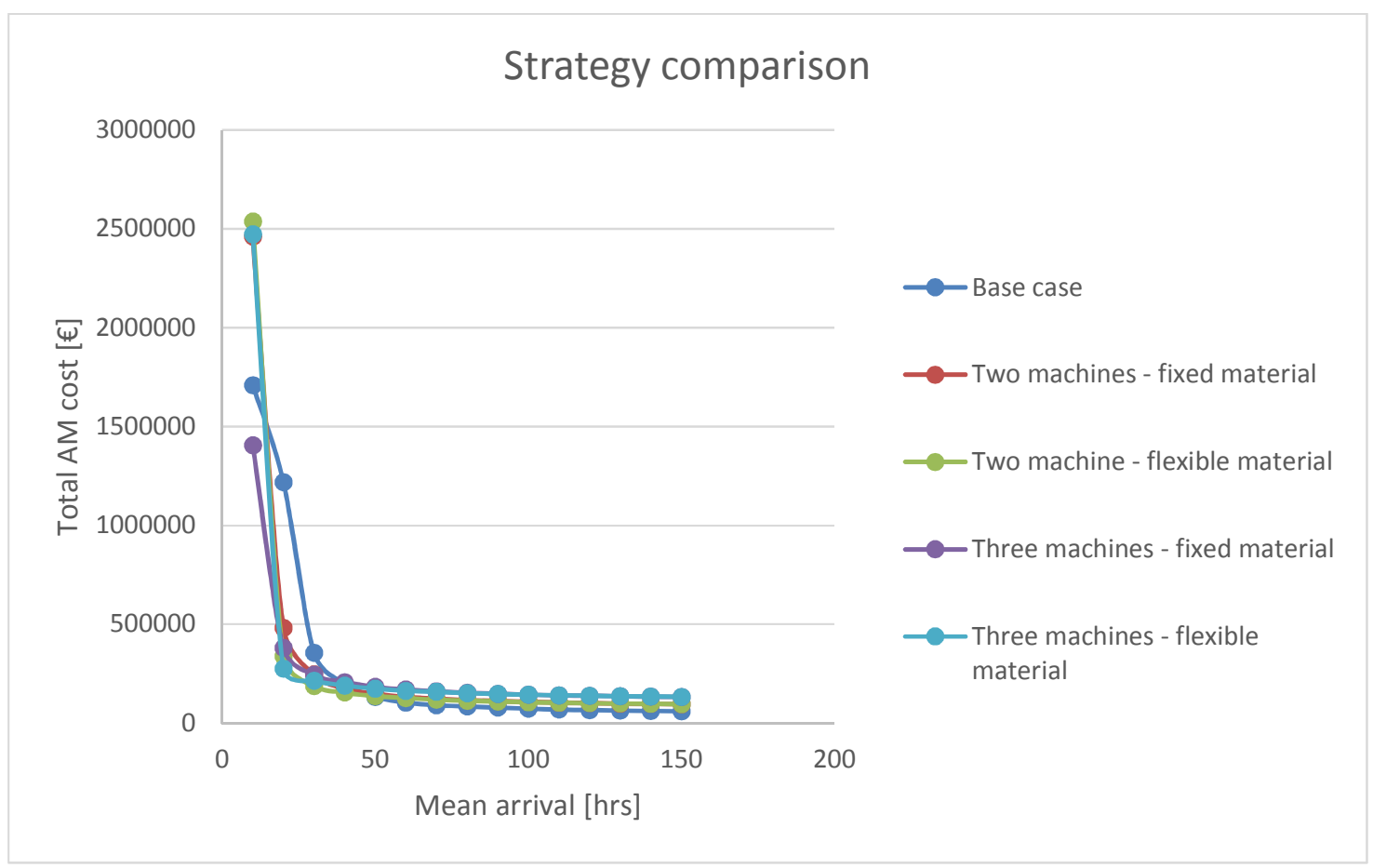

Figure 8-1: Strategy comparison 


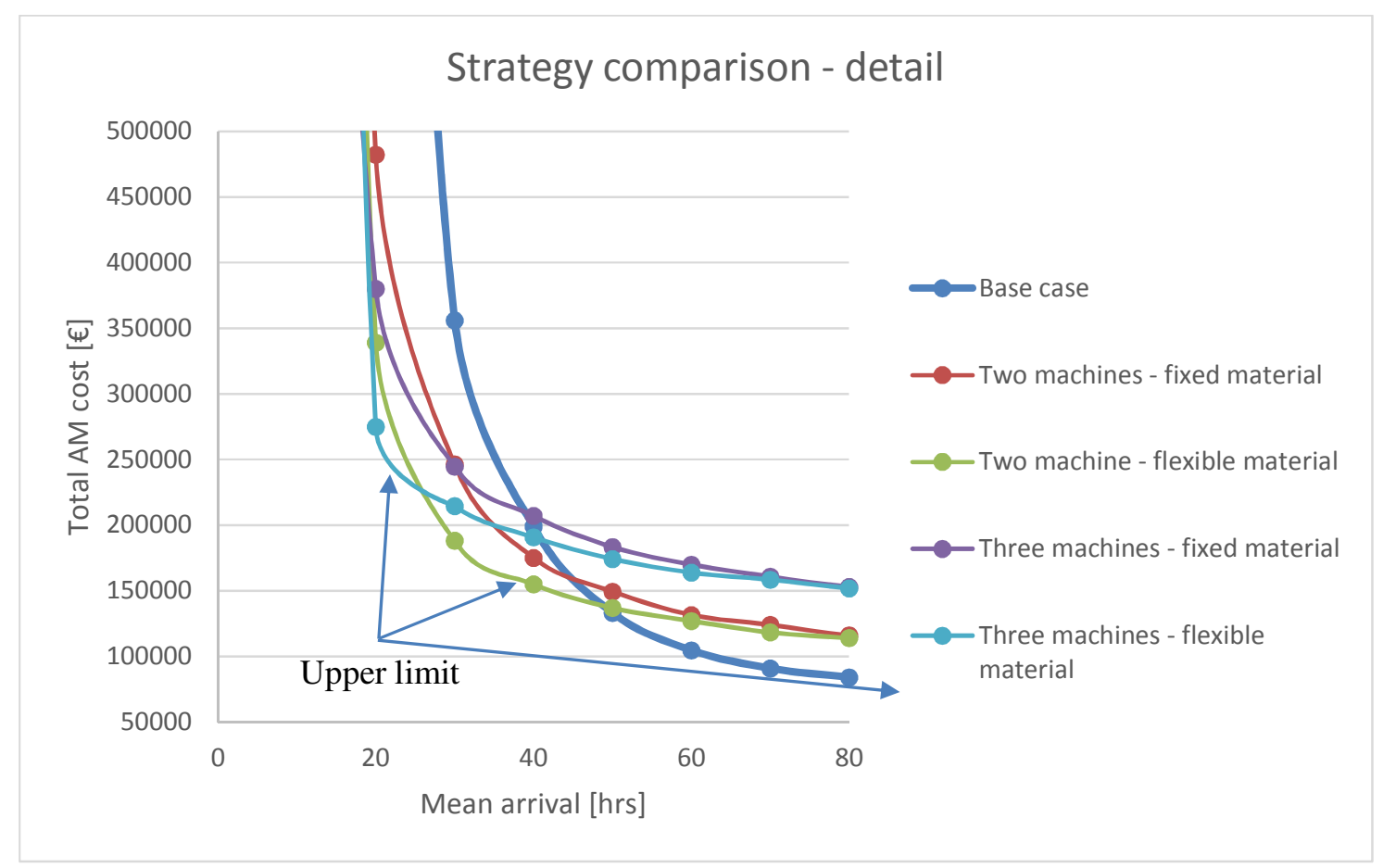

Figure 8-2: Strategy comparison - detail

Figure 8-1 and Figure 8-2 illustrate this effect. Focusing on the flexible material strategies and the base case the cost curve shows an approximately linear behavior before the upper limit is exceeded. (A lower mean arrival time results more spare part requests.) When the upper limit is exceeded the penalties become a strong cost driver the more the inter-arrival time of spare part requests increases. The base case reaches its upper limit early (100 hrs), but when the inter-arrival time of spare part requests further increases the cost increase due to penalties is relatively slow. This is due to the fact that the inter-arrival times of part requests are relatively low in the working range of a one machine setup. Since the one machine setup is the simplest approach it is logical that it works also at the lowest cost level.

If it becomes necessary the system performance can be increased by adding a second machine. This lifts the system cost to a new level and into a new working range. The illustration allows the 
assumption that this strategy is beneficial from a cost perspective in a working range with a mean arrival time between 28 and $50 \mathrm{hrs}$. When the upper limit is exceeded the impact of penalties is stronger than in the one machine solution. This is logical due to the higher inter-arrival times of part requests and the resulting higher number of parts in queue when queuing occurs. The equivalent principle is valid for the three machine with flexible material strategy. What can be learned from this graphic is that each strategy, one or multi machine, has its specific application and needs to be adjusted to the actual requirements. Also changing spare part parameters like part size can influence the decision for a strategy.

\subsection{ADDITIONAL DISCUSSION}

\subsubsection{AM SPARE PART STRATEGY ANALYSIS FOR CASE STUDY}

In this subsection the use of AM as a potential alternative for the spare part supply of a real-world setting was analyzed. A dataset of spare parts was provided by a manufacturing company and was analyzed as described in chapter 4 . The following table presents a consumption profile of that specific spare parts set for further analysis.

A total of 3510 parts were consumed from the warehouse stock in the period of one year - neither a single AM machine is able to produce this amount of parts nor will two or three machines reach this output. The following table lists the output using the flexible material strategies and the base case. The content can also be illustrated in a graph, what enables an estimate to the required number of machines to reach a specific number of machines. 
Table 8-10: Consumption profile of spare part set ${ }^{10}$

\begin{tabular}{|c|c|c|c|c|}
\hline $\begin{array}{c}\text { No. of } \\
\text { consumption }\end{array}$ & $\begin{array}{c}\text { No. of } \\
\text { part types }\end{array}$ & $\begin{array}{c}\text { Total consumption } \\
\text { [pcs.] }\end{array}$ & $\begin{array}{c}\text { Value of total } \\
\text { consumption [€] }\end{array}$ & $\begin{array}{c}\text { Current stock } \\
\text { value [€] }\end{array}$ \\
\hline $0-1$ & 523 & 50 & 32,530 & 237,212 \\
\hline $2-9$ & 76 & 279 & 59,148 & 34,947 \\
\hline $10-49$ & 25 & 687 & 39,427 & 12,499 \\
\hline $50-149$ & 6 & 672 & 13,828 & 4,235 \\
\hline $150-1,000$ & 3 & 1,822 & 38,723 & 1,463 \\
\hline Total & $\mathbf{6 3 3}$ & $\mathbf{3 , 5 1 0}$ & $\mathbf{1 8 3 , 6 5 6}$ & $\mathbf{2 9 0 , 3 5 6}$ \\
\hline
\end{tabular}

Applying the function ten machines are needed to cover the total demand. This results in a heavy investment, which cannot be justified by further analysis without expensive tradeoffs. A check of the consumption of the specific spare parts helps it this situation. In the presented consumption profile, all values tend to follow an $\mathrm{ABC}$ distribution. 3 part types are consumed 1,822 times and represent a stock value of only $1,463 €$. On the other hand, there are types of 523 parts that are consumed a total of 50 times but represent a stock value of $237,212 €$. These parts clearly represent the more "valuable" and "critical" part sets. When only these high value-added parts are considered, AM appears to become a reasonable option in this case. The simulation model of the base case predicted an average output of 87 parts per year with an acceptable penalty. Since only 50 parts will be consumed in the real system, already the one-machine system would be sufficient from a service level perspective. Furthermore, the comparison of the base case and the real

\footnotetext{
10 "No. Of consumption" describes the range of consumption a specific type was consumed. Example row 1: 3 part different part types were consumed between 300 and 1000 times each. So these part types are consumed often. If the consumption of the different part types is summed up, 1822 parts are consumed in total with a value of consumption of $38,723 €$ and a total stock value of $1,463 €$. The data represents one year of data collection.
} 
system shows that AM is a cost attractive solution for spare part supply under appropriate circumstances.

It should also be noted that the fact that the AM system is able to produce 87 parts at its upper limit implies that the system is capable of handling temporary supply surges of up to about $150 \%$ of the original rate. The output can be increased further by applying more machines if the investment is justifiable (red line indicates the trend).

\begin{tabular}{|l|c|c|}
\cline { 2 - 3 } \multicolumn{1}{c|}{} & $\begin{array}{c}\text { AM parts } \\
\text { out }\end{array}$ & $\begin{array}{c}\text { \# of } \\
\text { machines }\end{array}$ \\
\hline Three machines with flexible material - No waiting & 431 & 3 \\
\hline Two machines with flexible material - No waiting & 215 & 2 \\
\hline Base case - No waiting & 87 & 1 \\
\hline
\end{tabular}

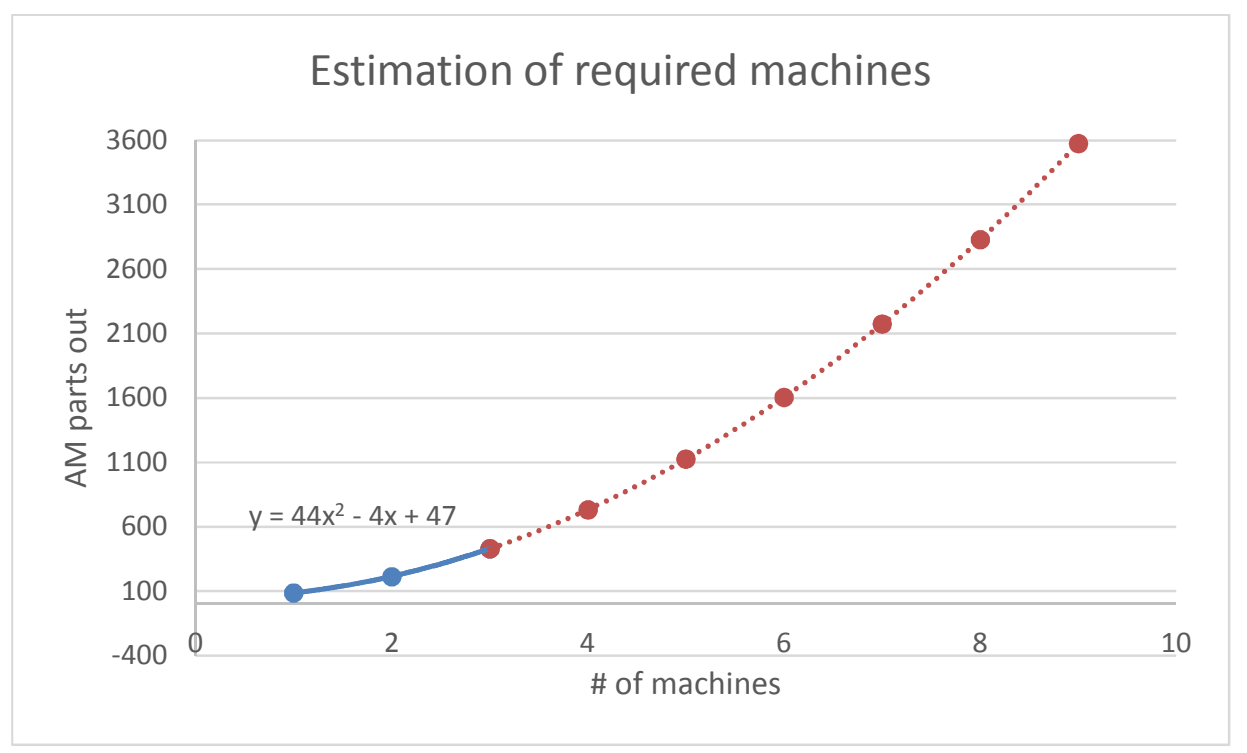

Table 8-11: AM parts out using two, three or the base case strategy with flexible material 


\subsubsection{INFLUENCE OF CO2 EMISSIONS}

Many publications assume that $\mathrm{AM}$ is able to reduce $\mathrm{CO}_{2}$ emission. This hypothesis cannot be proven by this thesis but two facts support the idea. The following results can be drawn based on the base case results for an upper limit of $150 \mathrm{hrs,} \mathrm{which} \mathrm{is} \mathrm{a} \mathrm{reasonable} \mathrm{approximation} \mathrm{of} \mathrm{some}$ of the actual warehouse situation with low turnover items. In this case the low turnover of parts indicates that approximation that $89 \%$ of the part types are stored without any use. This consequently implies that the manufacturing and transport of unnecessary spare parts to the warehouse would result in unnecessary $\mathrm{CO}_{2}$ emissions. Furthermore, these parts account for approximately $1,389 \mathrm{~kg}$ of materials which do not need to be manufactured in the first place. For AM strategy, both aspects would likely contribute to the reduction of $\mathrm{CO}_{2}$ emissions compared to a warehouse. Referring to a study by the ALBA Group the $\mathrm{CO}_{2}$ savings are estimated (ALBA Group, 2011). The study contains the following information presented in Table 8-12.

1.2 billion tons of steel were produced by primary and secondary ${ }^{11}$ production in $2009.13 \%$ of the material was delivered by secondary production. When steel is recycled 0.97 ton $\mathrm{CO}_{2}$ are produced for every ton of material. Compared to primary production processes recycling saves 64 $\%$ of the primary production process (ALBA Group, 2011). This would result in a mixed CO2 production (primary plus secondary production) of 1.45 ton for every ton of steel. Therefore, for the previously described spare part stock, approximately 2 tons of $\mathrm{CO}_{2}$ would be produced as a result of over-stocking.

This calculation is not intended to be accurate, as it still lacks various details such as transportation and other process steps. However, it can be reasonably expected that with additional information the environmental benefits of adopting AM strategy can be further justified.

${ }^{11}$ Recycling 
Table 8-12: Non-required part on stock

\begin{tabular}{|c|c|c|c|}
\hline Low turnover parts only & Unit & Value (AM) & $\begin{array}{c}\text { Warehouse } \\
\text { data }\end{array}$ \\
\hline Parts consumed (base case) & pcs. & \multicolumn{2}{|c|}{59} \\
\hline Parts types in warehouse & pcs. & 0 & 523 \\
\hline Consumed parts from warehouse & $\%$ & --- & 11 \\
\hline Unnecessary parts types in storage & pes. & $\mathbf{0}$ & 512 \\
\hline Unnecessary parts types in storage & $\%$ & $\mathbf{0}$ & 89 \\
\hline
\end{tabular}

Averaged values

\begin{tabular}{|l|l|c|c|}
\hline Consumed material & $\mathrm{kg}$ & 183 & 180 \\
\hline Consumed material per consumed part ${ }^{12}$ & $\mathrm{~kg}$ & 3 & 3 \\
\hline Total material in storage $^{13}$ & $\mathrm{~kg}$ & 40 & 1569 \\
\hline Unnecessary material in storage (average) & $\mathbf{k g}$ & $\mathbf{0}$ & $\mathbf{1 3 8 9}$ \\
\hline
\end{tabular}

${ }^{12}$ Consumed material by AM divided by the parts consumed.

${ }^{13}$ Regarding AM - Material is assumed to be delivered in $80 \mathrm{~kg}$ bags and to be ordered just in time. This results in an average of $40 \mathrm{~kg}$ which can be assumed to always be on stock. 


\subsection{SPARE PARTS ON DEMAND - A SIMULATION BASED DECISION MAKING FRAMEWORK}

This thesis demonstrated a practical way to analyze the application of AM for spare part supply. The following points summarize the executed steps in a general way and present a proceeding for application.

1. Analyze the spare part stock

a. Sort for specific process related parameters such as material, building volume or other specific properties, which prescribe a specific AM-process.

b. Define the value of each spare part type per piece.

c. Define the allowed time to manufacture for each spare part type.

d. Define the penalty of each spare part time if not delivered in time.

e. Based on the previous information create a general spare part set, representing the total stock including the total stock value. (In this thesis ABC-analysis showed a good approximation to the real stock - this is assumed to be typical for spare parts).

2. Analyze the AM process information:

a. Process related Building space volume, buiding speed, available material, energy consumption

b. Cost related Material price, machine purchase price, maintenance cost, operator cost, (depreciation time)

3. Set up and apply the simulation model

a. Identify the parameter of interest. For example Total cost of AM, Total AM penalty, "AM parts out" and the queueing behavior deliver a good performance feedback. 
b. Follow the procedure by Kelton et. al (2010) for the simulation study setup. Analyze the results and draw conclusions

Execution of experiments - It is important to set limits for evaluation of the experiments. We identify in this dissertation the most important limit as a so called "upper limit." An upper limit is defined by the "accepted penalty" which should not exceed a defined value. In this work the accepted penalty is defined in the base case and represents the penalty at the breakeven point of warehousing and AM cost. It is also possible to pre-specify an "accepted penalty" that represents the monetary penalty cost paid for not being able to deliver the spare parts on time. In practice, the accepted penalty may vary depending on specific cases at hand, but it should remain as an important input parameter in the decision making framework. The point at which a system works at its upper limit defines the best strategy or system performance in the specific setup. Different strategies or setups will have different upper limits. Therefore the upper limit can be used as reference point to compare several strategies or setups against each other.

Analyzing the results - will be different for each case, depending on the issue of interest. For example for the base case it was appropriate to compare the Total AM cost against the Total warehousing cost over the utilization of the system. During technical investigations, it was better to compare the different strategies by the Total AM cost. The next section introduces several factor of interest helping to analyze the system.

Figure 8-3 illustrates the described process. 


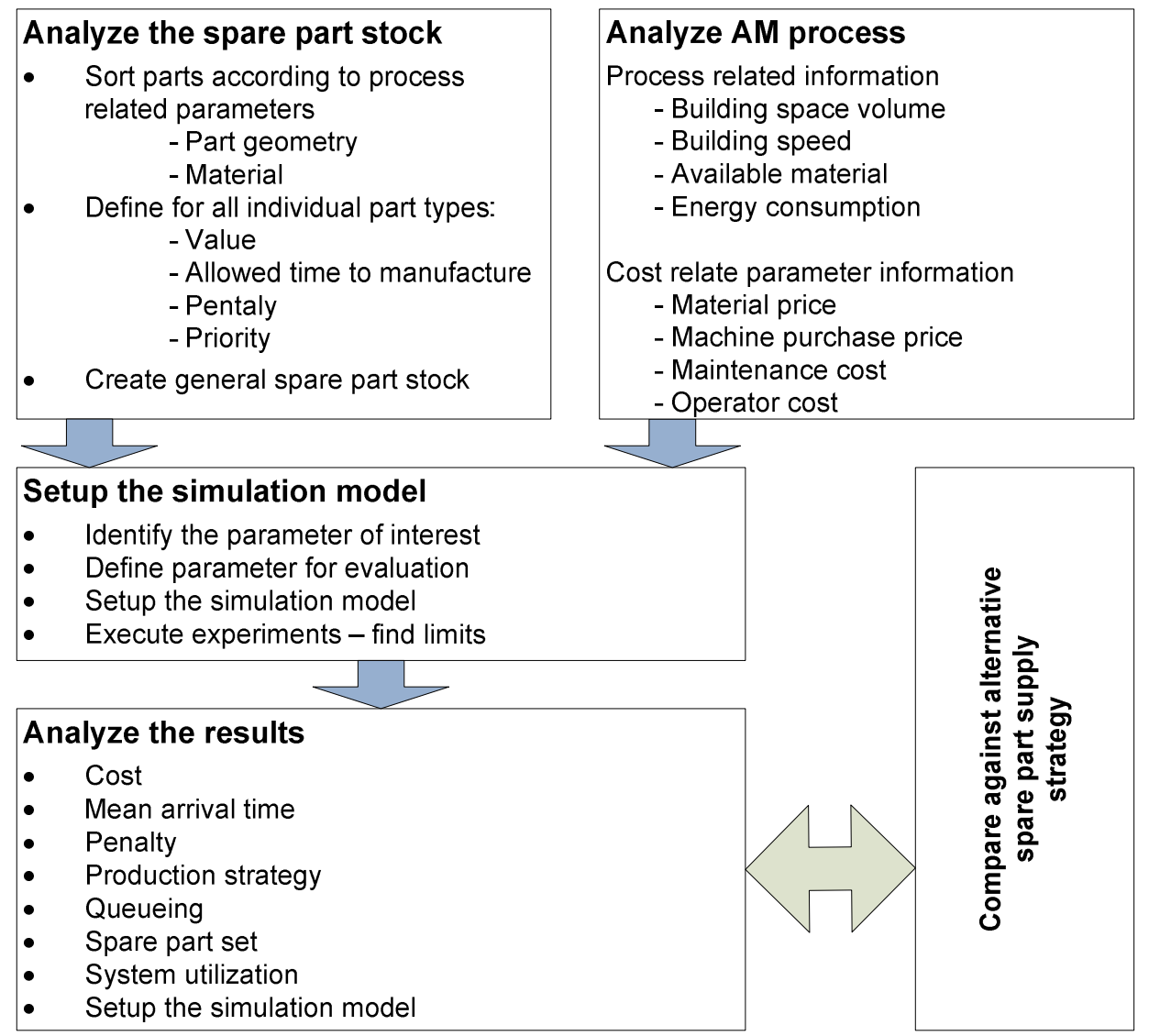

Figure 8-3: Spare parts on demand - a simulation based decision framework 


\subsection{FACTORS FOR EVALUATION}

During simulation and analysis, the following factors are of major interest for the system performance:

Cost - Cost is the overall result of the simulation. It allows comparing different strategies to each other and a comparison of completely different concepts such as warehousing. One exception to this is that the cost of AM may only be a secondary factor in certain situations. For example on an air craft carrier storage space is very limited and therefore to be evaluated as extremely valuable. In consequence, only the parameters relating to system performance may be considered.

Mean arrival time - The mean arrival time between spare part requests is the direct input to the system and the most important control variable of the system. Additionally, the distribution type of the part arrivals is a factor, which can be considered here.

Penalty - Penalty is a cost driver and indicates the performance level of the system. Therefore, the accepted penalty, represented by the sum of charged penalties, is used to control the system. For spare part supply in particular, the penalty should be minimized to the accepted level, since a missing spare part might create unwanted or extended downtimes of facilities, machines or equipment.

Production strategy - The selected strategy is the key input for the overall service level of the entire system. It describes the setup of machines, for example two machines with a fixed material assignment operating in a waiting mode. Special care should be taken on this issue.

Queuing - Is a good indicator of system stress. When queuing occurs, manufacturing time increases rapidly and additive manufacturing is no longer an option for spare part supply due to increased penalties. 
Spare parts set - The spare part size, the allowed time to manufacture and the actual mean arrival time of spare part requests may decide if a spare part set is interesting for the application. Knowledge about the spare part stock properties is the first important step for a good evaluation. Chapter 8.2.1 demonstrates an option to fit the spare part stock to the system properties and make AM work.

System utilization - Indicates at which level the system is able to operate in a stable state and how the system can be utilized with respect to the lower, upper and highest limit.

\subsection{ADJUSTMENT OF DISTRIBUTION OF SPARE PARTS PROCUREMENT}

Referring back to the model by Pérès and Noyes (2006) for illustrational reasons several things can be learned from the applied simulation:

1. In the "rapid spare part manufacturing" a "Time in queue" (h) should be considered before the actual production can start (This is an addition to the model by Pérès and Noyes (2006)). For a regular spare part production the waiting time in queue is essential for the success of a system. It should be the target to reach a waiting time in queue of zero for spare part on supply application. This will lead back to the original optimized assumption by Pérès and Noyes (2006).

2. To eliminate waiting time "Detection \& diagnosis" (a) is a good starting point. The earlier the need for a spare part is known, the better the production run can be planned, since the allowed time to manufacture is extended by the prediction of failure. A well thought-out setup of maintenance strategies may help to reach this goal (preventive repairs, regular inspections or condition monitoring). 
3. "Manufacturing" (f) provides further potential for improvement. It can be considered to apply postponement strategies (for example form, assembly or manufacturing postponement).
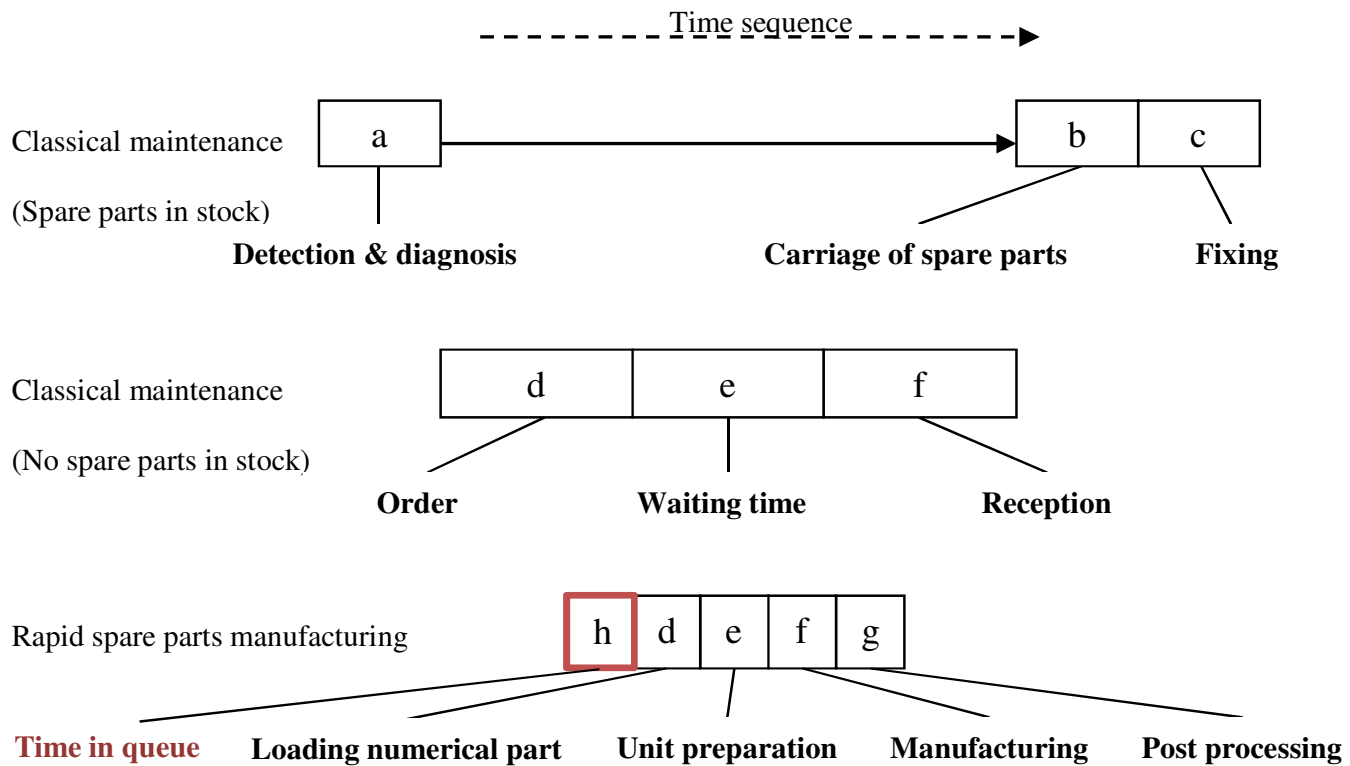

Figure 8-4. Comparison of time distribution for various strategies of spare parts procurement (Pérès \& Noyes, 2006) - Waiting time added 


\section{CONCLUSION}

This thesis analyzed some fundamental AM issues with respect to spare parts on demand. More importantly, it addresses the cost effective evaluation of using AM to make spare parts, compared to conventional warehousing, through the development of a simulation-based decision making framework. Although specific recommendations depend on particular scenarios where AM is an option, this thesis does offer some findings that are different from previously assumed deficits. In Chapter 2.2.2 several limitations were described. In respect to spare parts on demand the statements for AM process performance and cost can be modified.

AM process performance - It is stated that only a limited object size can be manufactured by AM. This can be an issue for regular production, but not for spare parts. It appears that the building space volume should be selected according to the biggest potential spare part since it will minimize the setup time. Therefore, in the spare part case, the performance of the system is not necessarily limited by the building space volume, but by the allowed time to manufacture. To meet the allowed time to manufacture, building speed, spare part size, system setup and cool down time are limiting, as already known, have potential to improve the process performance. Findings demonstrate that these parameters have a straightforward influence on the results. Further analysis of the available warehouse data did not show issues regarding part size. However, this needs to be evaluated individually for each spare part stock. For the presented simulation, the AM process performance was already performing equal to or better with the basic one machine solution than the actual warehouse, even without improving one of the process parameters. 
Cost - It is expensive to buy and maintain an AM machine. The same is true for a warehouse or workshop. The machine purchase price is therefore not as relevant a decision variable as considered by for example Neef et al (2005) from a spare part perspective. Also the material price is not necessarily too high. A cheaper price of machine and material will attract more customers, but the simulation model shows that the simulated AM process can already perform better than a warehouse under the given set of conditions, both from a cost and a performance perspective.

While the AM process performance parameters and cost issues are already in focus, the production strategy is not. As the results show the applied strategy of how and how many AMmachines will react on arriving spare part request has the most important impact. The selected strategy moves the total AM cost and the system performance to different levels. For further research, it can be of interest to focus more on the influence of several production strategies. As can be seen in the spare part size variation simulation, there is a correlation between the properties of the spare part stock and the selected production strategy. Consequently, more research in the area of spare part stock properties may allow to create smarter production strategies for a more efficient utilization of the AM machine.

As an example for a smarter production strategy, it is considered that adding parts to a production run might be beneficial. Adding parts to a production run can also be combined with a good building space packing strategy for parts, which is also an independent production strategy. Referring back to the waiting mode, waiting makes sense for a limited number of part combinations under the given set of conditions only. This is because the allowed time to manufacture can be exceeded for one or all parts in production, due to the longer production time. This can be equivalent to the adding part setup. But as it was shown for the waiting strategy for smaller parts this strategy can be beneficial. Another interesting strategy can be a machine with two building space volumes in which one is preparing the next production run while production is running in the other (similar to a two machine setup, but maintenance cost can reduce to a one 
machine setup). Also multi-material application in one production run (similar to the base case) can be of interest. Creative investigations might lead to further concepts.

As mentioned before the spare part stock takes a key role. When the target is making AM take part in spare part supply, it is important to take the whole set of aspects into consideration. This thesis starts to look at the process performance of AM with the spare part request arrival. This is a good stopping point for this simulation approach, since in a real life application the first point of interest would be maintenance. Well-considered and executed maintenance strategies reduce the number of unplanned arriving spare part requests. This means production becomes more plannable which in turn improves the AM system performance in terms of a possibly higher machine utilization.

Also spare part supply strategies can contribute to improving the system performance. One interesting topic is the issue of postponement strategies, such as form or assembly postponement. Also combinations with other supply strategies can improve the situation. For example when typically 5 parts of one type are stored due to their availability this number can be reduced. One part is stored and a new one will be produced if it is consumed. This could increase the allowed time to manufacture to a much more comfortable level, since the allowed time to manufacture is the most critical part attribute since it defines when the penalty is due.

In comparison to a classical warehousing of spare parts, AM for spare parts on demand is more complex. Due to the required production, the knowledge of the required parts must be more detailed than it is necessary when the parts are already available on stock. This makes it difficult to apply AM in every situation.

Already now AM is an option to reduce spare part stocks in an efficient way. It must be evaluated on an individual basis if the efforts are worth it to gain the spare part information and sufficient production strategy is available. 


\section{REFERENCES}

Adam, S. (1989). Optimierung der Anlageninstandhaltung. Berlin: Schmidt (Erich).

Agarwala, M., Bourell, D., Beaman, J., Marcus, H., \& Barlow, J. (1995). Direct selective laser sintering of metals. Rapid Prototyping Journal, 1(1), 26 - 36.

Agarwala, M., Bourell, D., Beaman, J., Marcus, H., \& Barlow, J. (1995). Post-processing selective laser sintered metal parts. Rapid Prototyping Journal, 1(2), 36 - 44.

ALBA Group. (02 2011). www.alba.info. Von www.alba.info: https://www.alba.info/fileadmin/alba/pressemappe/recycling_fuer_den_klimaschutz/Recy cling_fuer_den_Klimaschutz.pdf abgerufen

Alciatore, D. G., \& Wohlers, T. T. (1996). Importing and reshaping digitized data for use in rapid prototyping: a system for sculpting polygonal mesh surfaces. Rapid Prototyping Journal, $2(1), 13-23$.

Alfredsson, P. (1997). Optimization of multi-echelon repairable item inventory systems with simultaneous location of repair facilities. European Journal of Operational Research, 99, $584-595$.

Allen, S. G., \& D'esopo, D. A. (1968). An ordring policy for repairable stock items. Operations Research, 16(3), 482 - 489 . 
Anderson, G., \& Parker, G. (2002). The effect of learning on the make/buy decision. Production and Operations Management, 11(3), 313.

Atzeni, E., Ippolito, R., Iuliano, L., \& Gatto, A. (2003). Selective laser sintering: an evaluation of the performances of snad sintered products. Proceedings of the 6th AITeM Conference Enhancing the Science of Manufacturing, (S. 492 - 505).

Atzeni, E., Iuliano, L., Minetola, P., \& Salmi, A. (2010). Redesign and cost estimation of rapid manufactured plastic parts. Rapid Prototyping Journal, 16(5), 308 - 317.

Bassoli, E., \& Atzeni, E. (2009). Direct metal rapid casting: mechanical optimization and tolerance calculation. Rapid Prototyping Journal, 15(4), 238 - 243.

Boone, C. A., Craighead, C. W., \& Hanna, J. B. (2007). Postponement: an evolving supply chain concept. International Journal of Physical Distribution \& Logistics Management, 37(8), $594-611$.

Boothroyd, G., Dewhorst, P., \& Knight, W. (1994). Product design for manufacture and assembly. New York: Marcel Dekker Inc.

Bosnjakovic, M. (2010). Multicriteria inventory model for spare parts. Slavonski Brod: University of applied science Slavonski Brod.

Brody, P., \& Pureswaran, V. (2013). The new software-defined supply chain. Somers: IBM Corporation.

Broll, W. (1997). Distributed virtual reality for everyone - a framework for networked VR on the Internet. (S. 121 - 128). Los Alamitos: IEEE.

Burbidge, J., Falster, P., Riis, J., \& Svendsen, O. (1987). Integration in manufacturing. Computers in industry, 9(4), 297 - 305. 
Cansizoglu, O., Harryson, O. L., West II, H. A., Cormier, D. R., \& Mahale, T. (2008). Applications of structural optimization in direct metal fabrication. Rapid Prototyping Journal, 14(2), 114 - 122.

Chen, Y., Zhou, C., \& Lao, J. (2011). A layer-less additive manufacturing process based on CNC accumulation. Rapid Prototyping Journal, 17(3), 218 - 227.

Cheng, W., Fuh, J. Y., Nee, A. Y., Wong, Y. S., Loh, H. T., \& Miyazawa, T. (1995). Multiobjective optimization of part-building orientation in stereolithography. Rapid Prototyping Journal, 1(4), 12 -23.

Christensen, J., \& Bandyopadhyay, A. (2000). Reverse engineering of clear solids using refractive index matching. Rapid Prototyping Journal, 6(2), 87 - 96.

Christopher, M. (1992). Logistics \& Supply chain management. Pitman publishing.

Cohen, M. A., Kleindorfer, P., \& Lee, H. (1986). Optimal stocking policies for low usage items in multi-echelon inventory systems. Naval Research Logistics Quarterly, 33, 17 - 38.

Cohen, M., Agrawal, N., \& Agraval, V. (2006). Achieving breakthrough service delivery through dynamic asset deployment strategies. Inerfaces, 36(3), 259 - 271.

Cohen, M., Kleindorfer, P. R., \& Lee, H. (1992). Multi-item service constrained (s,S) Policies for spare parts logistics systems. Naval Research Logistics, 39, 561 - 577.

Craig, B. (2005). Mobile Parts Hospital Update. AMPTIAC Quarterly, 9(2), 16.

Crane, N. B., Tuckerman, J., \& Nielson, G. N. (2011). Self-assembly in additive manufacturing: opportunities and obstacles. Rapid Prototyping Journal, 17(3), 211 - 217.

Das, S., Beaman, J. J., Wohlert, M., \& Bourel, D. L. (1998). Direct laser freeform fabrication of high performance metal components. Rapid Prototyping Journal, 4(3), 112 - 117. 
de Weck, O. L., \& Simchi-Levi, D. (January 2006). Classes of Supply for Exploration Logistics. Abgerufen am 17. February 2012 von MIT Space logistics project: http://speacelogistics.mit.edu/hmp.htm

de Weck, O. L., \& Simchi-Levi, D. (2006). Commercial vs. Interplanetary Supply Chains. MIT Space Logistics Center. NASA. Abgerufen am 5. 12012 von http://spacelogistics.mit.edu/hmp.htm

de Weck, O. L., \& Simchi-Levi, D. (January 2006). Interplanetary Supply Chain Management and Logistics. Abgerufen am 17. February 2012 von MIT Space logistics project: http://spacelogistics.mit.edu/hmp.htm

de Weck, O. L., \& Simchi-Levi, D. (January 2006). Measures of Effectiveness. Abgerufen am 17. February 2012 von MIT Space logistics project: http://spacelogistics.mit.edu/hmp.htm de Weck, O. L., \& Simchi-Levi, D. (January 2006). Modeling Demand for Human Exploration. Abgerufen am 17. February 2012 von MIT Space logistics project: http://spacelogistics.mit.edu/hmp.htm

de Weck, O. L., \& Simchi-Levi, D. (January 2006). Simulation. Abgerufen am 17. February 2012 von MIT Space Logistics Project: http://spacelogistics.mit.edu/hmp.htm

de Weck, O. L., \& Simchi-Levi, D. (2006). The Haughton-Mars Project. MIT Space Logistics Center. NASA. Abgerufen am 5. 12012 von http://spacelogistics.mit.edu/hmp.htm de Weck, O. L., \& Simchi-Levi, D. (2006). U.S. Military Supply Chain and Logistics Analogies. MIT Space Logistics Center. NASA. Abgerufen am 5. 12012 von http://spacelogistics.mit.edu/hmp.htm 
de Weck, O., \& Simchi-Levi, D. (2006). Haughton-Mars Project Expedition 2005 - Final Report. Florida: Kennedy Sace Center.

de Weck, O., \& Simchi-Levi, D. (January 2006). Lessons Learned. Abgerufen am 17. February 2012 von MIT Space logistics project: http://spacelogistics.mit.edu/hmp.htm

Denicoff, M., Fennell, J., Haber, S. E., Marlow, W. H., \& Solomon, H. (1964). A polaris logistic model. Naval Research Logistics Quarterly, 11(4), 259 - 272.

Dhakar, T., Schmidt, C., \& Miller, D. (1994). Base stock level determination for higher cost low demand crititcal repairable spares. Computers and Operations Research, 21(4), 411 420.

Dimitrov, D., Schreve, K., \& de Beer, N. (2006). Advances in three dimensional printing - state of the art and future perspectives. Rapid Prototyping Journal, 12(3), 136 - 147.

Dimitrov, D., Schreve, K., Taylor, A., \& Vincent, B. (2007). Rapid prototyping driven design and realization of large components. Rapid Prototyping Journal, 13(2), 85 - 91.

Dolenc, A., \& Mäkelä, I. (1996). Rapid prototyping from a computer scientist`s point of view. Rapid Prototyping Journal, 2(2), 18 - 25.

Drizo, A., \& Pegna, J. (2006). Environmental impacts of rapid prototyping: an overview of research to date. Rapid Prototyping Journal, 12(2), 64 - 71.

Evans, M. A., \& Campbell, R. I. (2003). A comparative evaluation of industrial design models produced using rapid prototyping and workshop-based fabrication techniques. Rapid Prototyping Journal, 9(5), 344 - 351. 
Filipini, R. (1997). Operations management research: some reflections on evolution, models and empirical studies in OM. International Journal of Operations \& Production Management, 17(7), 655 - 670.

Furrens, K. K. (1999). Standards for the RP industry. Rapid Prototyping Journal, 5(4), 169 - 178.

Gajpal, P., Ganesh, L., \& Rajendran, C. (1994). Crititcality analysis of spare parts using the analytic hierarchy process. International Journal of Production Economics, 35, 293 298.

Galluzzi, M., Zapata, E., Steele, M., \& de Weck, O. (2006). Foundations of Supply Chain Management for Space Application. Massachusetts: Americal institute of Aeronautics and Astronautics.

Gebhardt, A. (2007). Generative Fertigungsverfahren (Bd. 3). München: Carl Hanser Verlag.

Geraerds, M. (1992). The EUT maintenance model. International Journal of Production Economics, 24, 209 - 216.

Ghany, K. A., \& Moustafa, S. F. (2006). Comparison between the products of four RPM systems for metals. Rapid Prototyping Journal, 12(2), 86 - 94.

Gibson, I., \& Shi, D. (1997). Material properties and fabrication parameters in selective laser sintering process. Rapid Prototyping Journal, 3(4), 129 - 136.

Gibson, I., Rosen, D. W., \& Stucker, B. (2010). Additive Manufacturing Technologies - Rapid Prototyping to Direct Digital Manufacturing. New York: Springer.

Gibson, I., Rosen, D. W., \& Stucker, B. (2010). Distinction between AM and CNC machining. In I. Gibson, D. W. Rosen, \& B. Stucker, Additive manufacturing technologies (S. 9). New York Heidelberg Dordrecht London: Springer. 
Gilmore, J. H., \& Pine II, B. J. (May 2009). The four faces of mass customization. S. 91 - 101.

Greulich, M., Greul, M., \& Pintat, T. (1995). Fast, functional prototypes via multiphase jet solidification. Rapid Prototyping Journal, 1(1), 20 -25.

Grimaldi, D., \& al., e. (1998). Java-based distributed measurement systems. IEEE Transactions on Instrumentation and Measurement, 47(1), 100 - 103.

Gross, D., \& Ince, J. F. (1978). Spares provisioning for repairable items: Cyclic queues in light traffic. AIIE Transactions, 10(3), 307 - 315.

Gross, D.; Pinkus, C. E.;. (1979). Designing a support system for repairable items. Computers and Operations research, 6(1), 59 - 68 .

Hague, R., Campbell, I., Dickens, P., \& Reeves, P. (2001). Integration of solid freeform fabrication in design. Paper presented at Solid Freeform Symposium. Austin, Texas, USA.

Hague, R., Mansour, S., \& Saleh, N. (2004). Material and design considerations for rapid manufacturing. International Journal of Production Research, 42(22), 4691 - 4708.

Halbeisen, M. (2007). fmeainfocentre.com. Abgerufen am 24. 082007 von www.fmecainfocenter.com/foreign\%20language/halbeisen,pdf

Hasan, S., \& Rennie, A. (unknown). The application of rapid manufacturing technologies in the spare parts industry. Lancaster: Lancaster Product Development Unit.

Hausman, W. D., \& Scudder, G. D. (1982). Priority scheduling for repairable inventory systems. Management Science, 28(11), 1215-1232.

Hedges, M. (kein Datum). Advanced Repairs for Aerospace and Defence. Von http://www.optomec.com. abgerufen 
Hoek, R. v. (1998). Logistics and virtual integration. Postponement, outsourcing and the flow of information. International Journal of Physical Distribution and Logistics Management, 28(7), $508-523$.

Holmström, J., Partanen, J., Tuomi, J., \& Walter, M. (2010). Rapid manufacturing in the spare parts supply chain. Journal of Manufacturing Technology Management, 21(6), 687 - 697.

Hopkinson, N., \& Dickens, P. (2001). Rapid prototyping for direct manufacture. Rapid Prototyping Journal, 7(4), 197 - 202.

Hopkinson, N., \& Dickens, P. (2001). Rapid Prototyping for direct manufacture. Rapid Prototyping Journal, 7(4), 197 - 202.

Hopkinson, N., \& Dickens, P. (2003). Analysis of rapid manufacturing - using layer manufacturing processes for production. Proceedings of Institution of Mechanical Engineers Part C Journal of Mechanical Engineering Science, 217(1), 31 - 39.

Hopkinson, N., Hague, R., \& Dickens, P. (2006). Rapid Manufacturing: An Industrial Revolution for the Digital Age. Wiley.

Horngreen, C. T., Datar, S. M., \& Foster, G. M. (2007). Cost Accounting. Englewood, NJ: Prentice-Hall.

http://spacenet.mit.edu. (6. October 2009). Abgerufen am 03. January 2012 von SpaceNet: http://spacenet.mit.edu/spacenet_2-5.php

Hull, C., Feygin, M., Baron, Y., Sanders, R., Sachs, E., Lightman, A., \& Wohlers, T. (1995). Rapid Prototyping: current technology and future potential. Rapid Prototyping Journal, l(1), 11 - 19. 
Humphreys, P., Lo, V., \& McIvor, R. (2000). A decision support framework for strategic purchasing. Journal of Materials Processing Technology, 107, 353 - 362.

Ikhwan, M., \& Burney, F. (1994). Maintenance in Saudi industry. International Journal of Operations and Production Management, 14(7), 70 - 80.

Ippolito, R., Luliano, L., \& Gatto, A. (1995). Benchmarking of rapid prototyping techniques in terms of dimensional accuracy and surface finish. Annals of the CIRP, 44, S. 157 - 160.

Jedeck, S. (2007). Instandhaltungsstrategie zur Optimierung der Verfügbarkeit der Engpassanlage "Bandsäge" in der Aluminium-Barrenproduktion. Köln: Fachhochschule Köln.

Kaio, N., \& Osaki, S. (1978). Optimum planned maintenance policies with lead time for an operating unit in preventive maintenance. IEEE Transactions on reliability, 27, 270 271.

Kelton, W. D., Sadowski, P. R., \& Swets, B. N. (2010). Simulation with Arena (Fifth edition Ausg.). New York: McGraw Hill.

Kennedy, W. J., Patterson, J. W., \& Fredendall, L. D. (2002). An overview of recent literature on spare parts inventories. Interantional Jurnal Production Economics, 76, 201 - 215.

Kennedy, W. J., Patterson, J. W., \& Fredendall, L. D. (2002). An overview of recent literature on spare parts inventories. International Journal of Production Economics, 76(2), 201 - 215.

Kerbrat, O., Mognol, P., \& Hascoet, J.-Y. (2010). Manufacturability analysis to combine additive and subtractive processes. Rapid Prototyping Journal, 16(1), 63 - 72.

Kilpi, J., \& Vepsäläinen, A. (2004). Pooling of spare components between airlines. Journal of Ai Transportation Management, 10(2), 137 - 46. 
Kilpi, J., Töyli, J., \& Vepsäläinen, A. (2009). Cooperative strategies for the availability of repairable aircraft components. International Journal of Production Economics, 117, 360 -370 .

Kim, J., Shin, K., \& Yu, H. (1996). Optimal algorithm to determine the spare inventory level for a repairable-item inventory system. Computers and Operations Research, 23(3), 289 - 297.

Kispera-Moron, D., \& Swierczek, A. (2010). The selected determinants of manufacturing postponement within supply chain context: An international study. International journal of production economics, 133, $192-200$.

Lampel, J., \& Mintzberg, H. (1996). Customizing customization. Sloan Management review, 37, $21-30$.

Lee, H. L. (2002). Aligning supply chain strategies with product uncertainties. California Management Review, 44(3), 105 - 119.

Liou, F., Slattery, K., Kinsella, M., Newkirk, J., Chou, H.-N., \& Landers, R. (2007). Applications of a hybrid manufacturing process for application of metallic structures. Rapid Prototyping Journal, 13(4), 236 - 244.

Mars on Earth - The Haughton-Mars Project. (2010). Von Mars on Earth - The Haughton-Mars Project: http://marsonearth.org/ abgerufen

Mason-Jones, R., \& Towill, D. R. (1999). Using the Information Decoupling Point to Improve Supply Chain Performance. The International Journal of Logistics Management, 10(2), $13-26$. 
McCarthy, I., \& Anagnostou, A. (2004). The impact of outsourcing on the transaction costs and boundaries of manufacturing. International Journal of Production Economics, 88(1), 61 71.

McGrath, J. E. (1981). Dilemmatics. American Behavioral Scientist, 25(2), 179 - 210.

Mello, C. H., Martins, R. C., Parra, B. R., Pamplona, E. d., Salgado, E. G., \& Seguso, R. T. (2010). Systematic proposal to calculate price of prototypes manufactured through rapid prototyping and FDM 3D printer in a university lab. Rapid Prototyping Journal, 16(6), $411-416$.

Mognol, P., Rivette, M., Jegou, L., \& Lesprier, T. (2007). A first approach to choose between HSM, EDM and DMLS processes in hybrid rapid tooling. Rapid Prototyping Journal, 13(1), 7 - 16.

Moore, R. (1996). Establishing an inventory management program. Plant Egineering, 50(3), 113 $-116$.

Neef, A., Burmeister, K., \& Krempl, S. (2005). Vom Personal Computer zum Personal Fabricator. Hamburg: Murmann Verlag.

Oeldorf, G., \& Olfert, K. (2004). Materialwirtschaft (11 Ausg.). Herne: Kiehl.

Pagh, J. D., \& Cooper, M. C. (1998). Supply chain postponement and speculation strategies: how to choose the right strategy. Journal of busness logistics, 19(2), 13 - 30.

Peng, L., Huang, S. H., Mokasdar, A., Zhou, H., \& Hou, L. (4. May 2013). The impact of additive manufacturing in the aircraft spare part supply chain: supply chain operation reference (scor) model based analysis. Production Planning \& Control, S. 1-13. 
Penrose, H. (2008). Physical Asset Management for the Executive. Success by design management, 116.

Pérès, F., \& Durand, J. (2002). Maintainability Improvement of Isolated Systems through the use of Rapid Prototyping Techniques: A Prospective approach. Esreda Seminar (S. 27 - 28). Madrid: Esreda Seminar.

Pérès, F., \& Grenouilleau, J.-C. (2002). Initial spare part supply of an orbital system. Aircraft Engineering and Aerospace Technology, 74(3), 252-262.

Pérès, F., \& Noyes, D. (2006). Envisioning e-logistics development: Making spare parts in situ and on demand - State of the art and guidelines for future developments. Computers in industry, 57, 490-503.

Pérès, F., Grenouilleau, J. C., Housseini, O., \& Martin, C. (2002). Isolated Missions Manufacturing spare parts throug rapid prototyping. Air Force Journal of Logistics, 26(2), $10-43$.

Pérès, F., Grenouilleau, J. C., Housseini, O., \& Martin, C. (2002). Isolated Missions Manufacturing spare parts through rapid prototyping. Air Force Journal of Logistics, $26(2), 10-43$.

Rivette, M., Hascoet, J. Y., \& Mognol, P. (2007). A based graph methodology for hybrid rapid design. Journal of Engineering Manufacture, 221(4), 685 - 697.

Rosen, D. W. (2005). Direct digital manufacturing: issues and tools for making key decisions. Proceedings SME rapid prototyping and manufacturing conference. Dearborn.

Rötzel, A. (2001). Instandhaltung - eine betriebliche Herausforderung. Berlin, Offenbach: VDE Verlag. 
Ruffo, M., Tuck, C., \& Hague, R. (2007). Make or buy analysis for rapid manufacturing. Rapid Prototyping Journal, 13(1), 23 - 29.

Ruffo, M., Tuck, C., \& Hague, R. J. (2006). Cost estimation for rapid manufacturing - laser sintering production for low to medium volumes. Journal of Engineering Manufacture, 220(9), $1417-1427$.

Schulte, C. (1999). Logistik - Wege zur Optimierung der Supply Chain (Bd. 3). München: Franz Vahlen GmbH.

Sharman, G. (1984). The rediscovery of logistics. Harvard Business Review, 62, 71 - 79.

Shull, S. A., Gralla, E. L., de Weck, O. L., \& Shishko, R. (2006). The Future of Asset Management for Human Space Exploration: Supply Classification and an Integrated Database. Pasadena, CA: Jet Propulsion Laboratory, National Aeronautics and Space Administration.

Siddiqi, A., \& de Weck, O. L. (2006). Spare Parts Requirements for Space Missions with Reconfigurability and Commonality. Massachusetts: American Institute of Aeronautics and Astronautics.

Simkin, Z., \& Wang, A. (2014). Cost-Benefit Analyses for Final Production Parts. Wohlers associates. Inc.

Simpson, V. P. (1978). Optimum solution structure for a rapairable inventory problem. Operations Research, 19(2), 270 - 281.

Skipworth, H., \& Harrison, A. (15. May 2004). Implications of form postponement to manufacturing: a case study. International Journal of Production Research, 42(10), 2063 $-2081$. 
Smith, P. G. (1999). The business of RP. Rapid Prototyping Journal, 5(4), 179 - 185.

Smith, P. G., \& Reinertsen, D. G. (1998). Developing Products in Half Time: New rules, new tools. New York, NY: John Wiley \& Sons.

Sonmez, F. O., \& Hahn, H. T. (1998). Thermo-mechanical analysis of the laminated objectmanufacturing (LOM) process. Rapid Prototyping Journal, 4(1), 26 - 36.

Stölzl, S. (2000). Fehlertolerante Pedaleinheit für ein elektromagnetisches Bremssystem (Break by wire). Düsseldorf: VDI-Verlag.

Storch, S., Nellessen, D., Schaefer, G., \& Reiter, R. (2003). Selective laser sintering: qualifying analysis of metal based powder systems for automative applications. Rapid Prototyping Journal, 9(4), 240 - 251.

Stucker, B., \& Qu, X. (2003). A finish machining strategy for rapid manufactured parts. Rapid Prototyping Journal, 9(4), 194 - 200.

Tay, F. E., Khanal, Y. P., Kwong, K. K., \& Tan, K. C. (2001). Distributed rapid prototyping - a framework for internet prototyping and manufacturing. Intergrated Manufacturing Systems, 12(6), 409 - 415.

Tay, F., Khanal, Y., Kwong, K., \& Tan, K. (2001). Distributed rapid prototyping - a framework for internet prototyping and manufacturing. Integrated Manufacturing Systems, 12(6), $409-415$.

Tolochko, N. K., Mozzharov, S. E., Yadroitsev, I. A., Laoui, T., Froyen, L., Titov, V. I., \& Ignatiev, M. B. (2004). Selective laser sintering and cladding of single-component metal powders. Rapid Prototyping Journal, 10(2), 88 - 97. 
Twede, D., Clarke, R. H., \& Tait, J. (2000). Packaging postponement: a global packaging strategy. Packaging Technology and Sciences, 13(3), 105 - 15.

Unknown. (2007). Unknown. Instandhaltung - Technik, Management, Märkte(6/07), 16-20.

Vallabhajosyula, P., \& Bourell, D. L. (2011). Modeling and production of fully ferrous components by indirect selective laser sintering. Rapid Prototyping Journal, 17(4), 262 268.

van der Schueren, B., \& Kruth, J. P. (1995). Powder deposition in selective metal powder sintering. Rapid Prototyping Journal, 1(3), 23 - 31.

van Hoek, R. I. (2000). The role of third party logistics providers in mass customization. International Journal of Logistics Management, 11(1), 37 - 46.

Van Hoek, R. I., Commandeur, H. R., \& Vos, B. (1998). Reconfiguring logistics systems through postponement strategies. Journal of business logistics, 19(1), 33 - 53.

van Hoek, R. I., Commandeur, H. R., \& Vos, B. (1998). Reconfiguring loogistics systems through postponement strategies. Journal of business logistics, 19(1), 33 - 54.

van Hoek, R. L. (2001). The rediscovery of postponement a literature review and direktions for research. Journal of Operations Management, 19(2), 161 - 84.

VDI-Richtlinie_2892. (2006). Ersatzteile in der Instandhaltung. 4.

Walker, G., \& Weber, D. (1984). A transaction cost approach to make or buy decisions. Administrative Science Quarterly, 29, 113 - 141.

Walker, J. (1996). Agraphical aid for initial purchase of insurance type spares. Journal of the Operational Research society, 47, 1296 - 1300. 
Walter, M., Holmström, J., \& Yrjölä, H. (2004). Rapid manufacturing and its impact on supply chain management. Proceedings of the Logistics Research Network Annual Conference.

Wang, H. P., \& Li, J. K. (1991). Computer aided process planning. Elsevier.

Williams, J. D., \& Deckard, C. R. (1998). Advances in modeling the effects of selected parameters on the SLS process. Rapid Prototyping Journal, 4(2), 90 - 100.

Witter, A. (1995). Entwicklung eines Modells zur optimierten Nutzung des Wissenspotentials einer Prozess-FMEA. Düsseldorf: VDI-Verlag.

Wohlers, T. (1995). Future potential of rapid prototyping and manufacturing around the world. Rapid Prototyping Journal, 1(1), 4 - 10.

Wohlers, T. (2008). State of the industry. Annual Worldwide Progress Report. Wohlers Report.

Wohlers, T., \& Grimm, T. (2001a). Rapid production: key barriers to growth. Von Perspectives: Time-compression technologies: www.wohlersassociates.com/Apr01TCT.htm abgerufen

Wohlers, T., \& Grimm, T. (March/ April 2002). The real cost of RP. Time Compression Magazine.

Wysk, R. (July 2009). IMCRC newsletter. available at: www.lboro.ac.uk/eng/research/imcrc/pdf/Newsletter_July_2009.pdf.

Xing, B., Gao, W.-J., Battle, K., Nelwamondo, F. V., \& Marwala, T. (2011). e-Reverse Logistics for Remanufaturing-to-order: An Online Auction-based and Multi-Agent System Supported Solution. The (S. 78 - 83). Faculty of Engineering and the Buildt Environment.

Xu, F., Loh, H. T., \& Wong, Y. S. (1999). Considerations and selection of optimal orientation for different rapid prototyping systems. Rapid Prototyping Journal, 5(2), 54 - 60. 
Xu, F., Wong, Y. S., \& Loh, H. T. (2000). Toward generic models for comparative evaluation and process selection in rapid prototyping and manufacturing. Journal of Manufacturing Systems, 19(5), 283 - 296.

Xu, Z., Zhao, Z., \& Baines, R. W. (2000). Constructing virtual environments for manufacturing simulation. International Journal of Production Research, 38(17), 4171-4191.

Yang, B., \& Burns, N. (2003). Implications of postponement for the supply chain. International journal of production research, 41(9), 2075 - 2090.

Yang, B., Burns, N., \& Backhouse, C. (2004a). Management of uncertainty through postponement. International Journal of Production Research, 42(6), 1049 - 64.

Yuen, S. L. (2003). Postponement Strategies for Mobile Application Development - A Framework. 16 th Bled eCommerce Conference eTransformation (S. 934 - 948). Bled, Slovenia: University of Hong Kong.

Zäh, M. F. (2006). Wirtschaftliche Fertigung mit Rapid-Technologien. München: Carl Hanser Verlag.

Zhang, G., Tsou, Y.-c., \& Rosenberger, A. L. (2000). Reconstruction of the homunculus skull using a combined scanning and stereo-lithography process. Rapid Prototyping Journal, $6(4), 267-275$.

Zinn, W., \& Bowersox, D. (1988). Planning physical distribution with the principle of postponement. Journal of business logistics, 9(2), 117 - 136. 
APPENDIX 
Arena is a fully hierarchical high level simulation software which allows the user to use predefined modules and constructs. When necessary, it is possible to break the programming down to a low level where alternative programming languages such as Microsoft Visual Basic, C or other alternatives can be applied, which allows individual setups of a model. The work done in this study will use Arena as modeling tool and tries to use the predefined modules to keep a high programming level and provide transparency for the reader. To have an idea about the concept and the functionality of Arena this section provides an overview about the concepts and functions of the software. For more detail, refer to literature, which holds detailed information. ${ }^{14}$

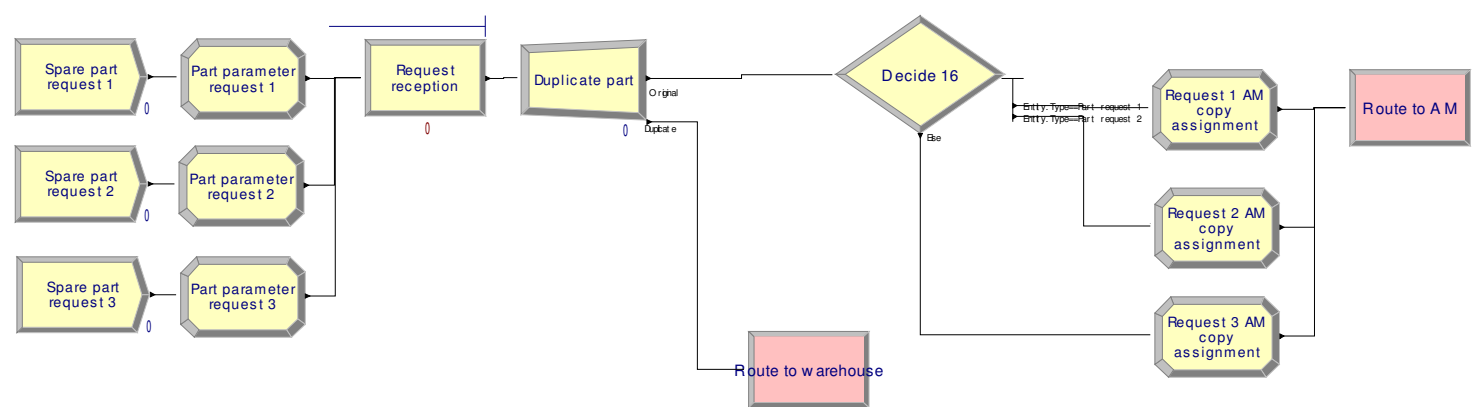

Figure 9-1: Graphical display of connected Arena modules

Figure 9-1 shows an extract of an Arena simulation model. It has great resemblance to a process flow chart and works very similarly. Entities, in this case spare part requests, are generated, enter the system, move through the process and leave the system when the process is finished. Arena allows to describe the way of an entity through a process in detail by use of attributes, variables, queues, resources and modules simulating logical actions. The following will introduce the most

14 "Simulation with Arena" Kelton et al. (2010) 
important Arena information to enable the reader to understand further explanations in the scope of this work. It will start with the basic modules.

Create module - The first thing which happens in a simulation model is the creation of an entity. In the create module the name and type of an entity is defined by the user. Also the time between arrivals and number of arrivals can be edited by changing the settings. Different types of entities can be created by several create modules in one simulation model.
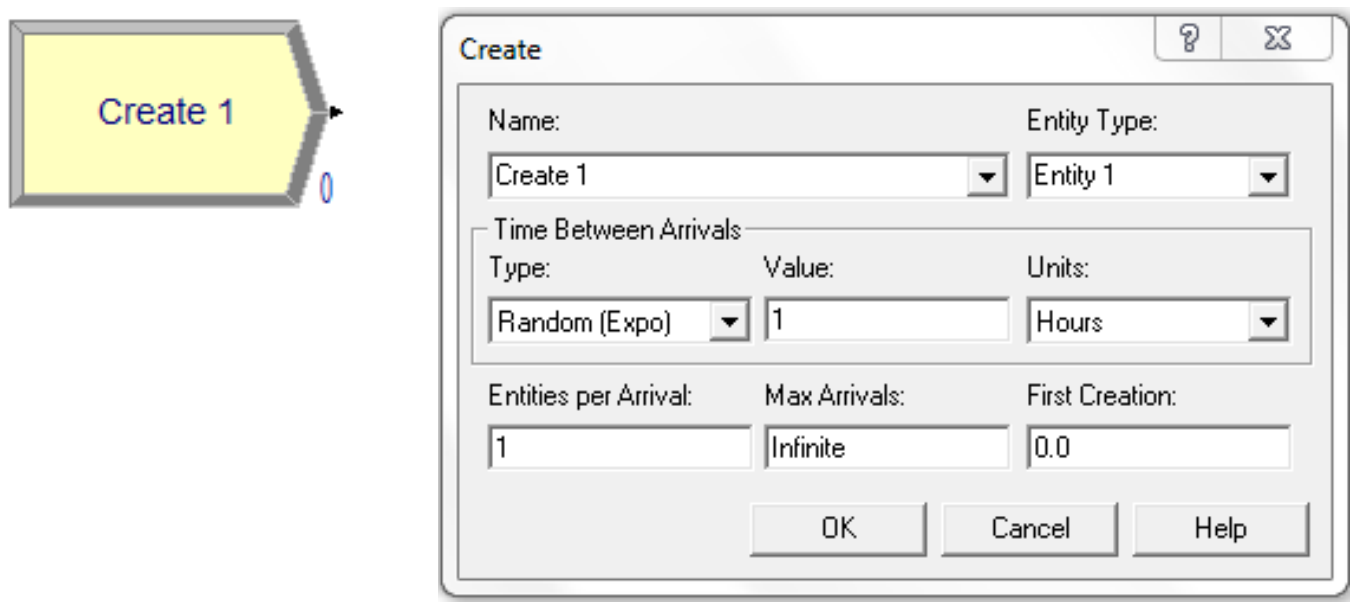

Figure 9-2: Create module

Assign module - The assign module allows to assign variables and attributes to an entity when it enters the module. It is also possible to change the entity type itself. The difference between variables and attributes must be explained. Both can be assigned to an entity and contain a specific value. A variable can be understood as a global variable that can be used or changed at every position in the model. An attribute is to understand as a local variable which is directly linked to an entity. While discussing variables it is important to know that there are two types of variables in Arena. The first type are user defined variables such as service time, building space, etc.. The other variables are Arena build-in variables which are automatically followed like number in queue, WIP, current simulation clock, etc.. According to Kelton et al (2010) variables 
can be used as trigger changing values over time and they can be useful to collect user defined statistics and metrics.
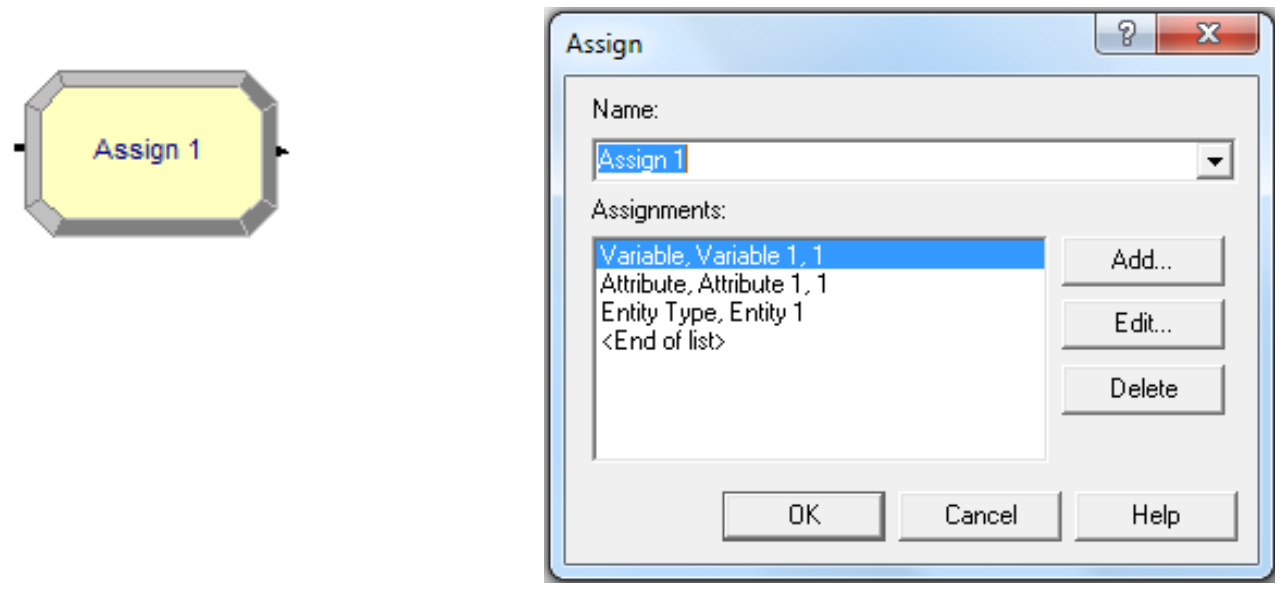

Figure 9-3: Assign module

Process module - The process module allows to simulate a process. In the following model the process module is typically used in the setting "Seize Delay Release". When an entity enters the module a resource is seized, for example a person, machine or something else that is required to perform the task. The time the process takes is defined by delay, which can be set in the module directly, and can follow various distributions or a mathematical expression. When the process is finished, the resource is released again and is available for the next process.

Due to the delay of processing it is logical that queuing occurs when the entities have to wait for processing. Therefore a symbol for the queue is shown above the process module, where the entities are displayed while waiting.

It is possible to set rules for the queue. The predefined rules are First in first out, Last in first out, Lowest attribute value and Highest attribute value. The preset for each queue is First in first out, which can be changed when required. Queues can also appear on other modules, for example the hold module. 

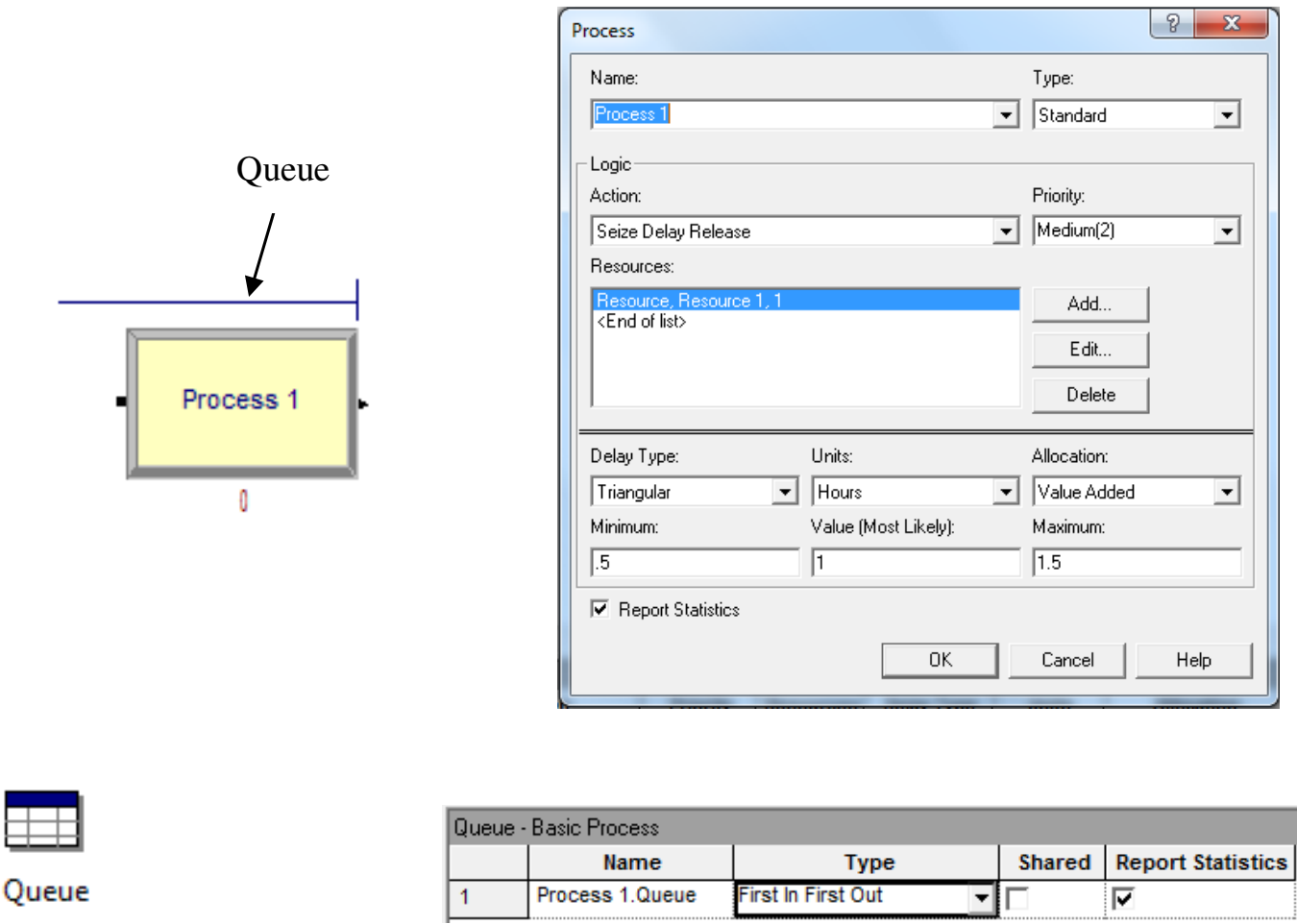

Figure 9-4: Process module and queue

Decide module - The decide module allows to direct entities by chance or condition to different paths through the process. For both, the decision can be 2-way or n-way.

The setup by chance follows assigned probabilities in percent. The proceeding is the same for $\mathrm{n}$ ways. Figure 9-5 shows a fifty percent chance that the entity will follow the true path, as opposed to following the false path. The decide module is also very interesting in the condition based setup, since it can analyze variables or attributes of entities and direct the entity accordingly. 


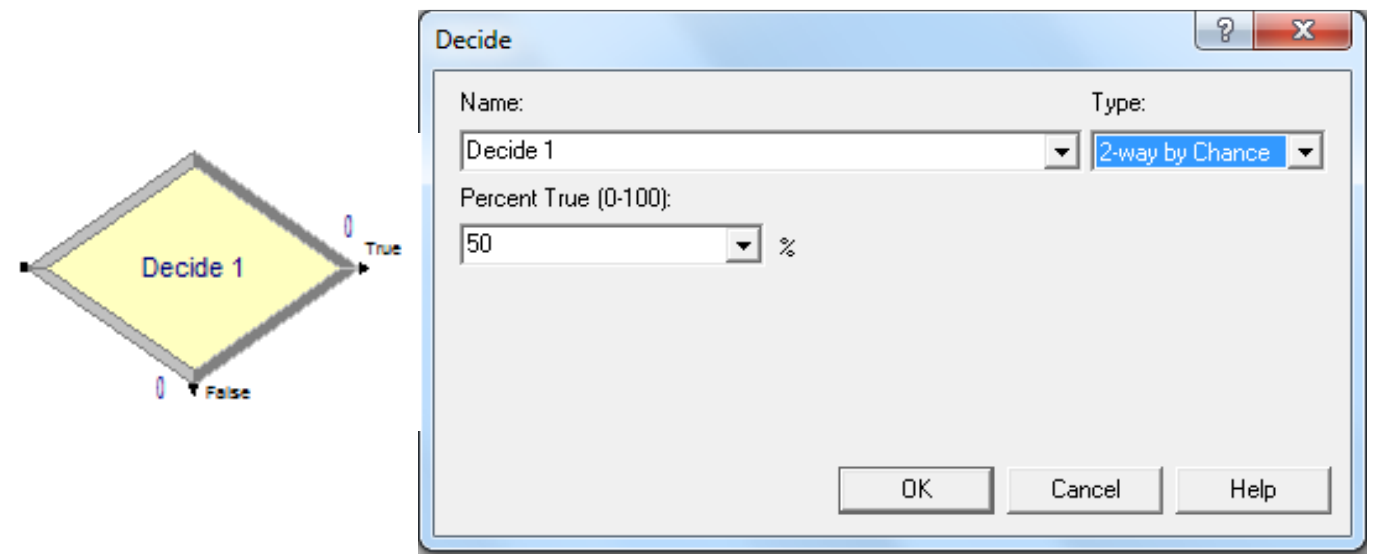

Figure 9-5: Decide module

Separate module - The separate module creates duplicates of entities or splits up arriving batches. The original entity will then follow the original path, while the duplicate will follow the duplicate path.
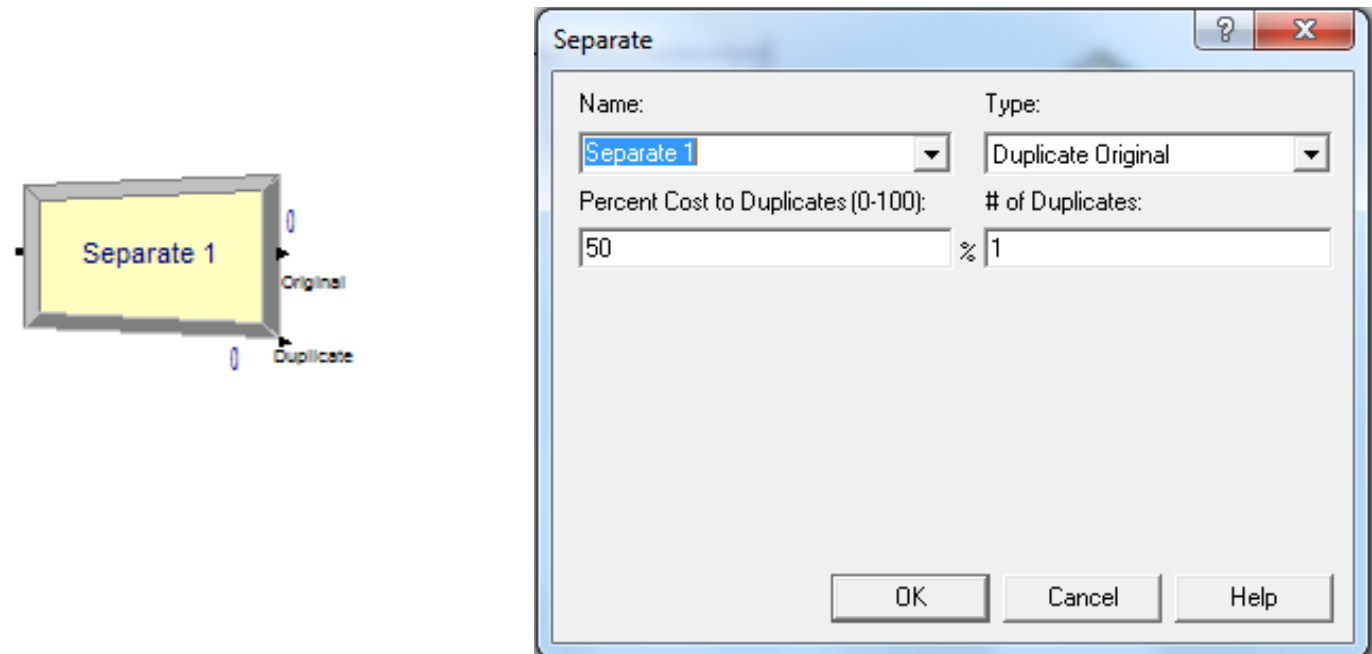

Figure 9-6: Separate module 
Hold module - The hold module is able to hold entities in a queue until a specific condition or a signal occurs. Then the entities in queue can pass the hold module. The next arriving entities will then again be held until a condition or signal is set. When the setup is condition based, the module scans for example process or queue parameters like "number in queue equals zero". The signal setup waits for an arriving signal. When the signal occurs the hold module allows the entities to pass. A signal is generated by a signal module.
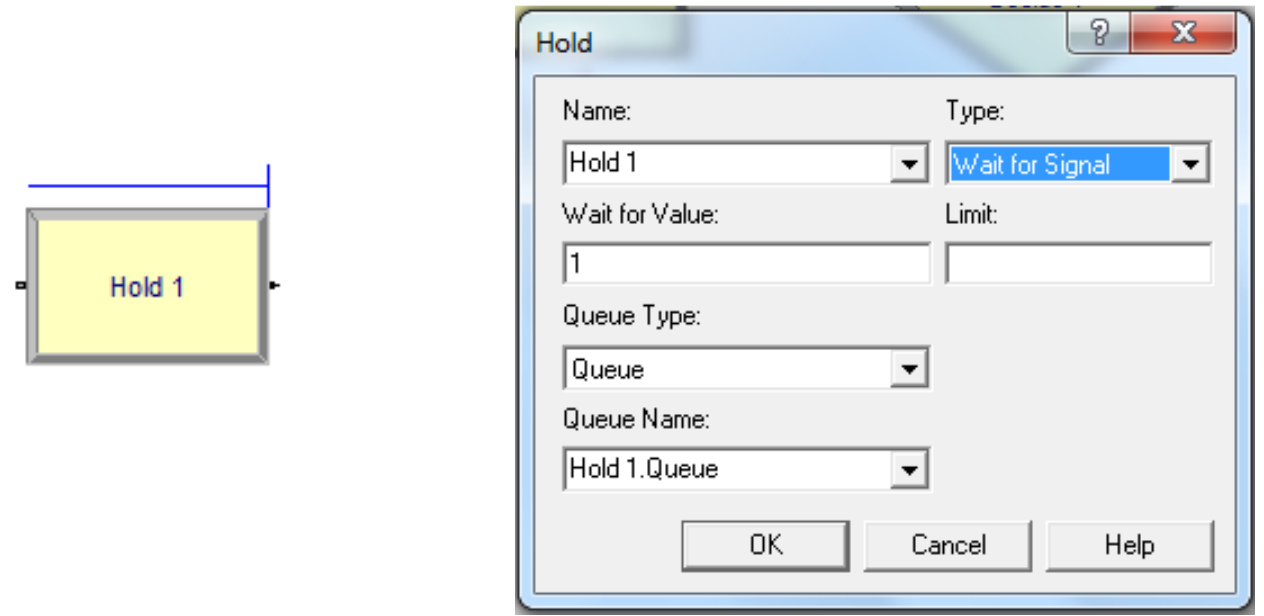

Figure 9-7: Hold module

Signal module - The signal module sends a signal to the whole model when an entity enters the module. In Figure 9-8 Signal 1 sends the value 1 as a signal. When for example a hold module, which waits for the signal 1 , receives the signal, it will allow the queued entities to pass. The signal activates all modules which are waiting for signal 1. 

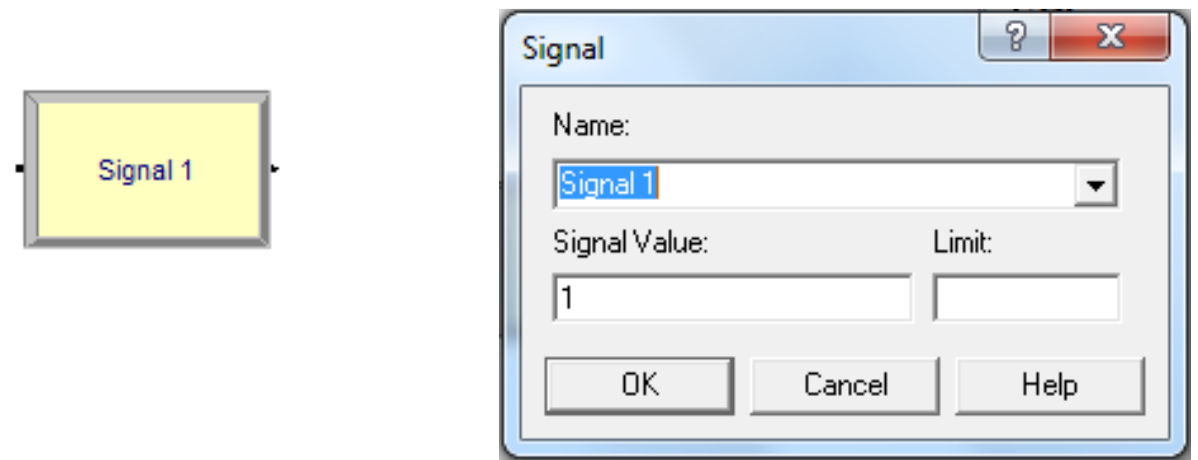

Figure 9-8: Signal module

Route and Station module - The route and station module typically appear together. The route module allows to send entities to a station without having the modules connected directly. This is beneficial when modules become complex and a direct connection is messing the view. It should be said that modules are always connected to each other, to guide the entity through the process. This can be avoided by the route and station idea. In Figure 9-9 the Route 1 module will send an entity to Station 1.
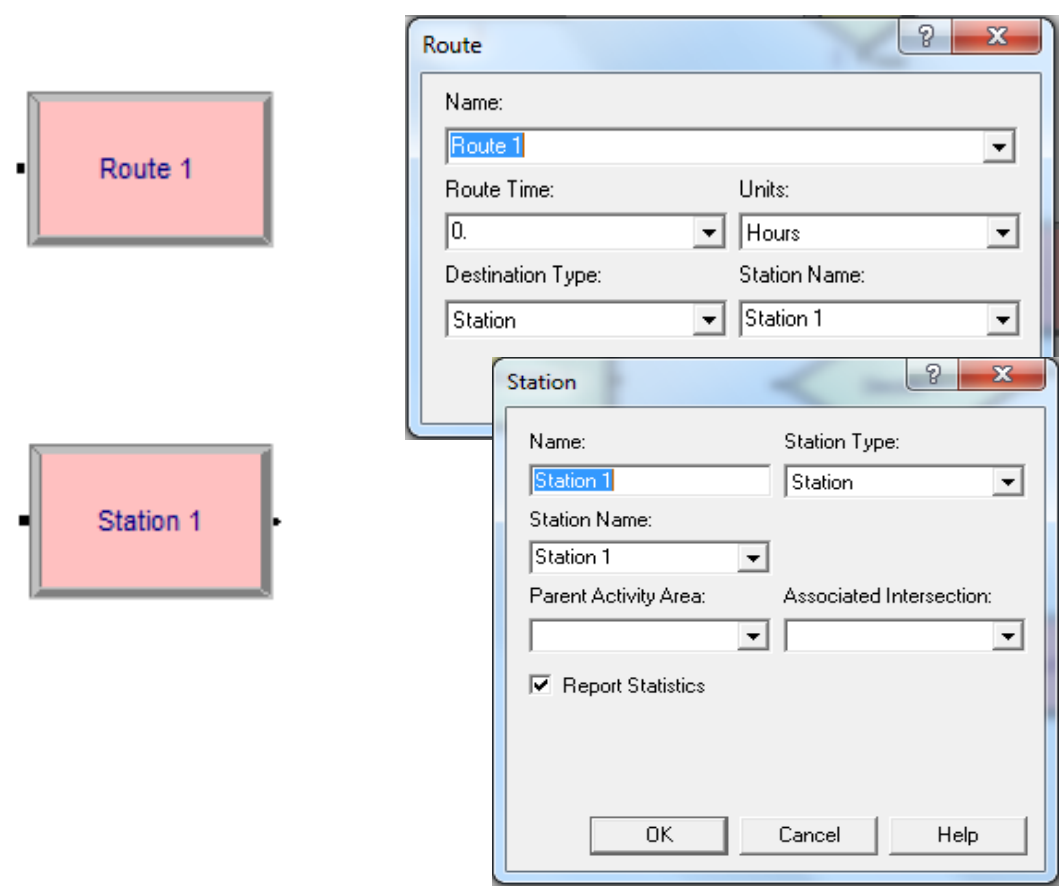

Figure 9-9: Route and Station module 
Dispose module - Every created entity must leave the system. This happens by use of the dispose module. When an entity enters the module it is removed from the system.
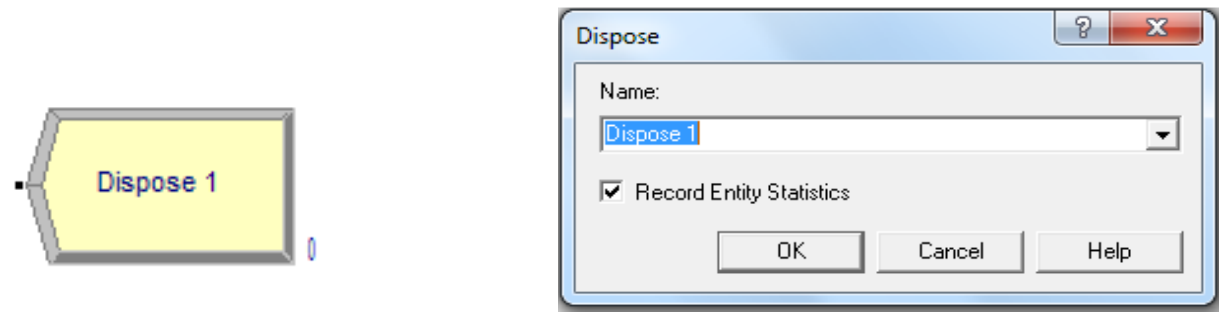

Figure 9-10: Dispose module

Data modules - Data modules are not placed in the model window and no entity will run through them. The data modules contain additional information to queues, entities etc. and allow to describe details on a lower level. The data modules are organized as lists and can be edited by the user. They allow direct access to objects, variables and attributes.

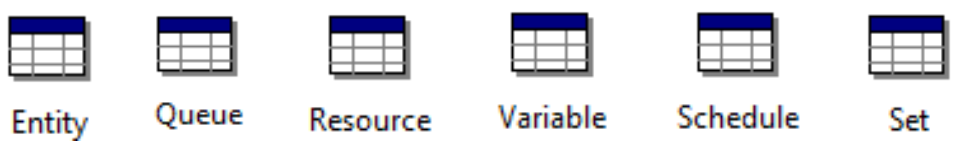

Figure 9-11: Data modules

By arranging the explained modules and data modules, it is possible to set up a simulation model. When the model is ready the simulation can start. But before the model can run the "run setup" should take place. Arena offers a context menu to set the replication parameters. The most important settings are the number of replications, warm up period, replication length. and the time units. Number of replications is important for statistical reasons. The more replications of the simulation are run, the more accurate will be the result. (For each replication a new set of random numbers is selected, which is the basis for the setup of the event calendar and generates 
randomized results.) A useful number of replication will be defined later. A warm up period is to apply when a system needs to be followed under continuous conditions. When an empty system begins to operate, processes and queues are all idle. The warm up period should be set until the system is in "balance". This assures a better accuracy of the results without the effect of an idle system. The replication length defines the time frame the system will actually simulate and record statistics. The base time unit is also an important setting which should be carefully followed throughout the whole model. Mistakes with this unit may lead to significant errors. After the run setup the model can run.

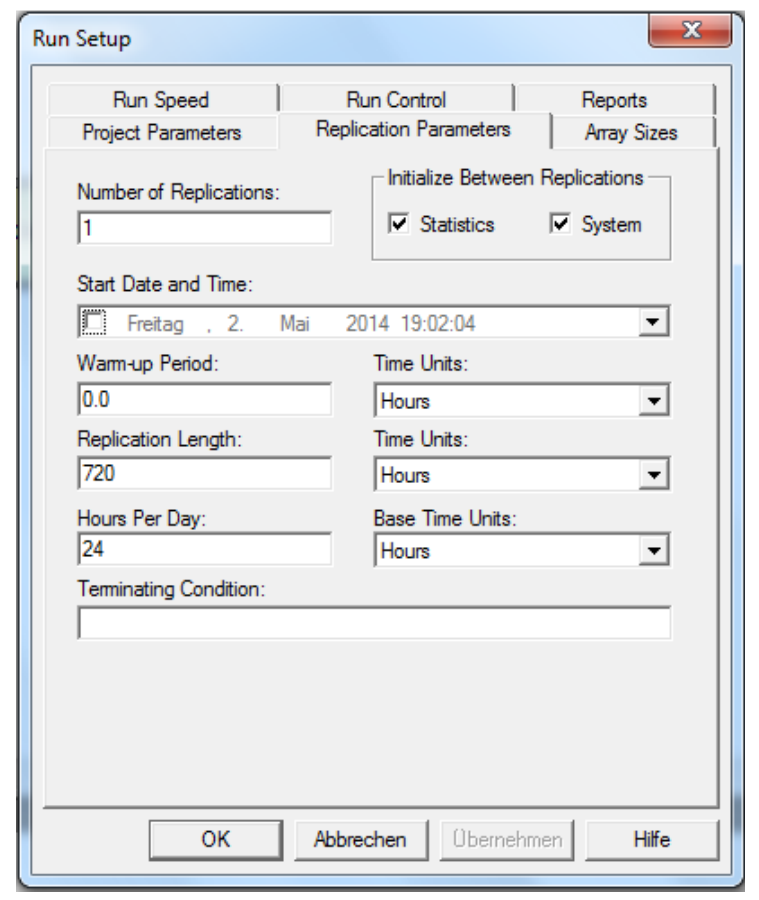

Figure 9-12: Run setup

When the model starts to run it is important to be aware of the simulation clock and event calendar, which interact together. The simulation clock is a variable keeping track of time during simulation. Since Arena is an event driven simulation keeping track of time means keeping track 
of events happening at times planned in the event calendar. This is due to the fact that between events nothing happens, so there is no need to follow this time.

Event is a key word in Arena. "An event is something that happens at an instant of (simulated) time that might change attributes, variables, or statistical accumulators." (Kelton et al, 2010). These events are planned in an event calendar to keep track of the simulation. Kelton et al describe the idea: "When the logic of the simulation calls for it, a record of information for a future event is placed on the event calendar. This event record contains identification of the entity involved, the event time, and the kind of event it will be. Arena places each newly scheduled event on the calendar so that the next (soonest) event is always at the top of the calendar. [...] When it is time to execute the next event, the top record is removed from the calendar and the information in this record used to execute the appropriate logic" (Kelton et al, 2010).

With this basic information it should be possible to follow the setup of the simulation model presented in this work. 

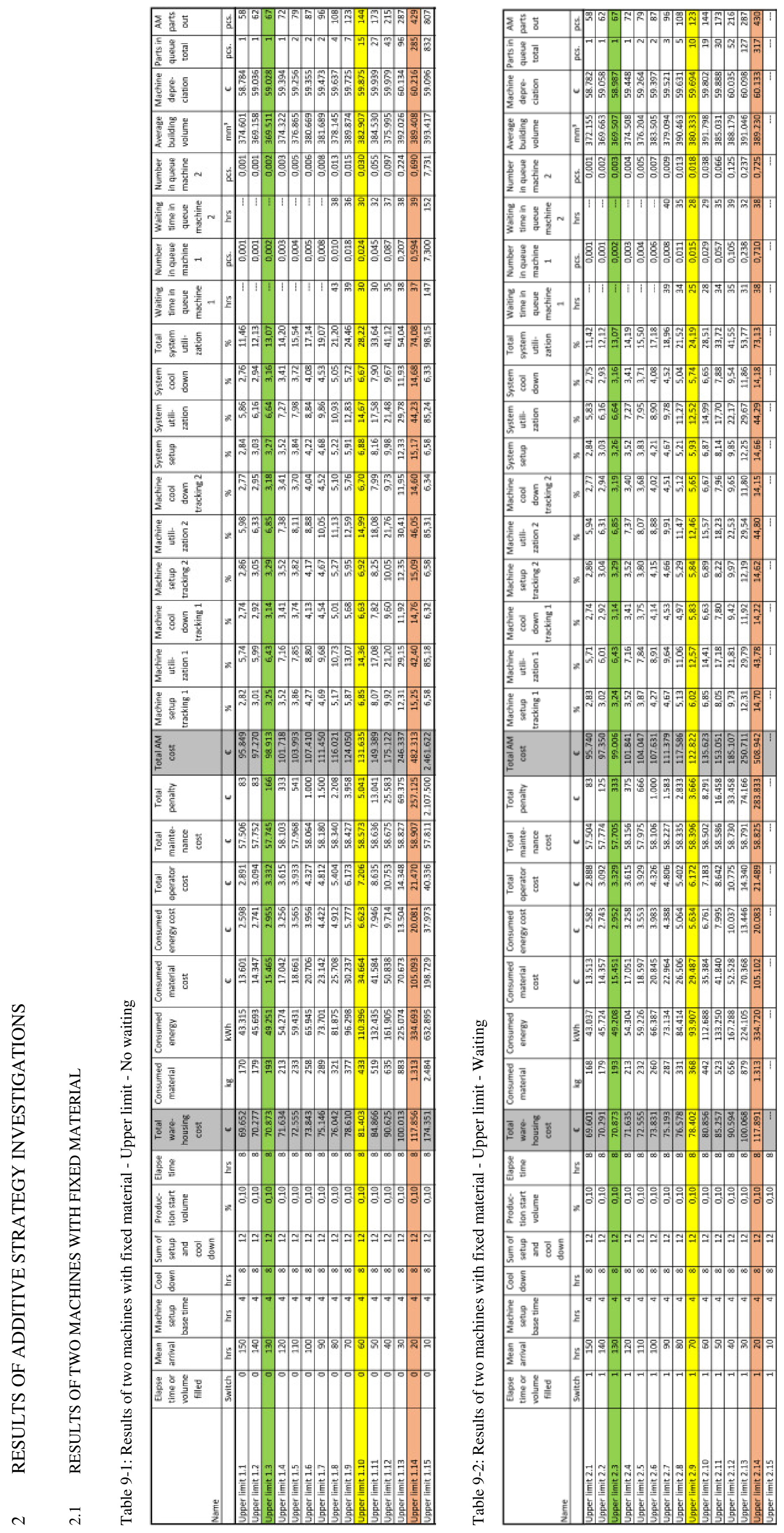


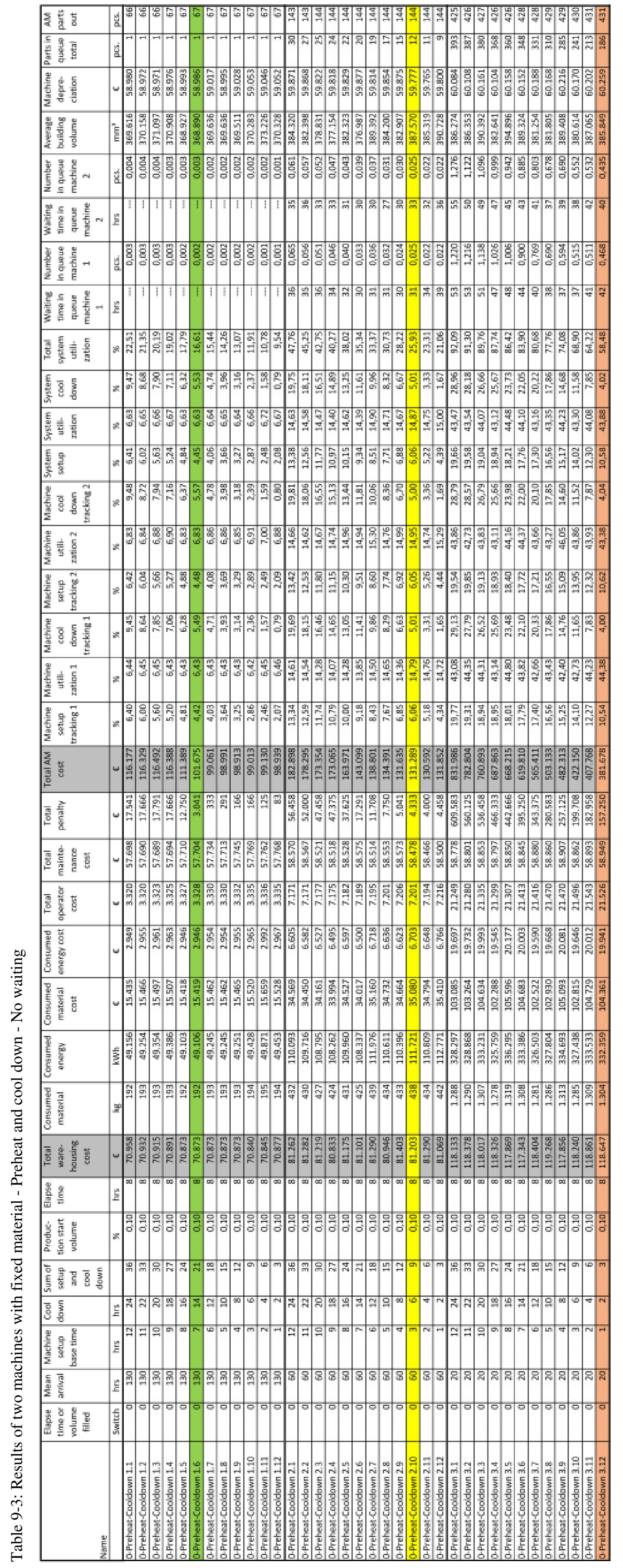




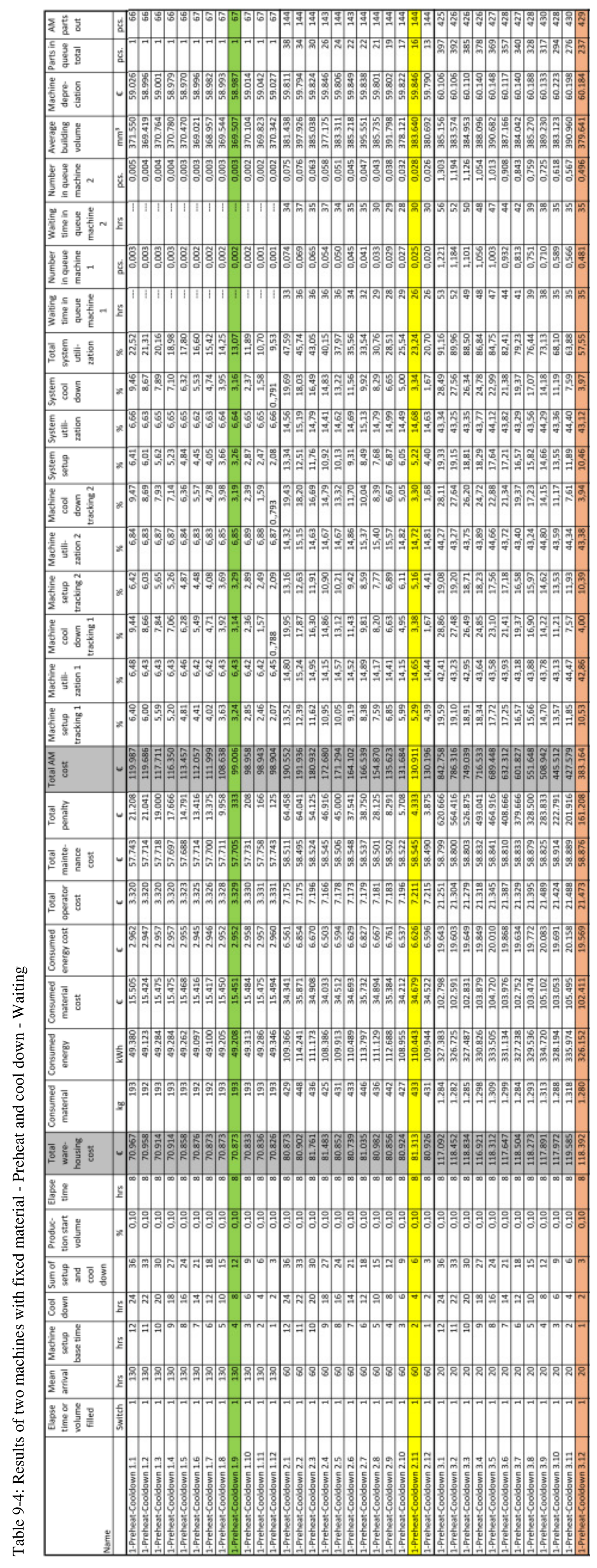



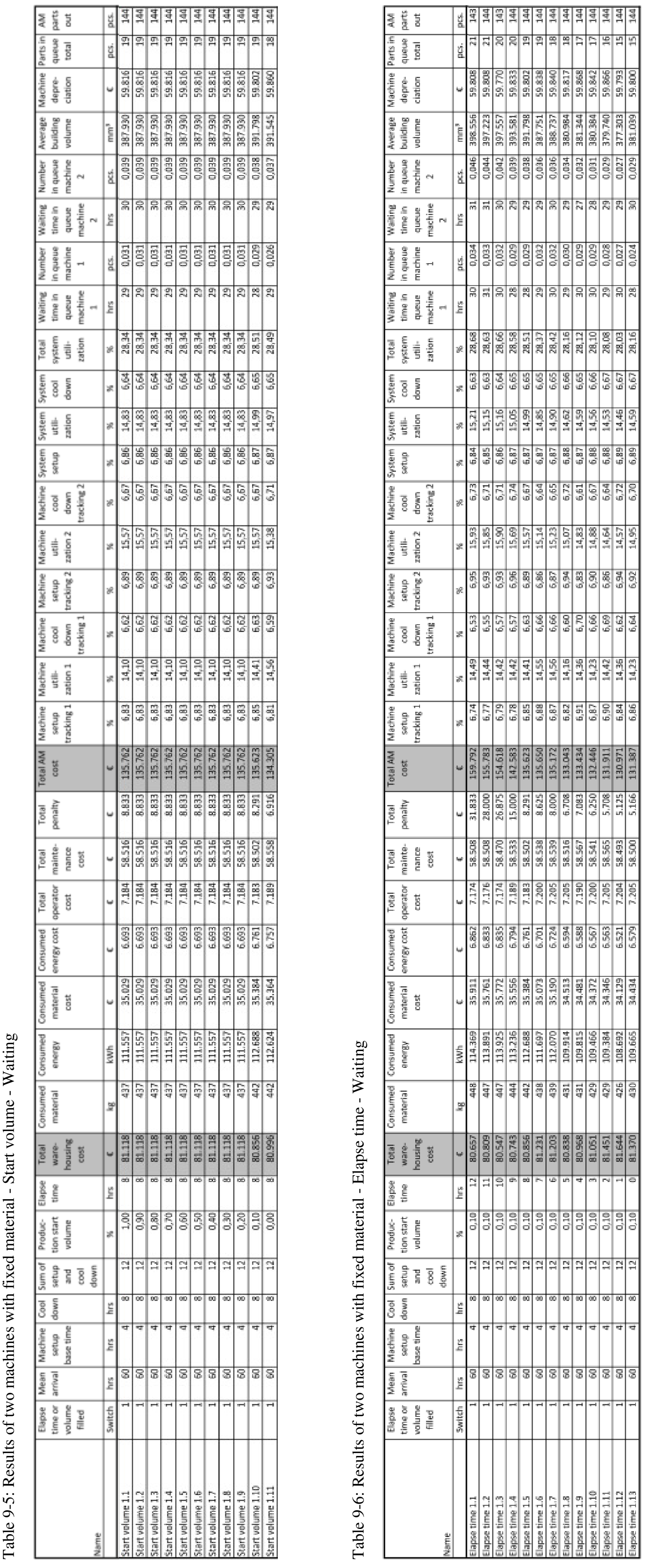

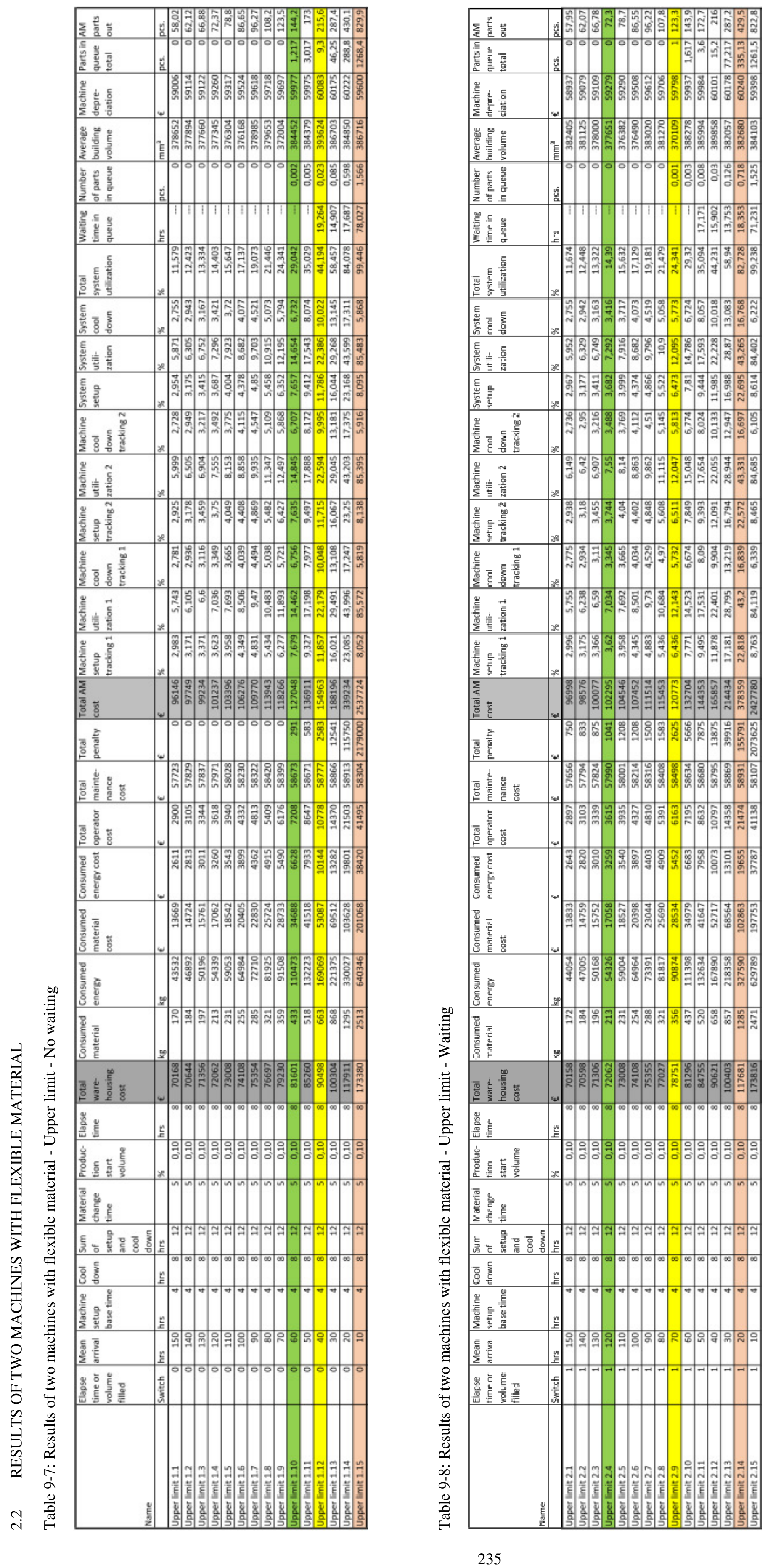


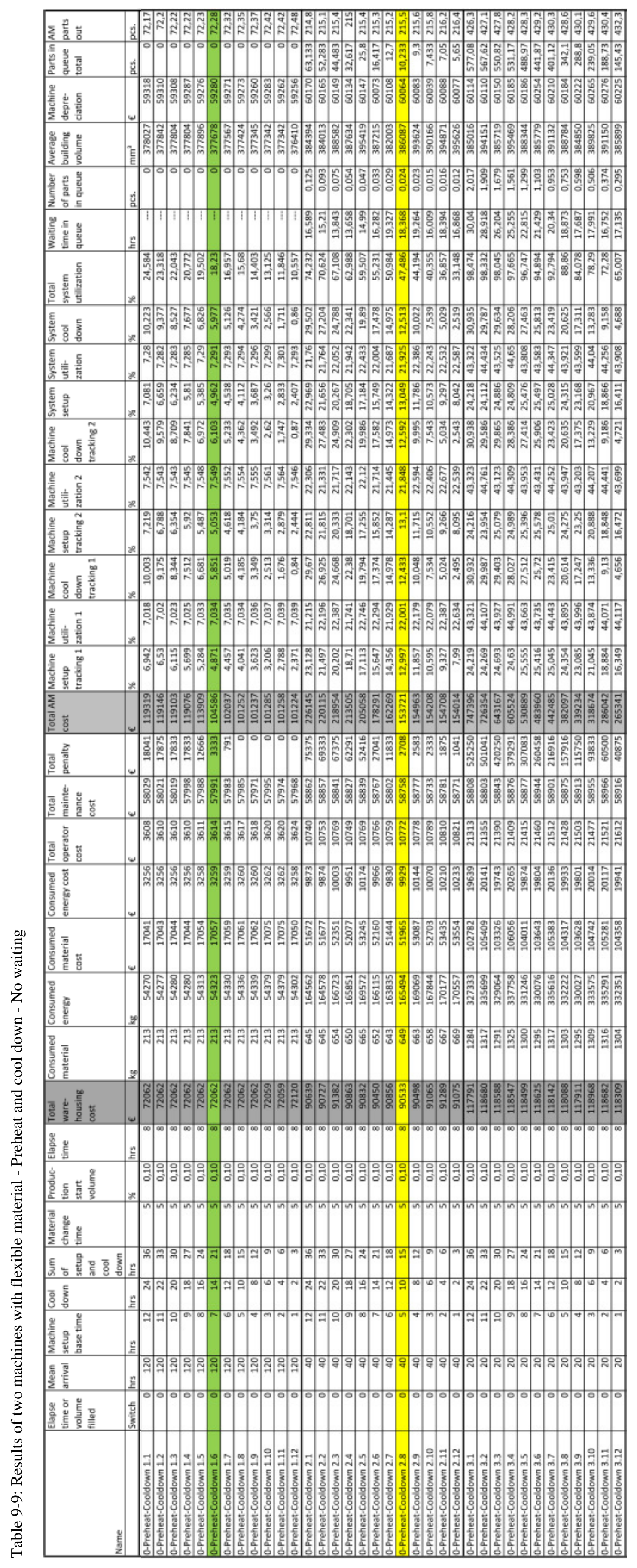




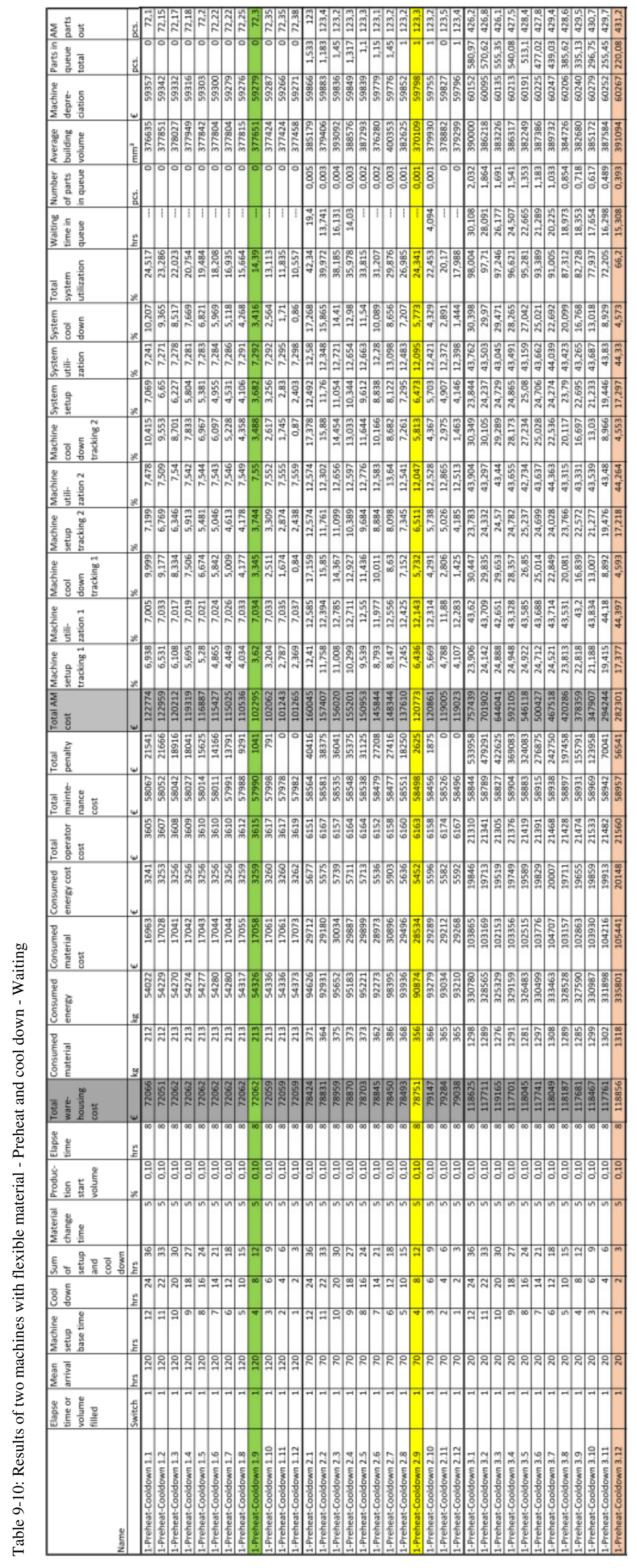



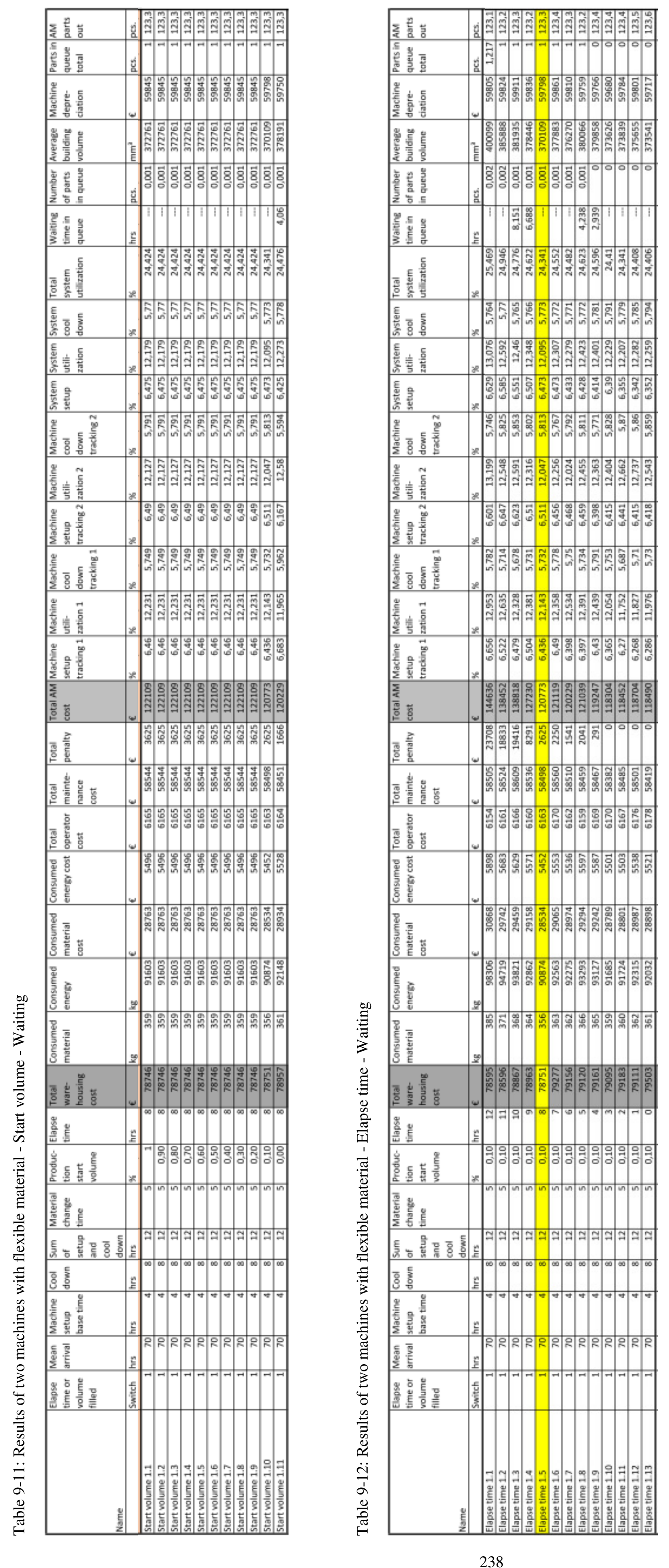


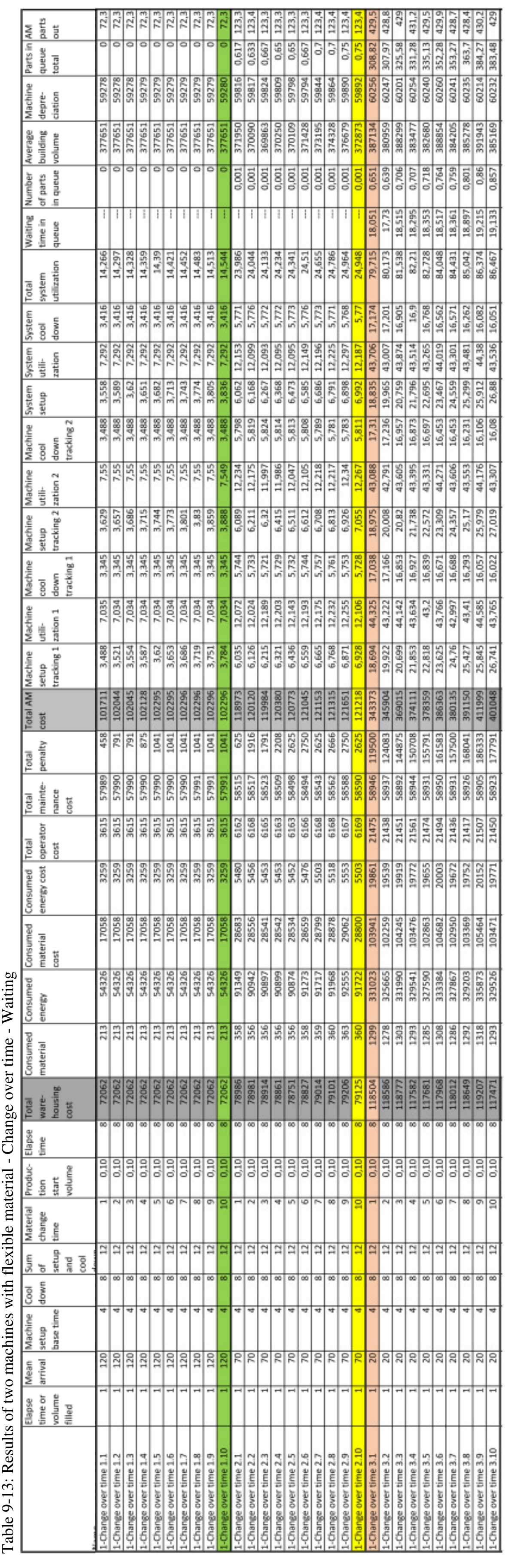




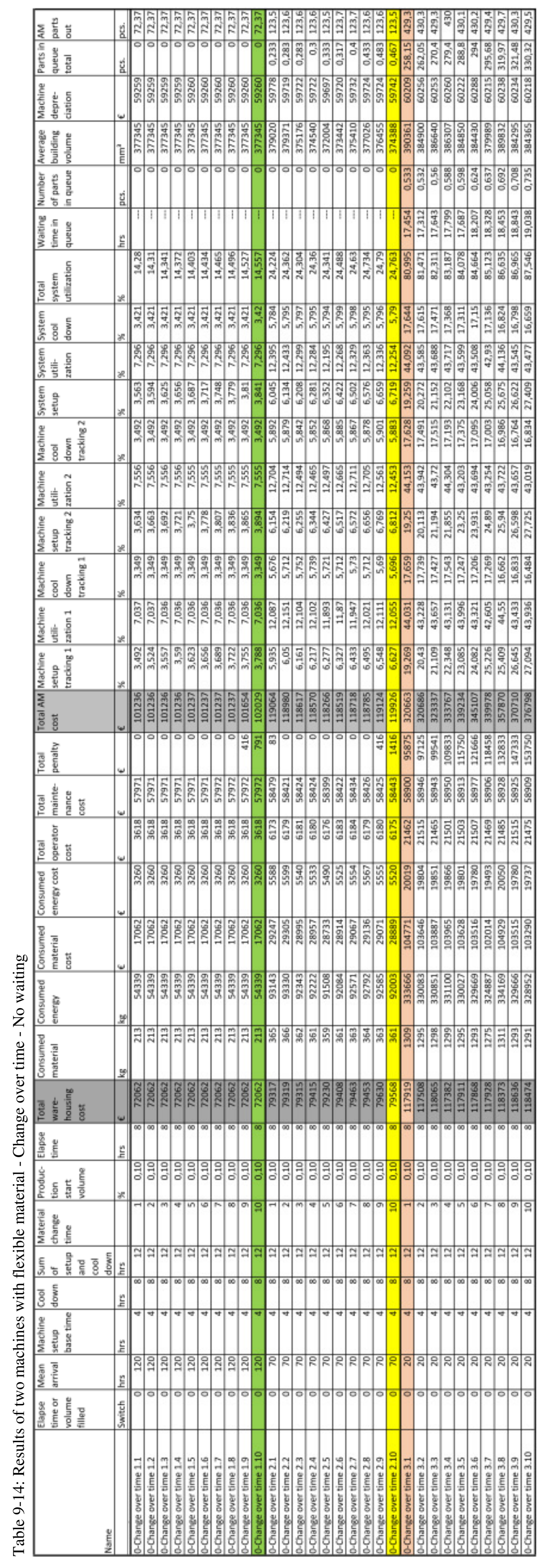



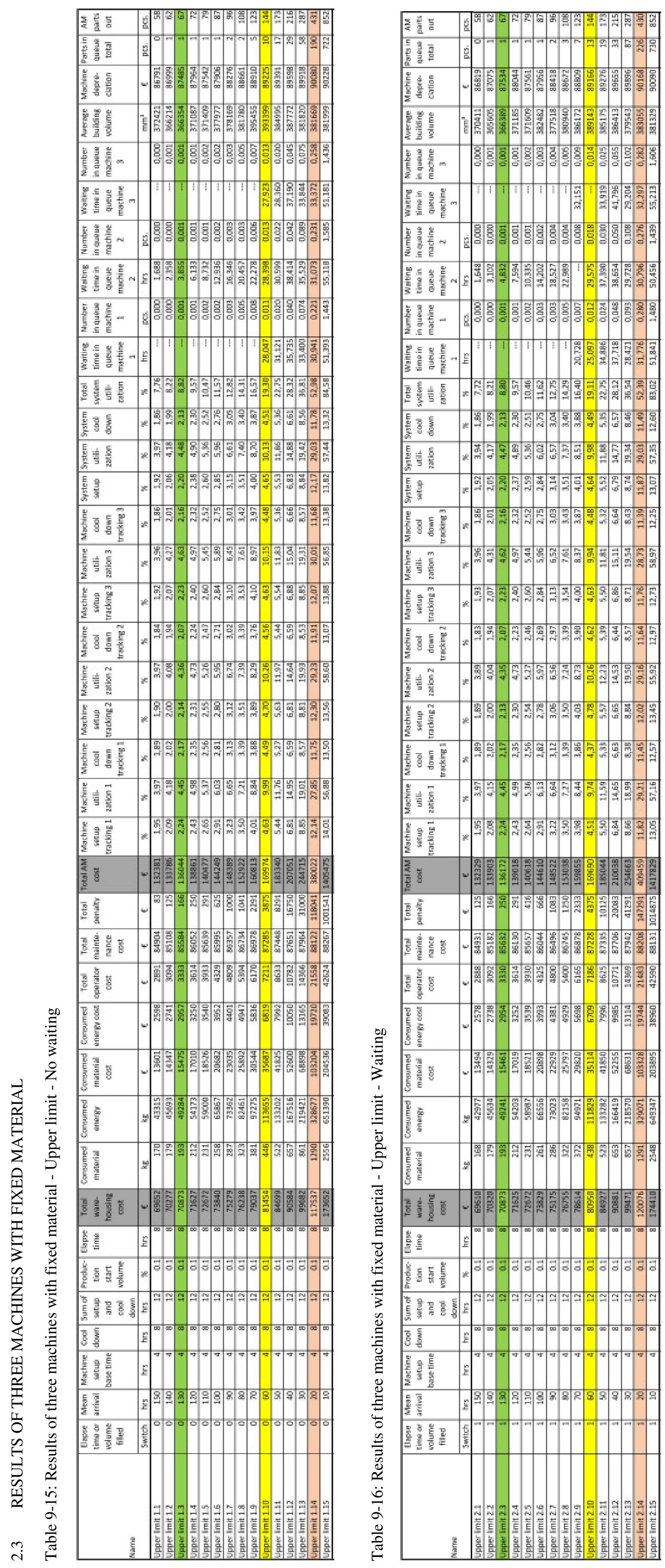


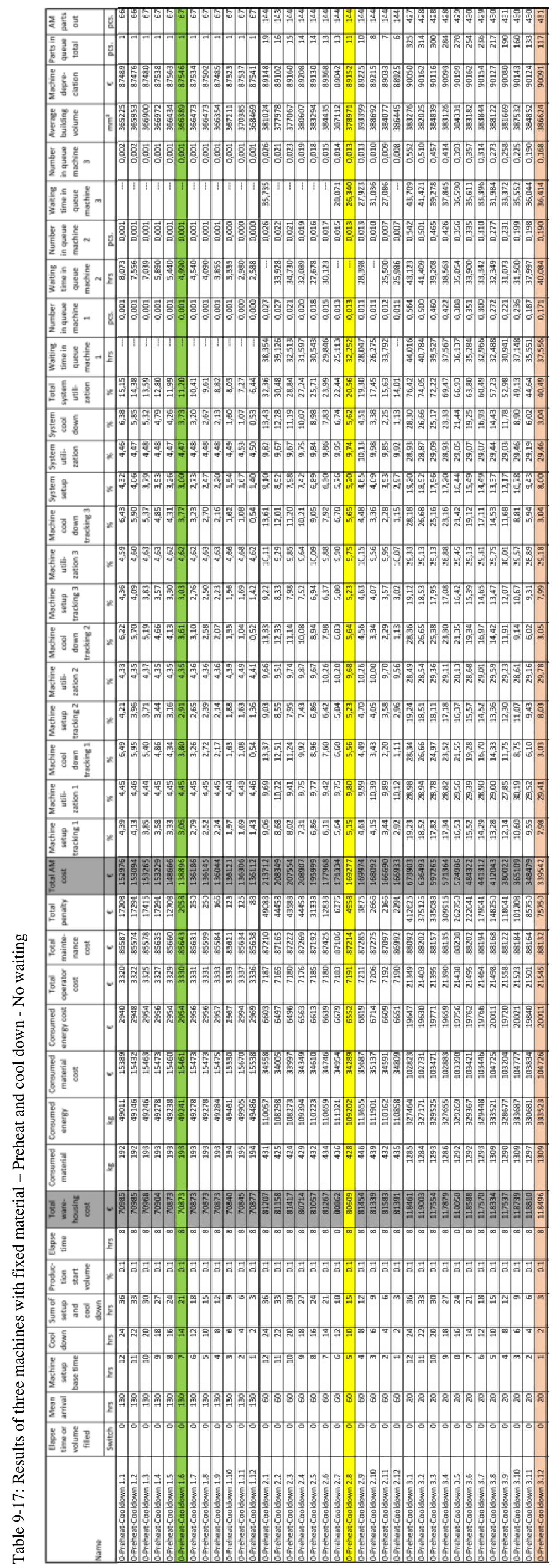




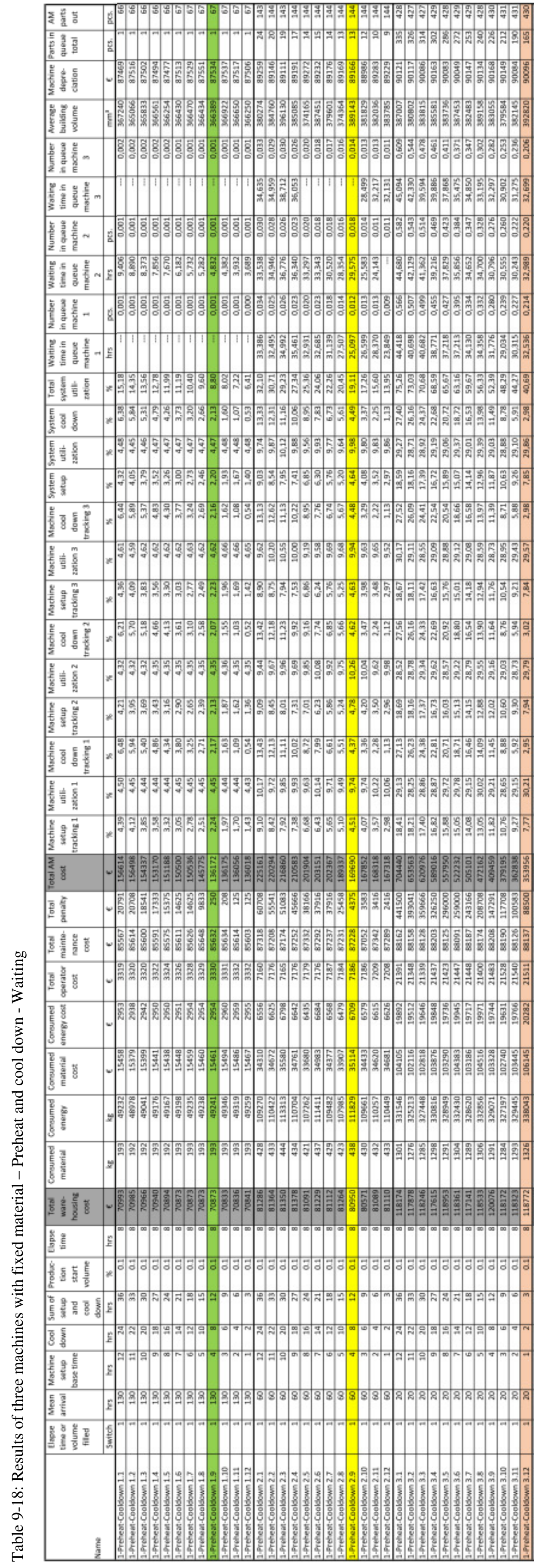



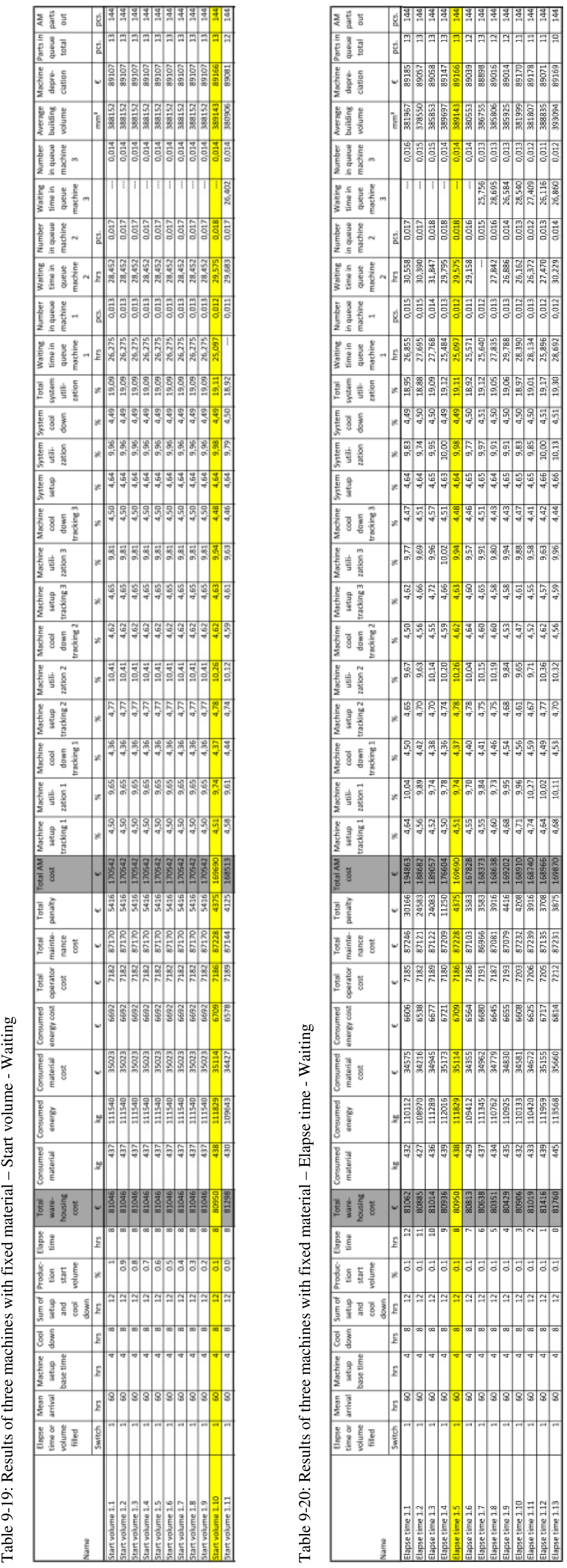

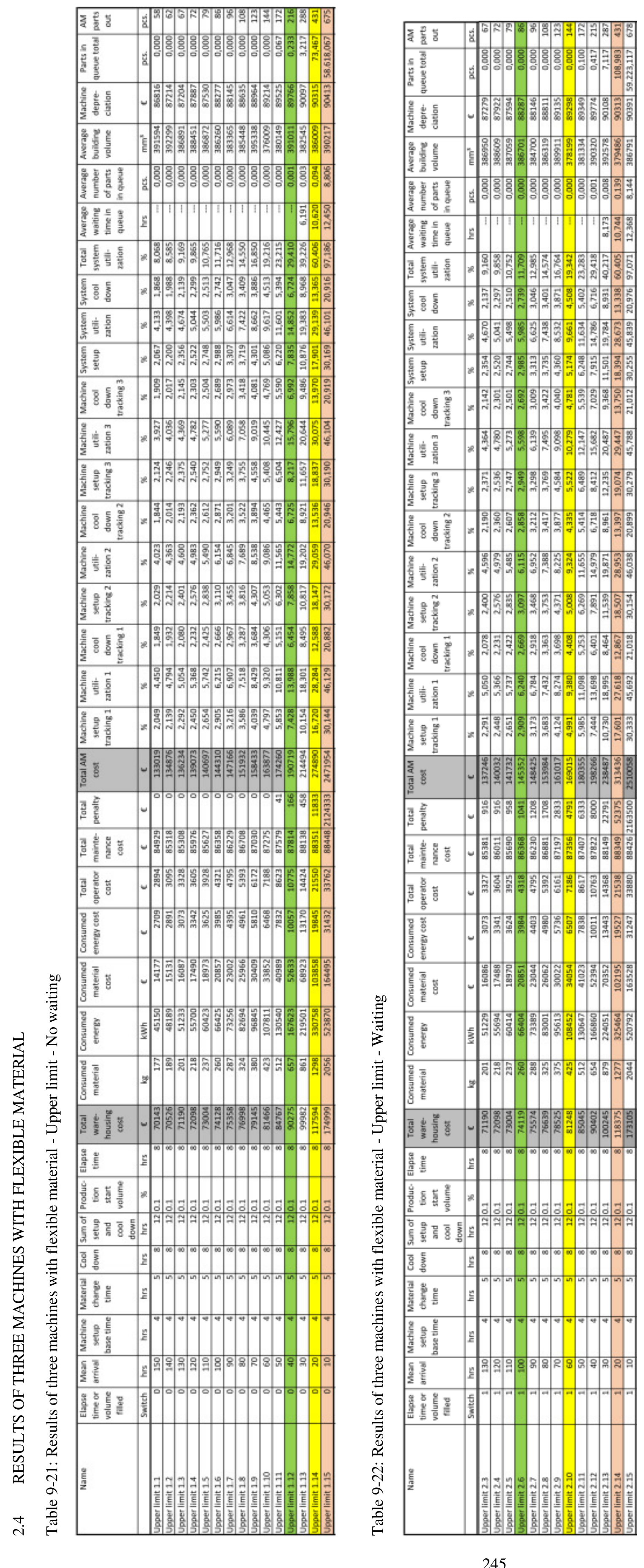


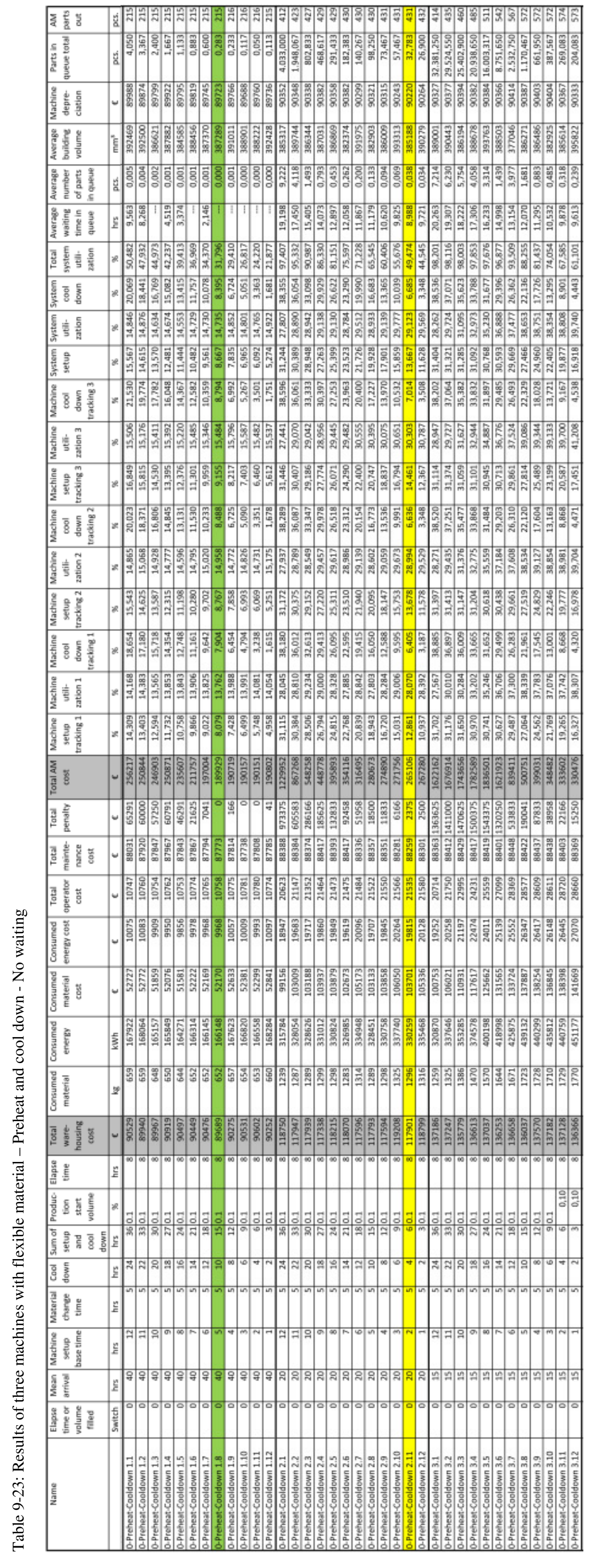




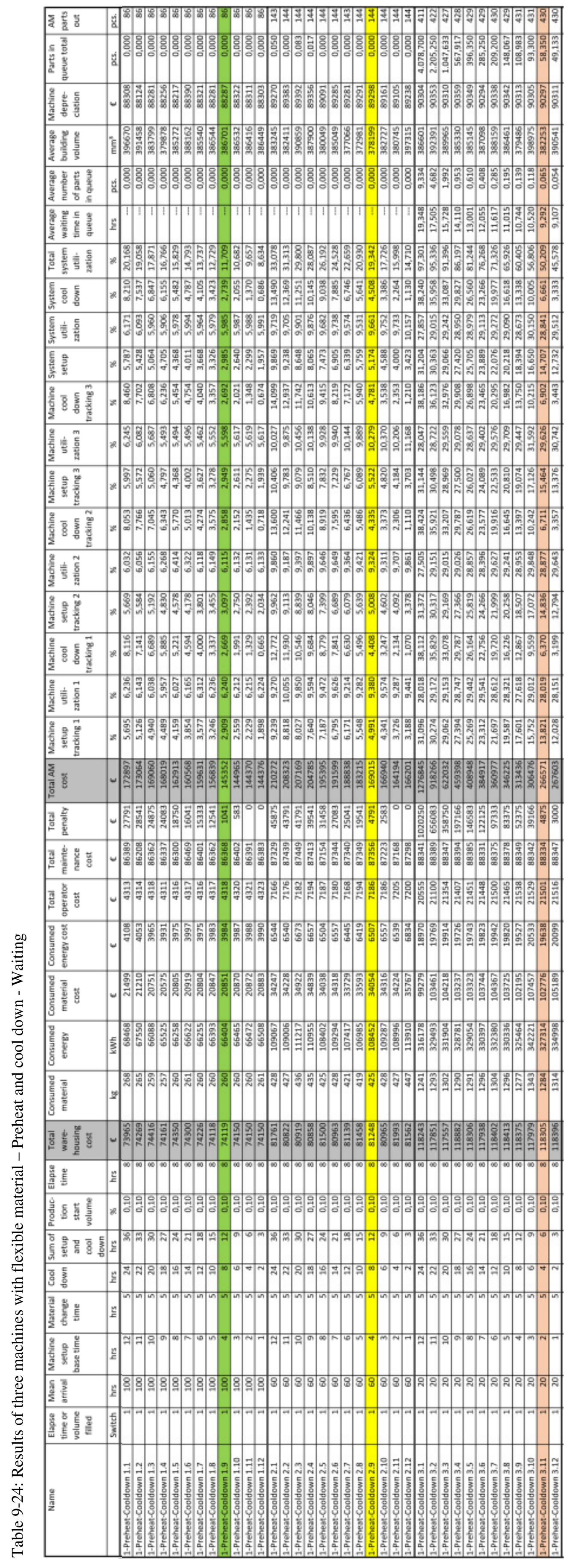



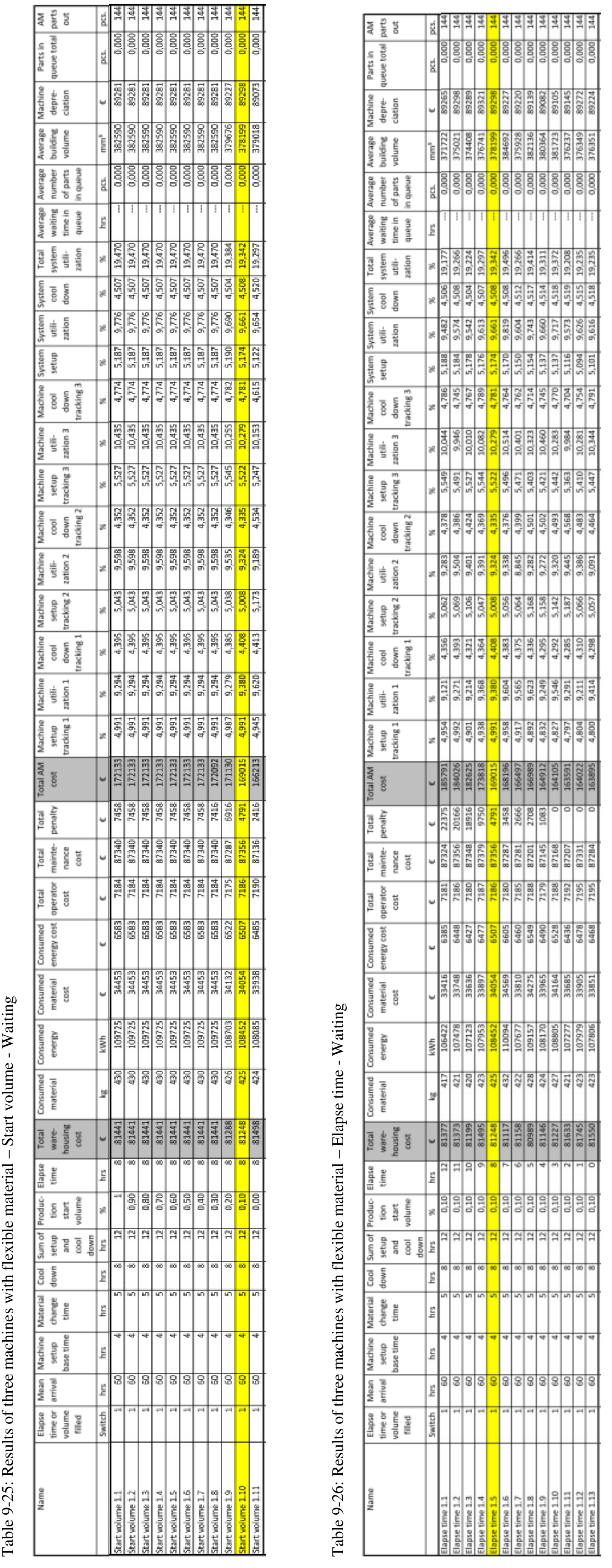


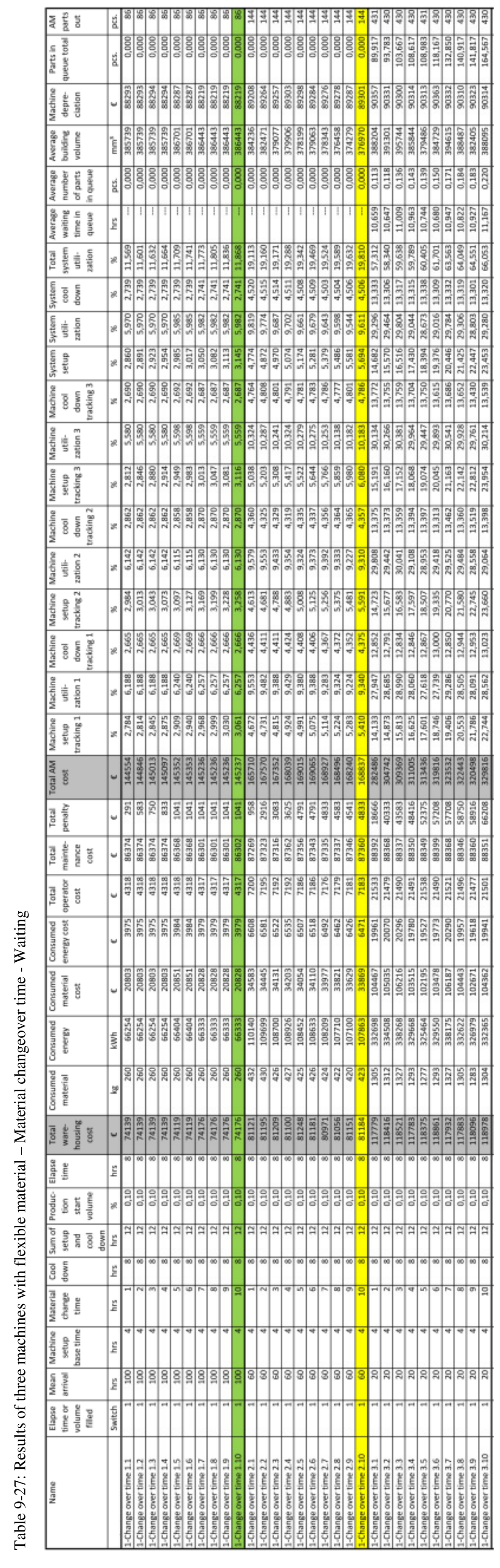




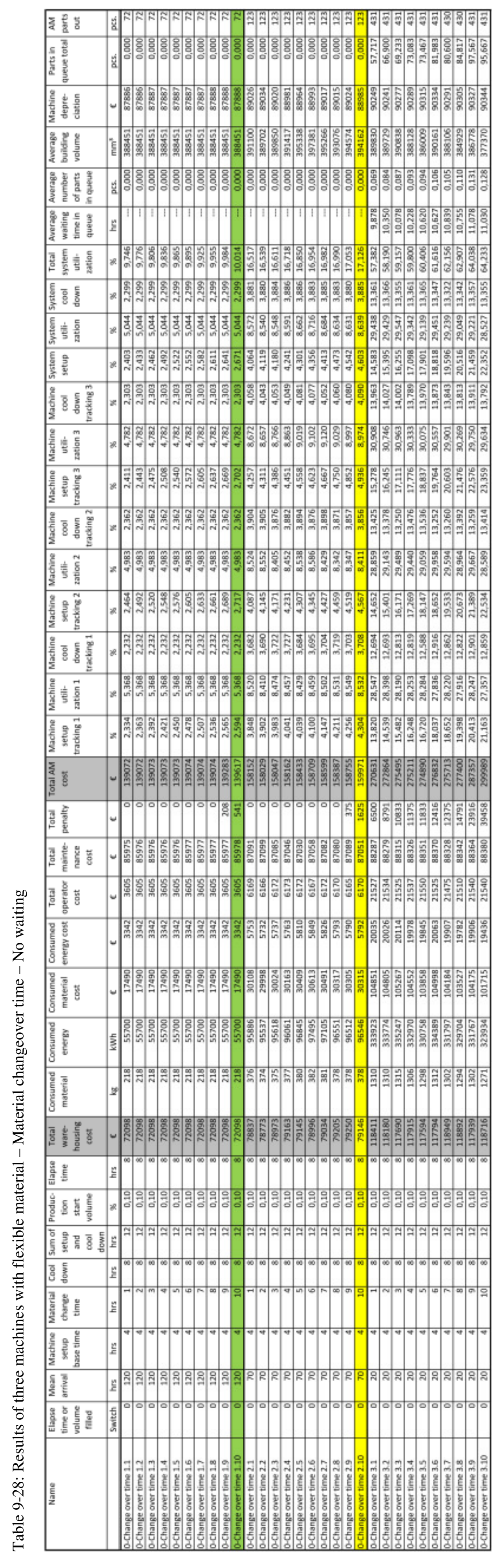




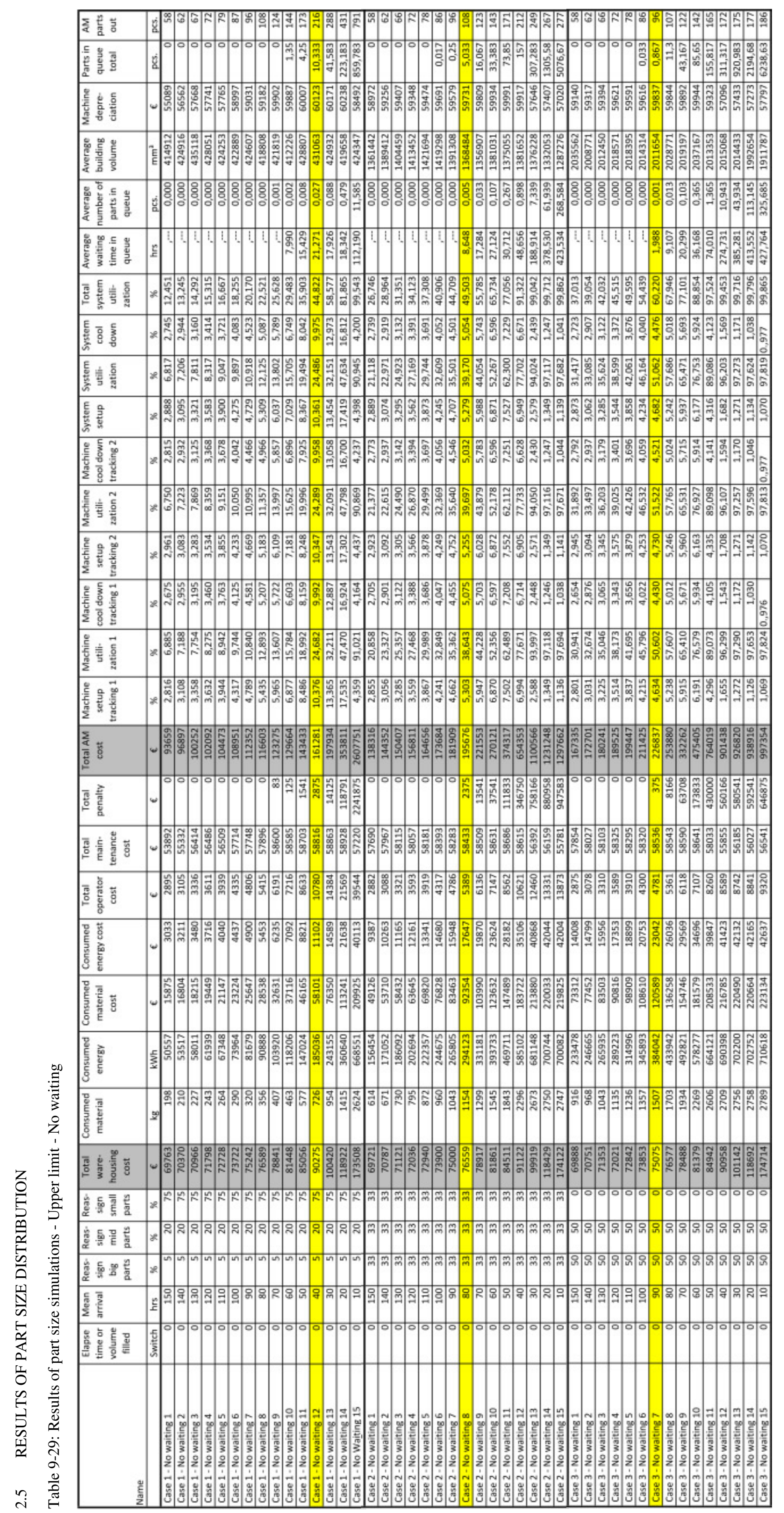




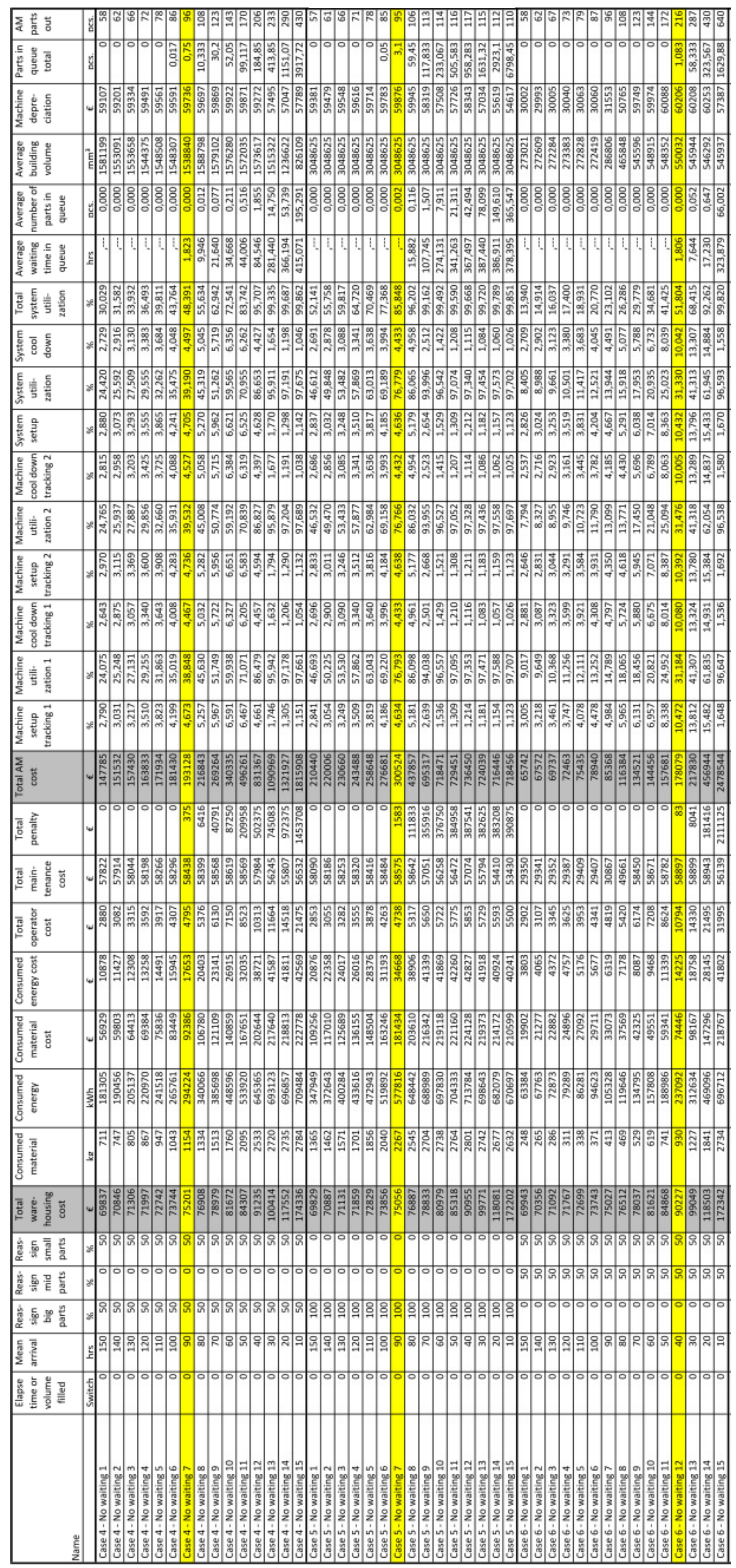




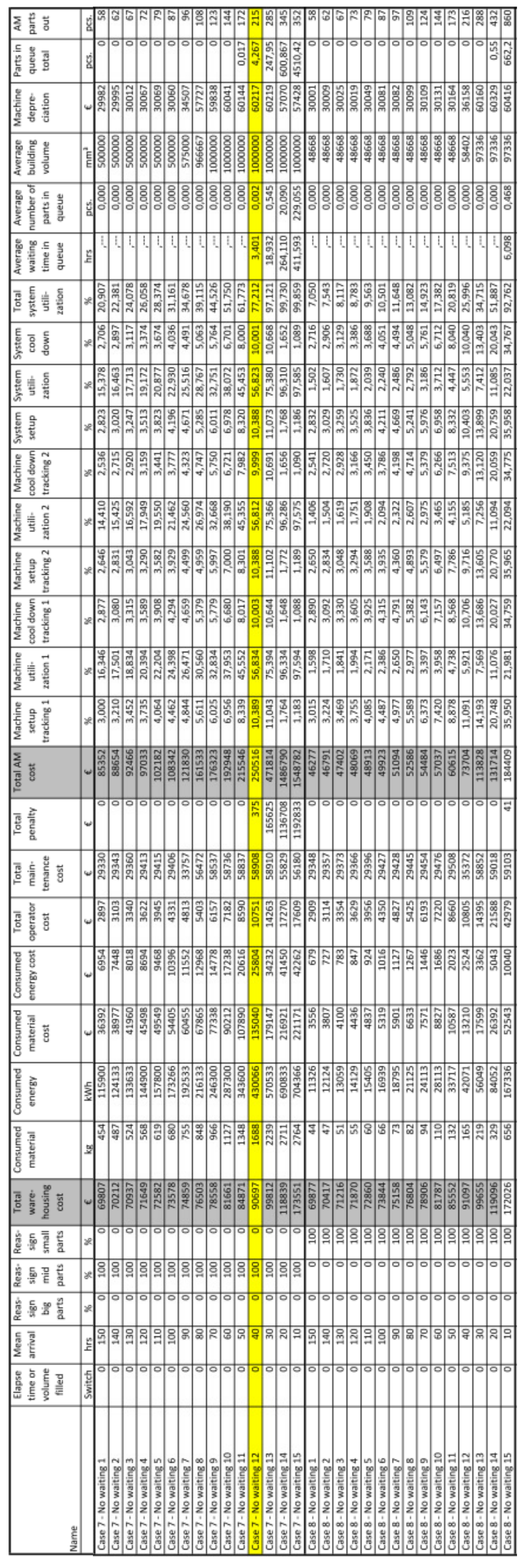




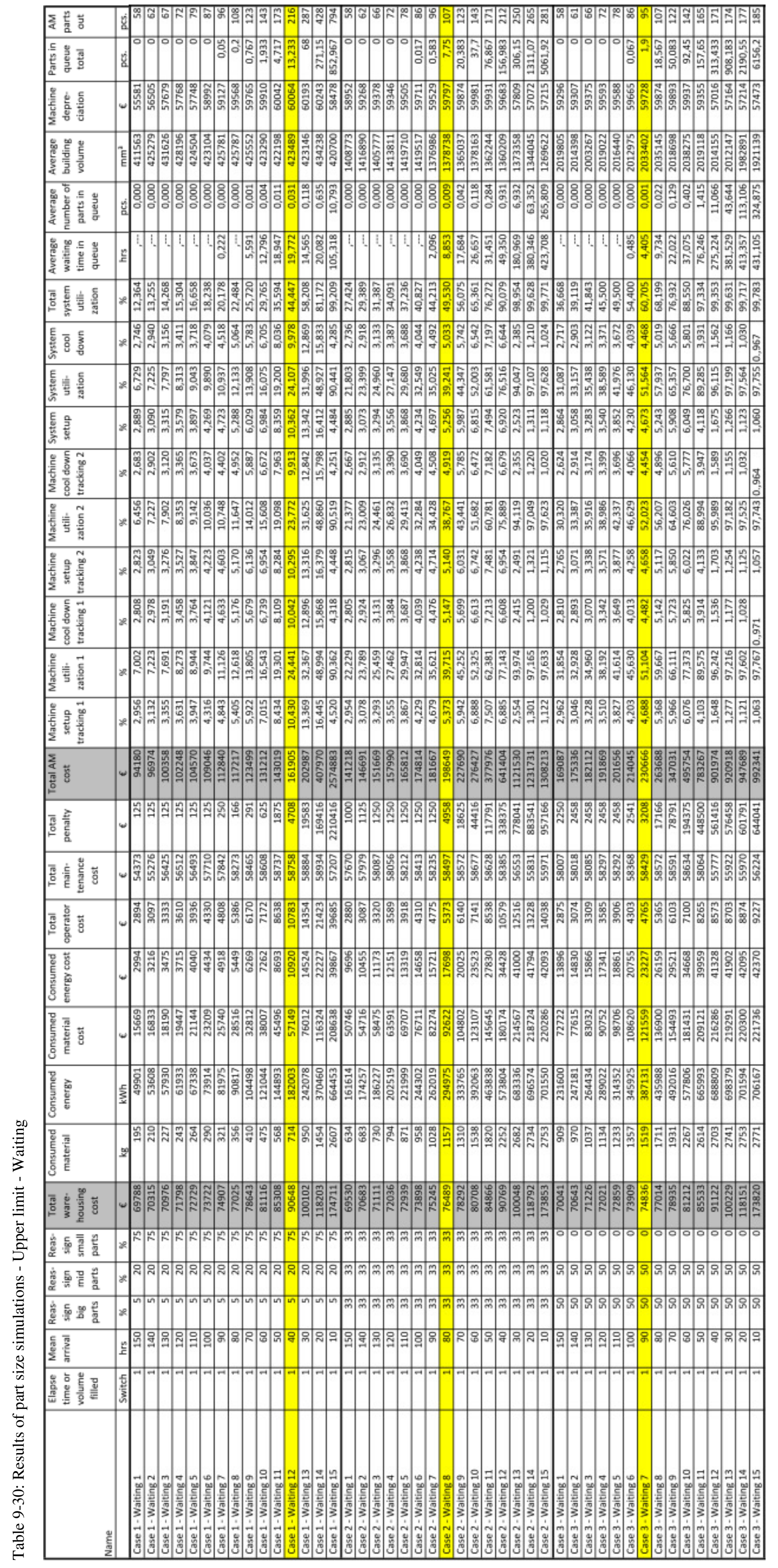




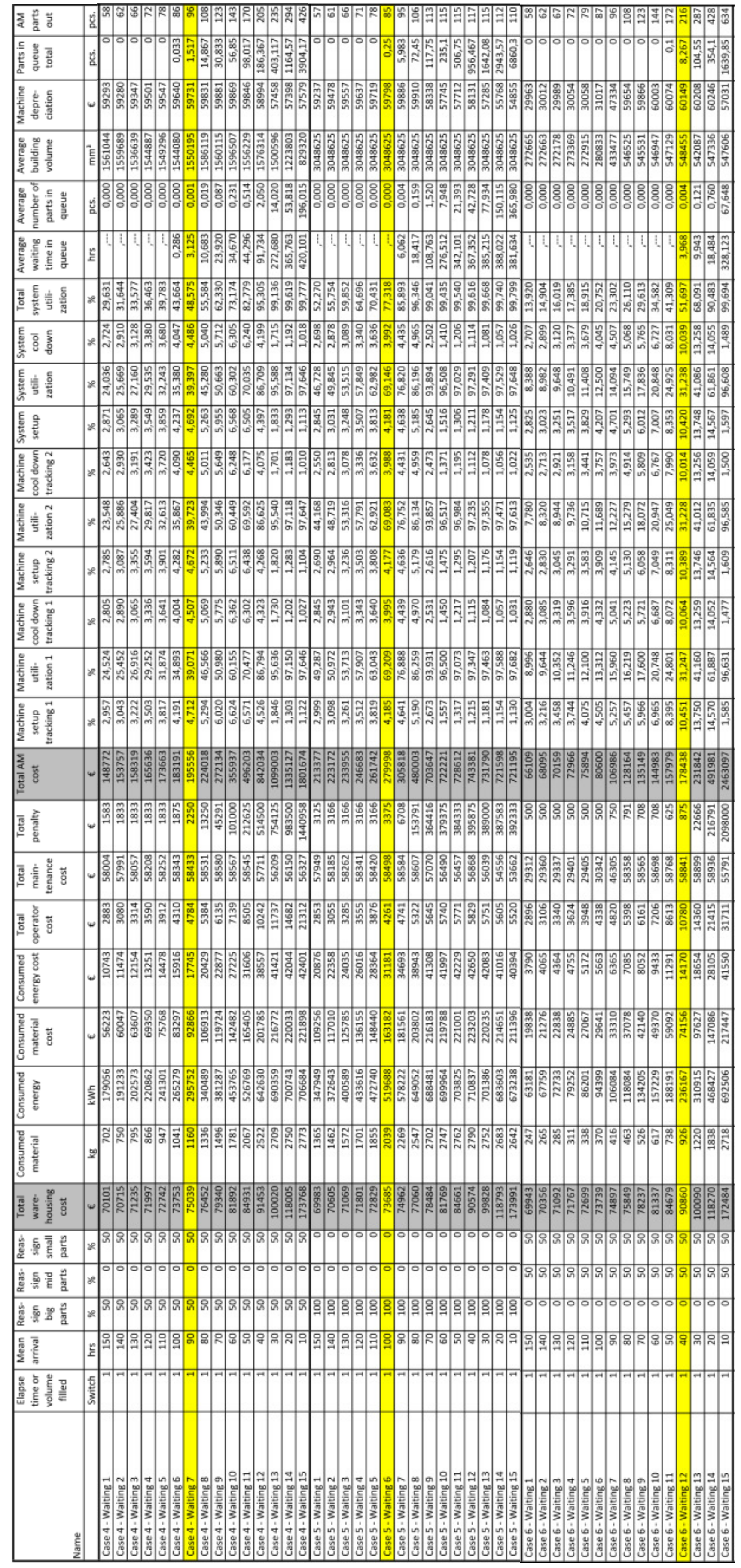




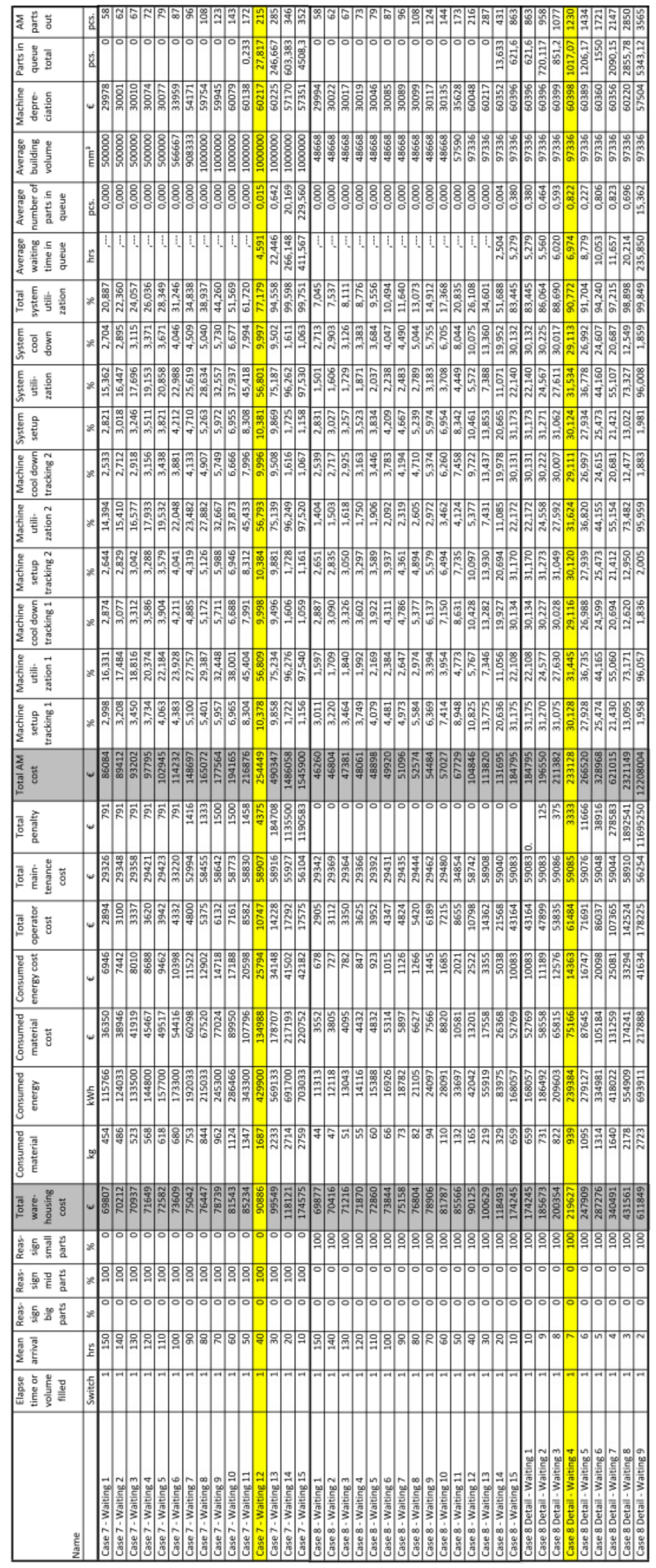



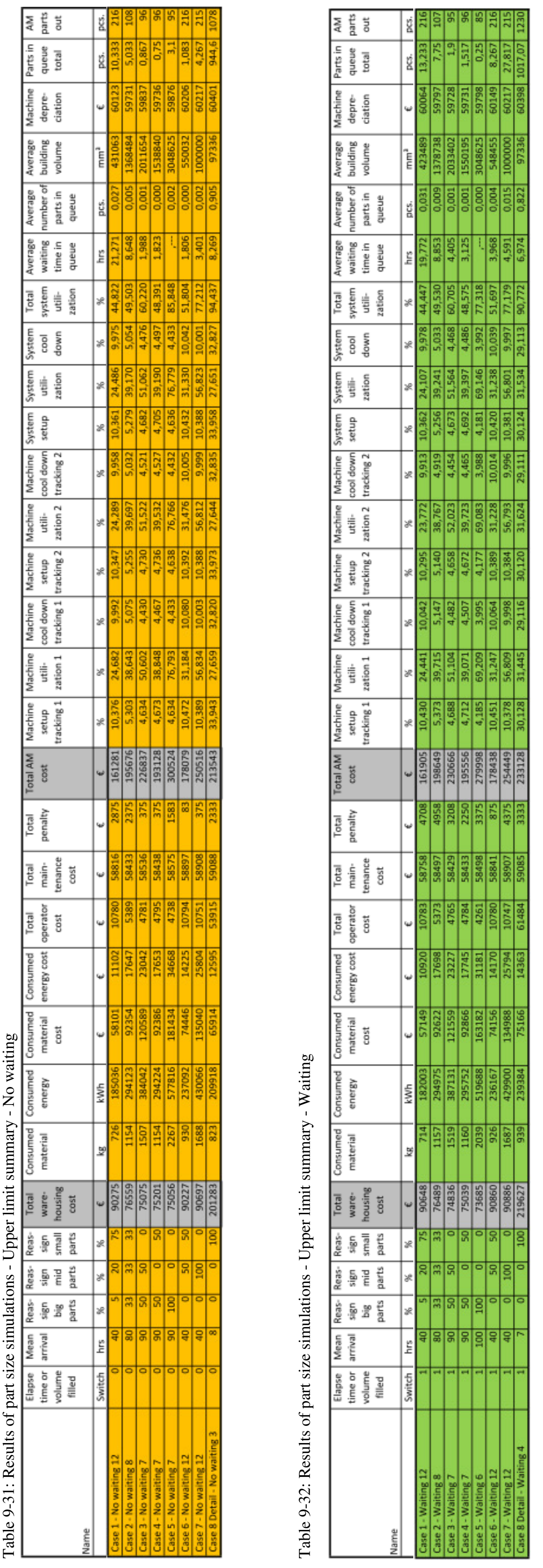


\section{CURRICULUM VITAE}

NAME: $\quad$ Stefan Jedeck

ADDRESS: Rembrandt-Straße 10

41549 Dormagen

Germany

DOB: $\quad$ Dormagen, NRW - May 09, 1981

EDUCATION

\& TRAINING: $\quad$ Electrical Assistant - specialized in data technology (Technical diploma)

Werner-von-Siemens Schule, Köln

$1998-2001$

Dipl.-Ing. (FH), Design engineering

Cologne University of Applied Sciences

$2002-2006$

Dipl.-Wirt.-Ing. (FH), Business engineering

Cologne University of Applied Sciences

$2006-2007$

Ph.D., Industrial engineering

University of Louisville

$2009-2015$ 
PROFESSIONAL

BACKGROUND:

Project engineer

BIS Instandhaltung Neuss GmbH

Department - Maintenance \& Projects

$2007-2009$

Project engineer

Hydro Aluminium Deutschland GmbH

Department - Technology delivery and Smelter systems since 2009 